Received by 0ST NUREG/CR-5273

SEP $221989 \quad$ EGG-2555

Vol. 2

\title{
SCDAP/RELAP5/MOD2 Code Manual
}

SCDAP Code Structure,

Models, and Solution Methods

Edited by C. M. Allison, E. C. Johnson

EG\&G Idaho, Inc.

Prepared for

U.S. Nuclear Regulatory

Commission 


\section{AVAILABILITY NOTICE}

Availability of Reference Materials Cited in NRC Publications

Most documents cited in NRC publications will be avallable from one of the following sources:

1. The NRC Public Document Room, 2120 L Street, NW, Lower Level, Washington, DC 20555

2. The Superintendent of Documents, U.S. Government Printing Office, P.O. Box 37082, Washington, DC 20013-7082

3. The National Technical Information Service, Springfleld, VA 22161

Although the listing that follows represents the majority of documents clted in NRC publications, it is not Intended to be exhaustive.

Referenced documents avallable for Inspection and copying for a fee from the NRC Public Document Room Include NRC correspondence and Internal NRC memoranda; NRC Office of Inspection and Enforcement bulletins, circulars, Information notices, inspection and investlgation notices: Ucensee Event Reports; vendor reports and correspondence; Commission papers; and applicant and licensee documents and correspondence.

The following documents in the NUREG serles are avallable for purchase from the GPO Sales Program: formal NRC staff and contractor reports, NRC-sponsored conference proceedings, and NRC booklets and brochures. Also avallable are Regulatory Guides, NRC regulations in the Code of Federal Regulations, and Nuclear Regulatory Commission issuances.

Documents avallable from the National Technical Information Service include NUREG series reports and technical reports prepared by other federal agencies and reports prepared by the Atomic Energy Commission, forerunner agency to the Nuclear Regulatory Commission.

Documents avallable from public and speclal technical libraries include all open Iterature Items, such as books, Journal and periodical articles, and transactlons. Federal Register notices, federal and state legislation, and congresslonal reports can usually be obtained from these librarles.

Documents such as theses, dissertations, forelgn reports and translations, and non-NRC conference proceedings are avallable for purchase from the organization sponsoring the publication cited.

Single copies of NRC draft reports are available free, to the extent of supply, upon written request to the Office of Information Resources Management, Distribution Section, U.S. Nuclear Regulatory Commission, Washington, DC 20555.

Coples of Industry codes and standards used In a substantive manner in the NRC regulatory process are malntalned at the NRC Library, 7920 Norfolk Avenue. Bethesda, Maryland, and are avallable there for reference use by the public. Codes and standards are usually copyrighted and may be purchased from the originating organization or, If they are American National Standards, from the American National Standards institute, 1430 Broadway, New York, NY 10018.

\section{DISCLAIMER NOTICE}

This report was prepared as an account of work sponsored by an agency of the United States Government. Neither the United States Government nor any agency thereof, or any of their employees, makes any warranty, expresed or implied, or assumes any legal liability of responsibility for any third party's use, or the results of such use, of any information, apparatus, product or process disclosed in this report, or represents that its use by such third party would not infringe privately owned rights. 


\section{DISCLAIMER}

This report was prepared as an account of work sponsored by an agency of the United States Government. Neither the United States Government nor any agency Thereof, nor any of their employees, makes any warranty, express or implied, or assumes any legal liability or responsibility for the accuracy, completeness, or usefulness of any information, apparatus, product, or process disclosed, or represents that its use would not infringe privately owned rights. Reference herein to any specific commercial product, process, or service by trade name, trademark, manufacturer, or otherwise does not necessarily constitute or imply its endorsement, recommendation, or favoring by the United States Government or any agency thereof. The views and opinions of authors expressed herein do not necessarily state or reflect those of the United States Government or any agency thereof. 


\section{DISCLAIMER}

Portions of this document may be illegible in electronic image products. Images are produced from the best available original document. 


\section{SCDAP/RELAP5/MOD2 Code Manual}

SCDAP Code Structure,

Models, and Solution Methods

Manuscript Completed: June 1989

Date Published: September 1989

Edited by

C. M. Allison, E. C. Johnson

Contributing Authors

C. M. Allison, G. A. Berna, T. C. Cheng, D. L. Hagrman,

G. W. Johnsen, D. M. Kiser, C. S. Miller, V. H. Ransom,

R. A. Riemke, A. S. Shieh, L. J. Siefken, J. A. Trapp, R. J. Wagner

EG\&G Idaho, Inc.

Idaho Falls, ID 83415

Prepared for

Division of Systems Research

Office of Nuclear Regulatory Research

U.S. Nuclear Regulatory Commission

Washington, DC 20555

NRC FIN A6360 


\section{ABSTRACT}

The SCDAP/RELAP5 code has been developed for best-estimate transient simulation of light water reactor coolant systems during a severe accident. The code models the coupled behavior of the reactor coolant system, the core, and the fission products and aerosols in the system during a severe accident transient as well as large and small break loss-of-coolant accidents, operational transients such as anticipated transient without SCRAM, loss of offsite power, loss of feedwater, and loss of flow. A generic modeling approach is used that permits as much of a particular system to be modeled as necessary. Control system and secondary system components are included to permit modeling of plant controls, turbines, condensers, and secondary feedwater conditioning systems.

The modeling theory and associated numerical schemes are documented in Volumes $I$ and II to acquaint the user with the modeling base and thus aid in effective use of the code. Volume III contains detalled instructions for code application and input data preparation. In addition, Volume III contains user guidelines that have evolved over the past several years from application of the RELAP5 and SCDAP codes at the Idaho National Engineering Laboratory, at other national laboratories, and by users throughout the wor $1 d$. 
○

-

- 


\section{EXECUTIVE SUMMARY}

The light water reactor (LWR) severe accident transient analys is code, SCDAP/RELAP5, has been developed at the Idaho National Engineering Laboratory (INEL) for the U. S. Nuclear Regulatory Commission (NRC) to provide an advanced best-estimate predictive capability for use in severe accident applications in support of the regulatory process. Code uses include analysis required to support rulemaking, licensing audit calculations, evaluation of accident mitigation strategies, and experiment planning and analysis. Specific applications of this capability have included analytical support for the loss-of-fluid test (LOFT), Power Burst Facility (PBF), ACRR, MIST, ROSA IV, and NRU experimental programs, as well as simulations of transients that lead to severe accidents, such as loss of coolant, anticipated transients without scram (ATWS), and operational transients in LWR systems. SCDAP/RELAP5 is a highly generic code that, in addition to calculating the behavior of a reactor coolant system (RCS) during a severe accident transient, can be used for simulation of a wide variety of hydraulic and thermal transients in both nuclear and nonnuclear systems involving steam-water noncondensible solute fluid mixtures.

SCDAP/RELAP5 was developed by integrating three separate codes, RELAP5/MOD2, SCDAP, and TRAP-MELT. These codes were combined to mode 1 the coupled interactions that occur between the core, the RCS, and the fission products during a severe accident. For example, blockage in the core, caused by fuel rod ballooning and meltdown, can have a significant effect on RCS flows. Fission products released from the core can have a significant effect on the RCS because of the heat produced during decay. These and many other coupled effects can have a significant effect on the release of fission products from the RCS.

The RELAP5/M0D2 code is based on a nonhomogeneous and nonequilibrium model for the two-phase system that is solved by a fast, partially implicit numerical scheme to permit economical calculation of system transients. The objective of the RELAP5 deveTopment effort from the outset was to produce a code that includes important first-order effects necessary for 
accurate prediction of system transients but is sufficientiy simple and cost-effective such that parametric or sensitivity studies are possible. The development of SCDAP/RELAP5 has this same focus.

The SCDAP code models the core behavior during a severe accident. Treatment of the core includes fuel rod heatup, ballooning and rupture, fission product release, rapid oxidation, zircaloy melting, $\mathrm{UO}_{2}$ dissolution, $\mathrm{ZrO}_{2}$ breach, flow and freezing of molten fuel and cladding, and debris formation and behavior. The code also models control rod and flow shroud behavior.

The TRAP-MELT code models the behavior of fission products and aerosols within the RCS. This treatment includes aerosol agglomeration (including Brownian motion, gravitational settling, and turbulent eddy effects), aerosol deposition (including gravitational settling, thermophoresis, and diffusion from laminar or turbulent flow), fission product evaporation and condensation, and chemsorption of vapors by stainless stee1.

The code includes many generic component models from which general systems can be simulated. The component models include fuel rods, control rods, pumps, valves, pipes, heat structures, reactor point kinetics, electric heaters, jet pumps, turbines, separators, accumulators, and control system components. In addition, special process models are included for effects such as form loss, flow at an abrupt area change, branching, choked flow, boron tracking, and noncondensible gas transport.

The system mathematical models are coupled into an efficient code structure. The code includes extensive input checking capability to help the user discover input errors and inconsistencles. Also included are free-format input, internal plot capability, restart, renodalization, and variable output edit features. These user conveniences were developed in recognition that generally the major cost associated with the use of a system transient code is in the engineering labor and $t$ ime involved in accumulating system data and developing system models, while the computer cost associated with generation of the final result is usually small. 
The development of the models and codes that constitute SCDAP/RELAP5 has spanned approximately 12 years from the early states of RELAP5 numerical scheme development to the present. SCDAP/RELAP5 represents the aggregate accumulation of experience in modeling core behavior during severe accidents, fission product and aerosol behavior, two-phase flow process, and LWR systems. The code development has benefited from extensive application and comparison to experimental data in the LOFT, PBF, Semiscale, ACRR, NRU, and other experimental programs.

Volumes I and II describe the basic theory and numerical methods used for the varlous system models. Volume III gives detalled descriptions of the input preparation and execution procedures and provides general guidelines on code application. 
○

-

- 
Development of a complex computer code such as SCDAP/RELAP5 is the result of a team effort. Acknowledgment is made of those who made significant contributions to the earlier versions of RELAP5, SCDAP, and TRAP-MELT; in particular, K. E. Carlson, Dr. H. H. Kuo, Dr. J. C. Lin, Dr. H. Chow, Dr. C. C. Tsai, L. R. Feinauer, and Dr. W. Bryce (UKAEA) for contributions to the RELAP5 code; G. H. Beers, E. R. Carlson, and 1. M. Howe for contributions to the SCDAP code; and M. R. KuIman, J. A. Gieseke, H. Jordan, and P. Baybutt for contributions to the TRAP-MELT code. Acknowledgment is also made to E. C. Johnson for her work in SCDAP/RELAP5 configuration control and user services.

The SCDAP/RELAP5 Program is indebted to the technical monitors responsible for directing the overall program; Mr. W. Lyon, Drs. J. Han, R. Landry, R. Lee, and $Y$. Chen, of the U.S. Nuclear Regulatory Commission and Dr. D. Majumdar. Mr. N. Bonicelli, and Mr. G. Berna, of the Department of Energy-Idaho Operations Office. Finally, acknowledgment is made of all the code users who have been very helpful in stimulating timely correction of code deficiencies. 
-

-

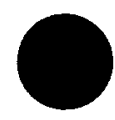




\section{CONTENTS}

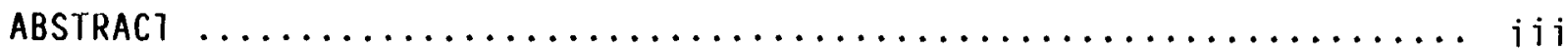

EXECUTIVE SUMMARY $\ldots \ldots \ldots \ldots \ldots \ldots \ldots \ldots \ldots \ldots \ldots \ldots \ldots \ldots$

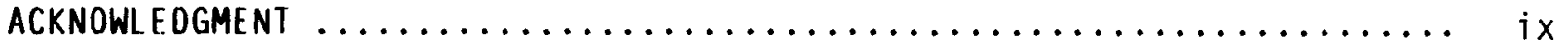

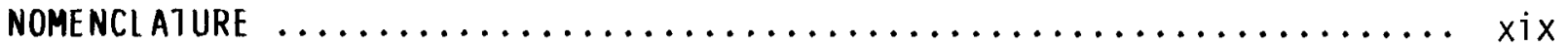

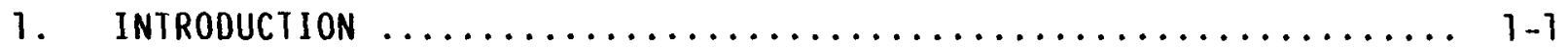

1.1 General Code Capabilities ..................... 1-1

1.2 Relationship to 0 ther NRC-Sponsored Software $\ldots \ldots \ldots \ldots \ldots$ 1-3

1.3 Status and Future Development Plans $\ldots \ldots \ldots \ldots \ldots \ldots \ldots \ldots$ 1-4

1.4 Quality Assurance $\ldots \ldots \ldots \ldots \ldots \ldots \ldots \ldots \ldots \ldots \ldots \ldots \ldots \ldots$

1.5 References $\ldots \ldots \ldots \ldots \ldots \ldots \ldots \ldots \ldots \ldots \ldots \ldots \ldots \ldots \ldots \ldots$

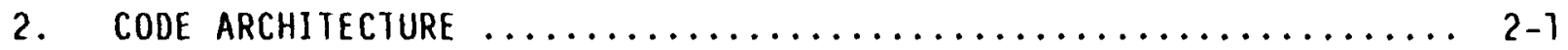

2.1 Computer Adaptability ...................... 2-1

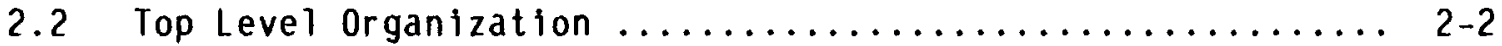

2.3 Input Processing overview $\ldots \ldots \ldots \ldots \ldots \ldots \ldots \ldots \ldots \ldots \ldots \ldots \ldots \ldots$

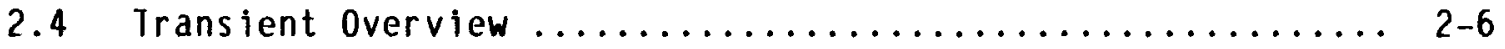

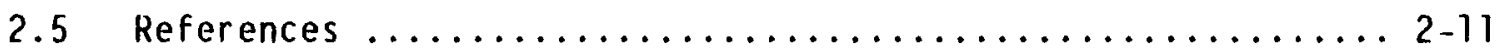

3. SEVERE ACCIDENT STRUCTURAL BEHAVIOR MODELS $\ldots \ldots \ldots \ldots \ldots \ldots \ldots \ldots$

3.1 Material 0xidation Mode1 ..................... 3-2

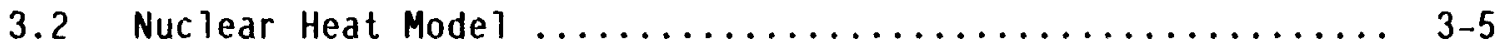

3.2.1 Fission Product Decay Power ................ 3-10

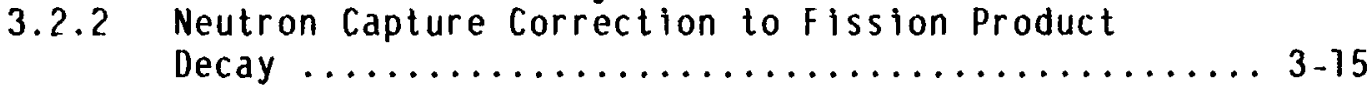

3.2.3 Actinide Decay Power ..................... 3-16

3.2.4 Radial Peaking Factor for Delayed Heat .......... 3-19

3.3 Effective Materials Properties Models .................. 3-19

3.3.7 Paralle1 and Series-Resistance Approach ......... 3-20

3.3.2 Integral Transformation Technique ............. 3-22

3.3.3 Application of Parallel and Series-Resistance Approaches in the Effective Heat Transfer Model (EFFHT) 
3.3.4 Model for Calculating Effective Volumetric Heat Generation .............................. 3-28

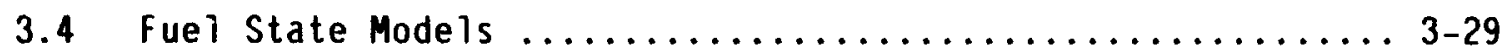

3.5 Heat Conduction Mode $\ldots \ldots \ldots \ldots \ldots \ldots \ldots \ldots \ldots \ldots \ldots .32$

3.5.1 Formulation of the Heat Conduction Governing

Equations .............................. 3-33

3.5.2 The Method of Weighted Residuals ............. 3-35

3.5.3 Two-Dimensional Conduction Solution/Reflood Model

for SCDAP Core Components ................. 3-42

3.6 Cladding Deformation Mode $15 . \ldots \ldots \ldots \ldots \ldots \ldots \ldots \ldots \ldots .43-43$

3.6.1 Sausage-Type Deformation Mode1 ............... 3-44

3.6.2 Localized Deformation Model .................... 3-50

3.7 Fuel Rod Internal Gas Pressure Model $\ldots \ldots \ldots \ldots \ldots \ldots \ldots$ 3-52

3.7.1 Correlations for Vold Volumes for Standard PWR and

BWR Fuel Rods ........................... 3-53

3.7.2 Corrections in Void Volume Calculations Due to

Varlation from Standard Design ............... 3-68

3.8 Liquefaction, Flow, and Solidification Model ........... 3-70

3.8.1 Calculation of where the Cladding and Fuel Have

Been Liquefied ............................. 3-76

3.8.2 Breach of Cladding Surface $\mathrm{ZrO}_{2}$ Layer ........... 3-78

3.8.3 Relocation of Liquefied $\mathrm{Zr}-\mathrm{U}-0 \ldots \ldots \ldots \ldots \ldots \ldots \ldots \ldots . \ldots \ldots$

3.8.4 Variable Initiation ........................ 3-93

3.9 Fission Product Release Models .................... 3-95

3.9.1 Release Model for Intact Rods .............. 3-95

3.9.2 Release During $\mathrm{UO}_{2}$ Liquefaction and

Fragmentation ..........................

3.9.3 Enthalpy of Reieased Gases ....................

3.10 Control Rod and Core Structure Mode 15 ................

3.10.1 Control Rod Models ........................ 3-117

3.10.2 Flow Shroud Mode 15 ................................

3.10.3 Spacer Grid Model ..........................

3.10.4 Boron Carbide Control Rod Model .................. 3-118

3.11 Radiation Model Description ........................ 3-133

3.11.1 Radiation Mode1 Governing Equations ............3-133

3.11 .2 View Factors ................................... 
3.11 .3 Mean Path Length ......................... 3-150

3.11 .4 Absorptivities and Emissivities ................ 3-151

3.12 Core Region Debris Modeling ....................

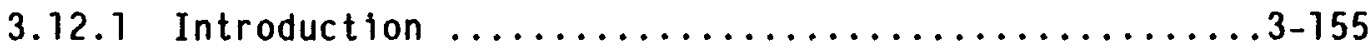

3.12 .2 Formation and Heatup of Nonporous Debris ...........

3.12.3 Formation and Heatup of Porous Debris ............ 3-161

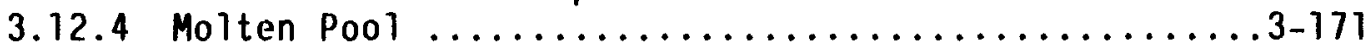

3.13 Core Slumping Models ........................

3.14 Model for Heatup of Lower Plenum Debris ............. 3-181

3.14.1 COUPLE Description ...................... 3-182

3.14.2 Variable Element Porosity ................... 3-183

3.14.3 Thermal Conductivity Model ................... 3-184

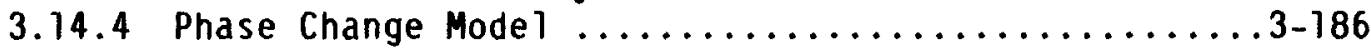

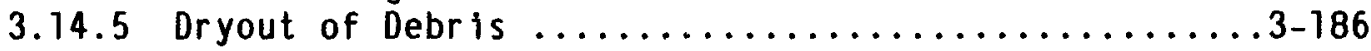

3.15 Model for Creep Rupture of Structural Components .........3-187

3.16 Model for CORA Out-of-Płle Experiments .............. 3-190

3.16.1 Description of the Electric Heater Rod Mode1 ......3-190

3.17 References ................................

4. AEROSOL AND FISSION PRODUCT BEHAVIOR $\ldots \ldots \ldots \ldots \ldots \ldots \ldots \ldots \ldots \ldots$

4.1 Formulation of the Fission Product Transport

Problem .................................. 4-1

4.2 Aerosol Agglomeration Models $\ldots \ldots \ldots \ldots \ldots \ldots \ldots \ldots \ldots . . \ldots$ 4-3

4.2.1 Definition of Particle Size Bins ............ 4-4

4.2.2 Agglomeration of Particles from Brownian Motion .... 4-6

4.2.3 Agglomeration Due to Differential Gravitational

Settling and Turbulence .................. 4-8

4.2.4 Total Agglomeration Kerne1 ............... 4-12

4.3 Aerosol Particle Deposition Models ................ 4-12

4.3.1 Gravitational Settling ................. 4-16

4.3.2 Thermophoresis ....................... 4-17

4.3.3 Diffusion and Inertial Deposition from Turbulent

Flow ................................4 4-19

4.3.4 Diffusion from Laminar Flow ................ 4-27

4.3.5 Effects of Pipe Bends ................... 4-22

4.4 Vapor Evaporation and Condensation $\ldots \ldots \ldots \ldots \ldots \ldots \ldots \ldots$ 
4.5 Heterogeneous Chemical Reaction between

Chemical Species and Walls .................... 4-30

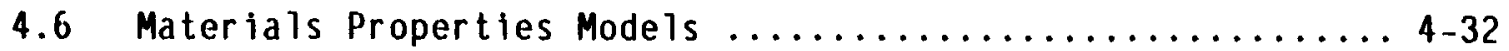

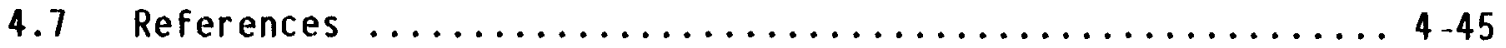

5. DECAY HEAT DISTRIBUIIONS FOR VOLATILES RELEASED

FOLLOWING FUEL DISRUPTION ........................ $5-1$

5.1 Fission Product Decay Heat Mode1 $\ldots \ldots \ldots \ldots \ldots \ldots \ldots \ldots$ 5-1

5.2 Fission Product Decay Heat Methodology $\ldots \ldots \ldots \ldots \ldots \ldots$ 5-1

5.2.1 Fission Product Decay Heat Model Results ........ 5-2

5.2.2 Fission Product Decay Heat Model Additional

Observations ........................ 5-2

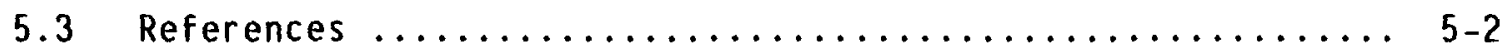

6. SCDAP/RELAP5 DECAY HEAT DEPOSITION MODEL $\ldots \ldots \ldots \ldots \ldots \ldots \ldots \ldots \ldots$

6.1 Energy Deposition Mode $1 \ldots \ldots \ldots \ldots \ldots \ldots \ldots \ldots \ldots \ldots \ldots$. 6 .

6.1.1 Gamma Energy Deposition-.Airborne Release ........ 6-7

6.1.2 Deposited Fission Product Release--Gamma Energy .... 6-2

6.1 .3 Beta Energy Deposition .................... 6-2

6.1.4 Deposited Fission Product Release--Beta Energy ..... 6-4

6.2 Gamma Attenuation Complete Absorption Model .......... 6-4

6.2.1 Partial Absorption Model ............... 6-6

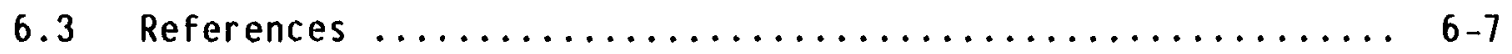

APPENDIX A--DISTRIBUTION OF AGGLOMERATED PARTICLES $\ldots \ldots \ldots \ldots \ldots \ldots \ldots$

APPENDIX B--DERIVATION OF GAS DENSITY EQUATION .............. B-1

APPENDIX C--DERIVATION OF EQUATIONS FOR EQUILIBRIUM VAPOR

CONCENTRATIONS FROM VAPOR PRESSURE INFORMATION $\ldots \ldots \ldots \ldots \ldots \ldots \ldots c-1$

FIGURES

1-1. SCDAP/RELAP5 reactor coolant system interactions $\ldots \ldots \ldots \ldots \ldots . \ldots 1-2$

$2-1 . \operatorname{SCDAP} /$ RELAP5 top leve1 structure $\ldots \ldots \ldots \ldots \ldots \ldots \ldots \ldots \ldots \ldots$

2-2. Modular structures of transient calculations in SCDAP/RELAP5 ... 2-7

2-3. Transient (steady-state) block structure $\ldots \ldots \ldots \ldots \ldots \ldots \ldots \ldots$ 


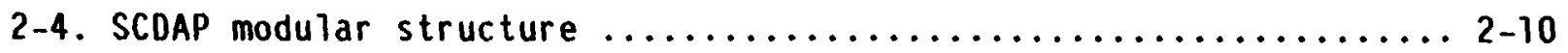

3-1. Comparison of decay heat components $\ldots \ldots \ldots \ldots \ldots \ldots \ldots \ldots . . \ldots \ldots$

3-2. Estimation of effective volumetric heat capacity in a

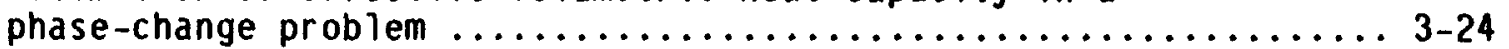

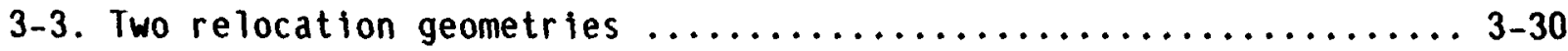

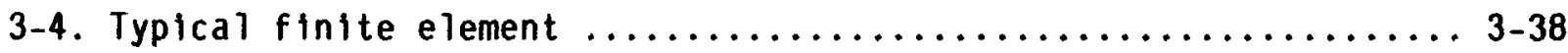

3-5. Relative plenum volume, $R_{p}$, resulting from FRAPCON-2 calculations for a standard PWR fuel rod design $\ldots \ldots \ldots \ldots \ldots . . .636$

3-6. Relative fuel void volume, Rvoid, resulting from FRAPCON-2 calculations for a standard PWR fuel rod design ............. 3-57

3-7. Relative plenum volume, $R_{p}$, resulting from FRAPCON-2 calculations for a standard BWR fuel rod design .............. 3-58

3-8. Relative fuel void volume, Rvoid, resulting from FRAPCON-2 calculations for a standard BWR fuel rod design ............. 3-59

3-9. Relative plenum volume, $R_{p}$, depending on standard case $R_{p, s t a n d}$ and correction factor, $K_{p} \ldots \ldots \ldots \ldots \ldots \ldots \ldots \ldots \ldots, 3-71$

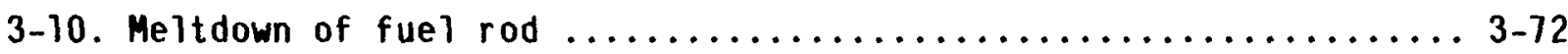

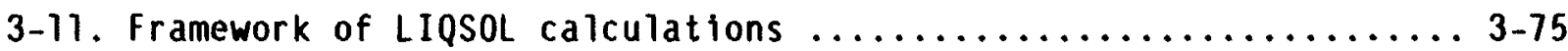

3-12. Frame of reference for LIQSOL equations in Table $3-12 \ldots \ldots \ldots .3-81$

3-13. Heat transfer from flowing mixture into axial slice of fuel

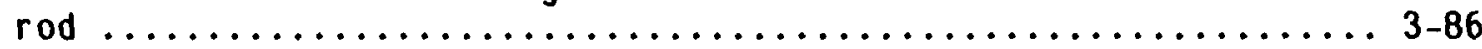

3-14. Axial slices at which equations are solved $\ldots \ldots \ldots \ldots \ldots \ldots . . \ldots .67$

3-15. Initial cladding temperature distribution for calculations, assuming finite thickness $\ldots \ldots \ldots \ldots \ldots \ldots \ldots \ldots \ldots \ldots \ldots \ldots \ldots \ldots \ldots \ldots . \ldots \ldots$

3-16. Hydrogen enthalpy calculated using Equation (3-157) ..........

3-17. Nodalization for fuel assemblies and control rods ............

3-18. $\mathrm{B}_{4} \mathrm{C}$ oxidation rate coefficient as a function of temperature ....3-124

3-19. One-dimensional, two-region nodalization for temperature response calculation ................................................ 25

3-20. Incompressible, viscous film flow over cylindrical geometry ....3-130 3-21. Slumping process for unsupported control rod segment $\ldots \ldots \ldots \ldots 3-132$ 
3-22. Radiation exchange between surfaces and between surfaces

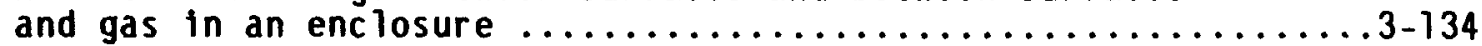

3-23. Radiation exchange between a rod surface and its

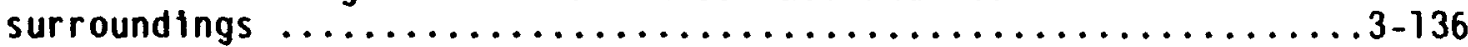

3-24. Geometry for determining view factors between rods $\ldots \ldots \ldots \ldots$ 3-145

3-25. Heat conduction process modeled for cohesive debris .......... 3-159

3-26. Example of calculated layout of rod-7ike and cohesive debr is

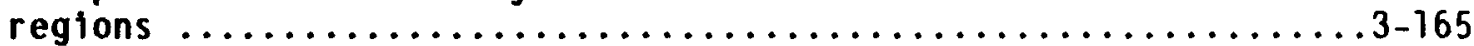

3-27. Configuration of partially quenched debris bed $\ldots \ldots \ldots \ldots \ldots \ldots 3-168$

3-28. Simplification applied in modeling movement of liquefied

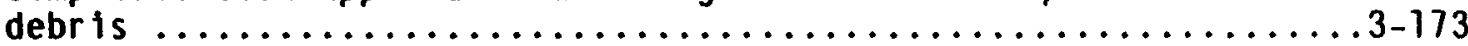

3-29. Heat transfer from pool of molten debris $\ldots \ldots \ldots \ldots \ldots \ldots \ldots \ldots$.

3-30. Postulated sequence of events leading to core material

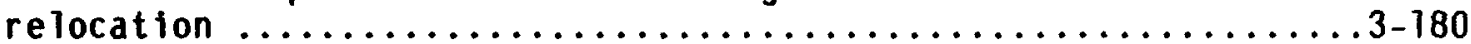

4-1. Major physical states and couplings at high temperature $\ldots \ldots \ldots 4-2$

4-2. Element of volume used to illustrate steady-state and we11mixed assumptions ............................... 4-14

4-3. Diagram used to calculate the fraction of particles that do not $h i t$ the pipe wall at a $90^{\circ}$ bend .................... 4-25

5-1. Decay heat contributions of selected elements (based on total decay heat of all released fission products) $\ldots \ldots \ldots \ldots \ldots \ldots \ldots 5-3$

A-1 Distribution of particles resulting from coagulation of a particle from bin $L_{1}$ and a particle from bin $L_{2} \ldots \ldots \ldots \ldots \ldots$

\section{TABLES}

3-1. Energy release from fission of $235 u \ldots \ldots \ldots \ldots \ldots \ldots \ldots \ldots$

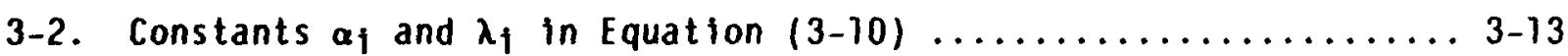

3-3. G Factors for times greater than $10,000 \mathrm{~s} \ldots \ldots \ldots \ldots \ldots \ldots \ldots$

3-4. PWR fuel rod data input for FRAPCON-2 calculations $\ldots \ldots \ldots \ldots . . .35$

3-5. BWR fuel rod data input for FRAPCON-2 calculations $\ldots \ldots \ldots \ldots \ldots 3-55$

3-6. Coefficients $(a, b, \alpha, \beta, Y)$ of the general empirical correlation for calculation of relative void volumes 
3-7. Relative fuel void volume, $R_{p}$, of a standard PWR fuel rod, comparison between FRAPCON-2 and FPRESS calculations ........ 3-62

3-8. Relative fuel void volume, Rvoid, of a standard PWR fuel rod, comparison between FRAPCON-2 and FPRESS calculations ......... 3-63

3-9. Relative plenum volume, $R_{p}$, of a standard BWR fuel rod, comparison between FRAPCON-2 and FPRESS calculations ......... 3-64

3-10. Relative fuel void volume, Rvoid, of a standard BWR fuel rod, comparison between FRAPCON-2 and FPRESS calculations ........ 3-65

3-11. Simplifying assumptions in the LIQSOL mode $1 \ldots \ldots \ldots \ldots \ldots \ldots \ldots$

3-12. Equation set for calculation of velocity and temperature of

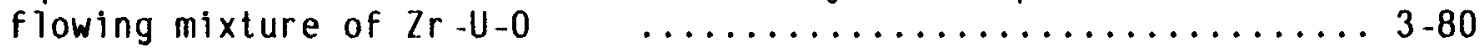

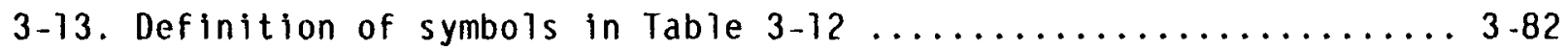

3-14. Definition of variables in Equation $(3-140) \ldots \ldots \ldots \ldots \ldots$

3-15. Adjustable constants for cesium and iodine release

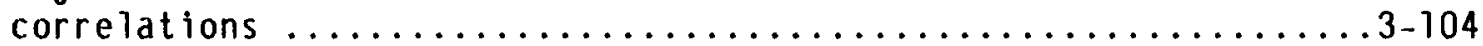

3-16. Constants $K 0$ and 0 in release rate coefficients taken from

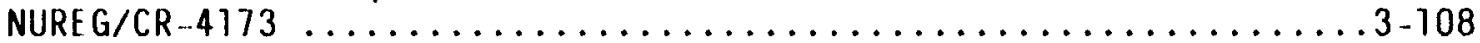

3-17. Thermodynamic properties of gap gases $\ldots \ldots \ldots \ldots \ldots \ldots \ldots \ldots \ldots \ldots 3-114$

3-18. Water vapor absorption data at $300 k \ldots \ldots \ldots \ldots \ldots \ldots \ldots \ldots \ldots \ldots$

3-19. Equations for calculating the time to creep rupture ........ 3-189

4-1. Vapor deposition velocities for heterogeneous chemical

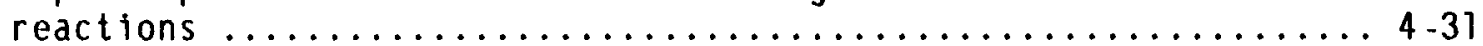

4-2. Required materials properties $\ldots \ldots \ldots \ldots \ldots \ldots \ldots \ldots \ldots \ldots \ldots$

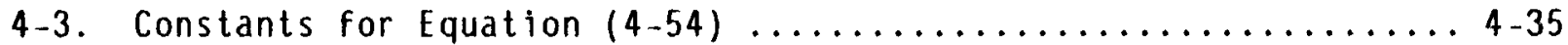

4-4. Constants used in gas thermal conductivity correlations ......4.43

5-1. Fractional decay heat contributions for selected fission product elements (based on total decay heat from all

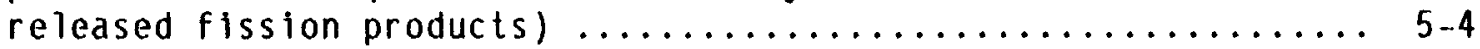

5-2. Estimated gamma decay power fractions for released fission products (based on total decay heat from all released fission

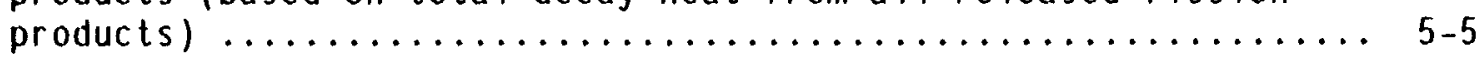

C -1 . Constants for Equation $(C-14) \ldots \ldots \ldots \ldots \ldots \ldots \ldots \ldots \ldots \ldots \ldots \ldots$ 
-

-

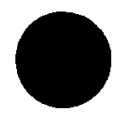


NOME NCL ATURE

A

$A_{1}$

$A_{\mathrm{l}}$

$A_{t}$

a

B

$\mathrm{B}_{1}$

b

$B_{X}$

By

C

$c_{0}$

$c_{d}$

$c_{g}$

$c_{p}$

$c_{V}$

c

D

$\mathrm{D}_{0}$

D)

Cross-sectional area $\left(\mathrm{m}^{2}\right)$, coefficient matrix in hydrodynamics, coefficient in pressure and velocity equations

Coefficient in heat conduction equation at boundaries

Surge line cross-sectional area $\left(\mathrm{m}^{2}\right)$

Throat area $\left(\mathrm{m}^{2}\right)$

Speed of sound $(\mathrm{m} / \mathrm{s})$, interfacial area per unit volume $\left(\mathrm{m}^{-1}\right)$, coefficient in gap conductance, coefficient in heat conduction equation, absorption coefficient

Coefficient matrix, drag coefficient, coefficient in pressure and velocity equations

Coefficient in heat conduction equation at boundaries

Coefficient in heat conduction equation, source vector in hydrodynamics

Body force in $x$ coordinate direction $\left(\mathrm{m} / \mathrm{s}^{2}\right)$

Body force in y coordinate direction $\left(\mathrm{m} / \mathrm{s}^{2}\right)$

Coefficient of virtual mass, general vector function, coefficient in pressure, and velocity equations delay neutron precursors in reactor kinetics, concentration

Coefficient in noncondensible energy equation $(\mathrm{J} / \mathrm{kg} \cdot \mathrm{K})$

Drag coefficient

Dimensional constant in correlation for $\Gamma_{\mathrm{g}}$

Specific heat at constant pressure $(J / \mathrm{kg} \cdot \mathrm{K})$

Specific heat at constant volume $(\mathrm{J} / \mathrm{kg} \cdot \mathrm{K})$

Coefficient in heat conduction equation, coefficient in new time volume-average velocity equation

Coefficient of relative Mach number, diffusivity, diameter $(\mathrm{m})$, heat conduction boundary condition matrix, coefficient in pressure and velocity equations

Coefficient in noncondensible energy equation $\left(\mathrm{J} / \mathrm{kg} \cdot \mathrm{K}^{2}\right)$

Coefficient of heat conduction equation at boundaries 
d

DISS

E

e

$\mathrm{Eu}$

F

FIF, FIG

FI

FWF , FWG

$f$

Ghead

G

Gc

Gr

g

$g_{Z}, g$

H

HLOSSF,

HLOSSG

h

$\mathrm{h}_{\mathrm{L}}$
Coefficient in heat conduction equation, droplet diameter (m)

Energy dissipation function $\left(W / \mathrm{m}^{3}\right)$

lotal energy $\left(U+v^{2} / 2\right)(\mathrm{J} / \mathrm{kg})$, enissivity, Young's modulus, term in iterative heat conduction algorithm, coefficient in pressure equation

Interfacial roughness

Euler number

lerm in iterative heat conduction algorithm, gray-body factor with subscript, frictional loss coefficient, vertical stratification factor

Interphase drag coefficients (liquid, vapor) $\left(s^{-1}\right)$

Interphase drag coefficient $\left(\mathrm{m}^{3} / \mathrm{kg} \cdot \mathrm{s}\right)$

Wall drag coefficients (liquid, vapor) $\left(\mathrm{s}^{-1}\right)$

Interphase friction factor, vector for liquid velocities in hydrodynamics

Pressure drop across valve due to gravity (Pa)

Mass velocity $(\mathrm{kg} / \mathrm{s})$, shear stress, gradient, coefficient in heat conduction, vector quantity, fraction of delayed neutrons in reactor kinetics

Dynamic pressure for valve (Pa)

Grashof number

Gravitational constant $\left(\mathrm{m} / \mathrm{s}^{2}\right)$, temperature jump distance $(\mathrm{m})$, vector for vapor velocities in hydrodynamics

Acceleration due to gravity $\left(\mathrm{m} / \mathrm{s}^{2}\right)$

Elevation $(m)$, volumetric heat transfer coefficient $\left(W / K \cdot m^{3}\right)$, head $(m)$

Form or frictional losses (1iquid, vapor) $(\mathrm{m} / \mathrm{s})$

Specific enthalpy $(\mathrm{J} / \mathrm{kg})$, heat transfer coefficlent $\left(W / m^{2} \cdot K\right)$, energy transfer coefficient for $\Gamma_{g}$, head ratio Dynamic head loss $(\mathrm{m})$ 


\section{$k_{B}$}

$$
k_{s}
$$

\section{ll}

M

N

$\mathrm{Nu}$

$$
\text { n }
$$

Identity matrix, moment of inertia $\left(N-m-s^{2}\right)$

Junction velocity $(\mathrm{m} / \mathrm{s})$

Energy form loss coefficient

Thermal conductivity $(\mathrm{W} / \mathrm{m} \cdot \mathrm{K})$

Boltzmann constant

Spring constant

Length, limit function

Surge line length (m)

Liquid level (m)

Mach number, molecular weight, pump two-phase multiplier, mass transfer rate, mass $(\mathrm{kg})$

Number of system nodes, number density $\left(\# / \mathrm{m}^{3}\right)$, pump speed $(\mathrm{rad} / \mathrm{s})$

Nusselt number

Unit vector, order of equation system

Valve closing back pressure $(\mathrm{Pa})$

Pressure $(\mathrm{Pa})$, reactor power $(W)$, channel perimeter $(\mathrm{m})$, turbine power $(\mathrm{J} / \mathrm{s})$

Nitrogen pressure in dome $(\mathrm{Pa})$

Relates reactor power to heat generation rate in heat structures

Atmospheric pressure (Pa)

Wetted perimeter (m), particle probability function

Specified pressure required to close a valve (Pa)

Prandt 7 number

Volumetric heat addition rate $\left(\mathrm{W} / \mathrm{m}^{3}\right)$, space dependent function, volumetric flow rate $\left(\mathrm{m}^{3} / \mathrm{s}\right)$

Total heat transfer to vapor dome (W)

Heat transfer rate $(W)$, heat flux $\left(W / m^{2}\right)$ 


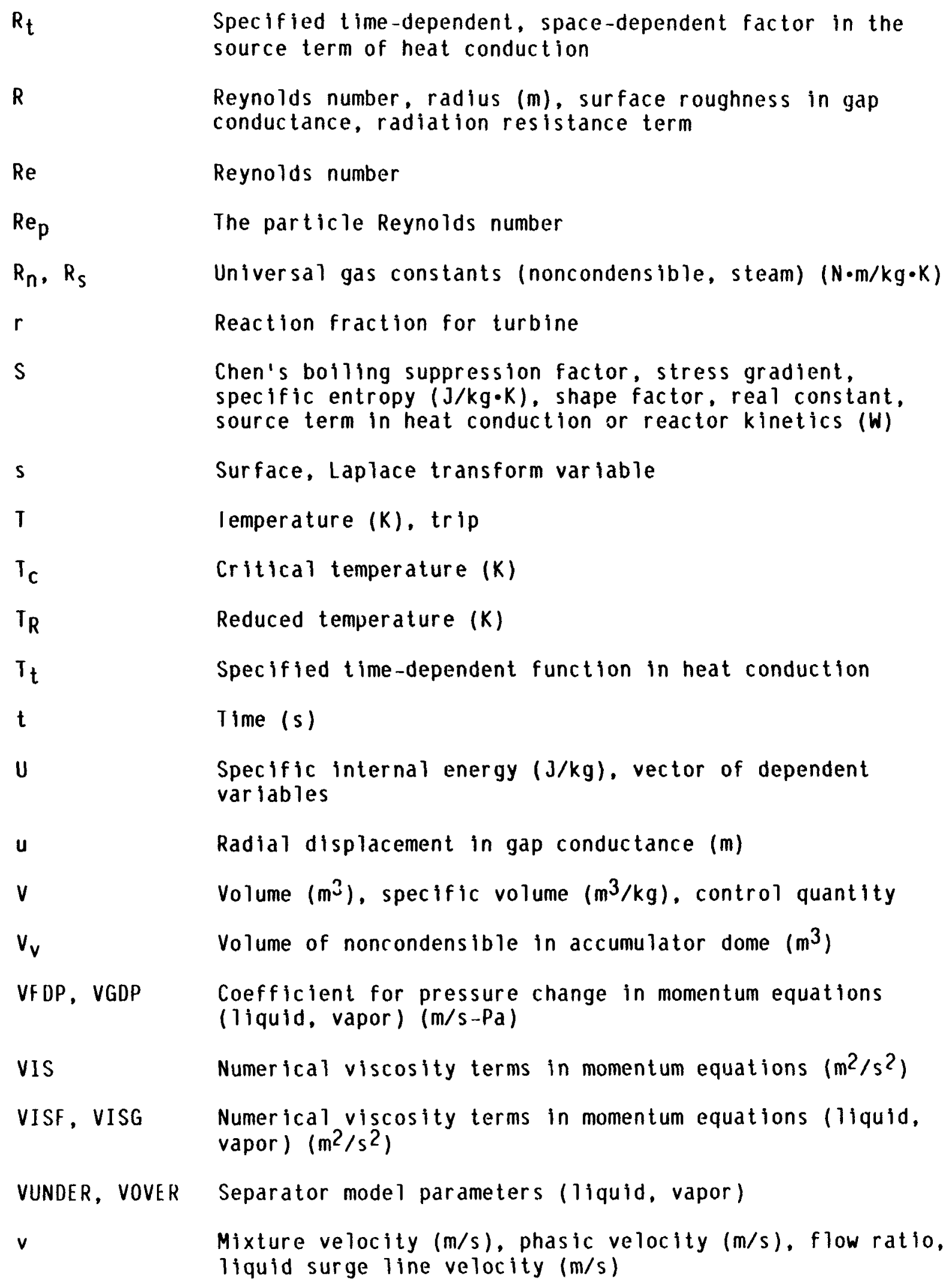

$R_{t}$

R

Re

$\mathrm{Re}_{\mathrm{p}}$

$\mathrm{R}_{\mathrm{n}}, \mathrm{R}_{\mathrm{s}}$

$r$

S

$\mathbf{S}$

T

$T_{c}$

$T_{R}$

$T_{t}$

$\mathrm{t}$

U

u

v

$v_{v}$

VFDP, VGDP

VIS

VISF, VISG

VUNDER, VOVER

V

Specified time-dependent, space-dependent factor in the source term of heat conduction

Reynolds number, radius (m), surface roughness in gap conductance, radiation resistance term

Reynolds number

The particle Reynolds number

Universal gas constants (noncondensible, steam) $(\mathrm{N} \cdot \mathrm{m} / \mathrm{kg} \cdot \mathrm{K})$

Reaction fraction for turbine

Chen's bolling suppression factor, stress gradient, specific entropy $(\mathrm{J} / \mathrm{kg} \cdot \mathrm{K})$, shape factor, real constant, source term in heat conduction or reactor kinetics (W)

Surface, Laplace transform variable

lemperature (K), trip

Critical temperature (K)

Reduced temperature (K)

Specified time-dependent function in heat conduction

Time (s)

Specific internal energy $(\mathrm{J} / \mathrm{kg})$, vector of dependent variables

Radial displacement in gap conductance (m)

Volume $\left(\mathrm{m}^{3}\right)$, specific volume $\left(\mathrm{m}^{3} / \mathrm{kg}\right)$, control quantity

Volume of noncondensible in accumulator dome $\left(\mathrm{m}^{3}\right)$

Coefficient for pressure change in momentum equations

(1 iquid, vapor) (m/s-Pa)

Numerical viscosity terms in momentum equations $\left(\mathrm{m}^{2} / \mathrm{s}^{2}\right.$ )

Numerical viscosity terms in momentum equations (1iquid, vapor) $\left(\mathrm{m}^{2} / \mathrm{s}^{2}\right)$

Separator model parameters (1iquid, vapor)

Mixture velocity $(\mathrm{m} / \mathrm{s})$, phasic velocity $(\mathrm{m} / \mathrm{s})$, flow ratio, liquid surge line velocity $(\mathrm{m} / \mathrm{s})$ 


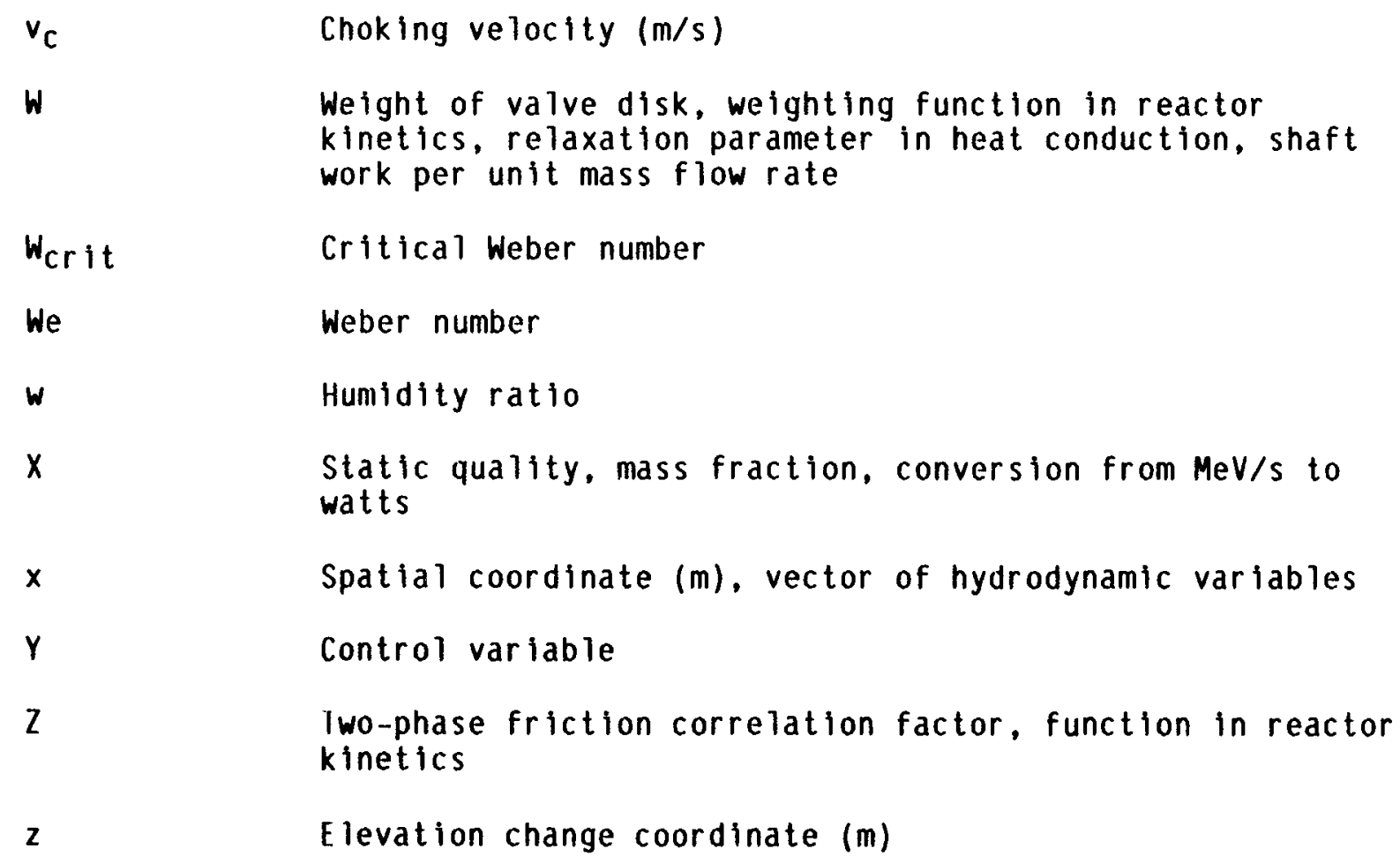

\section{Symbols}

$\alpha$

Void fraction, subscripted volume fraction, angular acceleration $\left(\mathrm{rad}_{/} \mathrm{s}^{2}\right)$, coefficient for least-squares $\mathrm{fit}$, speed ratio

$\beta$

Coefficient of isobaric thermal expansion $\left(K^{-1}\right)$, effective delayed neutron fraction in reactor kinetics

$\Gamma$

Volumetric mass exchange rate $\left(\mathrm{kg} / \mathrm{m}^{3} \cdot \mathrm{s}\right)$

$\Delta P_{f}$

Dynamic pressure loss $(\mathrm{Pa})$

$\Delta \mathrm{P}_{\mathrm{S}}$

Increment in steam pressure $(\mathrm{Pa})$

$\Delta V_{S}$

Increment in specific volume of steam $\left(\mathrm{m}^{3} / \mathrm{kg}\right)$

$\Delta \mathrm{t}$

Increment in time variable (s)

$\Delta \mathrm{t}_{\mathrm{c}}$

Courant time step (s)

$\Delta x$

Increment in spatial variable (m)

Area ratio, truncation error measure, film thickness $(\mathrm{m})$, impulse function. Deryagin number 
Coefficient, strain function, emissivity, tabular function of area ratio, surface roughness, wall vapor generation/condensation flag

Diffusion coefficient, multiplier, or horizontal stratification terms

Efficiency, bulk/saturation enthalpy flag

Relaxation time in correlation for $\Gamma$, angular position (rad)

Coefficient of isothermal compressibility $\left(\mathrm{Pa}^{-1}\right)$

Prompt neutron generation time, Baroczy dimensionless property index

Figenvalue, interface velocity parameter, friction factor, decay constant in reactor kinetics

Viscosity $(\mathrm{kg} / \mathrm{m} \cdot \mathrm{s})$

Kinematic viscosity $\left(\mathrm{m}^{2} / \mathrm{s}\right)$, Poisson's ratio

Exponential function, RMS precision

3.141592654

Density $\left(\mathrm{kg} / \mathrm{m}^{3}\right)$, reactivity in reactor kinetics (dollars)

Fission cross section

Depressurization rate $(\mathrm{Pa} / \mathrm{S})$

Surface tension $\left(\mathrm{J} / \mathrm{m}^{2}\right)$, stress, flag used in heat conduction equations to indicate transient or steady-state

Shear stresses $(N)$, torque $(N-m)$

Donored property, Lockhart-Martinel1i two-phase parameter, neutron flux in reactor kinetics, angle of inclination of valve assembly

lockharl-Martinelli parameter

Coefficient, fission rate (number/s)

Angular velocity ( $\mathrm{rad} / \mathrm{s})$, function variable in reactor kinetics 


\section{Subscripts}

a

B

b

CHF

C

$\mathrm{cm}$

con

cr

D

d

e

$\exp$

F

$F B, F B B$

f

$f g$

$f p$

$\mathrm{fr}$

g

ge

H

HE

HF

hy

1

Average value

Boron, dissolved solid

Bubble

value at critical heat flux

Vena contract, continuous phase, cladding, critical property, cross section

Cladding midpoint

Condensation

Critical property or condition

Drive line, vapor dome

Droplet, delay in control component

Thermodynamic equilibrium, equivalent quality in hydraulic volumes, value ring exit, elastic deformation

Used to indicate explicit velocities in choking

Wall friction, fuel

Film boiling, Bromley film bolling

Liquid phase

Phasic difference (i.e., vapor term-liquid term)

Onset of vapor pull-through

Frictional

Vapor phase, gap

Incipient liquid entrainment

llead

Homogeneous equilibrium

Homogeneous frozen

Hydrautic

Interface 
IB

Incipience of boiling

i

j, $\mathbf{j}+1, \mathbf{j}-1$

K

L

$\ell$

$M$

m

NB

n

o

$\mathbf{R}$

$r$

S

s

sat

$T$

TB

$\mathbf{t}$

t t

Inlet, interface

Nucleate bolling

Reference value

Rated values

Suction region

Saturated quantity

Turbulent, tangential

Fully turbulent
Spatial noding indices, junctions

Spatial noding indices, volumes

Spatial noding index, volumes, laminar

Left boundary in heat conduction

Rightmost boundary in heat conduction

Mixt"ie property, motor, mesh point

Noncondensible component of vapor phase

Relative Mach number, right boundary in heat conduction

Steam component of vapor phase

Point of minimum area, turbuient

Transition film boiling 


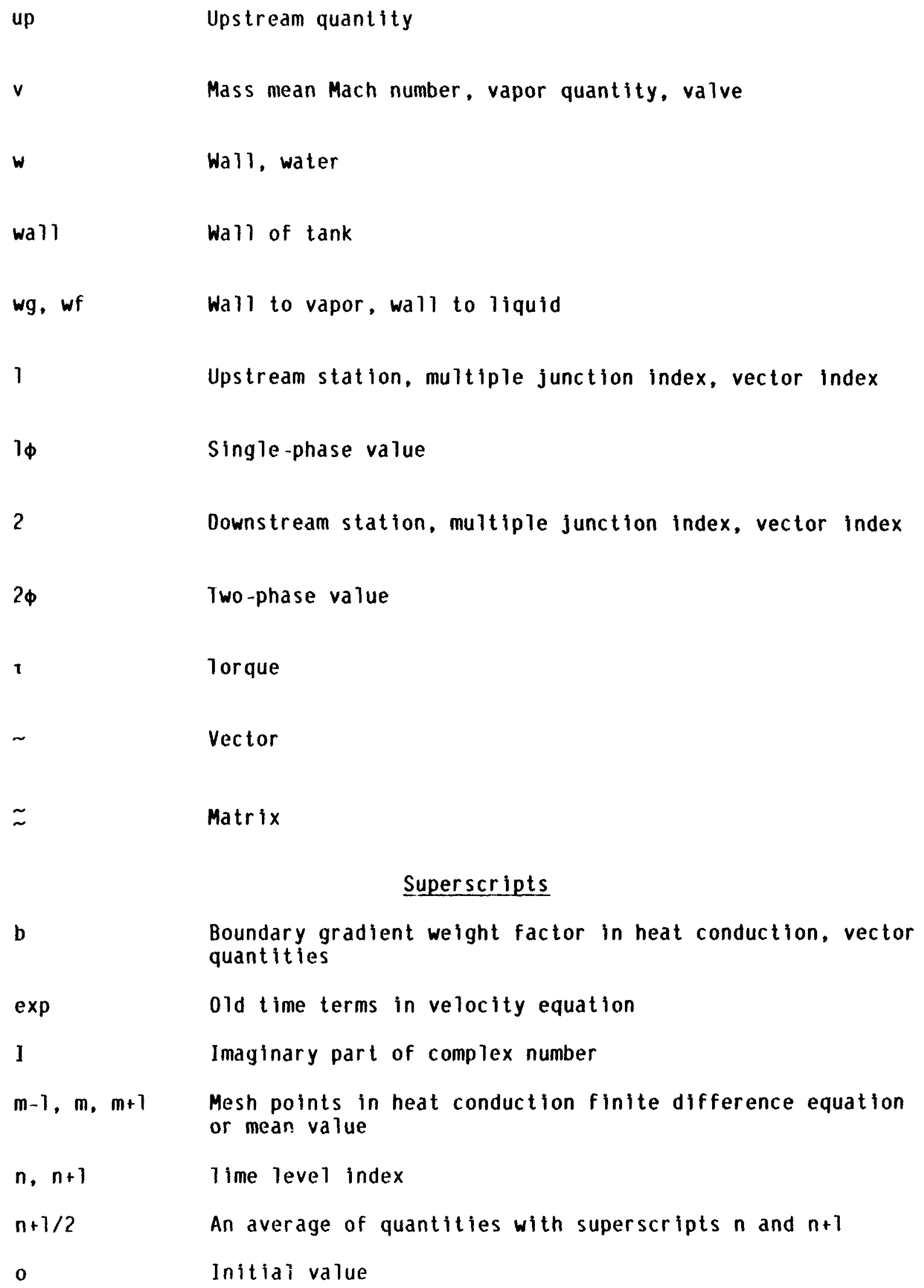

up

v

w

wall

wg, wf

1

$1 \phi$

2

$2 \phi$

1

$\sim$

$\sim$

b

$\exp$

I

$m-1, m, m+1$

$n, n+1$

$n+7 / 2$

o

Upstream quantity

Mass mean Mach number, vapor quantity, valve

Wa11, water

Wall of tank

Wall to vapor, wall to liquid

Upstream station, multiple junction index, vector index

Single-phase value

Downstream station, multiple junction index, vector index

Two-phase value

Torque

Vector

Matrix

\section{Superscripts}

Boundary gradient weight factor in heat conduction, vector quantities

01d time terms in velocity equation

Imaginary part of complex number

Mesh points in heat conduction finite difference equation or mean value

7 ime leve 1 index

An average of quantities with superscripts $n$ and $n+1$ Initiai value 
R

$\gamma$

S

v

$w$

1

2

*

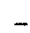

Real part of complex number

Right boundary in heat conduction

Saturation property, space gradient weight factor in heat conduction

Volume gradient weight factor in heat conduction

Wall

Vector index, coefficient in velocity equation

Vector index

lotal derivative of a saturation property with respect to pressure, local variable, bulk/saturation property

Derivative

Vector, average quantity

Donored quantity

Unit momentum for mass exchange, intermediate time variable

Linearized quantity, quality based on total mixture mass 


\section{VOLUME II: SCDAP CODE STRUCTURE, SYSTEM MODELS, AND SOLUTION METHODS}

\section{INTRODUCTION}

The SCDAP/RELAP5 computer code is designed to provide the overall reactor coolant system (RCS) thermal-hydraulic response, core damage progression, and fission product release and transport during severe accidents. The code is being developed at the Idaho National Engineering Laboratory (INEL) under the primary sponsorship of the Office of Nuclear Regulatory Research of the U.S. Nuclear Regulatory Commission (NRC). Secondary sponsors include the U. S. Department of Energy (DOE) and their contractors. The code is currently being used by the NRC, DOE, and associated organizations to support confirmatory experimental research, the TMI-2 accident evaluation, and the analyses of commercial light water reactors (LWRS) and DOE reactors.

\subsection{General Code Capabilities}

The code is the result of merging the RELAP5/MOD2, ${ }^{1-1} \operatorname{SCDAP},{ }^{1-2}$ and TRAP-MELT ${ }^{1-3,4}$ models. The RELAP5 models calculate the overall RCS therma 1-hydraulics, control system interactions, reactor kinetics, and the transport of noncondensible gases, fission products, and aerosols. The SCDAP models calculate the damage progression in the core structures and the formation, heatup, and melting of debris. The TRAP-MELT models calculate the deposition of fission products upon aerosols or structural surfaces; the formation, growth, or deposition of aerosols; and the evaporization of species from surfaces. These models are fully coupled at each time step. Their functional interaction is described in the bubble diagram shown in Figure 1-7.

The overall architecture of the code is described in more detail in Section 2 . 


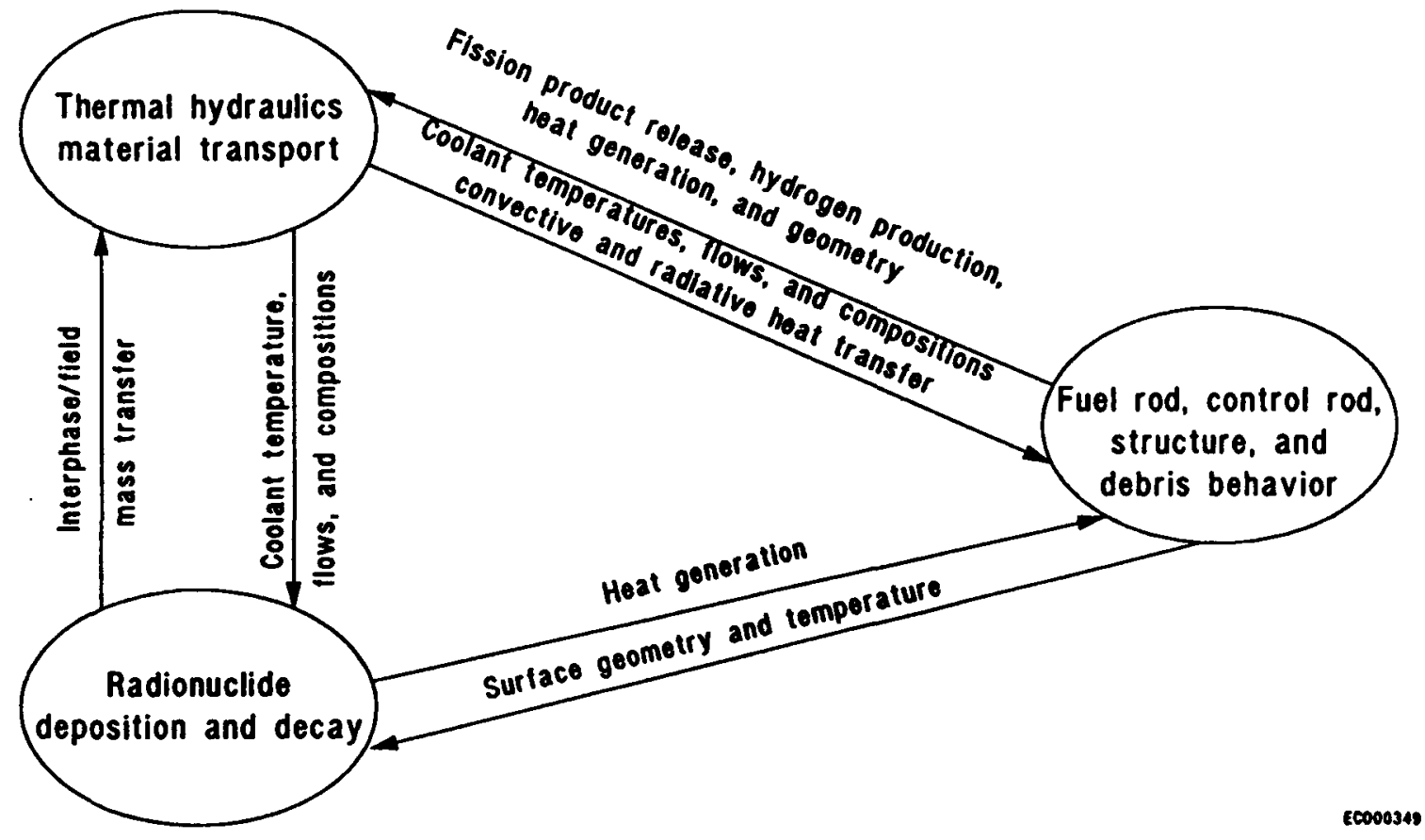

Figure 1-1. SCBAP/RELAP5 reactor coolant system interactions. 
SCDAP/RELAP5 is capable of modeling a wide range of system configurations from single pipes to different experimental facilities to full-scale reactor systems. The configurations can be modeled using an arbitrary number of fluid control volumes and connecting junctions, heat structures, core components, and system components. Flow areas, volumes, and flow resistances can vary with time through either user control or models that describe the changes in geometry associated with damage in the core. System structures can be modeled with RELAP5 heat structures, SCDAP core components, or SCDAP debris models. The RELAP5 heat structures are one-dimensional models with slab, cylindrical, or spherical geometries. The SCDAP core components include representative LWR fue 1 rods, silver-indium-cadmium $(\mathrm{Ag}-\mathrm{In}-\mathrm{Cd})$ and $\mathrm{B}_{4} \mathrm{C}$ control rods or blades, electricaliy heated fuel rod simulators, non-LWR core structures, and general structures. The SCDAP debris models use a general, two-dimensiona 1, finite-element, porous body subcode. The user defines the initial mesh for lower plenum structures and associated debris bed volumes. The debris bed is then created as the problem progresses. System components available to the user include pumps, valves, electric heaters, jet pumps, turbines, separators, and accumulators. Models to describe selected processes, such as fission product transport and deposition, reactor kinetics, control system response, and tracking noncondensible gases, can be invoked through user control. A detailed description of the configurations modeled by the code is presented in Volume III.

\subsection{Relationship to Other NRC-Sponsored Software}

The development of SCDAP/RELAP5 is closely related to the development of RELAP5/MOD3. Both codes share a common source deck. Separate codes are formed only prior to compilation, so changes made to the source deck are automatically reflected in both codes.

The development and application of the code is also related to several other NRC-sponsored software packages. Model improvements, led by theoretical work associated with the development of codes such as MELPROG $^{1-5}$ and FASTGRASS-VFP, ${ }^{1-6}$ include me $1 \mathrm{t}$ ejection from the vessel, 
steam explosions, and fission product release. Material properties are obtained through a standardized MATPRO ${ }^{1-7}$ 1ibrary. Animated plant response displays are possible through links to the Nuclear Plant Analyzer (NPA) ${ }^{1-8}$ display software. Detailed plant simulations from accident initiation through release of fission products to the atmosphere are made available through links to the CONTAIN ${ }^{1-9}$ containment response and CRAC2 ${ }^{1-10}$ or MACCS $^{1-11}$ atmospheric dispersion codes.

\subsection{Status and Future Development Plans}

SCDAP/RELAP5/M0D2 designates the second major modification of SCDAP/RELAP5. M0O2 represents a major expansion in the capability of the code to treat the later phases of an accident. This expansion was driven by SCDAP/RELAP5's role in the analys is of the TMI-2 accident and includes new models that treat

- the formation of debris beds either through the formation of a cohesive mass of molten or solidified material or through the accumulation of loose debris associated with the fragmentation or breakup of core materials;

o heatup and melting of debris beds;

- formation of a molten pool support by a crust of frozen material;

o thinning and fallure of the supporting crust;

- penetration and potential fragmentation of a molten jet of material;

o interaction of debris with the vessel wa11; and

o the fallure of the vessel wall.

M002 also represents major modeling additions in four other areas. First, BWR-specific control blade or rod models have been added to treat the 
unique features of $B_{4} C$. Second, electrically heated fuel rod simulator models have been added to treat fuel rod simulators with central, resistive heating elements. Third, models have been added that describe the thermal or mechanical failure of structures throughout the RCS to evaluate the potential for fallure due to creep rupture. Third, models have been added to treat the decay heating associated with fission products either present in the coolant stream or on structures. Although transparent to the user, MOD2 also incorporates significant changes in the programming structure of SCDAP/RELAP5. All machine-dependent data structures have been removed, greatly reducing the effort necessary to install the code on a variety of computers. Improvements in organization of the code and changes in important algorithms have reduced the run time significantly.

Future releases of the code will be focused on (a) model development to support the application of the code to a wider range of plant designs and conditions, (b) generation of non-CRAY versions of the code, and (c) reductions in the cost of code analysis.

Five major SCDAP/RELAP5 model development activities are underway to support a wider range of code applications:

1. The two-dimensional debris models are being generalized to describe the thermal response of structures embedded in debris beds and debris beds or structures anywhere in the system modeled by the code. As an example, with these changes, a detalled two-dimensional analysis can be performed for instrument tubes surrounded by debris, structures anywhere in the system, or debris carried outside the core or lower plenum. The input for these models is also being expanded to allow the user to initialize the code with preexisting debris beds.

a. Mention of specific products and/or manufacturers in this document implies neither endorsement or preference nor disapproval by the U.S. Government, any of its agencies, or EG\&G Idaho, Inc., of the use of a specific product for any purpose. 
2. A third field is being added to the two-fluid, six-equation hydrodynamic models. This field will be used to track the movement of molten material or debris through the system. This model can then be used to track the radial movement of me1t from the core to core barrel region, melt ejection, or the movement of debris through the RCS. The input for this model will also allow the user to initialize the code with a molten or debris field so that experiments starting with a melt can be directly analyzed.

3. The fission product transport models are also being generalized to allow additional species. In addition, the numerical algorithms used are being modified to reduce the cost of the calculations when this option is invoked.

4. Data interfaces are being developed that will allow SCDAP/RELAP5, other codes such as MELCOR ${ }^{1-11}$ and CONTAIN, ${ }^{1-9}$ and graphics processors such as the NPA to run in parallel on CRAY (and potentially other) computers with UNIX operating systems. These data interfaces will allow the codes to be loosely coupled at user-specified time steps. Although this approach is machineand operating-system-dependent, it will only require the addition of one or two subroutines to the existing codes.

5. Thermal-hydraulic and other system models are being improved through the RELAP5/MOD3 activities. These improvements include reflood heat transfer, inception of vertical and horizontal stratification, countercurrent flow limitations, metal-water reactions (for RELAP5 heat structures), condensation in horizontal pipes, downcomer penetration and emergency core cooling system (ECCS) bypass, and upper plenum deentrainment.

These improvements should be available in early 1990 at the current rate of deve lopment.

Creations of non-CRAY versions of the code will be built on the work started for SCDAP/RELAP5/MOD2. Through the RELAP5 activities, the RELAP5 
portion of the code was converted and tested on CDC-NOS/VE, VAX, and IBM computers at the INEL. Consequent7y, MOD2 wi11 execute RELAP5 input decks on the CRAY/XMP and CDC-NOS/VE, VAX, and IBM machines. Similar changes to the balance of SCDAP/RELAP5 will be available in future releases of the code $(1990)$.

other code improvements focused on the reduction in the cost of an analysis should be available over the longer term (1991 and beyond). These improvements concentrate on code input and output, addition of features that more fully automate control of transient calculations, and changes in coding structure and code numerics to further reduce run times. Proposed code improvements include:

- Automatic time step repetition to allow the code to repeat time advancements if error tolerances are exceeded

o Increased SCDAP component input error checking to reduce the time required to debug input decks

- Merged RELAP5 and SCDAP input and output to reduce the cost of interpretation of code results.

Future model improvement will also be performed on an "as-needed" basis as a result of a parallel model assessment and validation effort. However, a number of areas have been identified where model changes are likely. These include $\mathrm{ZrO}_{2}$ fallure and rivulet flow, aerosol formation, fission product transport and deposition, and debris behavior.

\subsection{Quality Assurance}

SCDAP/RELAP5 is maintained under a strict code-configuration system that provides a historical record of the changes in the code. Changes are made using an update processor that allows separate identification of improvements made to each successive version of the code. Modifications and improvements to the coding are reviewed and checked as part of a forma? 
quality program for software. In addition, the theory and implementation of code improvements are validated through assessment calculations that compare the code-predicted results to idealized test cases or experimental results.

SCDAP/RELAP5 must meet the quality assurance $(Q A)$ requirements of the INEL. $1-12$ The $Q A$ requirements at INEL are summarized as follows: First, the $Q A$ policy must be administered for each software development activity through an established organization. Second, all significant software development must be thoroughly documented. Third, procedures must be in place to assure the traceability and retrievability of each version of software. Fourth, each version of software shall be clearly identified as to name, version, and date of last revision. All output must display this identification. Fifth, all software must be verified and validated for its intended application.

The group responsible for the development of SCDAP/RELAP5, the Energy and Systems Technology Group (E\&ST) at INEL, has a team charged with the responsibility of administering the QA policy for the group. The leader of this team is the Quality Program Plan (QPP) manager. The QPP manager and Unit Managers have the responsibility for monitoring adherence to the $Q A$ policy.

A procedure with five basic stems has been established to implement the QA policy. In the first step, software is entered into the Software Index. Each entry must be approved by the QPP manager. In the second step, a quality level must be approved by the Unit Manager. For the third step, a Software Quality Assurance Plan (SQAP) will be written for each item in the Software Index. SQAPS will be maintained as controlled documents. The level of software verification and validation is specified in the SQAP. The fourth step is the review and approval of the SQAP by the Unit and QPP managers. The fifth step is the submittal of quality records as software development proceeds to the Quality Control Document Librarian. The SQAPs specify the quality records to be submitted. 
The SQAP for SCDAP/RELAP5 addresses the thirteen categories specified by the ANSI/IEEE Standard 730-1984. 1-13 These include: (a) completion of forms that state the purpose of the software, identification of documents that reference the software, and management of the software;

(b) documentation that explains the problem solved; (c) documentation of verification and validation of software; (d) documentation of software changes and the reverification of the software; and (e) documentation that keeps track of software problems and actions to correct the problems.

SCDAP/RELAP5 is being developed for critical applications and thus meets INEL quality standards associated with these applications. Critical applications implies that the calculations of the code could be used to determine the design of reactor safety systems. Failure of code calculations could involve undue risk to employees and the public health.

\subsection{References}

1-1. V. H. Ransom et a1., RELAP5/M002 Code Manual Volume 1 and 2 , NUREG/CR-4312, EGG-2396, Revision 1, Apr 111987.

1-2. C. M. Allison and G. H. Beers, "Comparisons of the SCDAP Computer Code with Bundle Data under Severe Accident Conditions," 7 th International SMIRT Conference, Chicago, IL, August 22-26, 1983.

1-3. H. Jordan and M. R. Kuhlman, TRAP-MELT2 User's Manual, NUREG/CR-4205, BMI-2124, May 1985.

1-4. H. Jordan, J. A. Gieseke, and P. Baybutt, TRAP-MELT User's Manual, NUREG/CR-0632, BMI-2017, February 1979.

1-5. W. J. Camp et. a1., MELPROG-PWR/MODO: A Mechanistic Code for Analys is of Reactor Core Melt Progression and Vessel Attack Under Severe Accident Conditions. NUREG/CR-4909, SAND85-0237, Apr 117987.

1-6. W. T. Shack et al.. Materials Science and Technology Division Light Water Reactor Safety Research Program Quarterly Report, January through March 1983, Volume I, NUREG/CR-3689. ANL-83-85 Volume I, June 1983.

1-7. D. L. Hagrman, G. A. Reyman, and R. E. Mason, MATPRO-Version 11 (Revision 2). A Handbook of Mater ials Properties for Use in the Analysis of Light Water Reactor Fuel Rod Behavior. NUREG/CR-0479, TREE-1280, Revision 2, August 1981. 
1-8. E. T. Laats and R. N. Hagen, "Nuclear Power Plant Simulation Using Advanced Simulation Codes Through a State-of-the-Art Horkstation," Proceedings of the 1985 Summer Computer Simulation Conference, Chicago, Illinois, July 22-24, 1985.

1-9. K. D. Bergeron et a1.. User's Manual for CONTAIN 1.0, A Computer Code for Severe Nuclear Reactor Accident Containment Analys is, NUREG/CR-4085, SAND84-1204, May 1985.

1-10. L. T. Ritchie et a 1., CRAC2 Model Description, NUREG/CR-2552, SAND82-0342, March 1984.

1-11. D. I. Chanin et a1.. MELCOR Accident Consequence Code System (MACCS), Vols. I, II, and III, NUREG/CR-4691, SAND86-1562, August 1989.

1-12. Energy and Systems Technology Standard Practice 4.0, Software Development Plan. December 1988.

1-13. ANSI/IEEE Standard 730-1984, "IEEE Standard for Software Quality Assurance Plans." 


\section{CODE ARCHITECTURE}

Modeling flexibility, user convenience, computer efficiency, and design for future growth were primary considerations in the selection of the basic architecture of the code. The architecture of SCDAP/RELAP5 is based upon that developed for RELAP5, ${ }^{2-1}$ SCDAP, ${ }^{2-2}$ and other 1arge codes that have been developed at the INEL. The top level of the architecture, input and output processing and transient control, follows the architecture of RELAP5. The lower levels under transient control utilize a combination of structures based on RELAP5, SCDAP, and TRAP-MELT. ${ }^{2-3}$ RELAP5-based logic determines the overall transient time step, evaluates trip logic, and advances the calculations for the RELAP5 heat structures, hydrodynamics, reactor kinetics, and control systems. SCDAP-based logic advances the calculations for the representative core components, debris behavior, and radiation heat transfer. SCDAP logic also advances the convective heat transfer calculations for those structures or debris associated with the SCDAP mode1s; however, the logic for convective heat transfer is derived from RELAP5. The fission product deposition solution logic was completely reorganized from that of TRAP-MELT and now follows the pattern established by RELAP5, although the logic of lower-level subroutines still has recognizable TRAP-MELT features.

\subsection{Computer Adaptability}

SCDAP/RELAP5 is written in FORTRAN 77. Compile time options are provided to allow operation on CRAY-1 and CRAY-XMP machines using either COS, CTSS, or UNIX operating systems. Compile time options are also being provided to allow operation on 64-bit machines (e.g., Cyber-NOS-VE, ETA) and 32-bit machines that have double-precision (64-bit), floating-point arithmetic (e.g., IBM, VAX, and many super-minis). A common source is maintained for all computer versions. Development is primarily on a CRAY computer, but compatibility checks are made on other computers. Reported errors are resolved on all computer versions derived from the common source. 


\subsection{Top Level Organization}

SCDAP/RELAP5 is coded in a modular fashion using top-down structuring. The various models and procedures are isolated in separate subroutines. The top level structure is shown in Figure 2-1 and consists of input, transient/steady-state, plotting, and stripping blocks.

The input block processes input, checks input data, and prepares required data blocks for a 11 program options and is discussed in more detail in Section 2.3.

The transient/steady-state block handles both the transient option and the steady-state option. The steady-state option determines the steady-state conditions if a properly posed steady-state problem is presented. Steady state is obtained by running an accelerated transient until the time derivatives approach zero. Thus, the steady-state option is very similar to the transient option but contains convergence testing algorithms to determine satisfactory steady state, divergence from steady state, or cyclic operation. If the transient technique alone were used, approach to steady state from an initial condition would be identical to a plant transient from that initial condition. Pressures, densities, and flow distributions would adjust quickly; but thermal effects would occur more slowly. To reduce the transient time required to reach steady state, the steady-state option artificially accelerates heat conduction by reducing the heat capacity of the conductors.

The plotting block produces time history plots of simulation results generated from the steady-state or transient blocks. This block can also produce plots from data saved on a restart plot file from an earlier simulation.

The strip block extracts simulation data from a restart plot file for convenient passing of SCDAP/RELAP5 simulation results to other computer programs. 


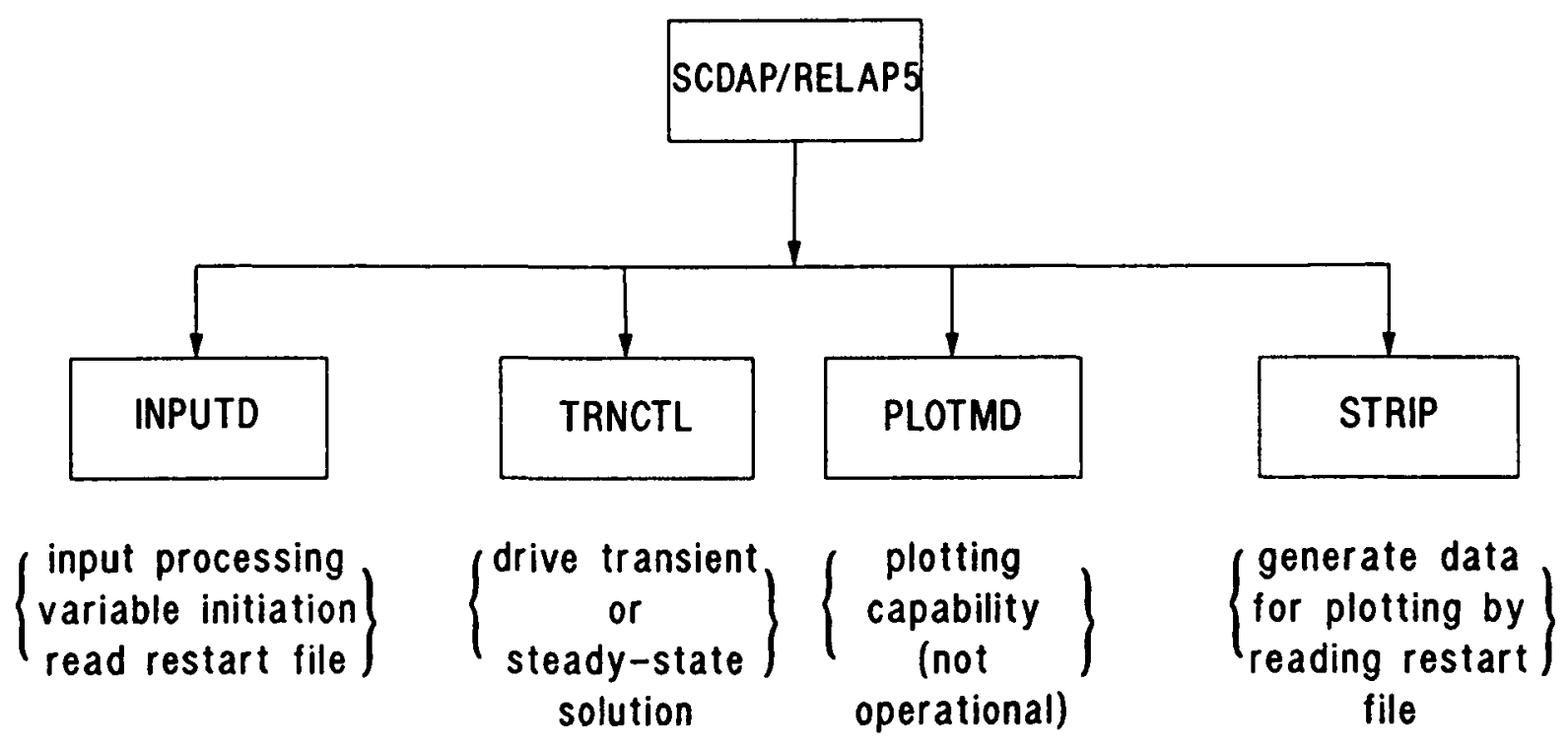

50000350

Figure 2-1. SCDAP/RELAP5 top Teve1 structure. 


\subsection{Input Processing Overview}

SCDAP/RELAP5 provides detailed input checking for system thermal-hydraulic and fission product behavior/transport models. Three input processing phases are used in the code. The first phase reads all input data, checks for punctuation and typing errors (such as multiple decimal points and letters in numerical fields), and stores the data keyed by card number such that the data are easily retrieved. A listing of the input data is provided, and punctuation errors are noted.

During the second phase, restart data from a previous simulation are read if the problem is a RESTART type, and all input data are processed. Some processed input is stored in fixed common blocks, but the majority of the data is stored in dynamic data blocks that are created only if needed by a problem and sized to the particular problem. In a NEW-type problem, dynamic blocks must be created. In RESTART problems, dynamic blocks may be created, deleted, added to, partially deleted, or modified as modeling features and components within models are added, deleted, or modified. Extensive input checking is done, but at this level checking is 7 imited to new data from the cards being processed. Relationships with other data cannot be checked because the latter may not yet be processed. As an llustration of this level of checking, junction data are checked to determine if they are within the appropriate range, such as positive, nonzero, or between zero and one; and volume connection codes are checked for proper format. However, no attempt is made at this point to check whether or not referenced volumes exist in the problem until all input data are processed.

The third phase of processing begins after all input data have been processed. Since all data have been placed in common or dynamic data blocks during the second phase, complete checking of interrelationships can proceed. Examples of cross-checking are: existence of hydrodynamic volumes referenced in junctions and heat structure boundary conditions: entry or existence of material property data specified in heat structures; and validity of variables selected for minor edits, plotting, or used in 
trips and control systems. As the cross-checking proceeds, cross-linking of the data blocks is done so that it need not be repeated at every $t$ ime step. The initialization required to prepare the model for start of transient advancement is done at this level.

Input data editing and diagnostic messages can be generated during the second and/or third phases. Input processing for most models generates output and diagnostic messages during both phases. Thus, input editing for these models appear in two sections.

As errors are detected, various recovery procedures are used so that input processing can be continued and a maximum amount of diagnostic information can be furnished. Recovery procedures include supplying default or benign replacement data, marking the data as erroneous so that other models do not attempt use of the data, or deleting the bad data. The recovery procedures sometimes generate additional diagnostic messages. often after attempted correction of input, different diagnostic messages appear. These can be due to continued incorrect preparation of data, but the diagnostics may result from the more extensive testing permitted as previous errors are eliminated.

As a convenience to the user, a check plot option is provided that will produce plots of input data such as for time-dependent volumes and junctions, general tables, plot comparison data tables, valve area and flow coefficients, etc. This option can be utilized by the input of the check plot general plot request input card. The plots are constructed upon completion of the third phase of input data processing so that all information processed by the code will be included. Once the option is activated, it will remain in effect for all subsequent restart or plot only jobs, including restarts with renodalization, until cancelled by the user with appropriate input. 


\subsection{Iransient Overview}

Figure 2-2 shows the functional modular structure for the transient calculations, while figure 2-3 shows the second-level structures for the transient/steady-state blocks or subroutines.

The subroutine TRNCTL shown in Figure 2-3 consists only of the logic to call the next lower level routines. Subroutine TRNSET brings dynamic blocks required for transient execution from disk into computer central memory, performs final cross-linking of information between data blocks, sets up arrays to control the sparse matrix solution, establishes scratch work space, and returns unneeded computer memory. Subroutine TRAN, the driver, controls the transient advancement of the solution. Nearly all the execution time is spent in this block, and this block is the most demanding of memory. Nearly all the dynamic data blocks must be in the central memory, and the memory required for instruction storage is high, since coding to advance all models resides in this block. The subroutine TRNFIN releases space for the dynamic data blocks that are no longer needed and prints the transient timing summary.

A description is next presented of the functions of all of the modules (subroutines) driven by TRAN.

The time step control module (named DTSTEP) determines the time step size, controls output editing, and determines whether transient advancements should be terminated. During program execution, this module displays such information as CPU time, problem time, and the maximum cladding temperature on a terminal screen.

The trip system module (named TRIP) evaluates logical statements. Each trip statement is a simple logical statement which has a true or false result. The decision of what action is needed resides within the components in other modules. For example, valve components are provided that open or close the valve based on trip values; pump components test trip status to determine whether a pump electrical breaker has tripped. 


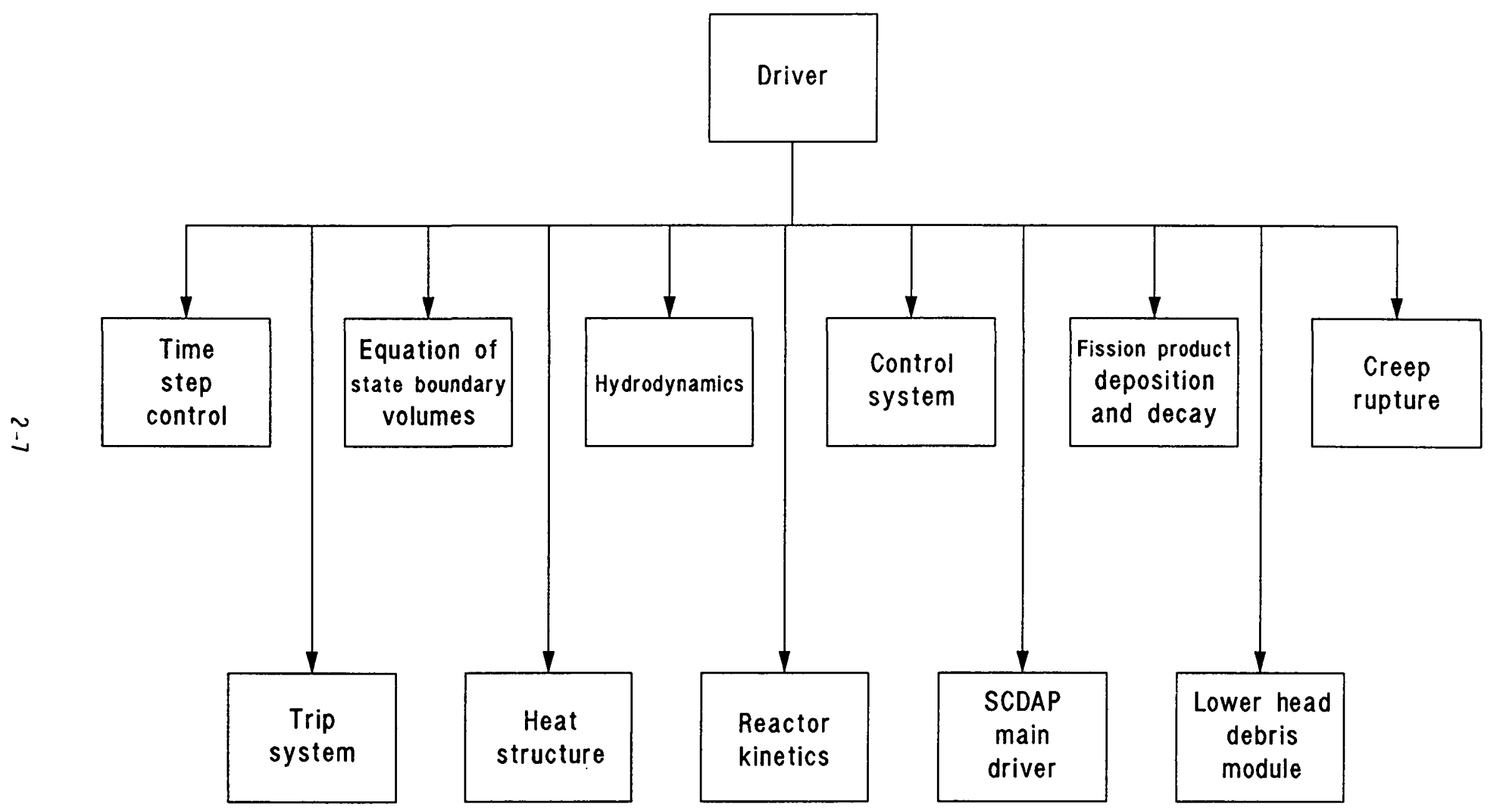

Figure 2-2. Modular structures of transient calculations in SCDAP/RELAP5. 


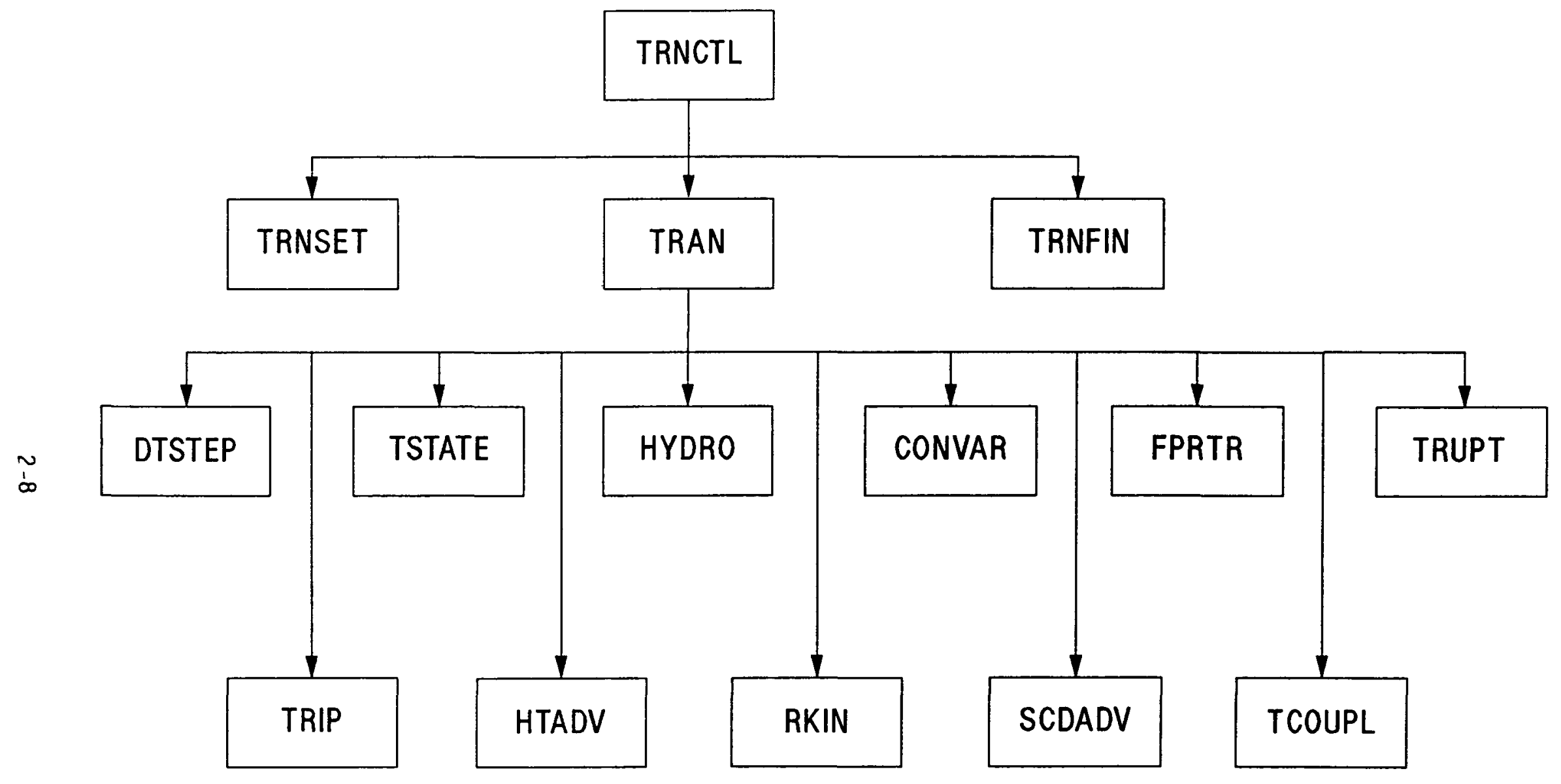

EC000352

Figure 2-3. Transient (steady-state) block structure. 
The equation of state boundary volume model (named TSTATE) calculates the thermodynamic state of the fluid in each hydrodynamic boundary volume.

The heat structure model (named HTADV) advances heat conduction/transfer solutions using previous-time-step reactor kinetics power and previous-time-step hydrodynamic conditions for computing heat transfer coefficients. It calculates heat transferred across solid boundaries of hydrodynamic volumes.

The hydrodynamics module (named HYDRO) advances the hydrodynamic solution.

The reactor kinetics module (named RKIN) advances the reactor kinetics of the code. It computes the power behavior in a nuclear reactor using the space-independent or point kinetics approximation which assumes that power can be separated into space and time functions.

The control system module (named CONVAR) provides the capability of simulating control systems typically used in hydrodynamic systems. It consists of several types of control components. Each component defines a control variable as a specific function of time advanced quantities. The time advanced quantities include quantities from hydrodynamic volumes, junctions, pumps, valves, heat structures, reactor kinetics, trip quantities, and the control variables themselves. This permits control variables to be developed from components that perform simple, basic operations.

The SCDAP driver module drives the SCDAP discrete components, SCDAP heat transfer modules, and slumping of core material into the lower plenum. It advances all of the SCDAP calculations with the exception of those done in the SCDAP debris module. It is further divided into six submodules, as shown in Figure 2-4. The intact core module (named SBNTAC) is the main driver for the SCDAP discrete components. It drives the fuel pin, silver-indium-cadmium control rod, boron carbide control rod blade, electrically heated fuel rod simulator, and other core structure models. 
$\stackrel{\sim}{0}$

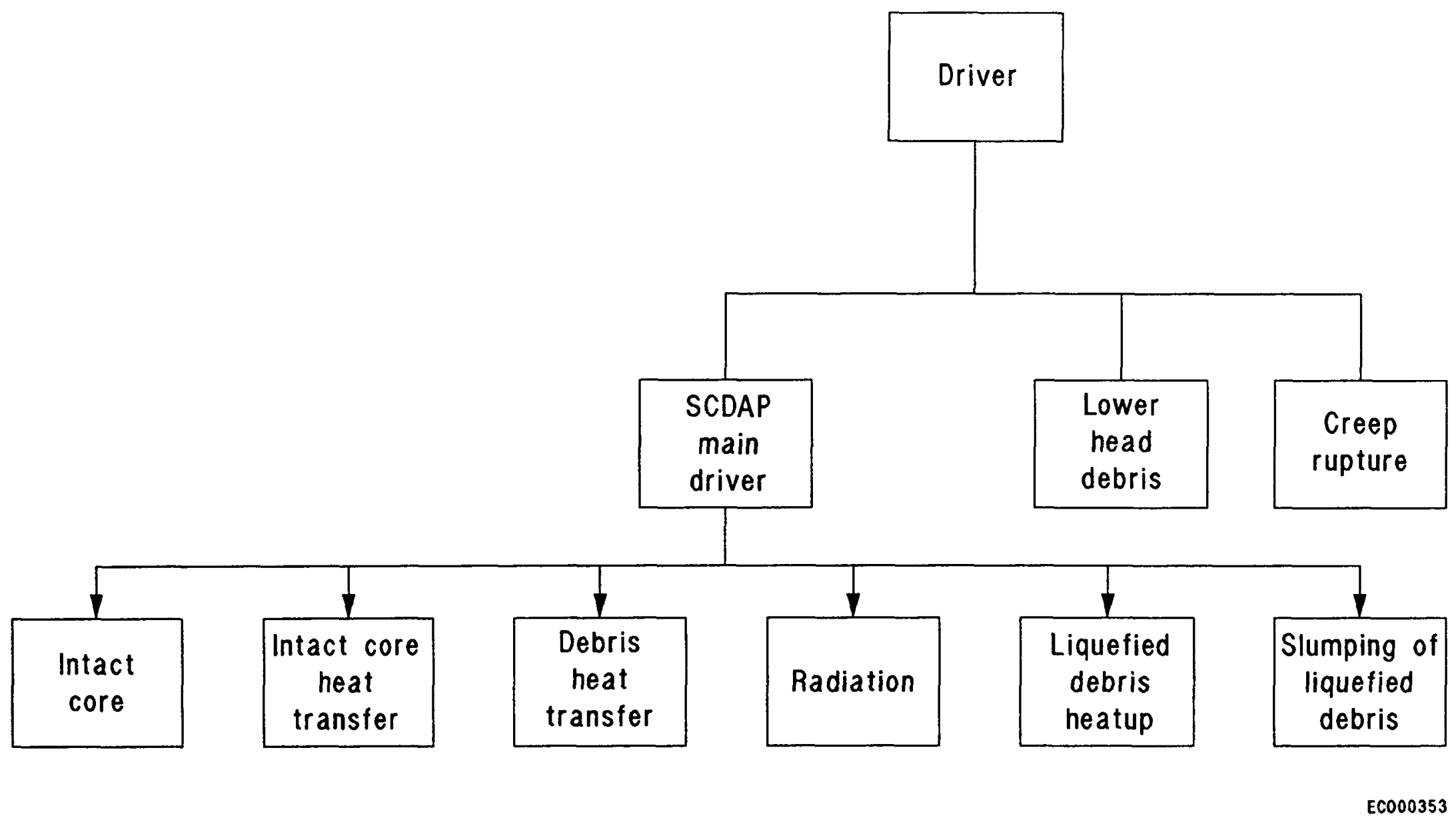

Figure 2-4. SCDAP modular structure. 
The intact core heat transfer module (named HTRC1) computes the convective heat transfer between coolant and intact core. The debris heat transfer module (named HTRC 3 A) computes the convective heat transfer between coolant and core debris. The radiation module (named RADCC2) calculates the radiative heat transfer between elements in the intact core including the heat transfer between fuel pin and coolant, fuel pin and shroud, etc. The liquefied debris heatup module (named HEATLD) calculates the extent of core liquefication and the heatup of the resulting molten pool of liquefied debris. The slumping of liquefied debris module (named SLUMP) models the slumping of liquefied debris into the lower plenum.

The fission product deposition and decay module (named FPRTR) performs fission product behavior and transport and radionuclide decay heating calculations.

The lower head debris module (named TCOUPL) calculates the heatup of debris that has slumped into the lower head of the reactor vesse1. The module also calculates the heatup of the lower head and the amount of heat transfer from debris to coolant.

The creep rupture module (named TRUPT) calculates the creep damage of the reactor vessel and piping as a function of stress, temperature, and time.

\subsection{References}

2-1. V. H. Ransom et a1., RELAP5/M0D2 Code Manual Volume 1 and 2, NUREG/CR-4312, EGG-2396, Revision 1, Apri17 1987.

2-2. C. M. Allison and G. H. Beers, "Comparisons of the SCDAP Computer Code with Bundle Data under Severe Accident Conditions," 7 th International SMIRT Conference, Chicago, IL, August 22-26, 1983.

2-3. H. Jordan and M. R. Kuhlman, TRAP-MELT2 User's Manual, NUREG/CR-4205, BMI-2124, May 1985. 


\section{SEVERE ACCIDENT STRUCTURAL BEHAVIOR MODELS}

The severe accident structural behavior models are invoked when SCDAP/RELAP5 is being used to calculate the behavior of an RCS during a severe accident. These models are used to calculate the behavior of fuel rods, control rods, blades, and other structures that constitute parts of a reactor core. In addition, these models can be used to represent structures unique to experimental facilities, such as electrically heated fuel rod simulations and debris beds formed during the course of the analysis.

The following sections describe the physical models used to calculate the significant phenomena occurring in the RCS during a severe accident. Some models apply to fuel rods, control rods, blades, and structures (such as the heat conduction model), while others are specific to only one core component. (For example, the ballooning model only applies to a fuel rod.)

The representative fuel rod, control rod, blade, structure, debris, and electrically heated fuel rod simulator models are described in the following subsections. These representative structural models are used to describe the thermal, mechanical, and chemical processes occurring during a severe accident.

The thermal models account for the materials properties, the nuclear and oxidation heat as well as reductions in heat source when fission products are released, and the radiation exchange between structures. They also calculate radial and axial temperature distributions. The thermal models apply to all of the representative structural models.

The mechanical models are used to calculate the deformation behavior of fuel and simulator rods for large cladding deformations (sausage or localized). A gas pressure model is used to calculate the driving force for large cladding deformation. The fuel rod gas pressure model uses the output of the fission gas release model, which is based on the PARAGRASs ${ }^{3-1}$ model. Release of cesium and iodine compounds are also calculated. 
Models that describe the early stages of damage of representative structures include models for (a) liquefaction, flow, and solidification of structure materials and (b) fragmentation of the structures. The feedback to the thermal models due to changes in geometry is also modeled.

Models that describe chemical processes associated with structural behavior are currently limited to materlal oxidation and fuel dissolution. Chemical interactions associated with the formation of eutectics, such as the interactions of zircaloy and stainless steel, are not modeled explicitly. However, changes in melting temperatures associated with these interactions can be controlled through user input.

In the following subsections, models used to describe fuel rod behavior for both representative fuel rod structures and electrically heated fuel rod simulators are discussed first. Then, features unique to the representative control rodiblade and core structures are discussed, followed by a discussion of structure-to-structure radiation models and debris behavior models. The section is completed with a discussion of the features unique to the electrically heated fuel rod simulator.

\subsection{Material Oxidation Model}

Material oxidation is described by either a steady-state or transient oxidation model and includes the associated generation of heat, production of hydrogen, and reduction of steam. The steady-state model uses oxidation rate equations with material temperatures defined by the component heat conduction model. This model is used for all materials other than zircaloy and for zircaloy when the oxidation heat generation rate is relatively 1ow. The transient mode1, used for zircaloy when the heat generation rate is high, solves for the material temperatures and oxidation rates simultaneously using a lumped parameter formulation for temperature. This mode1, which was originally designed for SCDAP where large time steps could be taken, is gradually being replaced as the component models are improved.

Material oxidation is defined using a parabolic rate equation 
where $m$ is the mass flow rate of steam normal to the surface.

A number of important assumptions are also made that are dependent upon the type of component or structures being modeled. These include the following ones. The surface areas and material volumes can either be based upon cylindrical or slab geometries. Volume changes due to oxidation are considered only for zircaloy. For structures with multiple material layers, including layers of frozen material, it is assumed that outer layers oxidize completely prior to any oxidation of inner layers. It is also assumed that once the outer layers are oxidized, they do not inhibit the flow of steam to inner layers so that the parabolic rate equations for the inner layers are solved, ignoring the presence of any outer layers. For ballooned and ruptured fuel rod cladding or input-defined fallure of the inner layer of a shroud, the oxidation rates are doubled in the falled regions, assuming the inside and outside of the cladding or shroud inner layer oxidize at the same rates. The steam availability is based upon the total oxidation rate.

\subsection{Nuclear Heat Model}

The energy release from fissioning of uranium is manifested in a variety of forms. Table 3-1 lists recoverable forms of energy from thermal fissioning of $U^{235}$ that are considered in the nuclear heat model and average energy per fission associated with each form. The Evaluated Nuclear Data File $e^{3-4}$ is the source of information for the first four forms of energy in Table 3-1, and the ANSI/ANS -5.1-1979 decay heat standard s-5 $^{3-5}$ the source for the fifth form of energy 1isted. The first three forms of energy in Table 3-1 are released at the time of the fission event and are collectively known as prompt nuclear heat. They account for about $92 \%$ of the recoverable fission energy. The remaining two forms of energy in Table 3-1 appear at some time after the fission event and are classified as delayed nuclear heat. This energy is due to the radioactive decay of a large number of different fission products and actinides $\left({ }^{239} \mathrm{U}\right.$ and ${ }^{239} \mathrm{~Np}$ in this mode1). Since radioactive decay is a random event that is characterized by an exponential probability distribution, the delayed nuclear heat is exponentially distributed in time following a fission event. 
TABLE 3-1. ENERGY RELEASE FROM FISSION OF $235_{\mathrm{U}}$

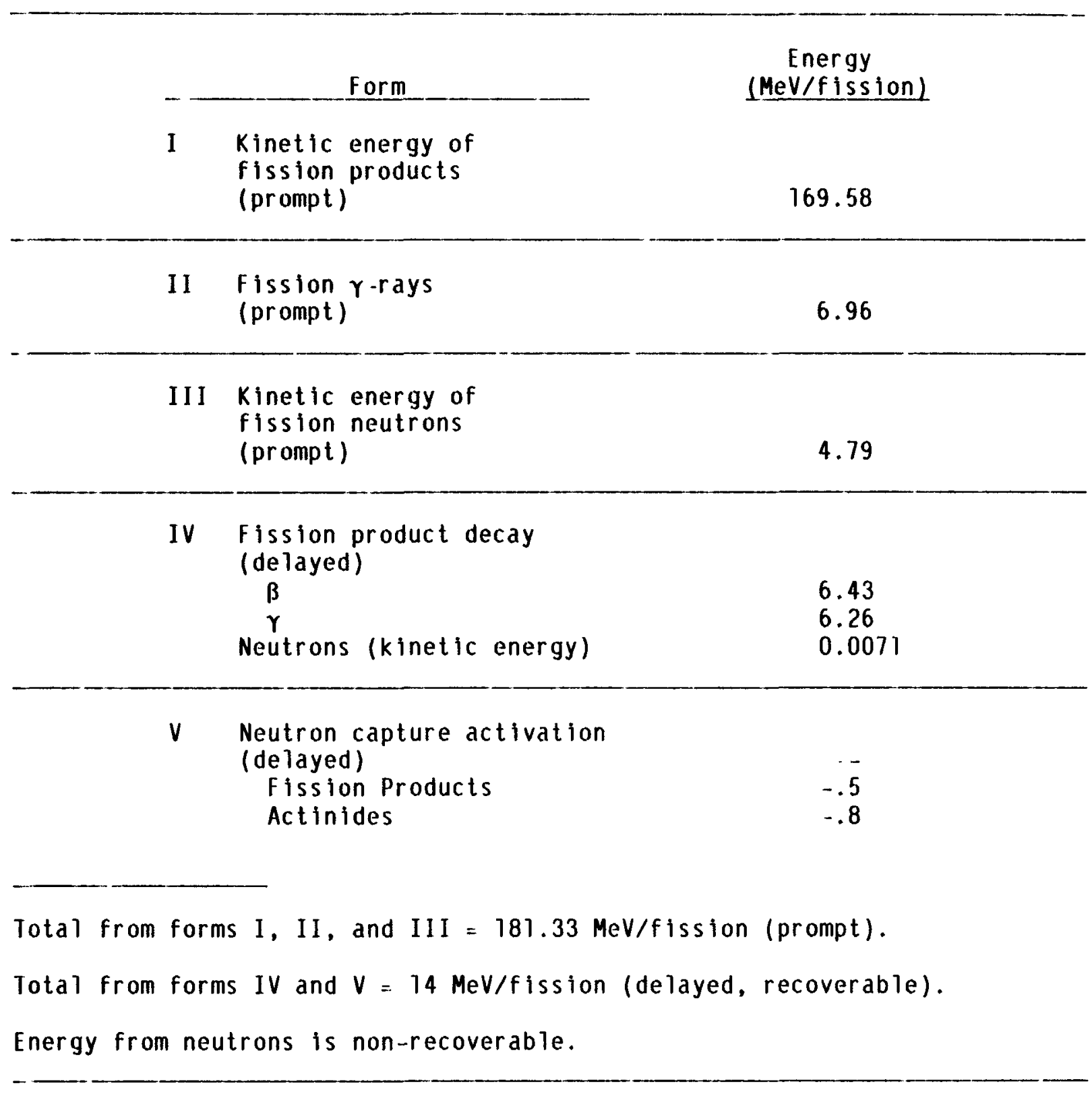


Prompt nuclear heat is determined by thermal neutron flux levels. Since neutron flux distributions are not determined by the code, the nuclear heat model requires that any prompt nuclear heat generated during the problem time be input to the model. Delayed nuclear heat is determined by the prior operating history. This is provided as input to the model by specifying the rod average total (prompt plus delayed) volumetric power for each time span prior to the start of the problem. For nonfuel rod components (i.e., control rods or structural material), the user must supply total power for the problem time period. For fuel rods, the user has the option of supplying total power for the problem time period and thus overriding the decay heat calculations. Additional required input information are fuel enrichment, fuel density, the rate of ${ }^{239} \mathrm{U}$ production (ratio of fission-producing neutron absorption in fuel to non-fission-producing neutron absorption in $\left.{ }^{238} \mathrm{U}\right)$, and axial and radial multiplication factors that convert the rod average prompt and delayed power to local power.

This model determines the delayed nuclear heat based on the ANSI/ANS-5.1-1979 decay heat standard, ${ }^{3-5}$ and the required nuclear data are based on the Evaluated Nuclear Data File. ${ }^{3-4}$ Nefther the delayed nuclear heat from neutron capture in structural material nor the energy added by fissioning due to delayed neutrons subsequent to reactor shutdown are considered. However, the user can force consideration of these effects by specifying their contributions as an additional prompt nuclear heat source. The delayed nuclear heat model is based on the following major assumptions:

- The fuel rods are of commercial LWR design.

- The bundle component remains intact and at initial density and volume. Movement of material due to fuel rod disruption is accounted for outside of this model by the SCDAP subroutines FSTATE and CFDAMG, depending on the state of the bundle. These routines maintain an inventory system that will trace a piece of material back to its original location in order to determine the 
current decay power. (The prompt power is not history-dependent; therefore, only the current location peaking factor and average power are required to determine current prompt power.)

o $\quad 235 U$ is the only fissile material.

- $\quad 238_{U}$ is the only fertile material. (This implies that the only actinide decay chain that will be considered is the ${ }^{239} \mathrm{U}$ to ${ }^{239} \mathrm{Pu}$ decay chain due to ${ }^{238} \mathrm{U}$ neutron absorption.)

- Gamma energy is completely recoverable with a flat radial distribution and the user-supplied axial distribution of energy deposition.

Most of the computations required for this model, including those for establishing the ANS-5.1-based delayed nuclear heat, are performed during initialization. These computations establish power history tables and axial and radial distribution tables. The volumetric power for any time and location within the analys is is determined by interpolating these tables.

The total nuclear heat source due to fissioning is represented as

$Q(z, r, t)=Q_{p}(t) Z_{p}(z) R_{p}(r)+Q_{d}(t) Z_{d}(z) R_{d}(r)$

where

$$
\begin{aligned}
& Q(z, r, t)=\text { total nuclear heat at axial position } z \text { and radial } \\
& \text { position } r \text { of the component at time } t\left(\omega / m^{3}\right) \\
& Q_{p}(t)=\text { component average prompt nuclear heat at } t \text { ime } t\left(\mathrm{~W} / \mathrm{m}^{3}\right) \\
& Z_{p}(z)=a x i a l \text { peaking factor for prompt heat at position } z \\
& R_{p}(r)=\text { radial peaking factor for prompt heat at position } r
\end{aligned}
$$




$Q_{d}(t)=$ component average delayed nuclear heat at $t$ ime $t\left(\mathrm{~W} / \mathrm{m}^{3}\right)$
$Z_{d}(z)=$ axial peaking factor for delayed heat at position $z$
$R_{d}(r)=$ radial peaking factor for delayed heat at position $r$.

For a fuel rod component, the user must supply the three factors of the first term of Equation $(3-8)\left(Q_{p}, Z_{p}, R_{p}\right)$ as well as the factor $Z_{d}$ from the second term of the equation. The user may either supply $Q_{d}$ or allow the model to calculate this term. For components other than fuel rods, the user must supply $Q_{d}{ }^{a}$ The factor $R_{d}$ is always determined by the model, although for components other than fuel rods, $R_{d}$ is set equal to $R_{p}$.

The factor $Z_{p}$ accounts for the axial distribution of prompt nuclear heat due to the neutron flux distribution. Since $Z_{p}$ may shift during the transient, the user can supply separate axial peaking factor arrays for different time periods. Under equilibrium conditions, the distribution of the delayed nuclear heat is the same as the prompt distribution. However, when the prompt distribution changes, the delayed distribution exponentially approaches the new shape with time. Therefore, the delayed distribution may be different from the prompt distribution; and the user can input a separate axial nuclear heat distribution for delayed nuclear heat. Since the conditions that cause the radial distribution of prompt heat are not expected to change significantiy with time, the user is oniy allowed to input one prompt radial distribution shape. The model always provides the radial distribution of delayed heat based on the user-supplied prompt radial distribution and the component type (fuel rod or nonfuel rod).

a. The user may also suppiy non-nuclear heat (i.e., electrical) through the terms in Equation $(3-8)$. It is suggested that the delayed nuclear heat model options not be used for such situations. 
Expanding the second term of Equation (3-8) (delayed nuclear heat) into its components yields

$Q_{d}(t) Z_{d}(z) R_{d}(r)=\left(D F G Q_{f d}+Q_{A d}\right) Z_{d}(z) R_{d}(r)$

where

$$
\begin{aligned}
& Q_{f d}=\text { rod average fission product decay power }\left(\mathrm{W} / \mathrm{m}^{3}\right) \\
& \begin{aligned}
Q_{A d} & =\text { rod average actinide }\left({ }^{239} \mathrm{U},{ }^{239} \mathrm{~Np}\right) \text { decay power }\left(\mathrm{W} / \mathrm{m}^{3}\right) \\
D F \quad & \text { reduction factor in decay heat due to loss of volatile } \\
& \text { fission products }
\end{aligned} \\
& \mathrm{G} \quad=\text { neutron capture correction to fission product decay. } \\
& \text { A comparison of the magnitude of these components is given in }
\end{aligned}
$$

Figure 3-1. The reduction in decay power due to loss of volatile fission products is discussed in Reference 3-6. The remaining components are discussed in the following sections of this report.

\subsubsection{Fission Product Decay Power}

Reference 3-5 provides an empirical correlation for the decay power per fission $t$ seconds after a fission pulse from the thermal fission of ${ }^{235} \mathrm{U}$. The form of the correlation is given by

$f(t)=\sum_{i=1}^{23} \alpha_{i} e^{-\lambda_{i} t}$

where

$\begin{aligned} f(t)= & \text { decay power per fission } t \text { seconds after a }{ }^{235} U \text { thermal } \\ & \text { fission pulse (MeV/fission.s) }\end{aligned}$ 


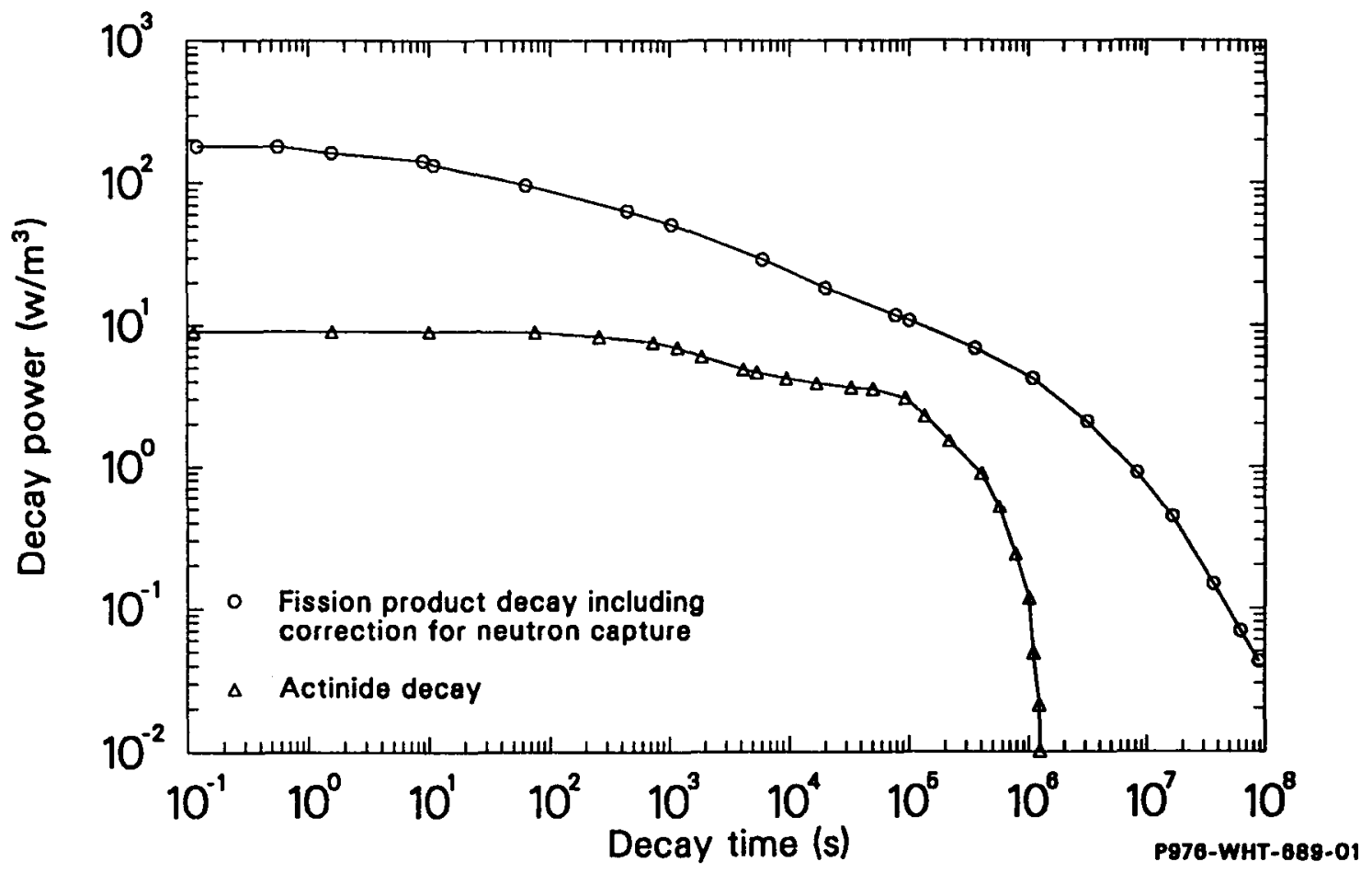

Figure 3-1. Comparison of decay heat components. 

$\begin{aligned} a_{i}= & \text { initial decay value of empirical (nonphysical) Group } i \\ & (\text { MeV/fission.s) }\end{aligned}$

$\lambda_{i}=$ time constant of empirical Group $i\left(s^{-1}\right)$.

The constants $\alpha_{i}$ and $\lambda_{i}$ are given in Table $3-2$.

The decay power after an operating period is the product of

Equation $(3-10)$ and the fission rate integrated over the operating period T:

$Q_{f d}(T)=\int_{0}^{T} f\left(t-T^{\prime}\right) F R\left(T^{\prime}\right) d T^{\prime}$

where $F R\left(T^{\prime}\right)$ is the fission rate of ${ }^{235} \mathrm{U}$ at time $T^{\prime}\left(\right.$ fission/m $\left.{ }^{3} \cdot \mathrm{s}\right)(\mathrm{W} / \mathrm{MeV})$.

The term $F R\left(T^{\prime}\right)$ is determined by

$F R\left(T^{\prime}\right)=Q_{p}\left(T^{\prime}\right) / E_{f}=\left[Q\left(T^{\prime}\right)-Q_{d}\left(T^{\prime}\right)\right] / E_{f}$

where

$$
\begin{aligned}
Q_{p}\left(T^{\prime}\right) & =\text { prompt nuclear heat at time } T^{\prime}\left(\mathrm{W} / \mathrm{m}^{3}\right) \\
Q\left(T^{\prime}\right) & =\text { total nuclear heat at time } T^{\prime}\left(\mathrm{W} / \mathrm{m}^{3}\right) \\
Q_{d}\left(T^{\prime}\right) & =\text { decay nuclear heat at time } T^{\prime}\left(\mathrm{H} / \mathrm{m}^{3}\right) \\
E_{f} & =\text { prompt energy per fission of }{ }^{235} \mathrm{U} \\
& =181.33 \text { (MeV/fission). }
\end{aligned}
$$

Substituting Equation (3-10) into Equation (3-11) and breaking the integration into a sum of operating periods for which FR is constant yieids 


\begin{tabular}{lcccccc}
1 & $\alpha_{i}$ & $\lambda_{i}$ & $i$ & $\alpha_{i}$ & $\lambda_{i}$ \\
\hline 1 & $6.5057 \times 10^{-1}$ & $2.2138 \times 10^{+1}$ & 13 & $2.5232 \times 10^{-6}$ & $1.0010 \times 10^{-5}$ \\
2 & $5.1264 \times 10^{-1}$ & $5.1587 \times 10^{-1}$ & 14 & $4.9948 \times 10^{-7}$ & $2.5438 \times 10^{-6}$ \\
3 & $2.4384 \times 10^{-1}$ & $1.9594 \times 10^{-1}$ & 15 & $1.8531 \times 10^{-7}$ & $6.6361 \times 10^{-7}$ \\
4 & $1.3850 \times 10^{-1}$ & $1.0312 \times 10^{-1}$ & 16 & $2.6608 \times 10^{-8}$ & $1.2290 \times 10^{-8}$ \\
5 & $5.5440 \times 10^{-2}$ & $3.3656 \times 10^{-2}$ & 17 & $2.2398 \times 10^{-9}$ & $2.7213 \times 10^{-8}$ \\
6 & $2.2225 \times 10^{-2}$ & $1.1681 \times 10^{-2}$ & 18 & $8.1641 \times 10^{-12}$ & $4.3714 \times 10^{-9}$ \\
7 & $3.3088 \times 10^{-3}$ & $3.5870 \times 10^{-3}$ & 19 & $8.7797 \times 10^{-11}$ & $7.5780 \times 10^{-10}$ \\
8 & $9.3015 \times 10^{-4}$ & $1.3930 \times 10^{-3}$ & 20 & $2.5131 \times 10^{-14}$ & $2.4786 \times 10^{-10}$ \\
9 & $8.0943 \times 10^{-4}$ & $6.2630 \times 10^{-4}$ & 21 & $3.2176 \times 10^{-16}$ & $2.2384 \times 10^{-13}$ \\
10 & $1.9567 \times 10^{-4}$ & $1.8906 \times 10^{-4}$ & 22 & $4.5028 \times 10^{-17}$ & $2.4600 \times 10^{-14}$ \\
11 & $3.2535 \times 10^{-5}$ & $5.4988 \times 10^{-5}$ & 23 & $7.4791 \times 10^{-17}$ & $1.5699 \times 10^{-14}$ \\
12 & $7.5595 \times 10^{-6}$ & $2.0958 \times 10^{-5}$ & & & &
\end{tabular}


$Q_{f d}(T)=\sum_{n=1}^{N} F R_{n}\left[\sum_{i=1}^{23} a_{i} \int_{T_{n-1}}^{T} e^{\left.-\lambda_{i}\left(T-T^{\prime}\right)_{d T^{\prime}}\right]}\right.$

where $N$ is the number of periods used to represent the time span 0 to $T$.

Integrating Equation (3-13) yields

$$
\begin{aligned}
Q_{f d}(T) & =\sum_{n=1}^{N} F R_{n}\left[\sum_{i=1}^{23} \frac{\alpha_{j}}{\lambda_{i}} e^{-\lambda_{j} T}\left(e^{\lambda_{i} T}-e^{\left.\lambda_{i} T_{n}-1\right)}\right]\right. \\
& =\sum_{n=1}^{N} F R_{n}\left[\sum_{i=1}^{23} \frac{\alpha_{i}}{\lambda_{i}} e^{-\lambda_{j}\left(T-T_{n}\right)}\left(1-e^{\left.-\lambda_{j} \Delta t_{n}\right)}\right]\right.
\end{aligned}
$$

where

$$
\Delta t_{n}=I_{n}-T_{n-1}(s) .
$$

Expanding Equation (3-14) and rearranging terms yields

$$
\begin{aligned}
& Q_{f d}(T)=\sum_{i=1}^{23}\left\{\ldots\left[F R_{1} \frac{\alpha_{i}}{\lambda_{i}}\left(1-e^{-\lambda_{i} \Delta t} 1\right) e^{-\lambda_{i} \Delta t} 2+F R_{2} \frac{\alpha_{j}}{\lambda_{i}}\left(1-e^{-\lambda_{i} \Delta t} 2\right)\right] e^{-\lambda_{i} \Delta t_{3}}\right. \\
& \cdots\} e^{-\lambda_{i} \Delta t_{N}+F R_{N}} \frac{i}{\lambda_{i}}\left(1-e^{-\lambda_{i} \Delta t_{N}}\right) .
\end{aligned}
$$

Equation (3-16) can be simplified by separating the decay heat into 23 components:

$$
Q_{f d, n}^{i}=Q_{f d, n-1}^{i} e^{-\lambda_{i} \Delta t} n+F R_{n} \frac{\alpha_{i}}{\lambda_{i}}\left(1-e^{-\lambda_{i} \Delta t} n\right)
$$


where

$Q_{f d, n}^{i}=i-t h$ component of decay heat after time step $n\left(W / m^{3}\right)$ $Q_{f d, n-1}^{i}=i$-th component of decay heat after time step $n-1\left(w / m^{3}\right)$.

The fission product decay heat is now in a form that can be updated each time step given the current fission rate and time step size.

\subsubsection{Neutron Capture Correction to Fission Product Decay}

Reference 3-5 provides two empirical methods for determining the neutron capture correction to fission product decay [the factor $G$ from Equation (3-8)]. One method is a table of values that is valid for shutdown times up to $10^{9} \mathrm{~s}$ and operating times up to 4 years for standard IWR operating conditions. The other method is a correlation that is valid for shutdown times up to $10^{4} \mathrm{~s}$, operating times up to 4 years, and fissions per initial fissile atom up to three. The correlation is used in the range for which it is valid (less the $10^{4} \mathrm{~s}$ ), since it is more accurate within this range; and the tables are used for times greater than $10^{4} \mathrm{~s}$. The correlation is given by

$G=1.0+\left(3.24 \times 10^{-6}+5.23 \times 10^{-10} t\right) T^{0.4} \Psi$

where

$\begin{aligned} \mathbf{G} & =\text { neutron capture correction to fission product decay } \\ t \quad & =\text { time since shutdown }(s) \\ T & =\text { operating time }(s) \\ \Psi \quad & =\text { fissions per initial fissile atom. }\end{aligned}$


$\Psi=\frac{1}{v} \int_{0}^{T} F R d l^{\prime}$

where

$v \quad=$ number of initial fissile atoms per unit volume (atoms $/ \mathrm{m}^{3}$ )

$F R=f i s s i o n$ rate per volume (fissions $\left./ m^{3} \cdot s\right)$.

The term $v$ is determined from the fuel pellet initial conditions by

$v=W \rho N_{0} / A t$

where

$$
\begin{aligned}
& w=\text { weight fraction of }{ }^{235} \mathrm{UO}_{2} \\
& \rho \quad=\text { fuel pellet density }\left(\mathrm{kg} / \mathrm{m}^{3}\right) \\
& \left.N_{0} \quad=\text { Avogadro's number, } 6.023 \times 10^{26} \text { (molecules/kg } \cdot \mathrm{mole}\right) \\
& \text { At } \quad=\text { Atomic weight of }{ }^{235} \mathrm{U0}_{2} .
\end{aligned}
$$

The table of values that are interpolated when conditions are outside the range of Equation $(3-18)$ is shown in Table $3-3$.

\subsubsection{Actinide Decay Power}

The actinide decay term in Equation (3-9) is calculated using the model supplied in Reference 3-5. This model assumes that the actinide decay power is due only to the decay of ${ }^{239} \mathrm{U}$ and ${ }^{239} \mathrm{~Np}$. The actinide power is given by 
TABLE 3-3. G FACTORS FOR TIMES GREATER THAN 10,000 S

Time After

Shutdown

(s)

1.0

1.5

2.0

4.0

6.0

8.0

$1.0 \times 101$

$1.5 \times 107$

$2.0 \times 10^{1}$

$4.0 \times 10^{1}$

$6.0 \times 101$

$8.0 \times 101$

$1.0 \times 10^{2}$

$1.5 \times 10^{2}$

$2.0 \times 10^{2}$

$4.0 \times 10^{2}$

$6.0 \times 10^{2}$

$8.0 \times 10^{2}$

$1.0 \times 10^{3}$

$1.5 \times 10^{3}$

$2.0 \times 10^{3}$

$4.0 \times 10^{3}$

$6.0 \times 10^{3}$

$8.0 \times 10^{3}$

$1.0 \times 10^{4}$

$1.5 \times 10^{4}$

$2.0 \times 10^{4}$

$4.0 \times 10^{4}$

$6.0 \times 10^{4}$

$8.0 \times 10^{4}$

$1.0 \times 10^{5}$
Time After

Shutdown

G

1.020

1.020

1.020

1.021

1.022

1.022

1.022

1.022

1.022

1.022

1.022

1.022

1.023

1.024

1.025

1.028

1.030

1.032

1.033

1.037

1.039

1.048

1.054

1.060

1.064

1.074

1.081

1.098

1.111

1.119

1.124
$-\underline{G}$

1.130

1.131

1.126

1.124

1.123

1.124

1.125

1.127

1.134

1.146

1.162

1.181

1.233

1.284

1.444

1.535

1.586

1.598

1.498

1.343

1.065

1.021

1.012

1.007 
$Q_{A d}=\frac{Q_{f}}{E_{f}}\left[F_{U 239}(t, 1)+F_{N P 239}(t, T)\right]$

where

$$
\begin{aligned}
& Q_{f}=\begin{array}{l}
\text { total maximum } \\
\left(\mathrm{W} / \mathrm{m}^{3}\right)
\end{array} \\
& E_{f}=\text { fission power during the operating history } \\
& \mathrm{F} \quad={ }^{239} \mathrm{U} \text { or }{ }^{239} \mathrm{~Np} \text { decay energy per fission (MeV/fission) }
\end{aligned}
$$

The terms $F_{\mathrm{U} 239}$ and $F_{\mathrm{NP239}}$ are given by

$$
\begin{aligned}
& F_{U 239}(t, 1)=R E_{U 239}\left(1-e^{-\lambda_{1} T}\right) e^{-\lambda_{1} t} \\
& F_{\text {NP239 }}(t, 1)=R E_{N P 239} \frac{\lambda_{1}}{\lambda_{1}-\lambda_{2}}\left(1-e^{-\lambda_{2} T}\right) e^{-\lambda_{2} t} \\
& -\frac{\lambda_{2}}{\lambda_{1}-\lambda_{2}}\left(1-e^{-\lambda_{1} T}\right) e^{-\lambda_{1} t}
\end{aligned}
$$

where

$$
\begin{aligned}
& \mathrm{R} \\
& \mathrm{T} \quad={ }^{239} \mathrm{U} \text { production per fission (atoms/fission) } \\
& t \quad=\text { operating time (s) } \\
& \mathrm{E}_{\mathrm{U} 239} \quad=\text { average decay energy of }{ }^{239} \mathrm{U}, 0.474(\mathrm{MeV}) \\
& \mathrm{E}_{\mathrm{NP239}} \quad=\text { average decay energy of }{ }^{239} \mathrm{~Np}, 0.419(\mathrm{MeV})
\end{aligned}
$$

a. Use of total maximum fission power is specified by Reference 3-6. 


$$
\begin{aligned}
& \lambda_{1} \quad={ }^{239} \mathrm{U} \text { decay constant, } 4.91 \times 10^{-4}\left(\mathrm{~s}^{-1}\right) \\
& \lambda_{2} \quad={ }^{239} \mathrm{~Np} \text { decay constant, } 3.41 \times 10^{-6}\left(\mathrm{~s}^{-1}\right) .
\end{aligned}
$$

\subsubsection{Radial Peaking Factor for Delayed Heat}

For nonfuel components, the radial distribution of delayed power, $R_{d}(r)$, is set equal to radial distribution of prompt power, $R_{p}(r)$. However, for fuel rods, $R_{d}(r)$ is not identical to $R_{p}(r)$ because $\lambda$-ray energy may be deposited a considerable distance from the location of generation. Since $\lambda$-ray energy is about one-half of the delayed power, $R_{d}(r)$ within a fuel rod is estimated by

$R_{d}(r)=0.5\left[1+R_{p}(r)\right]$.

The overall radial power distribution is determined by

$$
R^{j}=\frac{\left(G Q_{f d}+Q_{A d}\right) Z_{d}^{j}\left(1+R_{p}\right)\left(1+R_{p}\right) 0.5+Q_{p} Z_{p}^{j} R_{p}}{\left(G Q_{f d}+Q_{A d}\right) Z_{d}^{j}+Q_{p} Z_{p}^{j}}
$$

where the superscript $j$ denotes axial position and is required due to the possible difference in the prompt and delayed axial power distributions.

\subsection{Effective Materials Properties Model}

Effective heat transfer properties are used to model the effects of composition and changing material geometry within a region of a fuel rod, control rod, or flow shroud. These properties are used by the finite element heat conduction model as element properties. Volume-average techniques based on a parallel and series-resistance approach are used as well as the integral transformation technique, which is used for treating phase change, and are described in the following subsections. 


\subsubsection{Parallel and Series-Res istance Approach}

The effective materials properties and effective volumetric heat generation for a heat conduction element of volume, $v$, are approximated by volumetric averaging based on the parallel and series-resistance approach.

$(p c)_{e f f}=\frac{\int_{v} p c d v}{\int_{v} d v}$

$\frac{1}{k_{e f f}}=\frac{\int_{v} \frac{1}{k} d v}{\int_{v} d v}$

$q_{e f f}=\frac{\int_{v} q^{\prime \prime \prime} d v}{\int_{v} d v}$

With respect to one-dimensional Cartesian or cylindrical geometry, the following apply.

$(\rho c)_{\text {eff }}^{n}=\frac{\int_{x_{n}}^{x_{n+1}}(\rho c) d x}{\left(x_{n+1}-x_{n}\right)}$

$(\rho c)_{e f f}^{n}=\frac{\int_{r_{n}}^{r} n+1}{\left(r_{n+1}^{2}-r_{n}^{2}\right) / 2}$

$\frac{1}{k_{e f f}^{n}}=\frac{\int_{x_{n}}^{x_{n+1}} \frac{1}{k} d x}{\left(x_{n+1}-x_{n}\right)}$ 
$-\frac{1}{k_{e f f}^{n}}=\frac{\int_{r_{n}}^{r^{n+1}} \frac{1}{k} r d r}{\left(r_{n+1}^{2}-r_{n}^{2}\right) / 2}$

$q_{e f f}^{n}=\frac{\int_{n}^{x_{n+1}} q^{\prime \prime \prime d} d x}{\left(x_{n+1}-x_{n}\right)}$

$q_{e f f}^{n}=\frac{\int_{r_{n}}^{r} q_{n+1} \cdot \cdot r d r}{\left(r_{n+1}^{2}-r_{n}^{2}\right) / 2}$

where $x_{n}$ and $r_{n}, x_{n+1}$ and $r_{n+1}$ are the boundaries of a heat conduction finite element in Cartesian and cylindrical coordinates, respectively.

So, for a finite element with a number of layers with different heat transfer properties, the effective value of a generalized variable $U[(\rho c)$, $1 / k$, or $\left.q^{\prime \prime \prime}\right]$ is approximated by

$U_{e f f}^{n}=\frac{A_{l}^{n}}{A_{t}^{n}} \bar{U}_{1}^{n}+\ldots+\frac{A_{l}^{n}}{A_{t}^{n}} \bar{U}_{l}^{n}+\cdots+\frac{A_{L n}}{A_{t}^{n}} \bar{U}_{L n}$

where

$$
\vec{u}_{\ell}^{n}=\int_{T_{\ell}^{n}}^{T_{\ell+1}^{n}} u_{\ell}^{n} d T /\left(T_{\ell+1}^{n}-T_{\ell}\right)^{n}
$$



$u_{l}^{n}=$
heat transfer properties of the $\ell$-th layer within element $n$, which are considered to be dependent on temperature in cases of specific heat capacities and thermal conductivities.
$T_{\ell}^{n}=\begin{aligned} & \text { temperatures }(K) \text { at the material layer interfaces of the } \\ & \text { element }\end{aligned}$
$A_{l}^{n}=\left[\left(r_{\ell+1}^{n}\right)^{2}-\left(r_{\ell}^{n}\right)^{2},\left(m^{2}\right)\right]$, in cylindrical coordinates,
$A_{\ell}^{n}=\left[x_{\ell+1}^{n}-x_{\ell}^{n},(m)\right]$, in Cartesian coordinates
$A_{t}^{n}=\left[\left(r_{n+1}\right)^{2}-\left(r_{n}\right)^{2},\left(m^{2}\right)\right]$, in cylindrica $]$ coordinates,
$A_{t}^{n}=\left[x_{n+1}-x_{n}\right],(m)$, in Cartesian coordinates.

The basic assumption for the calculation of effective volumetric heat capacity [Equations (3-29) and (3-30)] is that the time derivative of temperature is nearly constant within a heat conduction element. Thus,

$\frac{\partial T}{\partial t}=\frac{\partial T}{\partial t}(r)$ and $\frac{\partial T}{\partial t}=\frac{\partial T}{\partial t}(x)$, respectively.

When calculating the effective thermal conductivity [Equations (3-31) and $(3-32)]$, the resulting heat flux in the heat conduction element is assumed to be the same as the heat fluxes in the real material layers within that element.

\subsubsection{Integral Transformation Technique}

The effective heat capacity is defined using an integral transformation (i.e. by introducing a new variable that is a smooth 
function of temperature even at the phase-change front). The application of an integral transformation introduces enthalpies within the heat conduction element in order to evaluate effective volumetric heat capacities. Because of $(\rho c)=d H / d T$, we then have

$H=\int_{T_{0}}^{T}(\rho c) d T$

where

$H=$ volumetric enthalpy at temperature $T\left(\mathrm{~J} / \mathrm{m}^{3}\right)$

$T_{0}=$ reference temperature where the enthalpy is equal to zero.

A heat conduction element is considered in one-dimensional Cartesian coordinates with three material layers consisting of a solid and a molten phase (e.g., zircaloy) and a small transition region. Figure 3-2 shows a volumetric enthalpy jump across the phase-change interphase, to which a

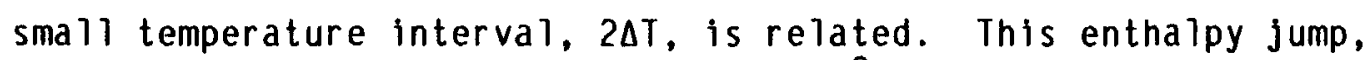
equivalent to the heat of fusion $h_{f}\left(\mathrm{~J} / \mathrm{m}^{3}\right)$, must be considered for the estimation of the effective volumetric heat capacity in the corresponding heat conduction element.

For the example in Figure 3-2, from Equations $(3-29)$ and $(3-30)$ and the assumption of a linear temperature profile within the element,

$$
\begin{aligned}
(\rho c)_{e f f}^{n}=\frac{\int_{x_{n}}^{x_{n+1}}(\rho c) d x}{\left(x_{n+1}-x_{n}\right)} \\
=\frac{\int_{x_{n}}^{x_{m}-\Delta x}(\rho c)_{m} d x+\int_{x_{m}-\Delta x}^{x_{m}+\Delta x}(\rho c)_{2 \Delta x} d x+\int_{x_{m}+\Delta x}^{x_{n+1}(\rho c)_{s} d x}}{\left(x_{n+1}-x_{n}\right)}
\end{aligned}
$$



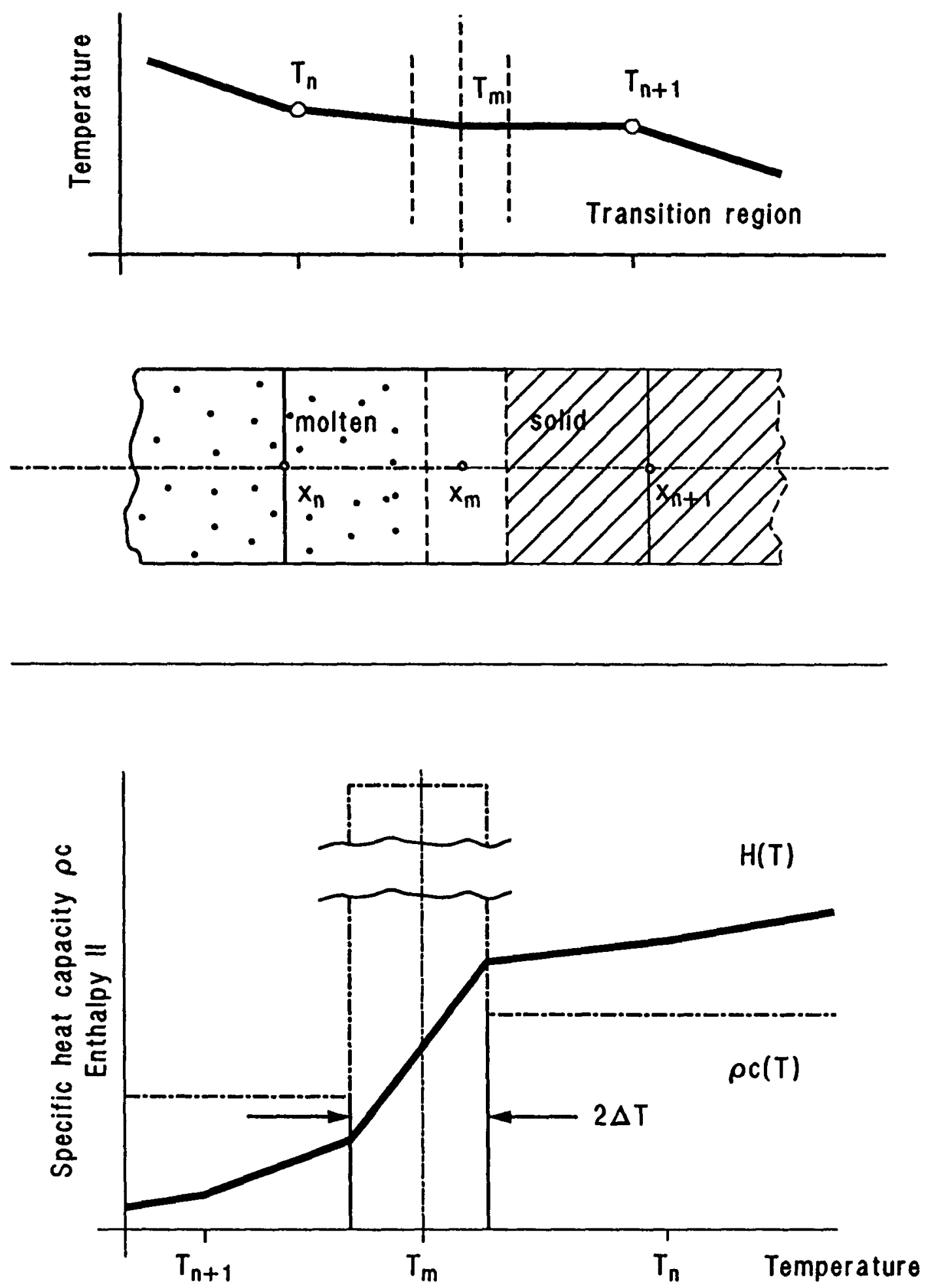

EC000072

Figure 3-2. Estimation of effective volumetric heat capacity in a phase-change problem. 


$$
\begin{aligned}
& =\frac{\int_{x_{n}}^{x_{m}-\Delta x}-\frac{d H}{d x}\left|\frac{d T}{d x}\right|_{m} d x+\int_{m}^{x_{m}+\Delta x}-\Delta x}{\left(x_{n+1}-x_{n}\right)} \frac{\frac{d H}{d x}\left|\frac{d T}{d x}\right|_{2 \Delta x} d x+\int_{m}^{x_{n+1}+\Delta x} \frac{d H}{d x}\left|\frac{d T}{d x}\right|_{s} d x}{(3-38)} \\
& =\frac{H_{x_{n+1}}-H_{x_{n}}}{\left(x_{n+1}-x_{n}\right) \cdot\left|\frac{d T}{d x}\right|_{E_{n}}}
\end{aligned}
$$

where

$H_{x_{n+1}}=\int_{T_{0}}^{T}(\rho c)_{s} d T$

$H_{x_{n}}=\int_{T_{0}}^{T_{m}-\Delta T}(\rho c)_{s} d T+\frac{T_{n}-\left(T_{m}-\Delta T\right)}{2 \Delta T} h_{f}$, if $\left(T_{m}-\Delta T\right)<I \leq\left(T_{m}+\Delta T\right)(3-40)$

$H_{x_{n}}=\int_{T_{0}}^{T_{m}-\Delta T}(\rho c)_{s} d T+h_{f}+\int_{T_{m}+\Delta T}^{T_{n}}(\rho c)_{m} d T$, if $T_{n}>\left(T_{m}+\Delta T\right)$.

and

$$
\begin{aligned}
(\rho c)_{s} & =\text { volumetric heat capacity for solid phase }\left(\mathrm{J} / \mathrm{m}^{3} \cdot K\right) \\
(\rho c)_{\mathrm{m}} & =\text { volumetric heat capacity for molten phase }\left(\mathrm{J} / \mathrm{m}^{3} \cdot K\right) \\
\mathrm{h}_{\mathrm{f}} & =\text { heat of fusion }\left(\mathrm{J} / \mathrm{m}^{3}\right) \\
\mathrm{l} & =\text { temperature }(K) .
\end{aligned}
$$

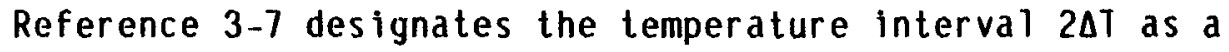
nonsensitive parameter in the range of $1 / 100$ to $1 / 500$ of the overal1 temperature difference in the problem. 


\subsubsection{Application of Paralle1 and Series-Resistance Approaches in the Effective Heat Transfer Model (EFFHT).}

Equation (3-31) is the basis of the effective materials properties model. Also, the effects of latent heat are included in the calculation of the effective volumetric heat capacity when a phase change occurs within a heat conduction element. The equations for evaluation of effective volumetric heat capacities for the general case of several layers with different materials properties including a phase change front are presented in Appendix $C$ of Reference 3-8.

The introduction of the integral transformation to replace volumetric heat capacities by enthalpies leads to expressions of the effective volumetric heat capacity with enthalpy differences [e.g., Equation (3-38)]. On the other side, differences of enthalpies relating to the same material, e.g.,

$$
H_{2}=\int_{T_{0}}^{T_{2}}(\rho c) d T, H_{1}=\int_{T_{0}}^{T_{1}}(\rho c) d T, T_{1}<T_{2}
$$

can be expressed by an integral of the corresponding volumetric heat capacity over the temperature difference,

$H_{2}-H_{7}=\int_{T_{1}}^{T_{2}}(\rho c) d T$.

So, using the example of Figure 3-2 and the deduction of Equation (3-38),

$(\rho c)_{e f f}^{n}=\frac{\int_{n+1}^{T} T_{m}^{-\Delta T}(\rho c)_{s} d T+\frac{T_{n}-\left(T_{m}-\Delta T\right)}{2 \Delta T} h_{f}}{\left(x_{n+1}-x_{n}\right) \frac{d T}{d x} E_{n}}$ 
if $\left(T_{m}-\Delta T\right)<T_{n} \leq\left(T_{m}+\Delta T\right)$

and

$(\rho c)_{e f f}^{n}=\frac{\int_{T_{n+1}}^{T}{ }_{m}^{-\Delta T}(\rho c)_{s} d T+h_{f}+\int_{-T_{m}+\Delta T}^{T}(\rho c)_{m} d T}{\left(x_{n+1}-x_{n}\right)\left|\frac{d T}{d x}\right|_{E_{n}}}$

if $T_{n}>\left(T_{m}+\Delta T\right)$

Thus, the final model uses integrals of volumetric heat capacities over the temperature differences of the corresponding material layers (with the addition of the heat of fusion in the case of a phase change) instead of enthalpy differences.

According to the general expression for the evaluation of effective material properties, $U_{e f f}^{n}$ in Equation (3-35), these integrals over temperature differences of the corresponding material layers within a heat conduction element are also performed for the reverse of the thermal conductivity. For a general variable $U$, the integral

$\int_{T_{1}}^{T_{2}} U d T$

is approximated by

$\int_{T_{1}}^{T_{2}} U d T=\frac{\left(U_{1}+U_{2}\right)}{2} \frac{\left(T_{2}-T_{1}\right)}{2}$

where 


$$
\begin{aligned}
& U_{1}=\text { value of } U \text { at } T=T_{1} \\
& U_{2}=\text { value of } U \text { at } T=T_{2} \\
& T_{1}=\quad \begin{array}{l}
\text { lower and upper temperatures at the corresponding boundaries } \\
T_{2}
\end{array} \quad \text { of the considered material layer. }
\end{aligned}
$$

The following materials (material layers) have been considered to exist for description of effective material properties. Layers specified by geometry-independent materials properties include unirradiated fuel, zircaloy cladding, $\mathrm{ZrO}_{2}$, 1 iquid $\mathrm{Zr}-\mathrm{U}-0$, frozen $\mathrm{Zr}-\mathrm{U}-0$, structural and absorber materials. Layers specified by geometry-dependent models include cracked fue 1, relocated fuel, and gaps or voids; heat transport through gaps and voids in the current EFFHT model is considered to be caused by conduction only.

\subsubsection{Model for Calculating Effective Volumetric Heat Generation}

Heat generation within a heat conducting component is given either in the form of volumetric heat generations $\left(w / m^{3}\right)$ for the different material layers between component center and component surface (e.g., nuclear heat generation in layers of solid fuel and liquid/frozen $\mathrm{Zr}-\mathrm{U}-0$ ) or in the form of specific heat generations per unit length $(\mathrm{W} / \mathrm{m})$. The latter is caused by chemical heat generation front(s) located at some distance(s) from the component center. According to the general expression for volumetric averaging of Equation (3-35), the effective volumetric heat generation in a heat conduction element with several material layers, given the volumetric heat generations of these layers, is

$q_{e f f}^{n}=\frac{\sum_{l=1}^{L_{n}} A_{l}^{n} q_{l}}{A_{t}^{n}}$

where $q_{\ell}$ is the volumetric heat generation within the $\ell$-th material layer. 


\subsection{Fuel State Models}

The fuel rod state modeling includes models for locating the radial position of fuel rod materials and changes in axial power peaking due to fuel axial relocation.

Information provided by the liquefaction and oxidation models (Section 3.1 and 3.8 , respectively) on new material radii at each axial elevation is transformed into information required by the effective heat transfer models (Section 3.3). This includes $\mathrm{UO}_{2}, 1$ iquid $\mathrm{Zr}-0-\mathrm{U}$, frozen $\mathrm{Zr}-\mathrm{O}-\mathrm{U}, \mathrm{ZrO}_{2}$, and gap radil.

In order to provide axial peaking factors as a function of elevation, the various anticipated geometries must be examined and the appropriate equations derived.

Two cases are expected to exist for component behavior where relocation is a concern. Figure 3-3 presents the two cases. Case (a) involves relocation of material due to liquefaction, flow, and solidification. Case (b) involves the relocation of fuel fragments to a ballooned region from the upper portion of a fuel rod. In both cases, material with a different peaking factor is moved into a region.

for Case (a), the new peaking factors in the fuel are unchanged; nowever, the peaking factor in the crust is found using the following equation.

$$
c^{F} F_{i+7}(z)=\left\{\begin{array}{l}
c_{i}^{F_{i}(z), \text { for } z>z_{2}} \\
\int_{z_{3}}^{z_{4}} \frac{F_{i}(z) A_{r}(z) d z}{V_{a}} \frac{A_{d}(z)}{A_{t}(z)}+\frac{c_{i}^{F}(z) A_{c}(z)}{A_{t}(z)}, \text { for } z_{1}<z<z_{2} \\
c^{F_{i}}(z), \text { for } z<z_{1}
\end{array}\right.
$$




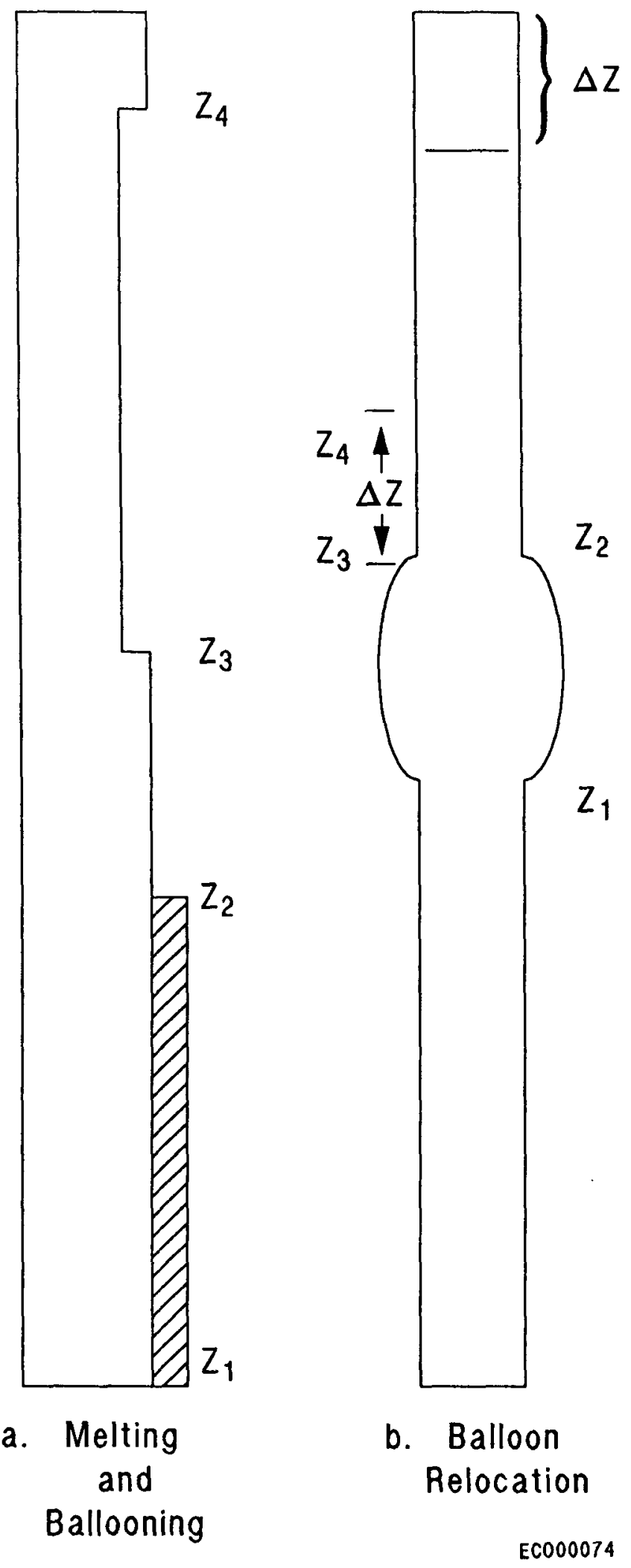

Figure 3-3. Two relocation geometries. 
where

$$
\begin{aligned}
& c^{F} i+1(z)=\text { axial peaking factor for delayed heating of the crust } \\
& \text { at } t \text { ime } i+1 \\
& c^{F}{ }_{i}(z)=\text { axial peaking factor for delayed heating of the crust } \\
& \text { at time } i \\
& F_{i}(z)=\text { average axial peaking factor at time } 2 \text { for } z_{3} \text { to } z_{4} \\
& A_{r}(z)=10 c a l \text { area of removed material }\left(m^{2}\right) \\
& A_{t}(z)=\text { total area of crust in the region at the end of time } \\
& \text { step }\left(m^{2}\right) \\
& A_{c}(z)=\text { crust area at the beginning of the time step }\left(m^{2}\right) \\
& \begin{aligned}
A_{a}(z)= & \text { area added to the crust at elevation } z \text { during the time } \\
& \text { step }\left(m^{2}\right)
\end{aligned} \\
& z=\text { axial elevations (m) } \\
& v_{a}=\text { total volume of crust added during the time step }\left(m^{3}\right) \text {. }
\end{aligned}
$$

For Case (b), the new peaking factors are calculated using the following equation:

$$
F_{i+7}(z)=\left\{\begin{array}{l}
F_{i}(z+\Delta z) \text { for } z_{2}<z \leq z_{3} \\
0 \text { for } z>z_{3} \\
\frac{\int_{z_{2}}^{z_{2}+\Delta z}}{F_{i}(z) A_{r}(z) d z} \frac{A_{a}(z)}{A_{a}(z)}+\frac{F_{i}(z) A_{f}(z)}{A_{t}(z)} \text { for } z_{1} \leq z \leq z_{2} \\
F_{i}(z) \text { for } z<z_{1}
\end{array}\right.
$$


where

$$
\begin{aligned}
& F_{i+1}(z)=\text { axial peaking factor for delayed heating at } t i m e ~ i+1 \\
& F_{i}(z)=\cdot \text { axial peaking factor for delayed heating at time } 1 \\
& A_{f}(z)=\text { the area of fue } 1 \text { in the zone at the beginning of the } \\
& \text { time step }\left(m^{2}\right) \\
& \Delta z \quad=\text { the change in elevation of the top of the fue } 1 \text { stack } \\
& \text { during the time step (m). }
\end{aligned}
$$

The local peaking factors are calculated using Equations (3-49) and (3-50) and will be used for only the delayed sources of energy generation. The prompt axial peaking factor profiles are supplied by the SCDAP/RELAP5 user. See Appendix A of Reference 3-9 for the method used to discretize peaking factors.

\subsection{Heat Conduction Mode 1}

The Finite Element Method (FEM) for heat conduction involves approximating temperature by dividing the solution region into a finite number of regions called elements. $3-7,10,11,12,13$ Temperature is expressed in terms of an assumed approximating function for each element. The weighting functions are defined as maximum at specified points (nodes) that lie on the element boundaries and decrease to zero at adjacent nodes. Adjacent elements have common nodes. The nodal temperatures are the desired unknowns; and, using the FEM, the entire temperature distribution can be determined by assembling the contributions of each element.

Although several ways exist to formulate the contributions of an element, the Galerkin Method of Weighted Residuals, which is the most versatile approach, ${ }^{3-7}$ is used in SCDAP/RELAP5. This method assumes a general functional behavior for the temperature within an element. Substitution of the approximation into the differential equation governing 
heat conduction and into the boundary conditions results in an error called a residual. The product of this residual and a weighting function is required to vanish in an average sense over the solution region.

After the element contributions are determined, the element contributions are assembled to obtain a set of simultaneous linear equations for the entire solution region. These equations are then solved, yielding the temperature at each node point.

The remainder of this section describes details of the formulation of the generalized heat conduction model.

\subsubsection{Formulation of the Heat Conduction Governing Equations}

The governing differential energy equation for a one-dimensional solid, written in a form that applies to any coordinate system, is obtained by dividing by the appropriate volume.

$$
\rho c_{p} \frac{\partial T}{\partial t}=\frac{1}{x^{a-1}} \frac{\partial}{\partial x}\left(k x^{a-1} \frac{\partial T}{\partial x}\right)+u
$$

where

$$
\begin{aligned}
\rho & =\text { material density }\left(\mathrm{kg} / \mathrm{m}^{3}\right) \\
c_{p} & =\text { material specific heat }[\mathrm{J} /(\mathrm{kg}-\mathrm{k})] \\
t \quad & =\text { time }(\mathrm{s}) \\
k \quad & =\text { material thermal conductivity }[\mathrm{W} /(\mathrm{m} \cdot \mathrm{K})] \\
\mathbf{u} & =\text { energy generation }\left(\mathrm{W} / \mathrm{m}^{3}\right) \\
T & =\text { temperature }(\mathrm{K})
\end{aligned}
$$




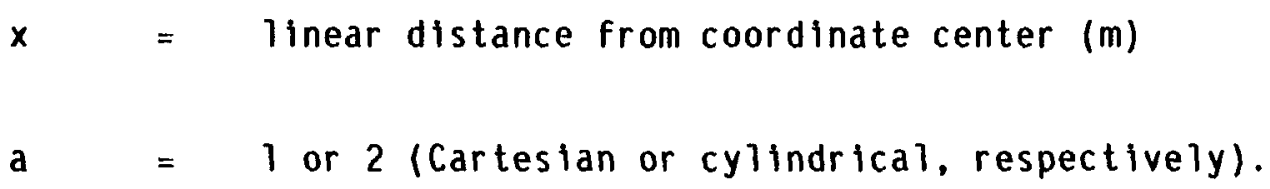

The boundary conditions written in a form that applies to any coordinate system are:

$-\left.x^{a-1} k \frac{\partial T}{\partial x}\right|_{1}=x^{a-1} q_{1}$

and

$\left.x^{a-1} k \frac{\partial T}{\partial x}\right|_{r}=x^{a-1} q_{r}$

where

$q_{1}=$ heat flux into the left end $\left(w / m^{2}\right)$

$q_{r}=$ heat flux into the right end $\left(w / m^{2}\right)$.

In general, the heat flux is

$q=q_{1}+h\left(T_{\infty}-T_{s}\right)$

where

$$
\begin{aligned}
& T_{s}=\text { component surface temperature }(K) \\
& T_{\infty}=\text { bulk coolant temperature }(K) \\
& q_{i}=\text { imposed heat flux }\left(W / m^{2}\right) \\
& h \quad=\text { surface heat transfer coefficient }\left(W / m^{2} \cdot K\right) .
\end{aligned}
$$




\subsubsection{The Method of Weighted Residuals}

The method of weighted residuals requires that the product of the residual and the weighting function vanish in some average sense over the solution domain. The residual is defined as the difference between the right-and left-hand side of Equation (3-51) when some approximating function is used for 7 . The weighting function for a node is chosen to be one at the node and zero at all other nodes and varies from one to zero in the two elements adjacent to the node. Therefore,

$\underset{j}{\text { region }} W_{\mathrm{j}} \mathrm{Rdx}=0, \mathrm{j}=1,2, \ldots M$

where

$$
\begin{aligned}
& R \quad=\text { the residual } \\
& W_{j} \quad=\text { the weighting factor of the } j-\text { th node } \\
& M \quad=\text { the number of nodes. }
\end{aligned}
$$

The residual is defined using Equation (3-51). Therefore, the $\mathrm{m}$-th residual is

$R_{m}=\frac{\partial}{\partial x}\left(k x^{\alpha-1} \frac{\partial T}{\partial x}\right)+u x^{a-1}-\rho c_{p} x^{a-1} \frac{\partial T}{\partial t}$

Thus the $m$-th contribution is defined as

$$
\int_{x_{m}}\left[w_{j} \frac{\partial}{\partial x}\left(k x^{a-1} \frac{\partial T}{\partial x}\right)+w_{j} u x^{a-1}-w_{j} \rho c_{p} x^{a-1} \frac{\partial T}{\partial t}\right] d x_{m} .
$$

Integrating by parts, Equation (3-57) becomes 


$$
\begin{gathered}
\left.W_{j} k x^{a-1} \frac{\partial T}{\partial x}\right|_{\text {ends }}-\int_{k x} a-1 \frac{\partial T}{\partial x} \frac{\partial W_{j}}{\partial x} d x+\int_{u} x^{a-1} W_{j} d x \\
-\int_{\rho c_{p} x^{a-1} \frac{\partial T}{\partial t} W_{j} d x .}
\end{gathered}
$$

From the boundary conditions, the following equation is obtained:

$$
\begin{aligned}
& \left.W_{j} k x^{a-1} \frac{\partial T}{\partial x}\right|_{\text {ends }}=W_{j}\left(\left.k x^{a-1} \frac{\partial T}{\partial x}\right|_{\substack{\text { right } \\
\text { end }}}-\left.k x^{a-1} \frac{\partial T}{\partial x}\right|_{\begin{array}{l}
\text { left } \\
\text { end }
\end{array}}\right) \\
& =w_{j}\left(q x^{a-1}\left|\begin{array}{l}
\text { in } \\
\text { right } \\
\text { end }
\end{array}+q x^{a-1}\right| \begin{array}{l}
\text { in } \\
\text { left } \\
\text { end }
\end{array}\right)
\end{aligned}
$$

Substituting Equation (3-59) into Expression (3-58), the following is obtained

$$
\begin{gathered}
W_{j}\left(\sum q x^{a-1}\right)-\int_{k x} a-1 \frac{\partial T}{\partial x} \frac{\partial W_{j}}{\partial x} d x+\int_{U x^{a-1} W_{j} d x} \\
-\int_{\rho c_{p}} x^{a-1} \frac{\partial T}{\partial t} W_{j} d x .
\end{gathered}
$$

If the solution domain, i.e., the physical region in which the temperatures are to be obtained, is divided into a discrete number of elements, Equation $(3-60)$ becomes

$$
\begin{aligned}
& \sum_{i=1}^{2} w_{j} x^{a-1} q_{i}-\sum_{i+1}^{n} \int_{x_{i}}^{x_{j}+1} k x^{a-1} \frac{\partial T}{\partial x} \frac{\partial w_{j}}{\partial x^{2}} d x \\
& +\sum_{i=1}^{n} \int_{x_{i}}^{x_{i+1}} u x^{a-1} w_{j} d x-\sum_{i=1}^{n} \int_{x_{i}}^{x_{j}+1} \rho c_{p} x^{a-1} \frac{\partial T}{\partial t} w_{j} d x=0
\end{aligned}
$$


where

$$
\begin{aligned}
& j \quad=1,2, \ldots M \text { (number of nodes) } \\
& n \quad=\text { number of elements. }
\end{aligned}
$$

As shown in Figure 3-4, a typical element is made up of the region between $x_{i}$ and $x_{i+1}$. The temperature profile is assumed to be linear through the element, with one-dimensional heat conduction (i.e, insulated surfaces on top and bottom). Therefore, the temperature within an element can be written as follows:

$T(x)=\mathbf{N}_{\mathbf{i}} T_{\mathbf{i}}+\mathbf{N}_{\mathbf{i}+\mathbf{T}} \boldsymbol{T}_{\mathbf{i}+1}$

where

$$
\begin{aligned}
& T(x)=\text { temperature at } x(K) \\
& T_{i}=\text { temperature at } x_{i}(K) \\
& T_{i+1}=\text { temperature at } x_{i+1}(K) \\
& N_{i}=\frac{x-x_{i}}{x_{i+1}-x_{i}} \text {, shape factor at } x_{i} \\
& N_{i+1}=\frac{x_{i+1}-x}{x_{i+1}-x_{i}} \text {, shape factor at } x_{i+1} \text {. }
\end{aligned}
$$

Differentiating Equation (3-62) with respect to time, the following equation is obtained.

$\frac{d T(x)}{d t}=N_{1} \frac{d T_{1}}{d t}+N_{1+1} \frac{d T_{1+1}}{d t}$. 


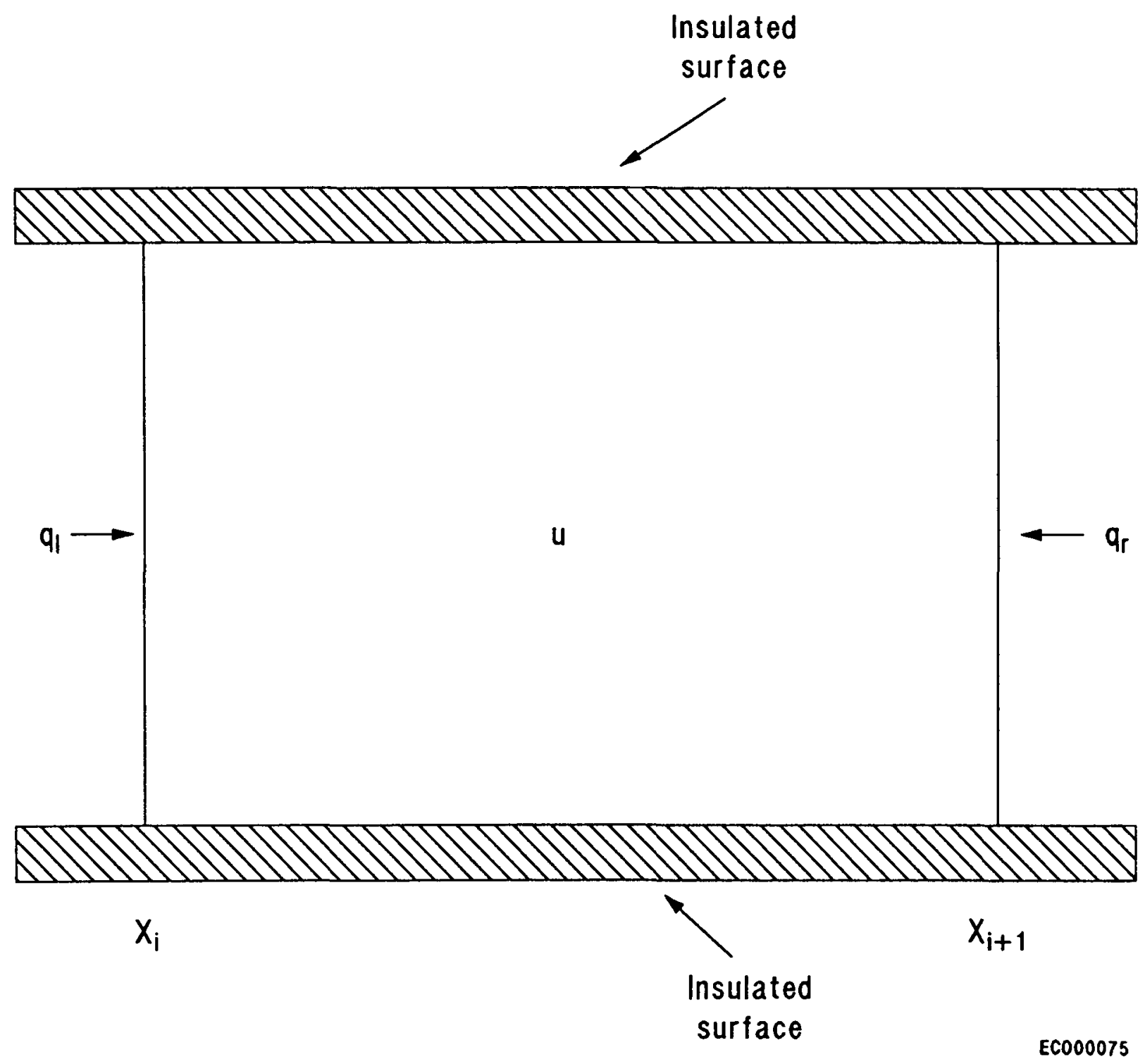

Figure 3-4. Typical finite element. 
Also, differentiating Equation (3-62) with respect to the spatial coordinate $x$, the following is obtained.

$\frac{d T(x)}{d x}=\frac{d N_{i}}{d x} T_{i}+\frac{d N_{i+1}}{d x} T_{i+1}$

Using the Galerkin method of weighted residuals, the weighting factor for the $i$-th equation is chosen to be the complete shape factor associated with that node, that is, $w_{j}=N_{i}$. The $i$-th element will contribute to the overall equation set for two shape factors. Applying this fact to Equation $(3-60)$, the total contribution from the $i$-th element to the complete set of equations for the domain is obtained. The result, written in matrix form, is

$\left[\begin{array}{l}N_{i} \\ N_{i+1}\end{array}\right] x^{a-1} q-\int_{x_{i}}^{x_{i+1}} k x^{a-1}\left[\begin{array}{r}\frac{d N_{j}}{d x} \\ \frac{d N_{j+1}}{d x}\end{array}\right] \frac{d N_{i}}{d x} \frac{d N_{i+1}}{d x}\left[\begin{array}{c}T_{i} \\ T_{i+1}\end{array}\right] d x$

$$
\begin{aligned}
& +\int_{x_{i}}^{x_{i+1}}\left[N_{i+1}^{N}\right] u x^{a-1} d x \\
& -\int_{x_{i}}^{x_{i+1}} x^{a-1} \rho c_{p}\left[\begin{array}{c}
N_{i} \\
N_{i+1}
\end{array}\right]\left[N_{i} N_{i+1}\right]\left[\begin{array}{c}
\frac{d t}{d t} \\
\frac{d T_{j+1}}{d t}
\end{array}\right] d x \text {. }
\end{aligned}
$$

or

$\left[\begin{array}{l}N_{i} \\ N_{i+1}\end{array}\right] x^{a-1} q-\int_{x_{i}}^{x_{i+1}} k x^{a-1}\left[\begin{array}{ll}\frac{d N_{i}^{2}}{d x} & \frac{d N_{j}}{d x} \frac{d N_{i+1}}{d x} \\ \frac{d N_{i}}{d x}-\frac{d N_{j+1}}{d x} & \frac{d N_{i+1}^{2}}{d x}\end{array}\right]\left[\begin{array}{c}T \\ T \\ i+1\end{array}\right]$ 
$+\left[\begin{array}{l}N_{i} \\ N_{i+1}\end{array}\right] u x^{a-1}-\rho c_{p} x^{a-1}\left[\begin{array}{ll}N_{i}^{2} & N_{i} N_{i+1} \\ N_{i} N_{i+1} & N_{i+1}^{2}\end{array}\right]\left[\begin{array}{l}\frac{d T}{d t} \\ \frac{d T_{i+1}}{d t}\end{array}\right] d x$

Based on the experience of others,,$^{3-7}$ the square matrix associated with the heat capacitance term is diagonally lumped, obtaining

$\left[\begin{array}{cc}N_{i}^{2} & N_{i} N_{i+1} \\ N_{i} N_{i+1} & N_{i+1}^{2}\end{array}\right]=\left[\begin{array}{cc}N_{i}\left(N_{i}+N_{i+1}\right) & 0 \\ 0 & N_{i+1}\left(N_{i}+N_{i+1}\right)\end{array}\right]$

Expression (3-65) can be written in a simpler form as

$$
\begin{gathered}
-\frac{k A}{\Delta x}\left[\begin{array}{cc}
1 & -1 \\
-1 & 1
\end{array}\right]\left[\begin{array}{c}
T_{i} \\
T_{i+1}
\end{array}\right]-\rho c_{p}\left[\begin{array}{ll}
v_{i} & 0 \\
0 & v_{i+1}
\end{array}\right]\left[\begin{array}{l}
\frac{d T_{i}}{d t} \\
\frac{d T_{i+1}}{d t}
\end{array}\right] \\
+u\left[\begin{array}{l}
v_{i} \\
v_{i+1}
\end{array}\right]+\left[\begin{array}{l}
q_{\text {in left }} \\
q_{\text {in right }}
\end{array}\right]
\end{gathered}
$$

where

$$
\begin{aligned}
A & =\frac{\int_{x_{i}}^{x_{i+1}} x^{a-1} d x}{\left(x_{i+1}-x_{i}\right)} \\
y_{1} & =\frac{\int_{x_{1}}^{x_{i+1}} x^{a-1}\left(x_{i+1}-x\right) d x}{\left(x_{i+1}-x_{1}\right)}
\end{aligned}
$$




$$
v_{i+1}=\frac{\int_{x_{i}}^{x_{i+1}} x^{a-1}\left(x-x_{i}\right) d x}{\left(x_{i+1}-x_{i}\right)} .
$$

These are the factors that account for geometry. The algebra to calculate the factors for slab and cylindrical geometries appears in Appendix A of Reference 3-14.

In matrix notation, Expression (3-68) becomes

$-[K]^{i}\{T\}-[C]^{i}\left\{\frac{d T}{d t}\right\}+\{q\}^{i}$,

where

$$
\begin{aligned}
& {[k]^{j}=\frac{k A}{\Delta x}\left[\begin{array}{cc}
1 & -1 \\
-1 & 1
\end{array}\right]} \\
& {[c]^{j}=\rho c_{p}\left[\begin{array}{cc}
v_{i} & 0 \\
0 & v_{i+1}
\end{array}\right]} \\
& {[q]^{i}=u\left[\begin{array}{ll}
v_{i}+q_{\text {in left }} \\
v_{i+1} & q_{\text {in right }}
\end{array}\right]}
\end{aligned}
$$

A backward time differencing is used in the SCDAP/RELAP5 FEM heat conduction model. This implies that

$$
\frac{d T}{d t}=\left\{\frac{T-T_{p}}{\Delta t}\right\}=\left\{\frac{T}{\Delta t}\right\}-\left\{\frac{p}{\Delta t}\right\}
$$

Expression (3-72) then becomes 
$[\mathrm{K}]^{i}[1]+\frac{1}{\Delta t}[C]^{i}[1]=\frac{1}{\Delta t}[C]^{i}\left[T_{p}\right\}+[q]^{i}$

or

$[E]^{\mathfrak{i}}[1]=\{F\}^{\mathfrak{1}}$

where

$$
\begin{aligned}
& {[E]^{i}=[K]^{i}+\frac{1}{\Delta t}[C]^{i}} \\
& \{F\}^{\mathfrak{i}}=\frac{1}{\Delta t}[C]^{\mathfrak{j}}\left[T_{p}\right\}^{\mathfrak{i}}+\{q\} .
\end{aligned}
$$

Equation (3-78) is actually two equations that are contributions from the $i$-th element. When the contributions from all the elements of the solution region are combined, a global matrix equation is formed:

$[E]\{1\}=\{F\}$.

This equation is then modified to account for the solution region boundary conditions. Examples of this accounting appears in Appendix $B$ of Reference 3-14 for three types of boundary conditions (fixed temperature, fixed heat flux, and heat transfer coefficient with bulk coolant temperature).

After Equation (3-81) is modified to account for the boundary conditions, the nodal temperatures are obtained using a Gaussian elimination technique.

\subsubsection{Two-Dimensional Conduction Solution/Reflood Model for SCDAP Core Components}

A two-dimensional conduction solution for intact SCDAP core components with cylindrical or rectangular geometries is also implemented in the 
SCDAP/RELAP5 code. In order to track the large axial temperature gradient within small axial distances for the core component reflood region, a user-specified option of fine mesh rezoning scheme is also included. The detailed formulation of the numerical scheme of the two-dimensional conduction solution/reflood model is described in Volume $I$ of this report.

\subsection{Cladding Deformation Mode 1s}

The cladding deformation models reported here are mechanistically based. Cladding experiences large elastic-plastic deformation during ballooning. Prandt 1 -Reuss equations ${ }^{3-15}$ based on true strains are employed to calculate plastic deformation. Plastic deformation of the cladding is assumed to be anisotropic and is analyzed using Hill's theory. 3-16

In the beginning of the analysis, the sausage-type deformation model is used for each fuel rod group. During the analysis, for a given fuel rod group, the sausage-type deformation model is replaced by the localized deformation model, and the calculations for the localized deformation begin if the following conditions are satisfied:

1. Maximum cladding true hoop stress is less than fallure stress, i.e., the cladding has not failed.

2. Maximum true hoop strain is $>5 \%$.

3. At a node having maximum true hoop strain, the axial gradient in cladding temperature is (a) $1 \mathrm{~K} / \mathrm{cm}$ if cladding temperature is $<1250 \mathrm{~K}$ or (b) $10 \mathrm{~K} / \mathrm{cm}$ if cladding temperature is $>1250 \mathrm{~K}$.

a. The sausage-type deformation model is the only model currently being used. The localized model was disabled since all of the experiments performed under boiloff conditions have shown sausage-type ballooning. If the code is applied to rapid blowdown transients, the localized model should be enabled. 
For a given fuel rod group, the above conditions are tested every component time step. If satisfied, the localized deformation model is used for the remaining portion of the analys is and the sausage-type deformation model is no longer used. If the above conditions are not satisfied, then the sausage-type deformation model is used for the next component time step.

The model for sausage-type cladding deformation is described first. Then, the model for localized cladding deformation is described. The assumptions used in developing these models are also discussed.

\subsubsection{Sausage-Type Deformation Mode 1}

The sausage-type deformation model is based on the following assumptions :

- Cladding deformation is axisymmetric.

- Cladding deforms like a membrane. There are no bending strains in the cradoing.

o Isotropic hardening is assumed in calculating the cladding yield stress.

- Once the outer diameter of the cladding is equal to the fuel rod pitch, no additional cladding deformation takes place.

- Cladding oxidation does not affect the cladding mechanical properties.

- Any constraint imposed by the spacer grids on cladding deformation is not taken into account.

- Once the inner diameter of the cladding is equal to the fue pellet diameter, no additional cladding deformation takes place. 
The sausage-type deformation model described here is similar to the model available in FRACAS-I ${ }^{3-17}$ except for the following two modifications:

1. Plasticity calculations are based on true strains. FRACAS-I uses engineering strains.

2. Anisotropic properties of cladding are taken into account in the calculation of effective stress and incremental plastic strains. FRACAS-I assumes that plastic deformation of cladding is isotropic.

In this model, the cladding strains are calculated at each component node of a fuel rod group. As cladding experiences elastic-plastic strains, an iterative scheme is required to assure the convergence of cladding strains. It may be necessary to use a small component time step (the time step used to analyze intact fuel rods) to assure the convergence. Theory used to calculate these strains is described next.

Sausage-type cladding deformation is a stress-driven process. First, the stresses in the cladding are calculated by satisfying the equilibrium conditions at each component node at the beginning of an iteration. The resulting expressions for the stresses are as follows:

$\sigma_{h}=\frac{p_{g} r_{j}-p_{c} r_{0}}{r_{0}-r_{i}}$

$\sigma_{a}=\frac{p_{g} r_{i}^{2}-p_{c} r_{0}^{2}}{r_{0}^{2}-r_{i}^{2}}$

$\sigma_{r}=-0.5\left(p_{c}+p_{g}\right)$ 
where

$\sigma_{h}=$ hoop stress $(\mathrm{Pa})$
$\sigma_{a}=$ axial stress $(\mathrm{Pa})$
$\sigma_{r}=$ radial stress $(\mathrm{Pa})$
$\boldsymbol{p}_{\mathbf{g}}=$ gas pressure $(\mathrm{Pa})$
$p_{c}=$ coolant pressure $(\mathrm{Pa})$
$r_{\mathbf{l}}=$ inside radius $(\mathrm{m})$
$r_{\mathbf{0}}=$ outside radius $(\mathrm{m})$.

Note that the inner and outer radii are current radii in Equations (3-82) through (3-84), so the calculated stresses are true stresses. The effective stress, ${ }^{3-18} \sigma_{e}$, is given by

$\sigma_{e}=\left[\operatorname{ACS} *\left(\sigma_{h}-\sigma_{a}\right)^{2}+\operatorname{AAS} *\left(\sigma_{a}-\sigma_{r}\right)^{2}+\operatorname{ARS} *\left(\sigma_{r}-\sigma_{h}\right)^{2}\right]^{0.5}$,

where ACS, AAS, and ARS are strength coefficients of anisotropicity for calculating effective stress. These coefficients are calculated with the aid of the MATPRO ${ }^{3-2}$ subroutine CANISO. At the beginning of a time step, the plastic increments during the time step are not known; so during the first iteration, they are assumed to be equal to zero in the calculations of the strength coefficients used in Equation (3-85).

If the effective stress, $\sigma_{e}$, is greater than the corresponding true effective yield stress (calculated using the MATPRO ${ }^{3-2}$ subroutine CSTRES), then the increments in the plastic strains are calculated using the Prandt1-Reuss equations and Hill's theory for anisotropic plastic deformation. 
The effective true strain in the cladding is calculated using the MATPRO ${ }^{3-2}$ subroutine CSTRNI that takes into account the effect of strain rate and cladding temperature. Since plastic deformation is an irreversible process, $d_{e p}$, the increment in the true effective strain, is zero or positive. The increments in the plastic strain components are calculated as follows:

$$
\begin{aligned}
d \varepsilon_{h, p}= & d_{e p}\left[A_{1}\left(\sigma_{h}-\sigma_{a}\right)\right. \\
& \left.+A_{2}\left(\sigma_{h}-\sigma_{r}\right)\right] \sigma / \sigma_{e} \\
d \varepsilon_{a, p}= & d_{e p}\left[A_{3}\left(\sigma_{a}-\sigma_{r}\right)\right. \\
& \left.+A_{1}\left(\sigma_{a}-\sigma_{h}\right)\right] / \sigma_{e}
\end{aligned}
$$

and

$$
\begin{aligned}
d \varepsilon_{r, p}= & d_{e p}\left[A_{2}\left(\sigma_{r}-\sigma_{b}\right)\right. \\
& \left.+A_{3}\left(\sigma_{r}-\sigma_{a}\right)\right] / \sigma_{e}
\end{aligned}
$$

where

$$
\begin{aligned}
& d \varepsilon_{h, p}=\text { increment in plastic hoop strain }(P a) \\
& d \varepsilon_{a, p}=\text { increment in plastic axial strain }(P a) \\
& d \varepsilon_{r, p}=\text { increment in plastic radial strain (Pa) }
\end{aligned}
$$

and $A_{1}, A_{2}$, and $A_{3}$ are coefficients of anisotropicity for calculating plastic strain increments.

The total true hoop strain is 


$$
\varepsilon_{h}=\varepsilon_{h, e}+\varepsilon_{h, t}+\varepsilon_{h, P}+d \varepsilon_{h, p}
$$

where

$$
\begin{aligned}
& \varepsilon_{h}=\text { total hoop strain at the end of the time step } \\
& \varepsilon_{h, e}=\begin{array}{l}
\text { hoop strain due to elastic deformation } \\
{\left[\sigma_{h}-v\left(\sigma_{a}+\sigma_{r}\right)\right] / E}
\end{array} \\
& \varepsilon_{h, t}=\begin{array}{l}
\text { hoop strain due to thermat deformation } \\
(\alpha \Delta T)_{h}
\end{array} \\
& \varepsilon_{h, P}=\begin{array}{l}
\text { hoop strain due to plastic deformation at the beginning } \\
\text { of the time step. }
\end{array}
\end{aligned}
$$

Equation (3-89) may be written as

$\varepsilon_{h}=\left[\sigma_{h}-v\left(\sigma_{a}+\sigma_{r}\right)\right] / E+(\alpha \Lambda T)_{h}+\varepsilon_{h, p}+d \varepsilon_{h, p}$.

Similariy,

$$
\varepsilon_{a}=\left(\sigma_{a}-v\left(\sigma_{r}+\sigma_{h}\right)\right) / E+(\alpha \Delta T)_{a}+\varepsilon_{a, p}+d \varepsilon_{a}, p
$$

and

$$
\varepsilon_{r}=\left(\sigma_{r}-v\left(\sigma_{a}+\sigma_{h}\right)\right) / E+(\alpha \Delta 1)_{r}+\varepsilon_{r, P}+d \varepsilon_{r, p} .
$$

The true hoop strain $\varepsilon_{h}$ is used to calculate cladding radil at the end of the iteration as follows:

$$
R_{m 1}=R_{m} e^{\epsilon_{n}} \text {. }
$$


where

$R_{m} \quad=$ original cladding mean radius $(m)$
$R_{m l} \quad=$ cladding mean radius at the end of the iteration $(m)$.

The cladding wall thickness is calculated assuming that the cladding cross-sectional area remains constant:

$T_{\text {wa11 }}=\frac{A_{c}}{2 \pi\left(R_{m 1}\right)}$

where

$$
\begin{aligned}
& T_{\text {wall }}=\text { cladding wall thickness at the end of the iteration }(m) \\
& A_{c}=\text { cladding cross section area }\left(m^{2}\right) .
\end{aligned}
$$

So, the cladding radil at the end of the iteration are

$$
\begin{aligned}
& r_{0}=R_{m 1}+\frac{T_{\text {wa11 }}}{2} \\
& r_{1}=R_{m 1}+\frac{T_{\text {wa11 }}}{2}
\end{aligned}
$$

The cladding radi $i$ in Equations (3-95) and (3-96) are used to calculate the void volume at the end of the iteration.

During the next iteration, the void volumes are used to update the fuel rod gas pressure model (see Section 3.7). The cladding radii from the last iteration [Equations (3-95) and (3-96)] are used to calculate stresses using Equations (3-82) through (3-84). The plastic strain increments from the last iteration using Equations $(3-85)$ through $(3-88)$ are used to 
calculate anisotropic strength coefficients (calculated using MATPRO routine (ANISO) which are used to calculate the effective stress in Equation (3-85). Then Equations (3-86) through (3-96) are solved. The iteration process continues until the calculated hoop stresses converge for each component node. The converged hoop stresses at each component node are compared with the corresponding failure stresses calculated using the MATPRO routine CMLIMT to determine whether or not the cladding has ruptured. Then the analysis will proceed to the next component time step. once a fuel rod cladding has ruptured, the cladding deformation calculations for the corresponding fuel rod bundle are no longer performed during the remaining portion of the analysis.

The flow area reduction for each representative fuel rod component is then computed by subtracting the change in the cross-sectional area of the fuel rod from the original flow area. No allowance is made for flow internal to the cladding that could result from cladding failure. The total change in flow area for each thermal-hydraulic volume is then computed from the sum of the changes in flow area for all of the fuel rods. Deformation of other core components, such as control rods or structures, are neglected. The fuel rod cladding local mid-radius strains, $\varepsilon_{h}$, are currentily 1 imited to $20 \%$ to allow for incoherencies in sausage-type ballooning.

\subsubsection{Localized Deformation Model}

The localized deformation model consists of two models that were developed earlier for the FRAP-T6 computer code. ${ }^{3-19}$ These models are:

1. Zircaloy cladding shape at failure--BALON2 mode $1^{3-18}$

2. Probabilistic flow area reduction model--FAR model. $3-20$

The BALON2 model calculates the localized cladding deformation for a single fuel rod at a selected axial location. The FARl model uses the uncertainty in the axial location of the maximum cladding temperature and 
calculates the probabilistic distribution of the cladding deformation along the axial direction for a bundle of fuel rods. The mean value of the cladding deformation is used to calculate the mean value of the flow area reduction at each component node of the bundle of fuel rods. The cladding localized deformation model for SCDAP/RELAP5 is based on the following as sumptions :

- Localized deformation is assumed to initiate at an axial location where the effective true strain in the cladding is a maximum and exceeds the corresponding instability true strain. This axial location is referred to as the ballooning location.

- The peak cladding temperature takes place close to the ballooning location so that the uncertainty in the ballooning location is the same as the uncertainty in the location of the peak cladding temperature.

o The effective plastic strain in the cladding along the fuel rod is not uniform.

- The inputs to the BALON2 model are assumed to represent an average rod in a given fuel rod bundle.

- The localized deformation of an individual rod does not affect the deformation of any other rod.

- The BALON2 model specifies the small variation in the temperature along the axial and circumferential directions near the ballooning location. The circumferential variation is nonaxisymmetric but has a diameter of symmetry. The axial variation is approximateiy symmetric with respect to the ballooning location. So, the resulting cladding deformation is nonaxisymmetric but has two planes of symmetry. 
- Isotropic hardening is assumed in calculating the cladding yield stress.

- The FARI model assumes that the maximum flow area reduction due to coplanar localized deformation is $90 \%$.

- Each group of fuel rods consists of only fuel rods and no control rod.

- Constraint imposed by the spacer grid on cladding deformation is not taken into account.

\subsection{Fuel Rod Internal Gas Pressure Model}

The fuel rod internal gas pressure is computed from the perfect gas law. This includes different volumes of gas at different temperatures as given by

$$
P=\frac{N_{m} R}{\sum \frac{V_{1}}{T_{1}}}
$$

where

$$
\begin{aligned}
P & =\text { internal gas pressure }\left(\mathrm{N} / \mathrm{m}^{2}\right) \\
N_{m} & =\text { moles of gas in fuel rod void volumes }(g \cdot m o l e) \\
R & =\text { universal gas constant }(\mathrm{N} \cdot \mathrm{m} / \mathrm{g} \cdot \mathrm{mole} \cdot \mathrm{K}) \\
V_{1} & =1 \text {-th volume }\left(\mathrm{m}^{3}\right) \\
T_{i} & =\text { temperature of gas in } i-t h \text { volume }(K) .
\end{aligned}
$$

The different volumes considered are: 
o Plenum volume.

- Fuel void volumes at each axial elevation that are the sum of crack, dish, gap lexcept contributions due to cladding ballooning), porosity, and roughness volumes.

- Additional gap volumes due to cladding ballooning at each axial e Tevation.

Thus, the gas pressure model becomes

$$
P=\frac{v_{m} R}{\bar{T}_{p}+\sum_{i=1}^{M} \frac{v_{v_{01 d, 1}}+v_{\text {gap }, 1}}{T_{f, i}}}
$$

where

$$
\begin{aligned}
& v_{p} \quad=\quad \text { plenum volume }\left(m^{3}\right) \\
& T_{p} \quad=\text { gas temperature in plenum }(K) \text { which is assumed to be } \\
& \text { coolant temperature at the top of the rod }+6 \mathrm{~K} \\
& M \quad=\text { number of axial nodes } \\
& v_{\text {void, } i}=\text { fuel void volume in } \mathfrak{j} \text {-th axial node }\left(\mathrm{m}^{3}\right) \\
& v_{\text {gap, } i}=\text { additional gap volume due to cladding ballooning in } \\
& i-t h \text { axial node }\left(m^{3}\right) \\
& T_{f, i}=\text { average fuel temperature in } i \text {-th axial node }(K) \text {. }
\end{aligned}
$$

\subsubsection{Correlations for Void Volumes for Standard PWR and BWR Fuel Rods}

Correlations were developed to account for the effects of fuel burnup and temperature on fuel void volumes for commercial PWR and BWR fuel rods. 
Twe Tve FRAPCON-2 $3-21$ cases were used, six for a standard PWR fuel rod and six for a standard BWR fuel rod. The detailed fuel rod data used are given in Kleijnen, ${ }^{3-22}$ while the basic data are listed in Tables 3-4 and 3-5. For a set of constant burnup states between 0.1 and about $30 \mathrm{MWd} / \mathrm{kgU}$, the average rod temperature was specified stepwise from 500 to $1100 \mathrm{~K}$ for the PWR rod, and from 500 to $1200 \mathrm{~K}$ for the BWR rod, with essentially zero power. Because of a constant temperature profile both in the radial and axial directions, the local temperatures were equal to the average rod temperatures for the FRAPCON-2 calculations. The peak temperatures of 1100 and $1200 \mathrm{~K}$ for PWR and BWR, respectively, have been defined as upper bounds of the temperature ranges taken into consideration because the FRAPCON-2 calculations showed cladding ballooning and rupture for temperatures greater than these peak temperatures. The coolant pressure was held constant at $15.51 \times 10^{6} \mathrm{~N} / \mathrm{m}^{2}$ and $7.14 \times 10^{6} \mathrm{~N} / \mathrm{m}^{2}$ for the PWR and BWR fue 1 rod calculations, respectively.

The relative plenum volumes,

$R_{p}=v_{p}^{\text {hot }} v_{p}^{\text {cold }}$

and the relative fuel void volumes,

$R_{\text {void }}=v_{\text {void }}^{\text {hot }} v_{\text {void }}^{\text {cold }}$

depend on fuel rod temperature and burnup and are shown in Figures 3-5 through 3-8, respectively, for the PWR and BWR fuel rod.

The FRAPCON-2 calculations show a jump in the temperature-dependence of both the relative plenum volumes and the relative fuel void volumes from the temperature range of 500 to $700 \mathrm{~K}$ to the temperature ranges of 800 to $1100 \mathrm{~K}$ and 800 to $1200 \mathrm{~K}$ for the PWR and BWR, respectively. This is an effect of the zircaloy material behavior, resulting in a strong increase of strain rate sensitivity and thus a significant increase of cladding hoop strain at temperatures above about $750 \mathrm{~K}$. The resulting decrease in 
TABLE 3.-4. PWR FUEL ROD DATA INPUT FOR FRAPCON -2 CALCULATIONS

Cladding inside diameter

$9.50 \times 10^{-3} \mathrm{~m}$

cladding thickness

$0.61 \times 10^{-3} \mathrm{~m}$

Diametric gap thickness

$0.191 \times 10^{-3} \mathrm{~m}$

Fuel pellet diameter

$9.31 \times 10^{-3} \mathrm{~m}$

Fuel pellet length

$15.20 \times 10^{-3} \mathrm{~m}$

Fuel pellet true density

$94 \%$

Fuel stack height

$3.66 \mathrm{~m}$

Fuel dish volume fraction

0.0147

Plenum Tength

$0.173 \mathrm{~m}$

Plenum volume

$1.04 \times 10^{-5} \mathrm{~m}^{3}$

Rod total void volume

$2.52 \times 10^{-5} \mathrm{~m}^{3}$

TABLE 3-5. BWR FUEL ROD DATA INPUT FOR FRAPCON-2 CALCULATIONS

Cladding inside diameter

$12.70 \times 10^{-3} \mathrm{~m}$

Cladding thickness

$0.864 \times 10^{-3} \mathrm{~m}$

Diametric gap thickness

$0.305 \times 10^{-3} \mathrm{~m}$

Fuel pellet diameter

$12.40 \times 10^{-3} \mathrm{~m}$

Fuel pellet length

$9.27 \times 10^{-3} \mathrm{~m}$

Fuel pellet true density

$94 \%$

Fuel stack height

$3.66 \mathrm{~m}$

Fuel dish volume fraction

0 .

Plenum length

$0.406 \mathrm{~m}$

Plenum volume

$4.52 \times 10^{-5} \mathrm{~m}^{3}$

Rod total void volume

$6.85 \times 10^{-5} \mathrm{~m}^{3}$ 


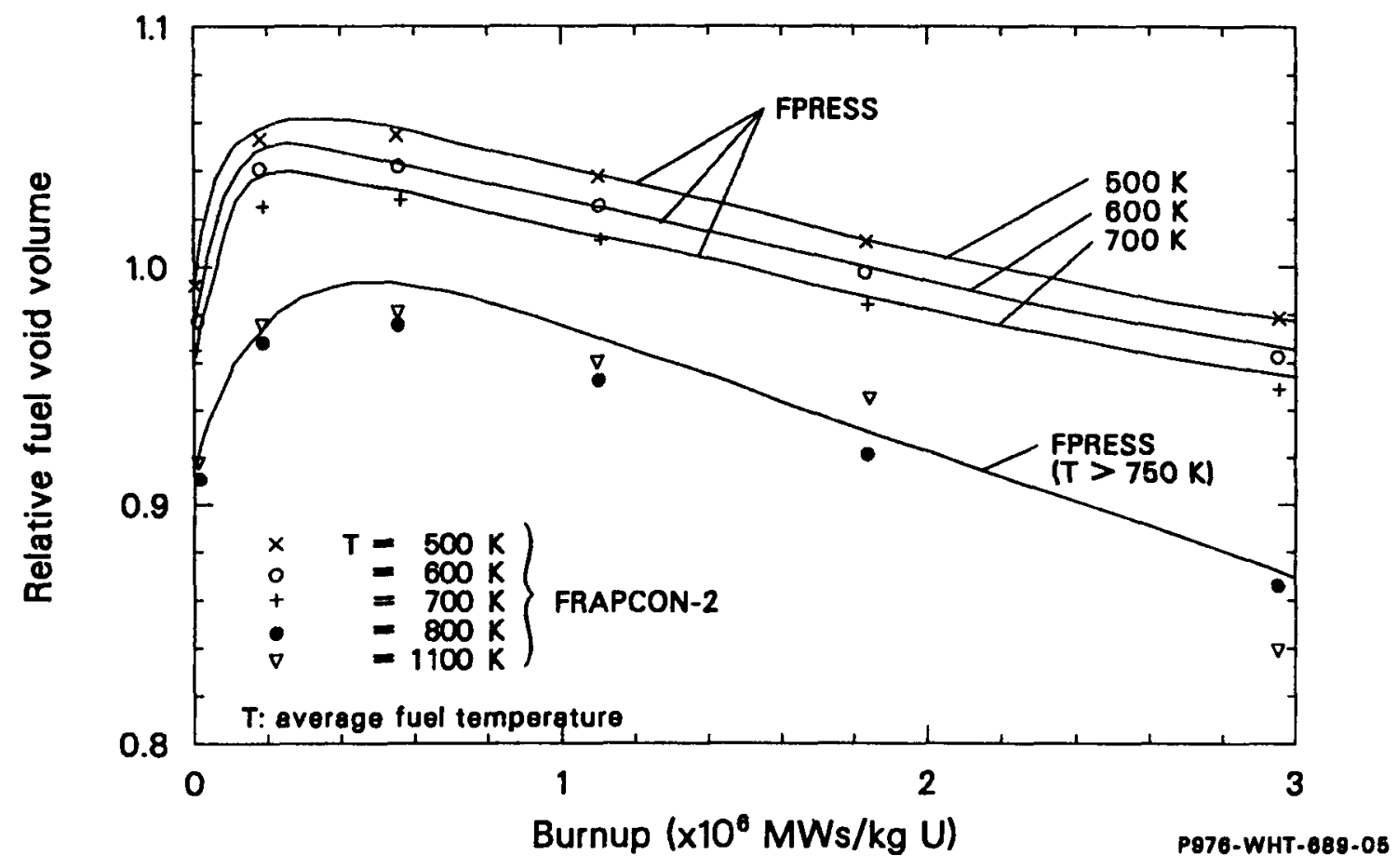

Figure 3-5. Relative plenum volume, $R_{p}$ resulting from FRAPCON-2 calculations for a standard PWR fuel rod design. 


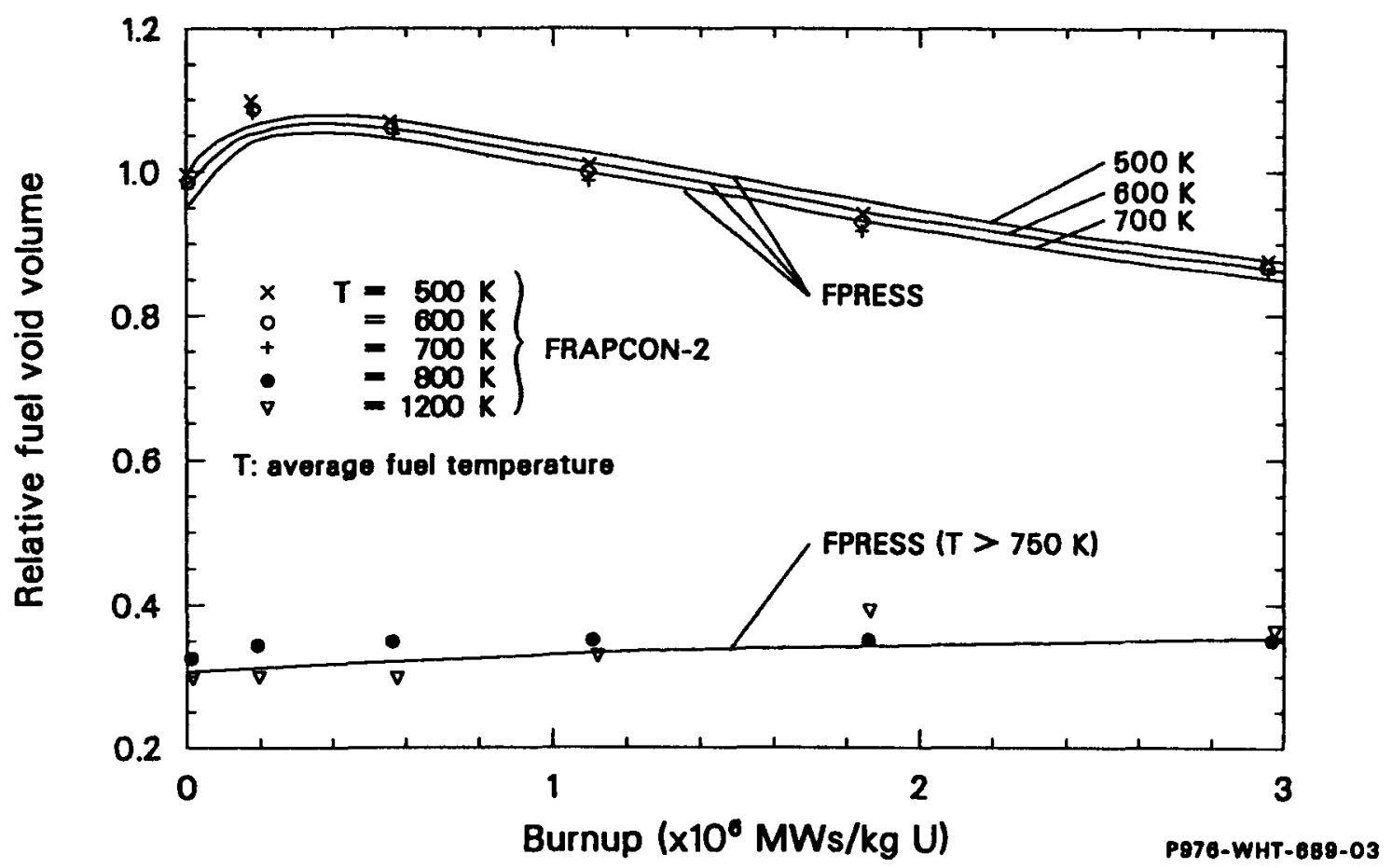

Figure 3-6. Relative fuel void volume, Ryoid resulting from FRAPCON-2 calculations for a standard PWR fuel rod design. 


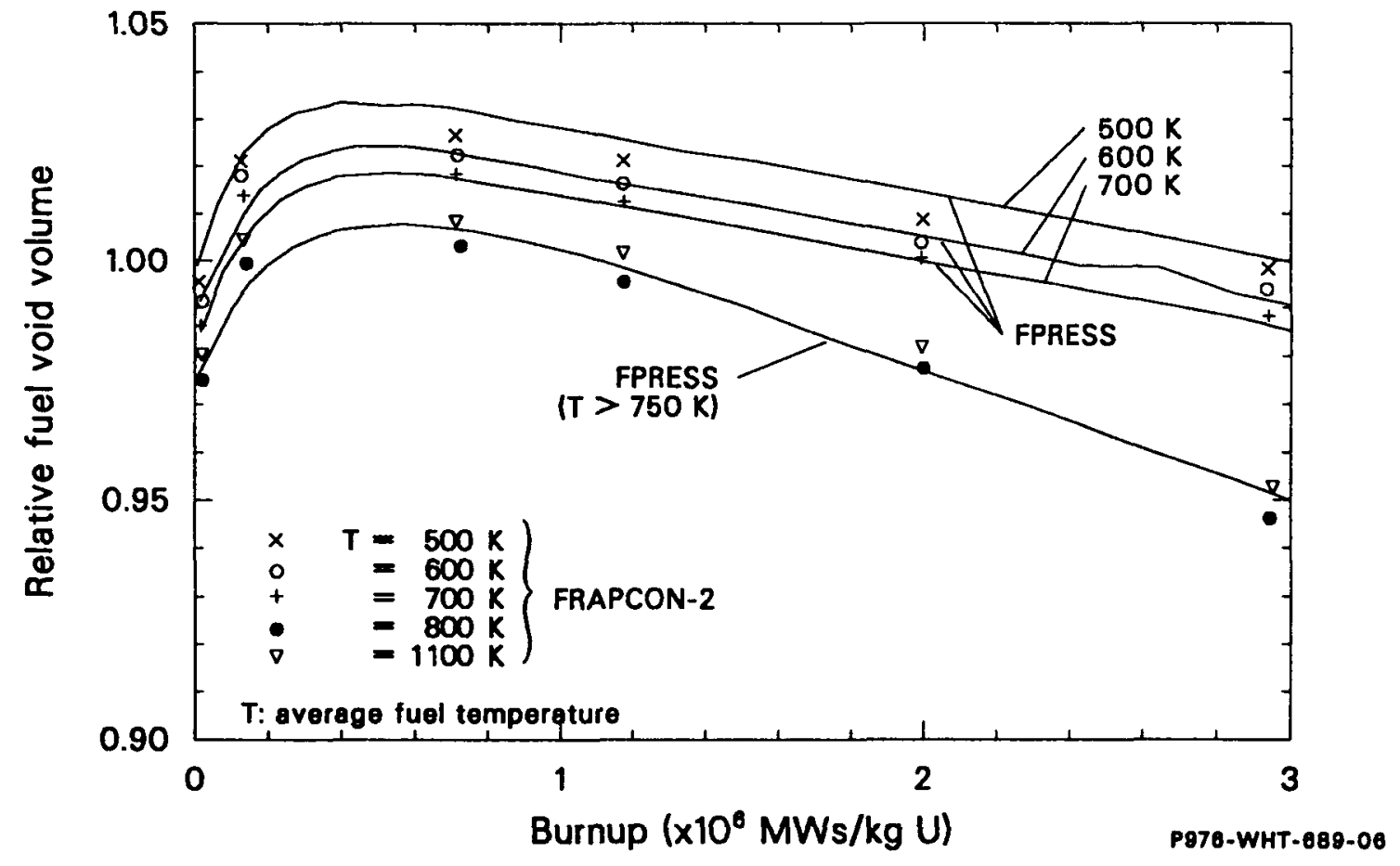

Figure 3-7. Relative plenum volume, $R_{p}$ resulting from FRAPCON-2 calculations for a standard BWR fuel rod design. 


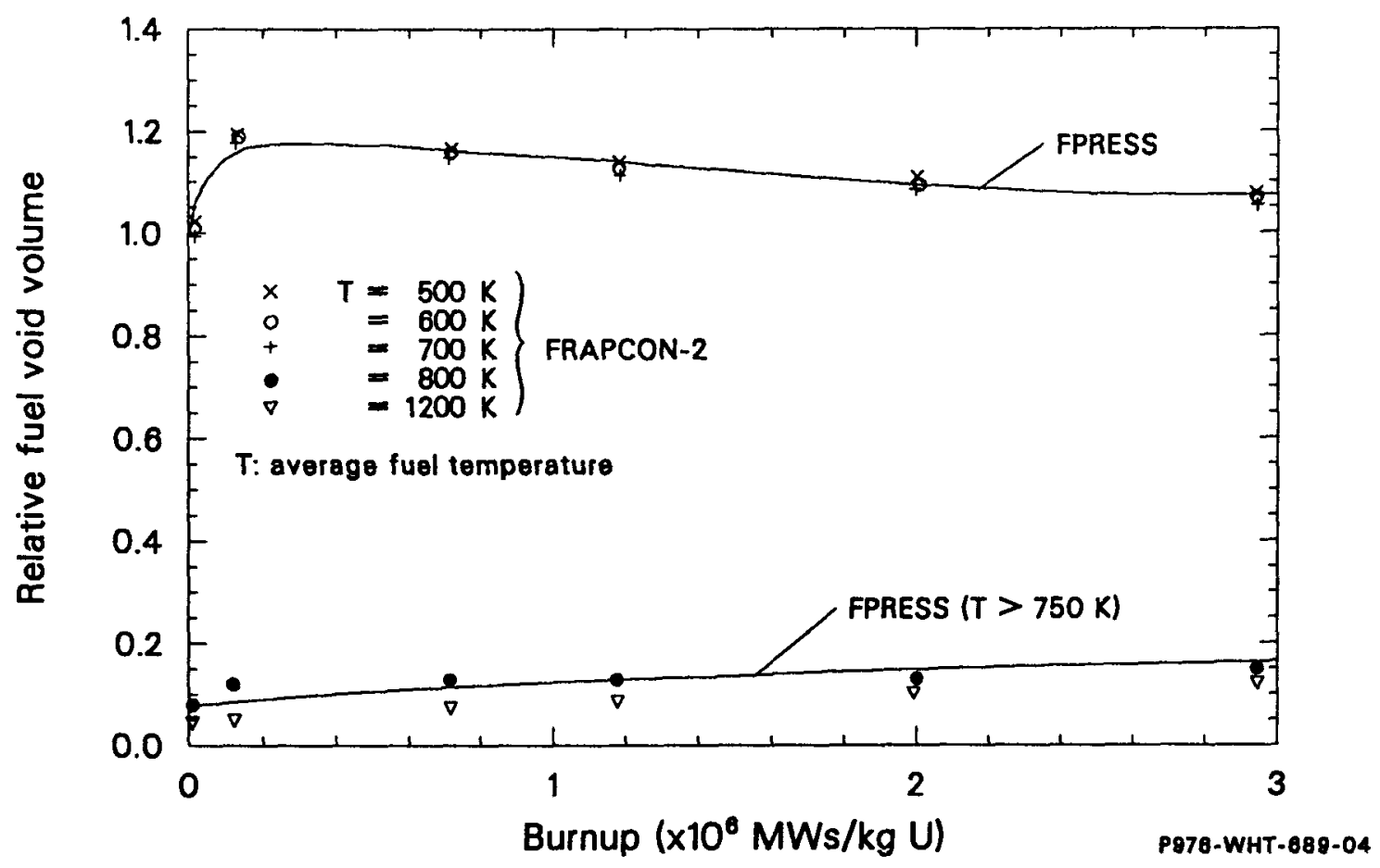

Figure 3-8. Relative fuel void volume, Rvoid resulting from FRAPCON-2 calculations for a standard BWR fuel rod design. 
cladding diameter for coolant pressures higher than the internal gas pressure causes a decrease in both the plenum volume and the fuel void volume.

The behavior of relative void volumes, as shown in figures $3-5$ through 3-8, can be approximated by a function of the form

$R=f(T) e^{\alpha B u}\left(1-\beta e^{\gamma B u}\right)$,

where

$R \quad=\quad$ relative void volume, related to the corresponding as-fabricated volume

$f(T) \quad=\quad a+b T$

T $=$ fuel rod temperature $(K)$

$a, b, \alpha, \beta, Y=$ coefficients, the values of which depend on the kind of kind of fuel rod (i.e... PWR or BWR rod) and on the temperature range (i.e., $500 \leq \mathrm{T} \leq 750 \mathrm{~K}$ or $750<T \leq 1100 \mathrm{~K}$ or $750<T \leq 1200 \mathrm{~K}$ )

Bu $\quad$ burnup (MWd/kgU).

The coefficients of Equation (3-101) are listed in Table 3-6 for the different reactor systems and temperature ranges. Tables 3-7 through 3-10 show comparisons between the FRAPCON-2 results and the results predicted using Equation (3-103). The differences in calculated relative plenum volumes and relative fuel void volumes for both the standard PWR and the standard BWR fuel rod, expressed by the relative error $\varepsilon$, are small.

The FRAPCON-2 results of relative plenum volumes, as shown in Figures 3-5 and 3-7, are interpreted as two overlapping effects that influence the hot plenum volume of both the standard PWR and the standard 
TABLE 3-6. COEFFICIENTS $(a, b, \alpha, \beta, \gamma)$ OF THE GENERAL EMPIRICAL

CORRELATION FOR CALCULATION OF RELATIVE VOID VOLUMES

Standard PWR

$\frac{R=(a+b T) e^{\alpha B u}\left[1-\beta e^{\gamma B u}\right]}{a}-\frac{\beta}{\alpha}-\frac{\gamma}{\alpha}-\frac{\gamma}{-}-\frac{1}{b}$

fuel rod

Plenum volume

$500 \leq \mathrm{T}$

$\leq 75 \overline{0} \mathrm{~K}$

$1.146-1.37 \times 10^{-4}-2.90 \times 10^{-3} \quad 0.0952 \quad-1.148$

$750 \leq T$

$\leq 1100 \mathrm{~K}$

$1.040 \quad 0.0$

$-5.19 \times 10^{-3}$

0.1126

$-0.3712$

Fuel void

volume

$500 \leq \mathrm{T}$
$\leq 750 \mathrm{~K}$

$1.175-1.11 \times 10^{-4}-7.498 \times 10^{-3} \quad 0.1247 \quad-0.6442$

$750 \leq \mathrm{T}$

$\leq 1100 \mathrm{~K}$

$0.360 \quad 0.0$

0.0

$0.1441-4.473 \times 10^{-2}$

Standard BWR

fue 1 rod

Plenum volume

$500 \leq 1 \quad 1.063 \quad-0.52 \times 10^{-4}-1.122 \times 10^{-3} 0.0425 \quad-0.5838$

$\leq 750 \mathrm{~K}$

$750 \leq T$

$\leq 1200 \mathrm{~K}$

$1.031 \quad 0.0$

$-2.344 \times 10^{-3}$

$0.0534-0.3070$

Fuel void

volume

\begin{tabular}{|c|c|c|c|c|c|}
\hline $\begin{array}{l}500 \leq 7 \\
\leq 750 \mathrm{~K}\end{array}$ & 1.198 & 0.0 & $-3.588 \times 10^{-3}$ & 0.167 & -1.288 \\
\hline $\begin{array}{l}750 \leq \mathrm{T} \\
\leq 7200 \mathrm{~K}\end{array}$ & 0.160 & 0.0 & 0.0 & 0.5343 & $-7.226 \times 10^{-2}$ \\
\hline
\end{tabular}


TABLE 3-7. RELATIVE FUEL VOID VOLUME, $R_{p}$, OF A STANDARD PWR FUEL ROD, COMPARISON BETWEEN FRAPCON-2 AND FPRESS CALCULATIONS

\begin{tabular}{|c|c|c|c|c|c|c|c|c|}
\hline & \multirow{2}{*}{$\begin{array}{l}\text { Burnup } \\
\text { (MWs/kgU) }\end{array}$} & \multicolumn{7}{|c|}{$\begin{array}{c}\text { Temper a ture } \\
(\mathrm{K})\end{array}$} \\
\hline & & 500 & 600 & 700 & 800 & 900 & 1000 & 1100 \\
\hline FRAPCON-2 & $\begin{array}{l}1.123 \times 10^{4} \\
1.901 \times 10^{5} \\
5.616 \times 10^{5} \\
1.106 \times 10^{6} \\
1.840 \times 10^{6} \\
2.938 \times 10^{6}\end{array}$ & $\begin{array}{l}0.992 \\
1.054 \\
1.055 \\
1.038 \\
1.011 \\
0.978\end{array}$ & $\begin{array}{l}0.987 \\
1.041 \\
1.042 \\
1.025 \\
0.997 \\
0.961\end{array}$ & $\begin{array}{l}0.965 \\
1.026 \\
1.029 \\
1.011 \\
0.984 \\
0.947\end{array}$ & $\begin{array}{l}0.911 \\
0.970 \\
0.975 \\
0.953 \\
0.920 \\
0.865\end{array}$ & $\begin{array}{l}0.913 \\
0.972 \\
0.977 \\
0.955 \\
0.921 \\
0.840\end{array}$ & $\begin{array}{l}0.915 \\
0.975 \\
0.978 \\
0.958 \\
0.950 \\
0.837\end{array}$ & $\begin{array}{l}0.977 \\
0.975 \\
0.980 \\
0.959 \\
0.944 \\
0.837\end{array}$ \\
\hline FPRESS & $\begin{array}{l}1.123 \times 10^{4} \\
1.901 \times 10^{5} \\
5.616 \times 10^{5} \\
1.106 \times 10^{6} \\
1.840 \times 10^{6} \\
2.938 \times 10^{6}\end{array}$ & $\begin{array}{l}0.989 \\
1.063 \\
1.058 \\
1.038 \\
0.013 \\
0.977\end{array}$ & $\begin{array}{l}0.976 \\
1.049 \\
1.044 \\
1.025 \\
1.000 \\
0.964\end{array}$ & $\begin{array}{l}0.964 \\
1.036 \\
1.031 \\
1.012 \\
0.988 \\
0.952\end{array}$ & $\begin{array}{l}0.926 \\
0.975 \\
0.993 \\
0.970 \\
0.930 \\
0.870\end{array}$ & $\begin{array}{l}0.926 \\
0.975 \\
0.933 \\
0.970 \\
0.930 \\
0.870\end{array}$ & $\begin{array}{l}0.926 \\
0.975 \\
0.993 \\
0.970 \\
0.930 \\
0.870\end{array}$ & $\begin{array}{l}0.926 \\
0.975 \\
0.993 \\
0.970 \\
0.930 \\
0.870\end{array}$ \\
\hline $\begin{array}{l}\text { Relative } \\
\text { Error } \\
\text { E }\end{array}$ & $\begin{array}{l}1.123 \times 10^{4} \\
1.901 \times 10^{5} \\
5.616 \times 10^{5} \\
1.106 \times 10^{6} \\
1.840 \times 10^{6} \\
2.938 \times 10^{6}\end{array}$ & $\begin{array}{l}<0.01 \\
<0.01 \\
<0.01 \\
-- \\
<0.01 \\
<0.01\end{array}$ & $\begin{array}{l}<0.01 \\
<0.01 \\
<0.01 \\
-- \\
<0.01 \\
<0.01\end{array}$ & $\begin{array}{l}<0.01 \\
<0.01 \\
<0.01 \\
<0.01 \\
<0.01 \\
<0.01\end{array}$ & $\begin{array}{r}0.02 \\
<0.01 \\
0.02 \\
0.02 \\
0.01 \\
<0.01\end{array}$ & $\begin{array}{r}0.01 \\
<0.01 \\
0.02 \\
0.01 \\
<0.01 \\
0.03\end{array}$ & $\begin{array}{l}<0.01 \\
-- \\
0.02 \\
0.01 \\
0.02 \\
0.03\end{array}$ & $\begin{array}{l}<0.02 \\
-- \\
0.01 \\
0.01 \\
0.01 \\
0.03\end{array}$ \\
\hline
\end{tabular}


TABLE 3-8. RELATIVE FUEL VOID VOLUME, Rvoid, OF A STANDARD PWR FUEL ROD, COMPARISON BETWEEN FRAPCON-2 AND FPRESS CALCULATIONS

\begin{tabular}{|c|c|c|c|c|c|c|c|c|}
\hline & \multirow{2}{*}{$\begin{array}{c}\text { Burnup } \\
\text { (MWs/kgU) }\end{array}$} & \multicolumn{7}{|c|}{$\begin{array}{c}\text { Temper a ture } \\
(K)\end{array}$} \\
\hline & & 500 & 600 & 700 & 800 & 900 & 1000 & 1100 \\
\hline FRAPCON-2 & $\begin{array}{l}1.123 \times 10^{4} \\
1.901 \times 10^{5} \\
5.616 \times 10^{5} \\
1.106 \times 10^{6} \\
1.840 \times 10^{6} \\
2.938 \times 10^{6}\end{array}$ & $\begin{array}{l}0.998 \\
1.099 \\
1.071 \\
1.007 \\
0.941 \\
0.876\end{array}$ & $\begin{array}{l}0.987 \\
1.090 \\
1.064 \\
0.997 \\
0.993 \\
0.870\end{array}$ & $\begin{array}{l}0.980 \\
1.083 \\
1.054 \\
0.989 \\
0.923 \\
0.859\end{array}$ & $\begin{array}{l}0.323 \\
0.341 \\
0.345 \\
0.345 \\
0.346 \\
0.349\end{array}$ & $\begin{array}{l}0.323 \\
0.343 \\
0.346 \\
0.345 \\
0.364 \\
0.353\end{array}$ & $\begin{array}{l}0.307 \\
0.302 \\
0.301 \\
0.336 \\
0.341 \\
0.352\end{array}$ & $\begin{array}{l}0.295 \\
0.291 \\
0.289 \\
0.324 \\
0.385 \\
0.352\end{array}$ \\
\hline FPRESS & $\begin{array}{l}1.123 \times 10^{4} \\
1.901 \times 10^{5} \\
5.616 \times 10^{5} \\
1.106 \times 10^{6} \\
1.840 \times 10^{6} \\
2.938 \times 10^{6}\end{array}$ & $\begin{array}{l}0.990 \\
1.068 \\
1.064 \\
1.017 \\
0.954 \\
0.868\end{array}$ & $\begin{array}{l}0.180 \\
1.0 .57 \\
1.054 \\
1.007 \\
0.954 \\
0.859\end{array}$ & $\begin{array}{l}0.971 \\
1.047 \\
1.043 \\
0.997 \\
0.935 \\
0.850\end{array}$ & $\begin{array}{l}0.308 \\
0.373 \\
0.321 \\
0.331 \\
0.335 \\
0.350\end{array}$ & $\begin{array}{l}0.308 \\
0.313 \\
0.321 \\
0.331 \\
0.335 \\
0.350\end{array}$ & $\begin{array}{l}0.308 \\
0.313 \\
0.321 \\
0.331 \\
0.335 \\
0.350\end{array}$ & $\begin{array}{l}0.308 \\
0.313 \\
0.321 \\
0.331 \\
0.335 \\
0.350\end{array}$ \\
\hline $\begin{array}{l}\text { Relative } \\
\text { Error } \\
\varepsilon\end{array}$ & $\begin{array}{l}1.123 \times 10^{4} \\
1.901 \times 10^{5} \\
5.616 \times 10^{5} \\
1.106 \times 10^{6} \\
1.840 \times 10^{6} \\
2.938 \times 10^{6}\end{array}$ & $\begin{array}{r}<0.01 \\
<0.03 \\
<0.01 \\
<0.01 \\
0.01 \\
<0.01\end{array}$ & $\begin{array}{r}<0.01 \\
<0.03 \\
<0.01 \\
0.01 \\
0.01 \\
0.01\end{array}$ & $\begin{array}{r}<0.01 \\
<0.03 \\
<0.01 \\
<0.01 \\
0.01 \\
0.01\end{array}$ & $\begin{array}{r}0.05 \\
<0.08 \\
0.07 \\
0.04 \\
0.03 \\
<0.01\end{array}$ & $\begin{array}{r}0.05 \\
<0.09 \\
0.07 \\
0.04 \\
<0.03 \\
<0.01\end{array}$ & $\begin{array}{r}<0.01 \\
0.04 \\
0.07 \\
0.01 \\
0.02 \\
<0.01\end{array}$ & $\begin{array}{c}<0.04 \\
0.08 \\
0.11 \\
0.02 \\
-- \\
<0.01\end{array}$ \\
\hline
\end{tabular}


TABLE 3-9. RELATIVE PLENUM VOLUME, Rp. OF A STANDARD BWR FUEL ROD, COMPARISON BETWEEN FRAPCON-2 AND FPRESS CALCULATIONS

$\dot{\omega}$

\begin{tabular}{|c|c|c|c|c|c|c|c|c|c|}
\hline & \multirow{2}{*}{$\begin{array}{c}\text { Burnup } \\
(M W s / k g U)\end{array}$} & \multicolumn{8}{|c|}{$\begin{array}{c}\text { Temperature } \\
(K)\end{array}$} \\
\hline & & 500 & 600 & 700 & 800 & 900 & 1000 & 1100 & 1200 \\
\hline FRAPCON-2 & $\begin{array}{l}0.691 \times 10^{4} \\
1.244 \times 10^{5} \\
7.085 \times 10^{5} \\
1.175 \times 10^{6} \\
1.996 \times 10^{6} \\
2.929 \times 10^{6}\end{array}$ & $\begin{array}{l}0.995 \\
1.021 \\
1.027 \\
1.021 \\
1.008 \\
0.998\end{array}$ & $\begin{array}{l}0.991 \\
1.018 \\
1.022 \\
1.016 \\
1.003 \\
0.993\end{array}$ & $\begin{array}{l}0.986 \\
1.013 \\
1.018 \\
1.012 \\
1.000 \\
0.988\end{array}$ & $\begin{array}{l}0.975 \\
0.999 \\
1.003 \\
0.995 \\
0.977 \\
0.946\end{array}$ & $\begin{array}{l}0.977 \\
1.000 \\
1.004 \\
0.996 \\
0.978 \\
0.948\end{array}$ & $\begin{array}{l}0.978 \\
1.001 \\
1.005 \\
0.997 \\
0.980 \\
0.950\end{array}$ & $\begin{array}{l}0.979 \\
1.003 \\
1.006 \\
0.999 \\
0.980 \\
0.950\end{array}$ & $\begin{array}{l}0.980 \\
1.005 \\
1.008 \\
1.001 \\
0.981 \\
0.952\end{array}$ \\
\hline FPRESS & $\begin{array}{l}0.691 \times 10^{4} \\
1.244 \times 10^{5} \\
7.085 \times 10^{5} \\
1.175 \times 10^{6} \\
1.996 \times 10^{6} \\
2.929 \times 10^{6}\end{array}$ & $\begin{array}{l}0.995 \\
1.016 \\
1.027 \\
1.021 \\
1.010 \\
0.998\end{array}$ & $\begin{array}{l}0.990 \\
1.011 \\
1.022 \\
1.016 \\
1.005 \\
0.993\end{array}$ & $\begin{array}{l}0.985 \\
1.006 \\
1.017 \\
1.012 \\
1.000 \\
0.988\end{array}$ & $\begin{array}{l}0.977 \\
0.993 \\
1.007 \\
0.998 \\
0.977 \\
0.953\end{array}$ & $\begin{array}{l}0.977 \\
0.993 \\
1.007 \\
0.998 \\
0.977 \\
0.953\end{array}$ & $\begin{array}{l}0.977 \\
0.993 \\
1.007 \\
0.998 \\
0.977 \\
0.953\end{array}$ & $\begin{array}{l}0.977 \\
0.993 \\
1.007 \\
0.998 \\
0.977 \\
0.953\end{array}$ & $\begin{array}{l}0.977 \\
0.993 \\
1.007 \\
0.998 \\
0.977 \\
0.953\end{array}$ \\
\hline $\begin{array}{l}\text { Relative } \\
\text { Error } \\
\varepsilon\end{array}$ & $\begin{array}{l}0.691 \times 10^{4} \\
1.244 \times 10^{5} \\
7.085 \times 10^{5} \\
1.175 \times 10^{6} \\
1.996 \times 10^{6} \\
2.929 \times 10^{6}\end{array}$ & $\begin{array}{c}-\overline{-} \\
<0.01 \\
-- \\
-\overline{0} \\
--\end{array}$ & $\begin{array}{c}<0.01 \\
<0.01 \\
-- \\
-- \\
<0.01 \\
--\end{array}$ & $\begin{array}{c}<0.01 \\
<0.01 \\
<0.01 \\
-- \\
-- \\
--\end{array}$ & $\begin{array}{l}<0.01 \\
<0.01 \\
<0.01 \\
<0.01 \\
<0.01\end{array}$ & $\begin{array}{l}<0.01 \\
<0.01 \\
<0.01 \\
<0.01 \\
<0.01\end{array}$ & $\begin{array}{l}<0.01 \\
<0.01 \\
<0.01 \\
<0.01 \\
<0.01 \\
<0.01\end{array}$ & $\begin{array}{l}<0.01 \\
<0.01 \\
<0.01 \\
<0.01 \\
<0.01 \\
<0.01\end{array}$ & $\begin{array}{l}<0.01 \\
<0.01 \\
<0.01 \\
<0.01 \\
<0.01 \\
<0.01\end{array}$ \\
\hline
\end{tabular}


TABLE 3-10. RELATIVE FUEL VOID VOLUME, Rvold, OF A STANDARD BWR FUEL ROD, COMPARISON BETWEEN FRAPCON-2 AND FPRESS CALCULATIONS

\begin{tabular}{|c|c|c|c|c|c|c|c|c|c|}
\hline & \multirow{2}{*}{$\begin{array}{l}\text { Burnup } \\
(\mathrm{MU} / \mathrm{s} / \mathrm{kgU}) \\
\end{array}$} & \multicolumn{8}{|c|}{$\begin{array}{c}\text { Temper a ture } \\
(\mathrm{K})\end{array}$} \\
\hline & & 500 & 600 & 700 & 800 & 900 & 1000 & 1100 & 1200 \\
\hline FRAPCON-2 & $\begin{array}{l}0.691 \times 10^{4} \\
1.244 \times 10^{5} \\
7.085 \times 10^{5} \\
1.175 \times 10^{6} \\
1.996 \times 10^{6} \\
2.929 \times 10^{6}\end{array}$ & $\begin{array}{l}1.017 \\
1.201 \\
1.170 \\
1.143 \\
1.102 \\
1.077\end{array}$ & $\begin{array}{l}1.007 \\
1.190 \\
1.159 \\
1.133 \\
1.095 \\
1.067\end{array}$ & $\begin{array}{l}0.994 \\
1.183 \\
1.148 \\
1.122 \\
1.084 \\
1.060\end{array}$ & $\begin{array}{l}0.075 \\
0.117 \\
0.124 \\
0.128 \\
0.136 \\
0.147\end{array}$ & $\begin{array}{l}0.075 \\
0.117 \\
0.124 \\
0.128 \\
0.136 \\
0.145\end{array}$ & $\begin{array}{l}0.057 \\
0.054 \\
0.085 \\
0.102 \\
0.121 \\
0.145\end{array}$ & $\begin{array}{l}0.041 \\
0.040 \\
0.077 \\
0.087 \\
0.107 \\
0.132\end{array}$ & $\begin{array}{l}0.040 \\
0.038 \\
0.068 \\
0.083 \\
0.098 \\
0.120\end{array}$ \\
\hline FPRESS & $\begin{array}{l}0.691 \times 10^{4} \\
1.244 \times 10^{5} \\
7.085 \times 10^{5} \\
1.175 \times 10^{6} \\
1.996 \times 10^{6} \\
2.929 \times 10^{6}\end{array}$ & $\begin{array}{l}1.017 \\
1.160 \\
1.162 \\
1.140 \\
1.102 \\
1.060\end{array}$ & $\begin{array}{l}1.017 \\
1.160 \\
1.162 \\
1.140 \\
1.102 \\
1.060\end{array}$ & $\begin{array}{l}1.017 \\
1.160 \\
1.162 \\
1.140 \\
1.102 \\
1.060\end{array}$ & $\begin{array}{l}0.075 \\
0.083 \\
0.113 \\
0.128 \\
0.144 \\
0.153\end{array}$ & $\begin{array}{l}0.075 \\
0.083 \\
0.113 \\
0.128 \\
0.144 \\
0.153\end{array}$ & $\begin{array}{l}0.075 \\
0.083 \\
0.113 \\
0.128 \\
0.144 \\
0.153\end{array}$ & $\begin{array}{l}0.075 \\
0.083 \\
0.113 \\
0.128 \\
0.144 \\
0.153\end{array}$ & $\begin{array}{l}0.075 \\
0.083 \\
0.113 \\
0.128 \\
0.114 \\
0.153\end{array}$ \\
\hline $\begin{array}{l}\text { Relative } \\
\text { Error } \\
\text { E }\end{array}$ & $\begin{array}{l}0.691 \times 10^{4} \\
1.244 \times 10^{5} \\
7.085 \times 10^{5} \\
1.175 \times 10^{6} \\
1.996 \times 10^{6} \\
2.929 \times 10^{6}\end{array}$ & $\begin{array}{r}0.03 \\
<0.01 \\
<0.01 \\
-\overline{0.02}\end{array}$ & $\begin{array}{r}<0.01 \\
0.03 \\
<0.01 \\
<0.01 \\
<0.01 \\
<0.01\end{array}$ & $\begin{array}{l}0.02 \\
0.02 \\
0.01 \\
0.02 \\
0.02 \\
--\end{array}$ & $\begin{array}{l}0 . \\
0.29 \\
0.09 \\
-. \\
0.06 \\
0.04\end{array}$ & $\begin{array}{l}-- \\
0.29 \\
0.09 \\
-- \\
0.06 \\
0.04\end{array}$ & $\begin{array}{l}0.32 \\
0.54 \\
0.33 \\
0.25 \\
0.19 \\
0.04\end{array}$ & $\begin{array}{l}0.83 \\
1 \\
0.59 \\
0.47 \\
0.35 \\
0.16\end{array}$ & $\begin{array}{l}0.88 \\
1 \\
0.66 \\
0.54 \\
0.47 \\
0.28\end{array}$ \\
\hline
\end{tabular}


BWR fuel rod. These are the fuel stack axial deformation and (under the special conditions of coolant pressures exceeding internal gas pressures) the significant decrease in plenum cladding diameter at temperatures $>750 \mathrm{~K}$. When the latter effect becomes dominant for plenum (cladding) temperatures exceeding $750 \mathrm{~K}$, the plenum volume calculation by the FPRESS model is performed in two different ways, depending on the temperature.

For plenum (cladding) temperatures $T_{p}$ in the range of $500 \leq T_{p}<750 \mathrm{~K}$, the plenum volume is calculated by linear super-position of the temperature-dependent contributions of the axial fuel zones due to fuel axial expansion:

$v_{p}=\left[\sum_{i=1}^{M} \frac{1_{i}}{1_{\text {tot }}^{\cot d}} R_{p}\left(T_{f, i}\right)\right] v_{p}^{\operatorname{cold}}$.

where

$$
\begin{aligned}
& v_{p}^{c o l d}=\text { plenum volume }\left(m^{3}\right) \\
& v_{p} \quad=\text { as-fabricated plenum volume }\left(m^{3}\right) \\
& 1_{1}=\text { length of axial fuel zone } i(\mathrm{~m}) \\
& 1_{\text {tot }}^{\text {cold }}=\text { total fuel stack length (m) } \\
& 1_{\text {tot }}=\text { total fuel stack length }(\mathrm{m}) \\
& =\sum_{i=1}^{M} i_{i} \\
& R_{p}\left(T_{i}\right)=\text { relative plenum volume, evaluated using } \\
& \text { Equation }(3-101) \text { with } 1=T_{i} \\
& T_{f, i=}=\text { average fuel temperature in axial zone } i(K) \text {. }
\end{aligned}
$$


For plenum (cladding) temperatures $T_{p}>750 \mathrm{~K}$, the plenum volume is approximated by

$v_{p}=R_{p}\left(T_{p}\right) v_{p}^{\operatorname{col} d}$

where

$$
\begin{aligned}
R_{p}\left(T_{p}\right)= & \begin{array}{l}
\text { relative plenum volume, evaluated using } \\
\text { Equation }(3-101) \text { with } T=T_{p}
\end{array} \\
T_{p} & \begin{array}{l}
\text { plenum (cladding) temperature, } 750<T_{p}<1100 \mathrm{~K} \text { for } \\
\text { standard PWR case and } 750<T_{p}<1200 \mathrm{~K} \text { for standard } \\
\text { BWR case. }
\end{array}
\end{aligned}
$$

$R_{p}\left(T_{p}\right)$ includes the effect of the fuel stack axial expansion with the assumption of a uniform axial fuel temperature $T_{F}$.

The fuel void volume in axial zone $i$ is calculated by

$$
v_{\text {void, } i}=R_{\text {void }}\left(T_{f, j}\right) v_{\text {void, } i}^{\text {cold }}
$$

where

$$
\begin{aligned}
& v_{\text {void,i }}=\text { fuel void volume in axial zone } i\left(m^{3}\right) \\
& R_{\text {vold }}\left(T_{f, i}\right)=\text { relative fuel void volume in axial zone } 1 \text {, } \\
& \text { evaluated by Equation (3-101) with } T=T_{f, i} \text { and } \\
& \text { the coefficients given in Table 3-6 } \\
& T_{f, i}=\text { average fuel temperature in axial zone } i(K) \\
& v_{\text {void, }}^{\text {cold }}=\text { as-fabricated void volume in axial zone } i\left(\mathrm{~m}^{3}\right) \text {. }
\end{aligned}
$$


For the case of internal gas pressure exceeding coolant pressure, no FRAPCON-2 calculations have been performed. Thus, the FPRESS model uses the information on relative void volumes provided by the FRAPCON-2 calculations for the temperature range of $500 \leq T \leq 750 \mathrm{~K}$. For maximum average fuel temperatures up to 1100 and $1200 \mathrm{~K}$, for a PWR and BWR respectively, the relative plenum and fuel void volumes are extrapolated from this lower temperature range in a linear manner using Equation (3-101).

As mentioned before, fuel temperatures have been 1 imited to $1100 \mathrm{~K}$ for the standard PWR fue 1 rod and to $1200 \mathrm{~K}$ for the standard BWR fuel rod, since FRAPCON-2 predicted significant permanent cladding deformation and cladding rupture at higher temperatures. Thus, with respect to the calculation of relative plenum and fuel void volumes on the basis of the empirical correlations, the FPRESS model will set all average fuel temperatures exceeding 1100 and $1200 \mathrm{~K}$ to these limiting values.

The corrections discussed in the next sections are used to model conditions beyond those of the FRAPCON-2 simulations.

\subsubsection{Corrections in Void Volume Calculations Due to Variation from Standard Design}

In order to include fuel rods with as-fabricated plenum and/or fuel stack lengths that differ significantly from the standard rods, a correction factor is introduced. This correction factor fits the calculated relative plenum volumes of the standard cases on different rod lengths.

The relative change in plenum volume due to temperature can be approximated by

$\frac{v_{p}^{\text {hot }}-v_{p}^{\text {cold }}}{v_{p}}=\frac{\left[\Delta L+(L+\Delta L) \alpha_{c l a d} \Delta T-\left(L \alpha_{f u e} \Delta T\right)\right] A^{\text {hot }}-\Delta L A^{\text {cold }}}{\Delta L A^{\operatorname{cold}}}$ 
where

$$
\begin{aligned}
& v_{p}^{\text {hot }}=\text { hot plenum volume }\left(m^{3}\right) \\
& v_{p}^{c o l d}=\text { as-fabricated plenum volume }\left(\mathrm{m}^{3}\right) \\
& \mathrm{L}=\text { as-fabricated fuel stack length }(\mathrm{m}) \\
& \Delta \mathrm{L} \quad=\text { as-fabricated plenum length }(\mathrm{m}) \\
& \Delta T=\text { temperature difference between hot and cold fuel rod } \\
& \text { state assuming a uniform rod temperature (K) } \\
& \alpha_{c l a d}=\text { expansion coefficient of cladding }(1 / K) \\
& \alpha_{\text {fue }}=\text { expansion coefficient of fuel }(1 / K) \\
& A^{\text {hot }}=\text { cross-sectional area of hot plenum }\left(m^{2}\right) \\
& A^{\text {cold }}=\text { cross-sectional area of as-fabricated plenum }\left(m^{2}\right) \text {. }
\end{aligned}
$$

With $A^{\text {hot }}=\delta A(\Delta T) A^{\text {cold }}$ and the assumption that $\Delta L$ is small compared to $L$, then

$\frac{v_{p}^{\text {hot }}}{v_{p}^{\operatorname{cold}}}-1 \approx \frac{L}{\Delta L} \Delta T\left(\alpha_{\text {clad }}-a_{\text {fue })}\right) \delta A(\Delta T)$

where

$$
\begin{aligned}
\delta A(\Delta T)= & \text { relative cross-sectional area of hot plenum (related } \\
& \text { to cross-sectional area of as-fabricated plenum). }
\end{aligned}
$$

Additionally, if $\delta A(\Delta T)$ is approximately independent of as-fabricated geometry (1.e., inner cladding radius) but only dependent on the temperature difference AT, a correction factor $K_{p}$ can be defined to be 


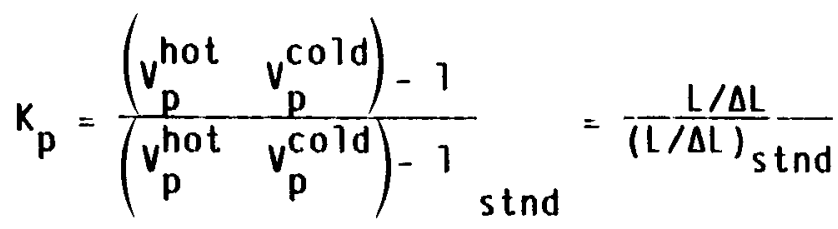

and the relative plenum volume for rods differing from standard geometries, becomes

$R_{p}=\frac{v_{p}^{\text {hot }}}{v_{p}^{\operatorname{co} T d}}=1+K_{p}\left(R_{p, s t n d}-1\right)$.

Figure 3-9 shows the relative plenum volume, $R_{p}$, depending on the standard relative plenum volume $R_{p, s t n d}$. The parameter shown in Figure 3-9 is the correction factor, $K_{p}$, ranging from 0.7 to 1.5 .

For fuel void volumes, it is assumed that the relative fuel void volume predicted by the empirical correlations holds for varying as-fabricated geometries (i.e., pellet radii and/or inner cladding radil). Thus, no correction factor has been introduced for relative fuel void volumes.

The plenum volume is calculated using Equations (3-102) and (3-103), while the fuel void volume is calculated using Equation (3-104).

\subsection{Liquefaction, Flow, and Solidification Model}

The LIQSOL (LIQuefaction-flow-SOLidification) model calculates the meltdown of fuel rods. In particular, LIQSOL models the dripping of liquefied fuel and cladding ( $Z r-U-0$ mixture) down the outside surface of a fuel rod and calculates the location at which the dripping mixture solidifies. The model is designed to calculate the physical situation shown in figure 3-10. From the time a liquefied mixture breaches the oxide shell containing it, the model calculates the downward movement of the mixture due to gravity and the cooling of a liquefied mixture due to heat conduction into the fuel rod. Prior to the time of breach, the model 


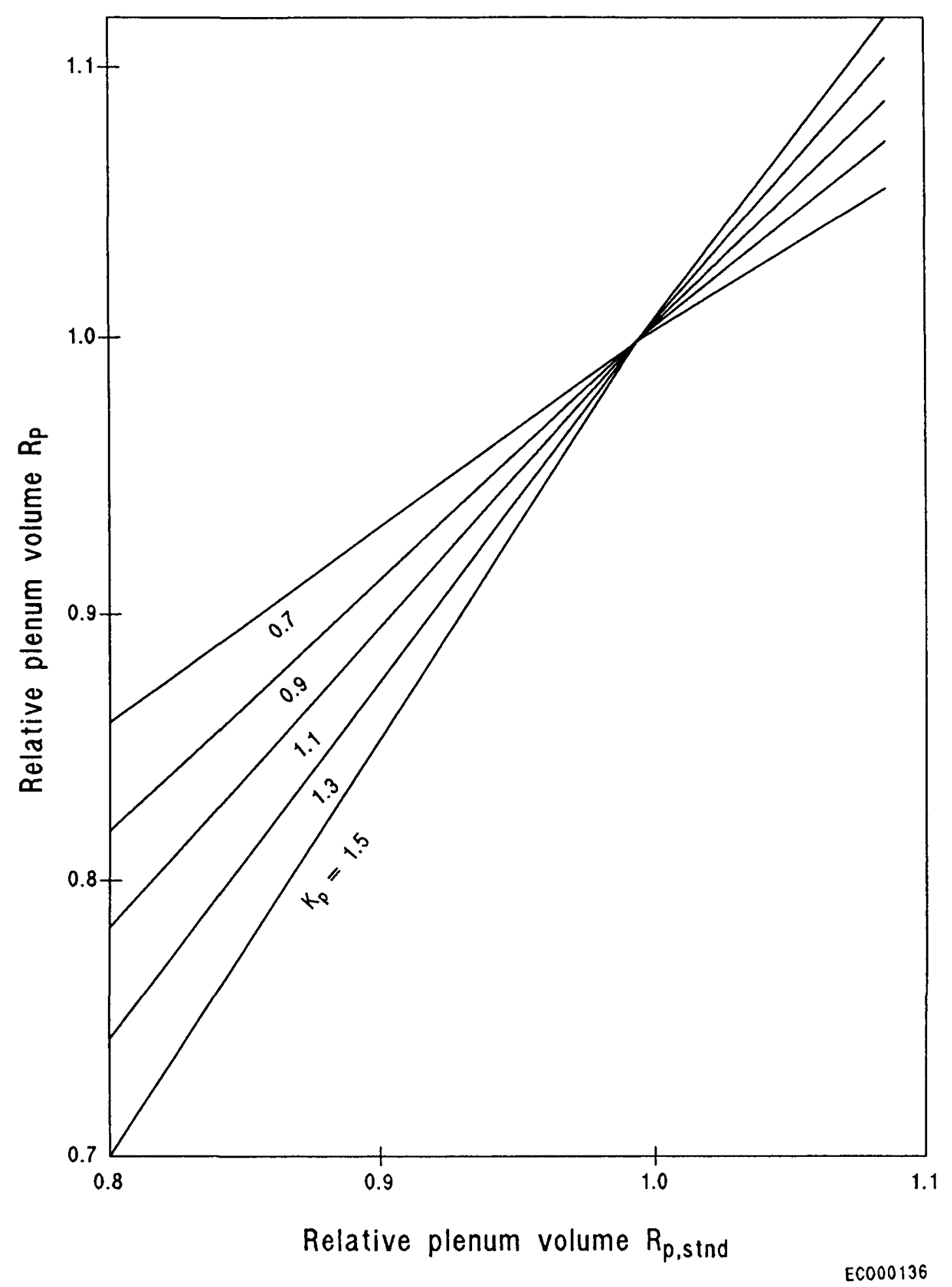

Figure 3-9. Relative plenum volume, $R_{p}$, depending on standard case $R_{p, s t a n d}$ and correction factor, $K_{p}$. 


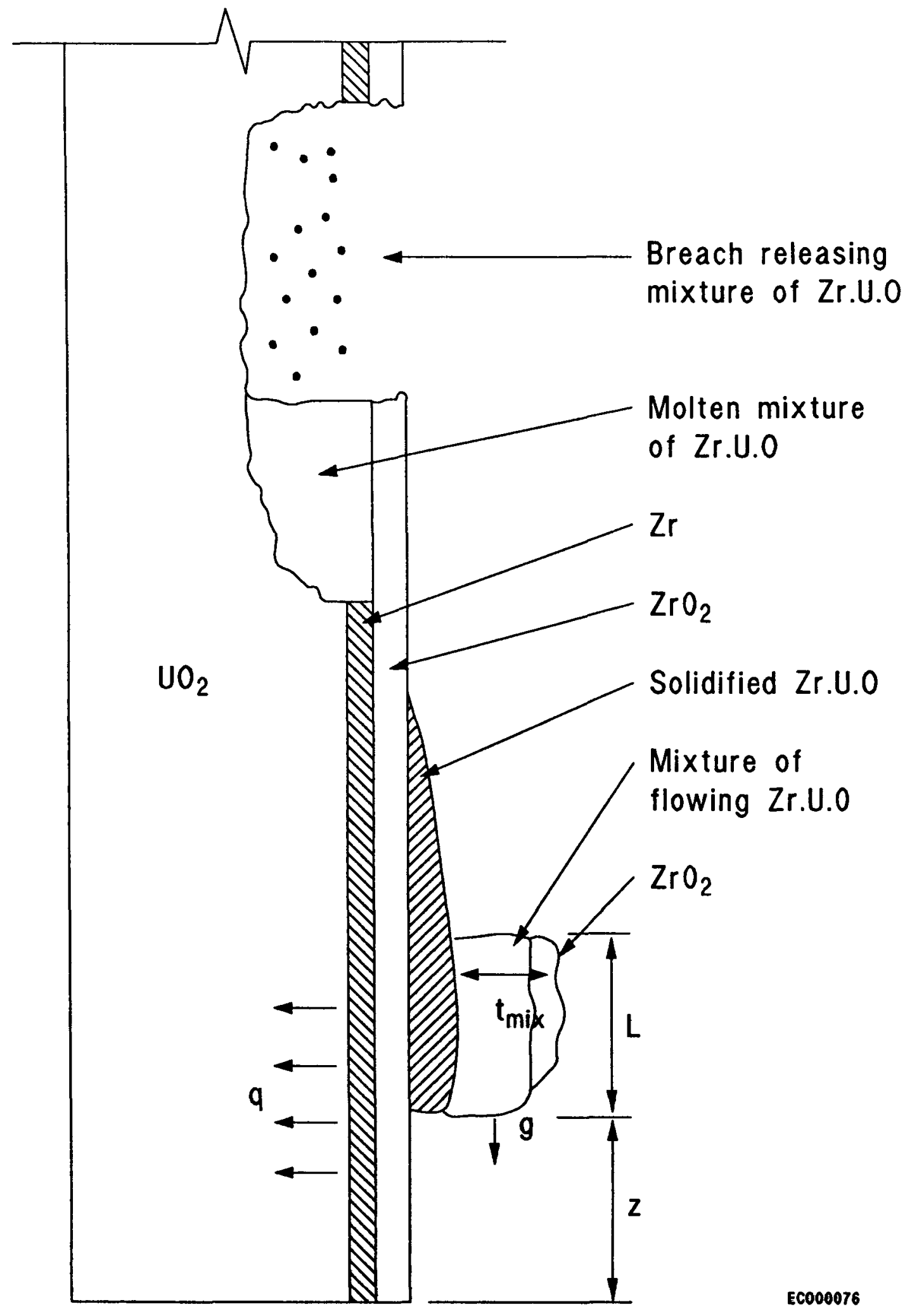

figure 3-10. Meltdown of fuel rod. 
determines the locations in the fuel rod where liquefied fuel and cladding are being contained by the cladding oxide shell.

The LIQSOL model is based upon several simplifying assumptions. Table 3-11 lists these assumptions. The most significant assumption is that liquefied fuel and cladding do not flow downward inside the cladding. This assumption is considered valid for unballooned fuel rods. For a case of liquefied fuel and cladding in a ballooned region, the assumption may not be valid if the fuel is uncracked and a large fuel-cladding gap exists. In this case, liquefied cladding is expected to flow downward inside the fuel rod and collect at the elevation at which the fuel-cladding gap is small enough to block the flow. However, if the fuel is cracked due to power cycling, the gap may be filled with fuel fragments, which should inhibit the relocation of liquefied cladding within the gap.

A second important assumption is that the complex pattern of $\mathrm{film}$, rivulet, and droplet flow of molten material can be approximated using a one-dimensional axisymmetric form. This approximation is most appropriate when the melt relocation is initiated at high temperatures (relative to zircaloy melting) and oxygen content where the liquefied material wets the underlying zircaloy cladding. The downward relocation of free-falling droplets, in particular, and small rivulets of material may be underpredicted under those conditions where spacer grids are not effective barriers to downward relocation of the melt.

The framework for the LIQSOL mode1, illustrated in Figure 3-11, is the stack of axial zones into which a fuel rod has been divided by the code user. The cladding temperatures and thicknesses of the cladding zirconium and $\mathrm{ZrO}_{2}$ layers are input to the model. The first axial zone is assumed to be at the bottom, and the last axial zone is assumed to be at the top of the fuel rod. The bottom of the fuel pellet stack is defined to have an elevation of zero.

The LIQSOL model performs calculations in three steps. The first step calculates where the cladding and fuel have been liquefled. The second 
1. Inside surface of cladding is in contact with outside surface of fuel pellet. Liquefied $\mathrm{Zr}-\mathrm{U}-0$ does not flow downward inside the cladding.

2. At temperatures less than $2400 \mathrm{~K}$, liquefied $\mathrm{Zr}$ does not dissolve $\mathrm{ZrO}_{2}$. At temperatures greater than $2400 \mathrm{~K}$. 1iquefied $\mathrm{Zr}$ instantly dissolves $\mathrm{ZrO}_{2}$.

3. Any breach formed in the oxide shell is large and does not apply any resistance to liquefied $2 r-U-0$ flowing through it.

4. Flowing mixture is axisymmetric and has uniform thickness.

5. Initial thickness of flowing mixture is average of in situ thickness.

6. Flowing mixture is thoroughty mixed and has uniform temperature.

7. Heat conduction from flowing mixture into fuel rod occurs only in the radial direction.

8. Flowing mixture oxidizes the same as a solid $\mathrm{Zr}$ cylinder.

9. Heat transfer from flowing mixture to steam and surrounding fuel rods is negligible. 

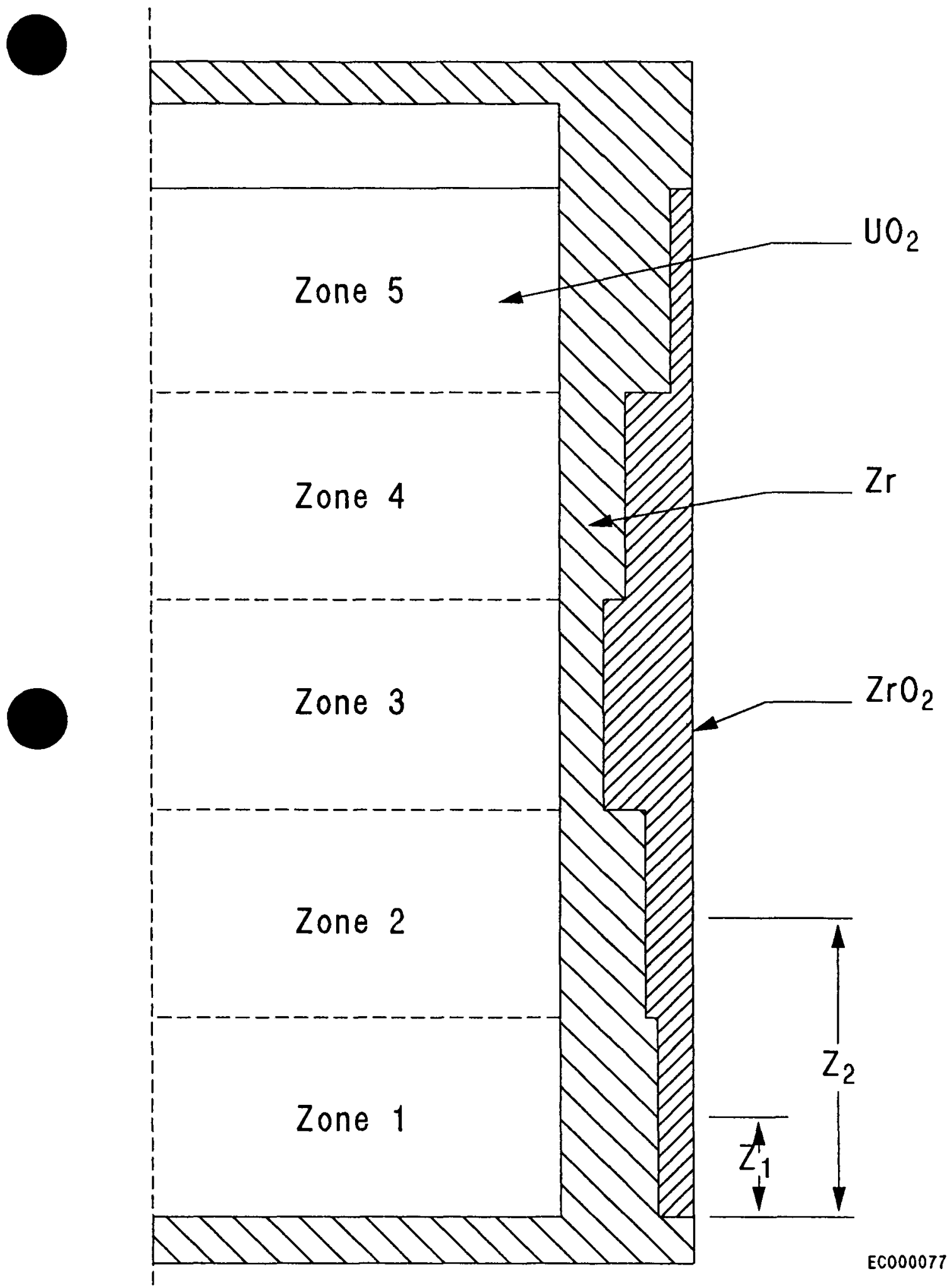

Figure 3-11. Framework of LIQSOl calculations. 
step calculates where the cladding oxide shell is breached. The third step calculates the relocation of the liquefied cladding and fuel that flows through a breach, down the outside surface of the fuel rod, and solidifies.

\subsubsection{Calculation of Where the Cladding and Fuel Have Been Liquefied}

This step calculates the amount and position of 1 iquefied $\mathrm{Zr}-\mathrm{U}-0$ contained by the $\mathrm{ZrO}_{2}$ layer on the outside of the cladding. The calculations are performed in the sections of the fuel rod with no breach in the $\mathrm{ZrO}_{2}$ layer.

The amount of liquefied zirconium in an axial zone of the fuel rod is calculated by the equation

$W_{z k}=\left\{\begin{array}{l}\pi\left[\left(r_{i k}+t_{z k}\right)^{2}-r_{i k}^{2}\right] \Delta z_{k} \rho_{z} ; T_{s k} \geq T_{L z} \\ 0 ; T_{s k}<T_{L z}\end{array}\right.$

where

$$
\begin{aligned}
& W_{z k}=\begin{array}{l}
\text { mass of liquefied zirconium in axial zone } k \text { of fuel rod } \\
(k g)
\end{array} \\
& r_{i k}=\text { inside radius of cladding in axial zone } k(m) \\
& t_{z k}=\text { thickness of unoxidized portion of cladding in axial } \\
& \Delta z_{k}=\text { hone } k(m) \\
& \rho_{z}=\text { density of unoxidized portion of cladding }\left(k g / m^{3}\right) \\
& T_{s k}=\text { cladding temperature in axial zone } k(k)
\end{aligned}
$$


$T_{L Z}=$ Tiquidus temperature of zirconium $(K)$.

The number of molecules of liquefied zirconium in an axial zone is calculated by the equation

$$
N_{Z}=1000 N_{A} \frac{W_{Z k}}{A_{Z}} \text {. }
$$

where

$$
\begin{aligned}
& N_{Z}=\text { number of molecules of liquefied zirconium } \\
& N_{A}=\text { Avogadro's number (molecules } / g \cdot \text { mole), } 6.0238 \times 10^{23} \\
& W_{Z k}=\text { mass of liquefied zirconium }(\mathrm{kg}) \\
& A_{Z}=\text { atomic weight of zirconium (awu), } 91.2 .
\end{aligned}
$$

Liquefied zirconium dissolves $\mathrm{UO}_{2}$ that it contacts. The dissolution begins at the outside surface of the fuel pellet and propagates as a front inward toward the fuel center. A model for the rate of dissolution was obtained from Hoffman, et a.$^{3-23}$ This model calculates fuel dissolution by the equations

$$
\begin{aligned}
& P_{2}=35.8+\left[\left(P_{1}-35.8\right)^{2}+1.0196 \times 10^{15} \exp (-677200 / R T) \Delta t\right]^{0.5} \\
& W_{u}=P_{2} W_{z} /\left(100 .-P_{2}\right) \\
& r_{m 2}=\left[r_{p}^{2}-W_{u} /\left(P_{u} \Delta Z \pi\right)\right]^{0.5}
\end{aligned}
$$

where

$$
\begin{aligned}
P_{2}= & \text { weight percent of } U_{2} \text { at end of time step in mixture of } \\
& U-2 r-0 \text { resulting from fue } 1 \text { dissolution by liquefied } \\
& \text { zirconium }
\end{aligned}
$$




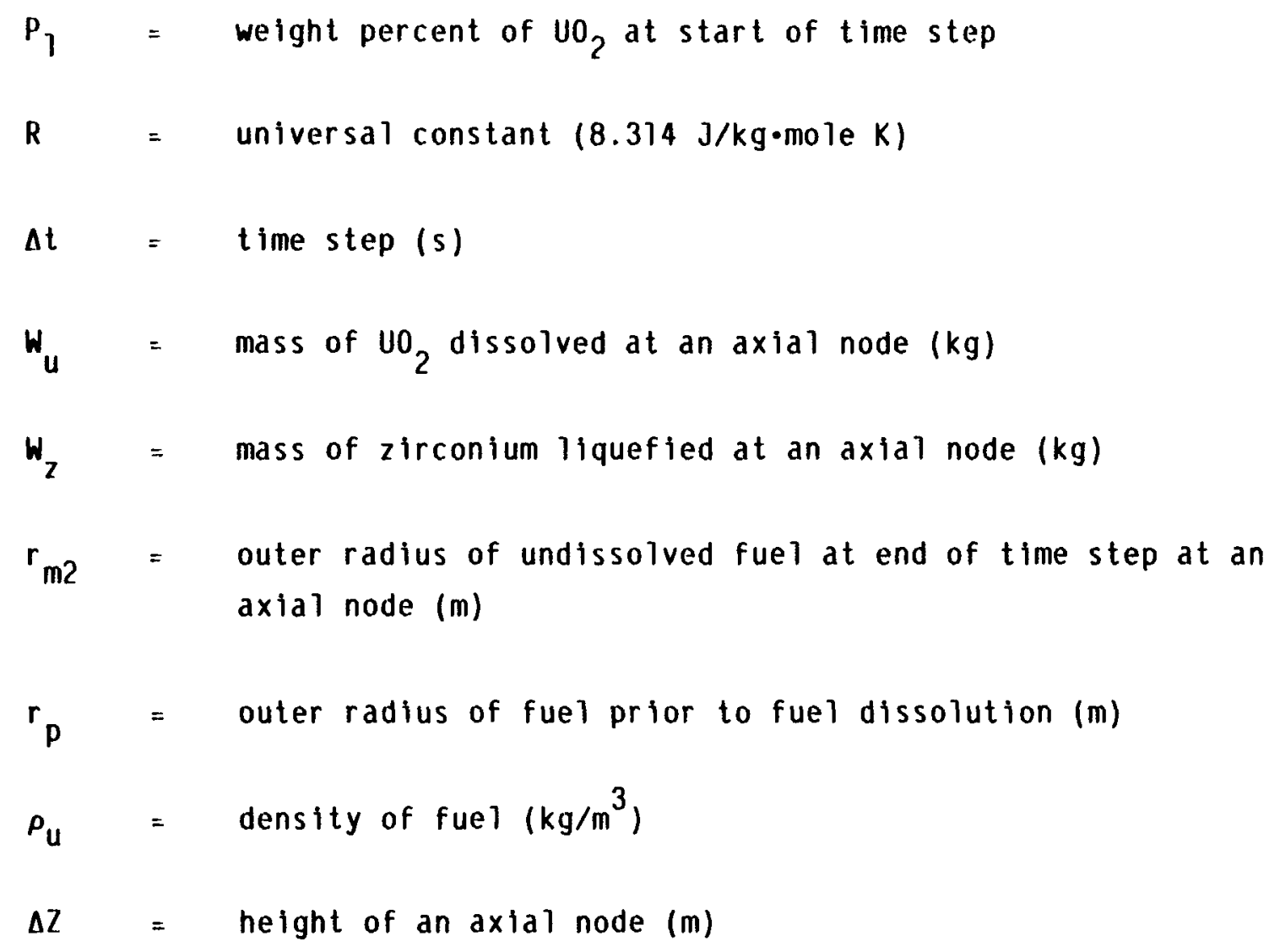

The calculated amount of fuel dissolution is limited to the amount at which equilibrium occurs as determined by the ternary phase diagram.

\subsubsection{Breach of Cladding Surface $\mathrm{ZrO}_{2}$ Layer}

This step calculates whether or not a breach of the cladding surface $\mathrm{ZrO}_{2}$ layer occurs during the time step. If no breach occurs, then no relocation of liquefied fuel and cladding is calculated. If a breach occurs, then liquefied fuel and cladding pour out of the breach and the position at which the mixture solidifies is calculated.

Criteria based in part on user-defined parameters are used to determine whether or not a breach occurs in a shell of cladding oxide that holds liquefied fuel and cladding. The variables in the criteria are temperature and extent of oxidation. The criterion is expressed by the logical operations 


$$
\left.\begin{array}{l}
\text { If } T_{\text {ox }}>T_{\text {fail }} \text { and } f_{\text {ox }}<f_{\text {input }} \\
\text { or } \\
\text { if } T_{o x}>T_{\text {melt }}
\end{array}\right] \text { then breach. }
$$

where

$$
\begin{aligned}
& T_{\text {ox }}=\text { temperature of oxide shell (K) } \\
& T_{\text {fail }}=\text { user-defined failure temperature of oxide shell } \\
& \text { (K) (recommended range of value is } 2300 \text { to } 2700 \mathrm{~K} \text { ) } \\
& f_{o x} \quad=\text { fraction of cladding oxidized at location at which the } \\
& \text { possibility of cladding breach is being evaluated } \\
& f_{\text {input }}=\text { user-defined extent of oxidation beyond which oxide } \\
& \text { shell does not breach even if its temperature exceeds } \\
& \text { the fallure temperature (recommended range of value is } \\
& 0.5 \text { to } 1 .) \\
& \mathrm{T}_{\text {melt }}=\text { temperature at which oxide shell melts ( 2950 K) }
\end{aligned}
$$

\subsubsection{Relocation of Liquefied $\mathrm{Zr}-\mathrm{U}-0$}

This step calculates the relocation of liquefied $\mathrm{Zr}-U-0$ that pours through a breach in the $\mathrm{ZrO}_{2}$ layer and flows downward until solidifying. The distance of flow depends upon the axial temperature distribution of the section of the fuel rod over which the liquefied mixture flows. The transient values of the mixture velocity and temperature are calculated to determine the distance of flow. A set of five equations is solved to determine the velocity and temperature. This set of equations is shown in Table 3-12. The frame of reference for these equations is shown in Figure 3-12. The equation symbols are defined in Table 3-13. 
TABLE 3-12. EQUATION SET FOR CALCULATION OF VELOCITY AND TEMPERATURE OF FLOWING MIXTURE OF $\mathrm{Zr}-\mathrm{U}-0$

\section{Phenomenon}

Modeled

\section{Equation}

Motion

$$
\frac{d V(t)}{d t}+\frac{f}{8 t_{\operatorname{mix}}}-V(t)^{2}-g=0
$$

Heat

conduction

$$
\begin{array}{rlrl}
q(z, t) & =\frac{1.224 \Delta T_{s} k}{(a t)^{0.5}} & & \left(t<t_{1}\right) \\
& =q_{1} \cong \frac{K}{\delta} \Delta T_{s} \exp \frac{-K_{z r O_{2} t}}{\rho_{z r} c_{z r} \delta^{2}} & \left(t \leq t<t_{2}\right) \\
& =q_{2} & \left(t>t_{2}\right)
\end{array}
$$

Cover

time

$$
\Delta t_{c}=\frac{L}{V(Z)}
$$

Heat

loss

$$
\frac{d Q(z)}{d z}=2 \pi r_{0} \int_{0}^{\Delta t} c(z, t) d t
$$

$$
\begin{array}{ll}
=15.381 r_{0}(\alpha)^{-0.5} \Delta T_{s} k\left(\Delta t_{c}\right)^{0.5} & \left(\Delta t_{c}<t_{1}\right) \\
=15.381 r_{0}(\alpha)^{-0.5} \Delta T_{s} k t_{1}^{0.5}+Q_{1} & \left(t_{1} \leq t<t_{2}\right) \\
=15.381 r_{0}(\alpha)^{-0.5} \Delta T_{s} k t_{1}^{0.5}+Q_{1}+Q_{2} \quad\left(t>t_{2}\right)
\end{array}
$$

Temperature change

$$
-\frac{d T_{\text {mix }}(z)}{d z}=\frac{1}{c_{p} M}-\frac{P_{o x}(t) \Delta t_{c}}{L}-\frac{d Q(z)}{d z}
$$




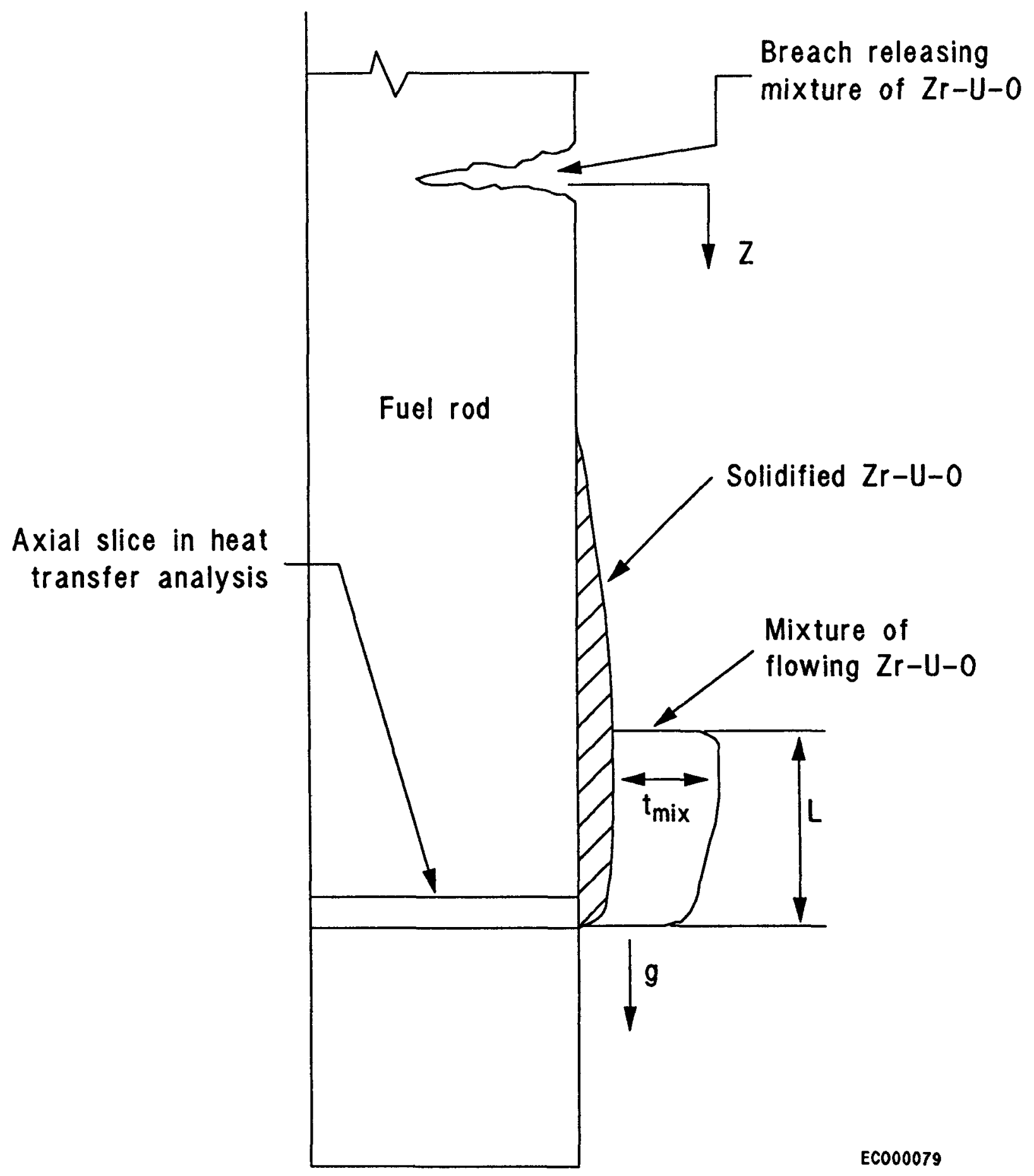

Figure 3-12. Frame of reference for LIQSOL equations in Table 3-12. 


\begin{tabular}{|c|c|c|}
\hline Symbol & Units & Definition \\
\hline$c_{p}$ & $\mathrm{~J} / \mathrm{kg} \cdot \mathrm{K}$ & Heat capacity of $\mathrm{Zr}-\mathrm{U}-0$ mixture. \\
\hline$f$ & -- & $\begin{array}{l}\text { Coefficient of friction between } \mathrm{Zr}-\mathrm{U}-0 \text { mixture } \\
\text { and surface over which it flows (calculated by } \\
\text { MATPRO function ZUFRIC). }\end{array}$ \\
\hline 9 & $\mathrm{~m} / \mathrm{s}^{2}$ & Acceleration of gravity. \\
\hline k & $W / m \cdot K$ & $\begin{array}{l}\text { Thermal conduct ivity of cladding oxide layer. } \\
\text { If oxide layer is covered with layer of } \\
\text { solidified } \mathrm{Zr}-\mathrm{U}-0 \text { then oxide and crust are } \\
\text { assumed to form a homogeneous layer and } \\
\text { thermal conductivity of this homogeneous layer } \\
\text { is used. }\end{array}$ \\
\hline $\mathrm{L}$ & $\mathbf{m}$ & Length of $\mathrm{Zr}-\mathrm{U}-0$ mixture. \\
\hline M & $\mathrm{kg}$ & Mass of $\mathrm{Zr}-\mathrm{U}-0$ mixture. \\
\hline$q(z, t)$ & $\mathrm{J} / \mathrm{m}^{2} \cdot \mathrm{s}$ & $\begin{array}{l}\text { Transient heat flux at cladding surface at } \\
\text { elevation } z \text { when cladding at this elevation is } \\
\text { covered with flowing } Z r-U-0 \text { mixture. }\end{array}$ \\
\hline$\frac{d Q(z)}{d z}$ & $\mathrm{~J} / \mathrm{m}$ & $\begin{array}{l}\text { Rate of change of mixture heat loss with } \\
\text { respect to elevation. }\end{array}$ \\
\hline$q_{1}$ & $\mathrm{~J} / \mathrm{m}^{2} \cdot \mathrm{s}$ & $\begin{array}{l}\text { Heat flux at cladding surface during time } \\
\text { interval in which cladding } Z r \text { layer is } \\
\text { absorbing heat from flowing mixture. Prior to } \\
\text { time } T_{1} \text { only the oxide and crust layers are } \\
\text { absorbing heat from the flowing mixture. The } \\
\text { term of } q_{7} \text { is considered when the cladding } \\
\text { oxide layer is thin or when the cover time is } \\
\text { large. }\end{array}$ \\
\hline$q_{2}$ & $\mathrm{~J} / \mathrm{m}^{2} \cdot \mathrm{s}$ & $\begin{array}{l}\text { Heat flux at cladding surface during time } \\
\text { interval in which fuel is absorbing heat from } \\
\text { flowing mixture. This term is considered when } \\
\text { the cover time is large. }\end{array}$ \\
\hline
\end{tabular}


TABLE 3-13. (continued)

\begin{tabular}{|c|c|c|}
\hline Symbol & Units & Definition \\
\hline$P_{0 x}(t)$ & W & $\begin{array}{l}\text { Heat generation rate due to oxidation in } \\
\text { mixture of flowing } Z r-U-0 \text {. This heat } \\
\text { generation rate is calculated by subroutine in } \\
\text { SCOAP named OXFLOW. }\end{array}$ \\
\hline$r_{0}$ & m & $\begin{array}{l}\text { Outer radius of cladding oxide layer. If } \\
\text { oxide layer is covered with layer of } \\
\text { solidified } Z r-U-0 \text {, then } r_{0} \text { is outer radius of } \\
\text { this layer of } Z r-U-0 \text {. }\end{array}$ \\
\hline $\mathbf{t}$ & s & $7 \mathrm{ime.}$ \\
\hline$\Delta \mathrm{t}$ & s & Time step. \\
\hline$\Delta t_{c}$ & s & $\begin{array}{l}\text { Length of time that a given point on cladding } \\
\text { surface is covered with } \mathrm{Zr}-\mathrm{U}-0 \text { mixture. }\end{array}$ \\
\hline$t_{1}$ & s & $\begin{array}{l}\text { Time at which cladding } 2 r \text { layer begins to } \\
\text { absorb amount heat from flowing mixture. For } \\
\text { a thin oxide layer, } t_{1}=0.167 \delta^{2} / \alpha \text {. }\end{array}$ \\
\hline$t_{2}$ & 5 & $\begin{array}{l}\text { Time at which fuel begins to absorb heat from } \\
\text { flowing mixture. }\end{array}$ \\
\hline $1 \mathrm{c}$ lad $(z)$ & K & $\begin{array}{l}\text { lemperature of cladding at elevation } z \text { just } \\
\text { prior to time at which cladding surface is } \\
\text { covered by flowing mixture of } 2 r-U-0 \text {. }\end{array}$ \\
\hline$t_{\operatorname{mix}}$ & m & Thickness of $\mathrm{Zr}-\mathrm{U}-0$ mixture. \\
\hline$T_{m i x}(z)$ & K & $\begin{array}{l}\text { lemperature of } Z r-U-0 \text { mixture when its leading } \\
\text { edge is at elevation } z \text {. }\end{array}$ \\
\hline$\Delta \mathrm{T}_{\mathrm{s}}$ & K & $T_{\operatorname{mix}}(z)-T_{c 1 a d}(z)$ \\
\hline$V(t)$ & $\mathrm{m} / \mathrm{s}$ & Velocity of $\mathrm{Zr}-\mathrm{U}-0$ mixture at time $t$. \\
\hline$V(z)$ & $\mathrm{m} / \mathrm{s}$ & $\begin{array}{l}\text { Velocity of } \mathrm{Zr}-U-0 \text { mixture when its leading } \\
\text { edge is at elevation } z\end{array}$ \\
\hline$z$ & m & Elevation of leading edge of $\mathrm{Zr}-\mathrm{U}-0 \mathrm{mixture}$ \\
\hline
\end{tabular}


TABLE 3-13. (cont inued)

\begin{tabular}{|c|c|c|}
\hline Symbol & Units & Definition \\
\hline$\alpha \frac{k}{\rho c_{p}}$ & $m^{2} / s$ & $\begin{array}{l}\text { Thermal diffusivity of cladding oxide layer. } \\
\text { If oxide layer is covered with layer of } \\
\text { solidified } \mathrm{Zr}-\mathrm{U}-0 \text {, then oxide and crust are } \\
\text { assumed to form a homogeneous layer and the } \\
\text { thermal conductivity of this homogeneous layer } \\
\text { is used. }\end{array}$ \\
\hline$\delta$ & m & Thickness of the $\mathrm{ZrO}_{2}$ layer. \\
\hline$Q_{1}$ & $\mathrm{~J} / \mathrm{m}$ & $\begin{array}{l}\text { Amount of heat loss from flowing mixture } \\
\text { between time } t_{1} \text { and } t_{2} \text {. }\end{array}$ \\
\hline$Q_{2}$ & $\mathrm{~J} / \mathrm{m}$ & $\begin{array}{l}\text { Amount of heat loss from flowing mixture after } \\
\text { time } t_{2} \text {. }\end{array}$ \\
\hline
\end{tabular}


The physical basis of the equations in Table $3-12$ is described as follows. The equation of motion calculates the mixture acceleration due to gravity and deceleration due to friction forces on the inside surface of the mixture. The equation for heat conduction calculates the rate at which heat is conducted from the mixture into the fuel rod as the mixture flows over its surface. The physical situation modeled by this equation is described in Figure 3-13. A temperature wave propagates into an axial slice of the fuel rod beginning at the instant the mixture contacts the surface of the axial slice. The amount of heat transferred into the axial slice is calculated using the integral method. The distance propagated by the temperature wave is proportional to the square root of time. The third equation in Table 3-12, the equation for cover time, calculates the length of time the axial slice is covered by the flowing mixture. The equation for heat loss calculates the rate of heat loss from the flowing mixture with respect to the distance the flowing mixture has moved. The last equation in Table 3-12 calculates the temperature change of the flowing mixture.

The equation set in Table $3-12$ is solved at a sequence of descending elevations as the mixture flows down the fuel rod. The equation of motion is solved numericaliy to determine the change in velocity and elevation of the mixture during one time step. The other equations are then solved at the elevation of the leading edge of the mixture at the end of this time step. Time steps between 0.001 to 0.01 s are used. Figure 3-14 illustrates the sequence of elevations at which the equations are solved. For this figure, $V_{1}$ is the average mixture velocity during the first time step. The solution at the $\mathbb{N}$-th elevation determines the initial conditions for the solution at the $(N+])$-th elevation. The solution continues in this manner until the flowing mixture has cooled to its solidus temperature. The terms $q_{1}$ and $q_{2}$ in Table 3-12 are important when the cladding oxide layer and crust layer are thin or the cover time is large.

The derivation of the equations to calculate the terms $q_{7}$ and $q^{2}$ is presented next. First, an equation is derived to calculate $t_{1}$, which is the time before which the cladding zircaloy layer does not absorb a 

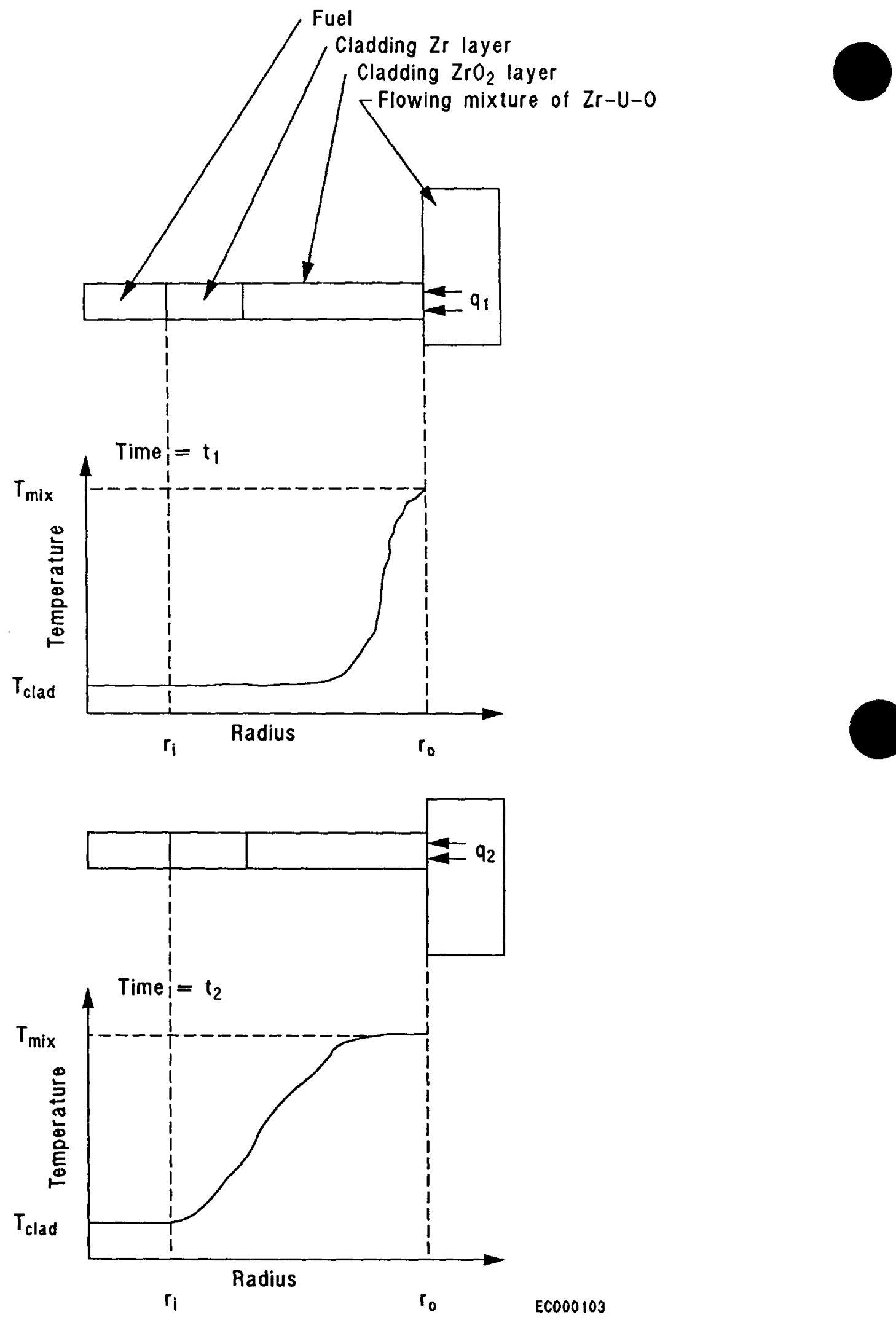

Figure 3-13. Heat transfer from flowing mixture into axial slice of fuel rod. 


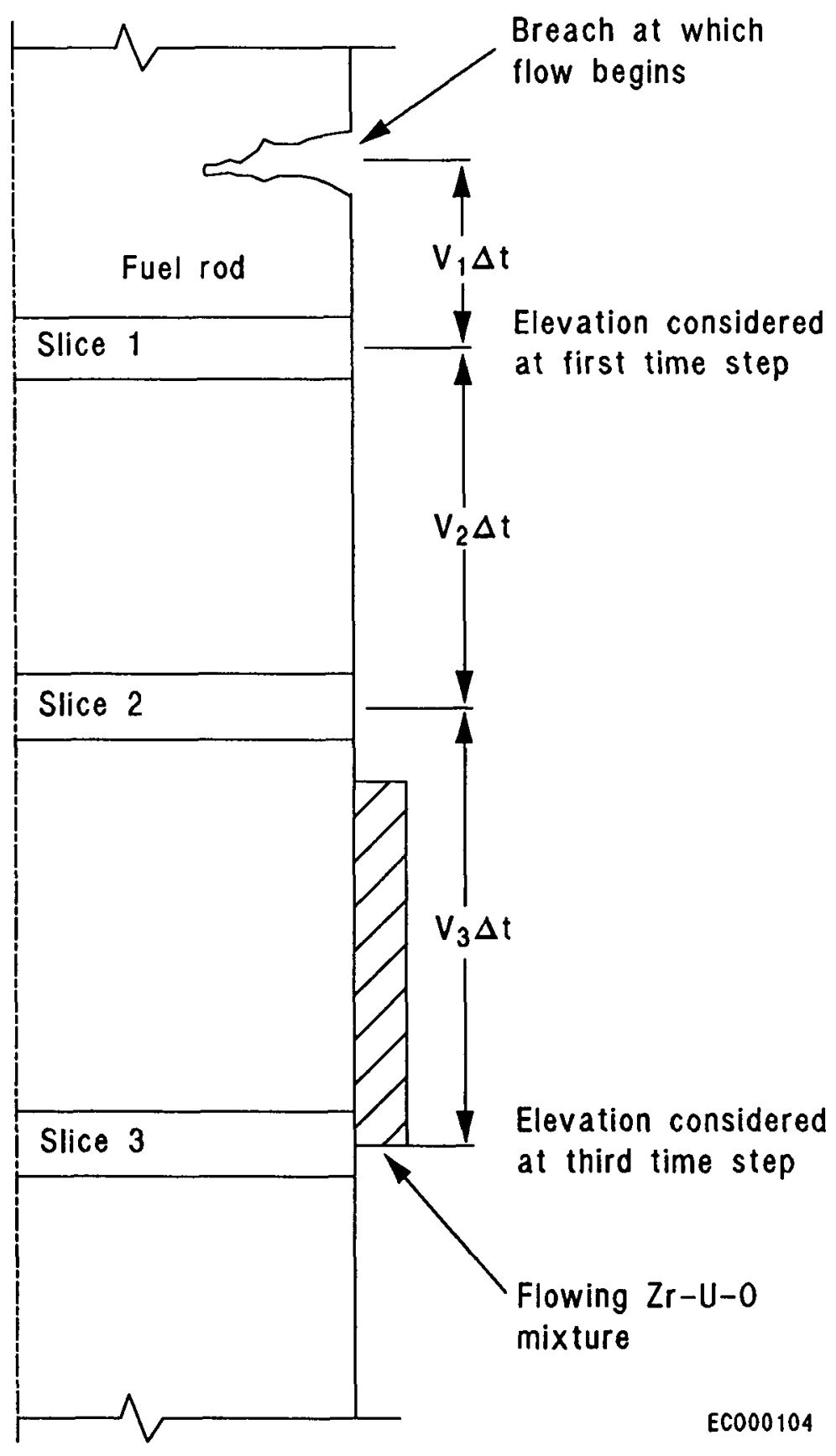

Figure 3-14. Axial slices at which equations are solved. 
significant amount of heat. Next, the equation is derived for calculating the heat flux at the cladding surface during the interval of time in which the cladding zircaloy layer is absorbing heat. Next, the equation is derived to calculate $t_{2}$, which is the time after which the fuel begins to absorb a significant amount of heat. Finally, the equation is presented for calculating the amount of heat absorbed by the fuel.

The cladding zircaloy layer is considered to begin to absorb heat at the time the cladding oxide and crust layer has absorbed the amount of heat corresponding with the temperature distribution shown in Figure 3-15. This temperature distribution is linear and varies from $T_{\text {cladk }}$ at the inside surface of the oxide and crust layer to $T_{c l a d k}+\Delta T_{S}$ at the outside surface. The time at which the cladding zircaloy layer begins to absorb heat is calculated from the equation

$$
\begin{aligned}
E_{1} & =2 \pi r_{0} \int_{0}^{t} q(z, t) d t \\
& =2 \pi r_{0} \int_{0}^{t_{1}} \frac{1.224 \Delta T_{s} k}{(\alpha t)^{0.5} d t}
\end{aligned}
$$

where

$$
\begin{aligned}
& E_{1}=\begin{array}{l}
\text { amount of heat corresponding with the temperature } \\
\text { distribution shown in Figure } 3-12 \\
0.5 \pi\left(r_{0}^{2}-r_{i}^{2}\right) \rho_{z 0} C_{z 0} \Delta T_{s}
\end{array} \\
& r_{i}=\text { inner radius of cladding oxide layer }(\mathrm{m}) \\
& \rho_{z 0}=\text { density of cladding oxide and crust layer }\left(\mathrm{kg} / \mathrm{m}^{3}\right) \\
& C_{z 0}=\text { heat capacity of cladding oxide and crust } 1 \text { ayer }(\mathrm{J} / \mathrm{kg} \cdot \mathrm{K}) .
\end{aligned}
$$




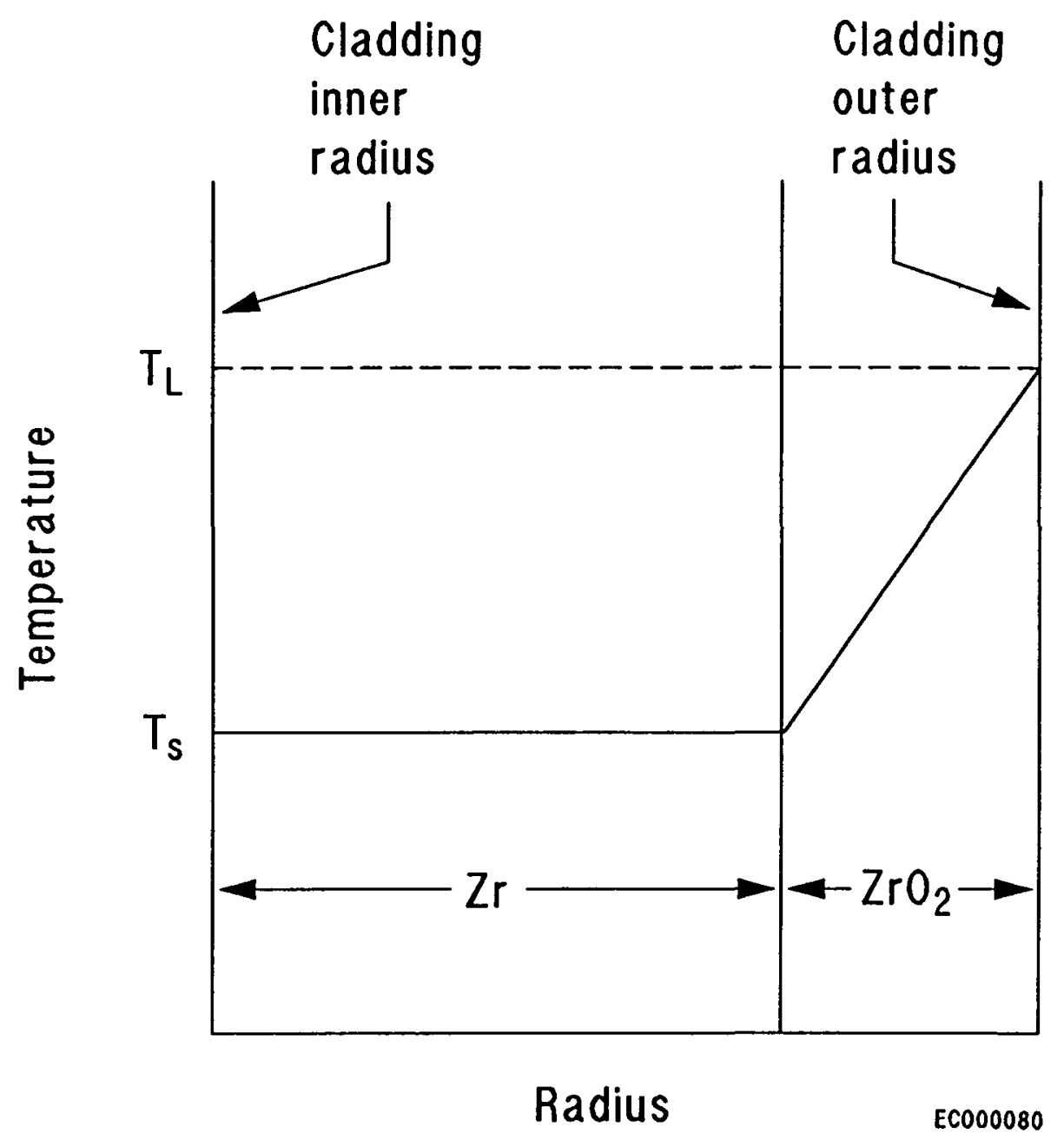

Figure 3-15. Initial cladding temperature distribution for calculations, assuming finite thickness. 
The result of solving the above equation for $t_{1}$ is

$t_{1}=0.667 a\left(\frac{E_{1}}{2 \pi r_{0} \Delta T_{s} k}\right)^{2} \simeq \frac{\delta^{2}}{\alpha}$

where $\delta$ is the thickness of the oxide layer.

The equation for calculating the heat conduction into the fuel rod between $t_{1}$ and $t_{2}$ is now derived. The assumption is made that the cladding zircaloy layer uniformly increases in temperature. Its initial temperature is $T_{c l a d}(z)$. The temperature distribution in the oxide and crust layer is assumed to remain linear. Its inside surface is equal to the temperature of the cladding zircaloy layer. Under the condition of this assumed temperature distribution, the rate of change of temperature of the zircaloy layer is given by the equation

$\left(\rho_{z} C_{z} V_{z}+0.5 \rho_{z 0} C_{z 0} V_{z 0}\right) \frac{d T}{d t}=2 \pi r_{\operatorname{mid}} \frac{k}{\left(r_{0}-r_{j}\right)}\left[T_{\operatorname{mix}}(z)-T\right]$

where

$$
\begin{aligned}
& \boldsymbol{P}_{\mathbf{z}}=\text { density of zircaloy }\left(\mathrm{kg} / \mathrm{m}^{3}\right) \\
& \mathbf{C}_{\mathbf{z}}=\text { heat capacity of zircaloy }(\mathrm{J} / \mathrm{kg} \cdot \mathrm{K}) \\
& \mathbf{v}_{\mathbf{z}}=\text { volume of zircaloy layer per unit } 1 \text { ength }\left(\mathrm{m}^{3} / \mathrm{m}\right) \\
& \mathbf{v}_{\mathbf{z}}=\text { volume of oxide and crust layer per unit } 1 \text { ength }\left(\mathrm{m}^{3} / \mathrm{m}\right) \\
& T=\text { temperature of cladding zircaloy layer }(\mathrm{K}) \\
& \mathbf{r}_{\mathbf{m i d}}=\text { radius of midplane of oxide and crust } 1 \text { ayer }(\mathrm{m}) .
\end{aligned}
$$

To solve the above equation for $T$, the coefficients in the equation are lumped as follows: 


$$
\begin{aligned}
& c_{1}=\rho_{z} C_{z} v_{z}+0.5 \rho_{z 0} c_{z 0} v_{z 0} \\
& c_{2}=2 \pi r_{m i d} \frac{k}{\left(r_{0}-r_{i}\right)} .
\end{aligned}
$$

The equation for $T$ then becomes

$$
\frac{d T}{d t}+\frac{C_{2}}{C_{1}} T-\frac{C_{2}}{C_{1}} I_{m i x}(z)=0 .
$$

The solution of the above first-order linear differential equation is

$$
T=T_{\operatorname{mix}}(z)-\Delta T_{s} \exp \left(-C_{2} t / C_{1}\right)
$$

The amount of heat transferred into the cladding after $t_{1}$ is given by the equation

$$
\begin{aligned}
Q_{1} & =\int_{t_{1}}^{t} c_{2}\left[T_{\operatorname{mix}}(z)-T\right] d t \\
& =\int_{t_{1}}^{t} c_{2} \Delta T_{s} \exp \left(-c_{2} t / c_{1}\right) d t \\
& =\int_{C_{1}}^{t_{1}} \Delta T\left(1-\exp \left[-c_{2}\left(t-t_{1}\right) / C_{1}\right]\right]
\end{aligned}
$$

where $Q_{1}$ is the amount of heat absorbed per unit length by cladding between time $t_{1}$ and $t(\mathrm{~J} / \mathrm{m})$.

The variable $t_{2}$ is the time at which the fuel begins to absorb heat. This variable is calculated assuming that the fuel remains insulated from the cladding until the cladding has absorbed $99 \%$ of the maximum 
possible amount of heat. This amount occurs at the time that the bracket term of Equation (3-122) equals 0.99 . The equation to be solved for time $t_{2}$ is

$\left[1-\exp \left[-C_{2}\left(t_{2}-t_{1}\right) / C_{1}\right]\right\}=0.99$

where $t_{2}$ is the time at which the fuel begins to absorb a significant amount of heat $(s)$.

The solution for $t_{2}$ is

$t_{2}=t_{1}-\left(c_{1} / C_{2}\right) \ln (0.01)$

A precise value of $t_{2}$ is not required because $t_{2}$ is only used in the case of a long cover time. The cover time $\left(\Delta t_{c}\right)$ may exceed $1 s$ in the case of a slowly moving mixture, but the value of $t_{2}$ is generally less than $0.05 \mathrm{~s}$. So a large fractional increase in $t_{2}$ does not cause a significant decrease in $\mathrm{Q}_{2}$, which is proportional to the square root of $\left(\Delta \mathrm{t}_{c}-\mathrm{t}_{2}\right)$.

The amount of heat transferred into the fuel is calculated using the integral method of solution. The calculation is similar to that for calculating the amount of heat transferred into the cladding oxide layer before the time $t_{j}$. The amount of heat transferred to the fue 1 is calculated by the equation

$Q_{2}=\frac{15.381 r_{f} \Delta T_{s} k_{f}\left(\Delta t_{c}-t_{2}\right)^{0.5}}{\left(\alpha_{f}\right)^{0.5}}$

where

$$
\begin{aligned}
& Q_{2}=\text { amount of heat absorbed by fuel per unit length }(\mathrm{J} / \mathrm{m}) \\
& r_{f}=\text { outer radius of fuel pellets }(\mathrm{m})
\end{aligned}
$$




$$
\begin{aligned}
& k_{f}=\text { thermal conductivity of fuel }(W / m \cdot K) \\
& \alpha_{f}=\text { thermal diffusivity of the fuel }\left(\mathrm{m}^{2} / \mathrm{s}\right) .
\end{aligned}
$$

\subsubsection{Variable Initiation}

Initial values must be calculated for several varlables in order to perform the solution of the equation set in Table 3-12. The variables that must be initialized are the mass, temperature, thickness, and length of the flowing mixture.

The mass of the mixture of flowing $\mathrm{Zr}-\mathrm{U}_{-0}$ is calculated by the equation

$$
M=\sum_{k=k_{f}}^{n} w_{Z k}+w_{u k}
$$

where

$$
\begin{aligned}
& M=\text { mass of } 1 \text { lquid } \mathrm{Zr}-\mathrm{U}-0 \text { that flows through breach }(\mathrm{kg}) \\
& k_{f}=\text { number of axial zone in which breach occurs } \\
& n=\text { number of highest axtal zone such that each axial zone } \\
& \text { from } k_{f} \text { to } n \text { contains iqquefied zircaloy } \\
& W_{z k}=\text { mass of liquefied zircaloy in axial zone } k(k g) \\
& W_{u k}=\text { mass of dissolved } U_{2} \text { in axial zone } k(\mathrm{~kg}) \text {. }
\end{aligned}
$$

The initial temperature of the flowing mixture is calculated by the equation

$$
T_{\text {liqo }}=\frac{1}{M} \sum_{k=k_{f}}^{n}\left(w_{z k}+w_{u k}\right) T_{s k}
$$


where

$$
\begin{aligned}
& T_{1 i g o}=\text { initial temperature of flowing mixture } \\
& T_{s k}=\begin{array}{l}
\text { temperature of mixture of liquefied } 2 r-U-0 \text { in axial } \\
\text { zone } k(K) .
\end{array}
\end{aligned}
$$

The volume of the flowing mixture of $\mathrm{Zr}-\mathrm{U}-0$ is calculated by the equation

$$
S_{0}=\frac{M}{\rho}
$$

where

$$
\begin{aligned}
& S_{0} \quad=\text { volume of flowing mixture }\left(\mathrm{m}^{3}\right) \\
& \rho \quad=\text { density of flowing mixture }\left(\mathrm{kg} / \mathrm{m}^{3}\right) .
\end{aligned}
$$

The thickness of the flowing mixture is assumed to be equal to the average thickness of the in situ liquid $\mathrm{Zr}-\mathrm{U}-0$. The thickness is calculated by the equation

$t_{1 i q 0}=\frac{1}{\left(n-k_{f}+1\right)} \sum_{k=k_{f}}^{n} \Delta r_{1 i q k}$

where

$$
\begin{aligned}
& t_{1 i q o}=\text { thickness of flowing mixture }(\mathrm{m}) \\
& \begin{array}{ll}
\Delta r_{1 i q k}= & \text { in situ thickness of annulus of liquid } Z r-U-0 \text { in axial } \\
\text { zone } k(m) .
\end{array}
\end{aligned}
$$

The length of the flowing mixture is calculated by the equation 
$L=S_{0} /\left[\left(r_{o k_{f}}+t_{1 i q o}\right)^{2}-r_{o k_{f}}^{2}\right] \pi$

where

$\mathrm{L}=$ 7ength of film of $2 r-U-0(m)$
$r_{\text {ok }}=$ outer radius of cladding in axial zone $k_{f}(m)$.

\subsection{Fission Product Release Models}

The models described in this section calculate the rate of fission product release from intact fuel rods and rods that have experienced fuel liquefaction or fragmentation. The models also calculate the enthalpy of the released fission products. This description has been divided into three subsections. The first subsection describes the current fission product release models for intact rods. The second, third, and fourth subsections describe the fission product release during the liquefaction or fragmentation of $\mathrm{UO}_{2}$ and the enthalpy of released fission products.

\subsubsection{Release Model for Intact Fuel}

SCDAP/RELAP5 models the release of fission products from the fuel to the gap using a combination of a theoretical model developed by Rest et a1., 3-24 to treat the release of xenon, krypton, cesium, iodine, and tellurium from solid fuel, and empirical models to treat other fission products.

The theoretical model is a simplified version of the FASTGRASS code that has been used for predicting the behavior of fission gas in $\mathrm{UO}_{2}$-based

a. The theoretical model is based upon PARAGRASS Version 50531, with the cesium lodide chemistry model deactivated because of an error in that version of PARAGRASS that resulted in an error in the iodine release. 
fuels during steady-state and transient conditions. $3-24,25,26,27,28$ Fission products released from the fuel are assumed to reach the fuel surface by successively migrating from the grains to grain faces and then to the grain edges, where the fission products are released through a network of interconnected tunnels of fission-gas-induced and fabricated porosity. This model treats the production of gas from fissioning nuclei. bubble nucleation and re-solution, bubble migration, bubble coalescence, gas bubble and channel formation on grain faces, interlinked porosity on grain edges, grain boundary microcracking, and grain growth and grain boundary sweeping.

The specific models used for xenon, krypton, cesium, lodine, and tellurium are described by Rest. 3-24,25,26,29 For completeness, an example of the equations used to describe the diffusion of gases to grain boundaries is described below. The concentration of atoms, $C_{g}$, within the spherical grain satisfies the equation

$\frac{\partial C_{g}}{\partial t}=\frac{1}{r^{2}} \frac{\partial}{\partial r}\left(D_{g} r^{2} \frac{\partial C g}{\partial r}\right)+K_{g}$

where

$$
\begin{aligned}
& \mathbf{D}_{\mathbf{g}}=\text { atom diffusion coefficient } \\
& \mathbf{K}_{\mathbf{g}}=\text { the rate of generation of atoms. }
\end{aligned}
$$

In general, Equation (3-131) is solved with the boundary conditions

$$
\begin{aligned}
& c_{g}=0 \text { at } t=0 \text { for } 0 \leq r \leq d_{g} / 2 \\
& c_{g}=0 \text { at } r=d_{g} / 2 \text { for } t_{0} \leq t \leq t_{0}+h
\end{aligned}
$$$$
\frac{\partial C_{g}}{\partial r}=0 \text { at } r=0 \text { for } t_{0} \leq t \leq t_{0}+h
$$ 
where

$$
\begin{aligned}
d_{g} & =g r a i n d i a m e t e r \\
h & =\text { time interval between times } t_{0} \text { and } t_{0}+h .
\end{aligned}
$$

The diffusive flow of the fission gas bubbles to the grain boundaries is also governed by Equation (3-131). For this case, it is assumed that gas bubbles are not being nucleated and are essentially noninteracting.

The coupling of the diffusive flow problem to other processes affecting fission gas behavior (e.g., gas atom re-solution, gas atom trapping by gas bubbles) is accomplished by solving equations of the form

$$
\frac{d Y_{i}}{d t}=-a_{i} Y_{i}^{2}-b_{1} Y_{i}+c_{i}
$$

where

$$
\begin{aligned}
& Y_{1} \quad=\quad \text { density of intragranular gas atoms (bubbles) } \\
& a_{i} y_{i}^{2} \quad=\quad \text { rate at which gas atoms (bubbles) are lost owing to } \\
& \text { gas bubble nucleation (coalescence) } \\
& b_{1} Y_{i}=\text { rate at which gas atoms (bubbles) are lost owing to } \\
& \text { diffusive flow and diffusion into gas bubbles (gas } \\
& \text { atom re-solution) } \\
& C_{i}=\text { rate at which gas atoms are gained owing to gas atom } \\
& \text { re-solution and fission of uranium nuclei (i.e., the } \\
& \text { rate gas bubbles are gained owing to bubble } \\
& \text { nucleation and diffusion of gas atoms into bubbles). }
\end{aligned}
$$

A more detalled description of the above variables is also given in Table 3-14. 
TABLE 3-14. DEFINITION OF VARIABLES IN EQUATION (3-140)

\begin{tabular}{|c|c|c|c|}
\hline $\mathbf{Y}_{\mathbf{i}}$ & $a_{1} y_{i}^{2}$ & $b_{1} Y_{1}$ & $c_{1}$ \\
\hline $\begin{array}{l}\text { Density of intragranular gas } \\
\text { atoms and VFPs }\end{array}$ & $\begin{array}{l}\text { Rate at which gas atoms are lost } \\
\text { owing to gas bubble nucleation }\end{array}$ & $\begin{array}{l}\text { Rate at which atoms and VFPs are } \\
\text { lost owing to diffusive flow to } \\
\text { the grain boundaries, grain } \\
\text { boundary sweeping. diffusion } \\
\text { into gas bubbles, and chemical } \\
\text { reactions }\end{array}$ & $\begin{array}{l}\text { Rate at which atoms and VFPs } \\
\text { gained owing to atom resolution, } \\
\text { fisston of uranium nuclel, and } \\
\text { chemical reactions }\end{array}$ \\
\hline $\begin{array}{l}\text { Density of intragranular gas } \\
\text { bubbles }\end{array}$ & $\begin{array}{l}\text { Rate at which gas bubbles are } \\
\text { lost owing to bubble coalescence }\end{array}$ & $\begin{array}{l}\text { Rate at which gas bubbles are } \\
\text { lost owing to diffusive flow to } \\
\text { the grain boundarles, grain } \\
\text { boundary sweeping, and gas atom } \\
\text { re-solution }\end{array}$ & $\begin{array}{l}\text { Rate at which gas bubbles are } \\
\text { gained owing to bubble } \\
\text { nucleation and diffusion of gas } \\
\text { atoms into bubbies }\end{array}$ \\
\hline $\begin{array}{l}\text { Density of grain-face gas bubbles } \\
\text { and VFPs }\end{array}$ & $\begin{array}{l}\text { Rate at which gas bubbles are } \\
\text { lost owing to bubble coalescence }\end{array}$ & $\begin{array}{l}\text { Rate at which gas bubbles and } \\
\text { VFPs are lost owing to diffusion } \\
\text { to grain edges, formation of } \\
\text { grain channels, microcracking, } \\
\text { and chemical reactions }\end{array}$ & $\begin{array}{l}\text { Rate at which gas bubbles and } \\
\text { VFPs are gained owing to } \\
\text { intragranular migration to grain } \\
\text { faces, and chemical reactions }\end{array}$ \\
\hline $\begin{array}{l}\text { Density of grain-edge gas bubbles } \\
\text { and VFPs }\end{array}$ & $\begin{array}{l}\text { Rate at which gas bubbles are } \\
\text { lost owing to bubble coalescence }\end{array}$ & $\begin{array}{l}\text { Rate at which gas bubbles and } \\
\text { VFPs are lost owing to long-range } \\
\text { grain-edge bubble interconnection, } \\
\text { microcracking, and chemical } \\
\text { reactions }\end{array}$ & $\begin{array}{l}\text { Rate at which gas bubbles and } \\
\text { VFPs are gained owing to } \\
\text { migration of grain-face fission } \\
\text { products to grain edges and } \\
\text { chemical reactions }\end{array}$ \\
\hline
\end{tabular}

Density of intragranular gas 
Equation (3-131) is discretized in time using backward Euler approximation to give the following equation:

$\frac{1}{Y^{2}}=\frac{\partial}{\partial Y}\left(D g Y^{2} \frac{\partial}{\partial Y}(g)-\frac{C g}{h}+\frac{C g(t-h)}{h}+K g=0\right.$.

By applying a variational principle and setting the first variation to zero, we obtain

$\int_{0}^{1 / 2 \mathrm{Dg}} 4 \pi\left[0.5 \mathrm{Dg}\left(\frac{\left.\partial \mathrm{Cg}_{\mathrm{L}}\right)^{2}}{\partial Y}+\frac{\mathrm{Cg}}{2 h}-\frac{\mathrm{Cg}(t-h)}{h}+\mathrm{Kg} \mathrm{Cg}\right] Y^{2} \mathrm{dY}=0\right.$

The spherical grain is then split into two concentric regions of approximately equal volume. In each region, the gas concentration is represented by a quadratic function. In the central region 1 , the concentration function is constrained to have $\partial \mathrm{Cg} / \partial Y=0$ at $y=0$. In the outer region II, the concentration function is constrained to have a value of $\mathrm{Cg}=0$ at $\mathrm{Y}=\mathrm{dg} / 2$. The two functions are also constrained to be continuous at the common boundary of the two regions. This leaves three free parameters, $c_{1}, c_{2}$, and $c_{3}$. These are chosen to be gas -atom concentrations at positions corresponding to the midpoint radius of Region I, the boundary between the regions, and the midpoint radius of Region II, respectively.

$$
\begin{aligned}
& \text { Hence, for Region } I \text {, } \\
& C g=C_{1}\left(0.64-a^{2}\right) / 0.48+C_{2}\left(a^{2}-0.167 / 0.48\right) \\
& \text { and for Region } 11 \\
& C g=5 C_{2}\left(10 a^{2}-19 a+9\right)+10 C_{3}\left(18 a-10 a^{2}-8\right)
\end{aligned}
$$


where

$\mathbf{a}=2 \mathrm{Y} / \mathrm{dg}$.

Equations (3-138) and (3-139) are substituted for $\mathrm{Cg}$ in Equation (3-137) and an extremum is found by differentiating with respect to $C_{1}, C_{2}$, and $C_{3}$ in turn. A set of three linear equations is thus obtained. The solution of this set of equations expressed $c_{j}$ in terms of $D g$, dg, and $q_{j}$. The $q_{j} s$, $\mathrm{j}=1,2, . .13$, are integrals which, when directly evaluated, are $q_{1}=$ $4.552, . . \mathrm{q}_{13}=0.1083$.

The flux of gas atoms to the boundary (in units of atoms $/ \mathrm{cm}^{3} \cdot \mathrm{s}$ ) is given by

$J=-\left.6(D g / d g) \frac{\partial C g}{\partial r}\right|_{r=d g / 2}$

This term $\mathrm{J}$ is one of the terms in the expression for the rate at which gas atoms are lost, given by the term $b_{i} y_{i}$ in Equation (3-135). It is determined by Wood et a $7^{3-30}$ that the best expression for the average concentration within the grains, $\operatorname{Cg}(\mathrm{av}$.$) , is given by$

$\operatorname{Cg}($ av. $)=0.2876 C_{1}+0.2176 C_{2}+0.4216 C_{3}$.

At the end of an iteration, the concentrations $c_{1}, c_{2}$, and $c_{3}$ in Equation (3-140) are scaled by imposing the condition that the average concentration equals to that calculated by use of Equation (3-135), 1.e..

$\operatorname{Cg}(\mathrm{av})=.Y_{i}$

The modifled $C_{1}, C_{2}$, and $C_{3}$ then become the initial values of these concentrations (i.e., $c_{1}(t-h), c_{2}(t-h), c_{3}(t-h)$ ) to be used for the next iteration. The diffusion of gas bubbles is treated analogousiy to that for fission gas atoms, but with $\mathrm{Kg}=0$ in Equation (3-136). 
The elemental fission yields of the fission gases are xenon $(0.2635)$, krypton (0.0465), cesium (0.1507), lodine (0.011), and tellurium (0.02519). These quantities are in units of atoms per fission event. Multiplication by fission rate per unit volume gives the fission gas generation rate in units of atoms $/ \mathrm{s} / \mathrm{m}^{3}$. Because very little fission gas is released during steady-state calculations, the calculation of initial inventories is dominated by the fission gas generation rate.

This version of the PARAGRASS model differs from the older versions in the following significant ways:

o Two options for grain growth are included:

a. An empirical law is used to calculate grain growth; grain boundary sweeping of $f$ ission products is proportional to the volume swept by the growing grains;

b. A theoretical grain-growth model is fully coupled to the grain boundary sweeping model.

- A model for the effect of $\mathrm{UO}_{2}$ oxidation is included, using a grain growth activation energy approprlate for stoichiometric $\mathrm{UO}_{2}$.

o The fission product tellurium is included with lodine, cesium, and cesium iodide. The effects of the oxidation state of the cladding on tellurlum release are included (i.e., cladding not completely oxidized and cladding oxidized more than $90 \%$ ). When the cladding is not more than $90 \%$ oxidized, onty $1 / 40$ of the tellurium release is allowed to come out. 0therwise, all of the tellurium release comes out.

- Theoretical models to calculate the instantaneous rate of change of the bubble radius have been included. Previous verstons of PARAGRASS handled the nonequilibrium growth of gas bubbles by 
modifying the bubble coalescence rates by an appropriate factor. Equilibrium values of the bubble radius were used in the calculation of various material properties, e.g., the calculation of bubble diffusivities.

- The model for the behavior of gas bubbles on grain surfaces has been improved. In the previous version, the effect of external stress on intragranular bubble growth was inadvertently decoupled.

- A more efficient method for the time integration of Equation $(3-135)$ is used.

Once the fission products are released to the gap by the PARAGRASS model, another model, described below, determines the release of fission products from the gap to the coolant. Noble gases are released from the gap instantaneously upon cladding breach. Additional noble gas release from the fuel following breach is then set equal to the PARAGRASS computed values. Cesium and lodine are treated differently. The cesium and iodine are accumulated in the gap until the cladding is breached. Subsequent release from the fuel rod gap upon cladding failure is based on the mode $1^{3-31}$ that includes a burst and diffusion release component. The burst component describes the release when the cladding initially fails and depressurizes. The diffusion component describes the timed release of the remaining cesium and iodine. The model assumes the diffusion component to be independent of the burst component.

The burst component for both cesium and lodine is given by ${ }^{3-31}$

$M_{B}=\alpha V_{B}(M / A)^{a} \exp (-C / T) M_{B}$

where

$$
M_{B}=\text { mass of cesium or lodine released during the burst }(\mathrm{kg})
$$




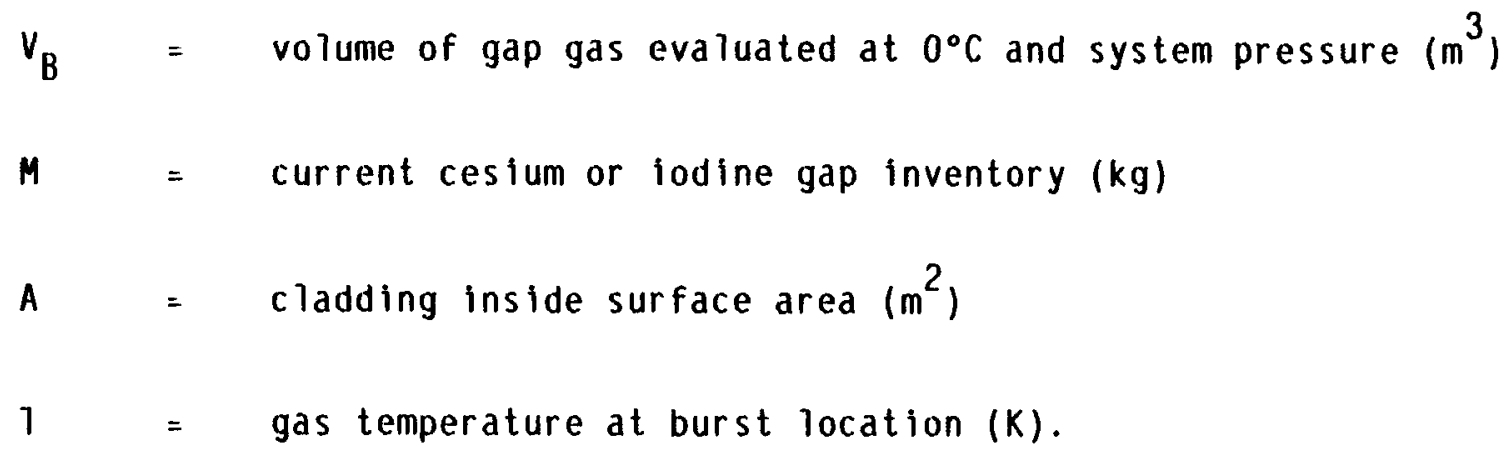

The parameters $\alpha, a$, and $C$ in Equation (3-136) are adjustable constants that were evaluated from the data. ${ }^{3-31}$ Values of the parameters are given in Table 3-15 for both cesium and iodine.

The parameter $V_{B}$ in Equation $(3-143)$ is determined by assuming that the thermal equation of state is valid. Therefore, the gas volume is given by

$$
v_{B}=\frac{T_{v}}{P} \sum_{i} M_{i} R_{i}
$$

where

$$
\begin{aligned}
T_{v} & =273 \mathrm{~K} \\
P & =\text { system pressure }\left(\mathrm{N} / \mathrm{m}^{2}\right) \\
R^{i} & =\text { gas constant for species } i(\mathrm{~J} / \mathrm{kg} \cdot \mathrm{K}) \\
M_{i} & =\text { gap inventory of species } i(\mathrm{~kg}) .
\end{aligned}
$$

Equation $(3-136)$ is stated to be valid $3-31$ for the temperature range of 970 to $1170 \mathrm{~K}$ but is currently used for all burst temperatures encountered for which the fuel rod is not severely disrupted. 
TABLE 3-15. ADJUSTABLE CONSTANTS FOR CESIUM AND IODINE RELEASE CORRELATIONS

\begin{tabular}{|c|c|c|c|}
\hline & Parameter & Cesium & Iodine \\
\hline & $\left(\mathrm{kg} / \mathrm{m}^{3}\right)\left(\mathrm{kg} / \mathrm{m}^{2}\right)^{-a}$ & 553.13 & 25.834 \\
\hline a & - & 0.8 & 0.8 \\
\hline c & $\left(k^{-1}\right)$ & $7.42 \times 10^{3}$ & $3.77 \times 10^{3}$ \\
\hline$\delta$ & $(\mathrm{kg} \mathrm{Pa} / \mathrm{ms})\left(\mathrm{kg} / \mathrm{m}^{2}\right)^{-\mathrm{a}}$ & $8.3647 \times 10^{7}$ & $5.371 \times 10^{6}$ \\
\hline & $(k-1)$ & $1.98 \times 10^{4}$ & $1.48 \times 10^{4}$ \\
\hline
\end{tabular}


The diffusion component is given in the form of a release over a time step for which the parameters are constant at beginning of time step values:

$$
M_{d}=M\left[1-\exp \left(D_{R} \Delta t / M\right)\right]
$$

where

$$
\begin{aligned}
& M_{d}=\begin{array}{l}
\text { mass of cesium or iodine released by diffusion during the } \\
\text { time step }(\mathrm{kg})
\end{array} \\
& D_{R}=\text { rate of release by diffusion at start of time step }(\mathrm{kg} / \mathrm{s}) \\
& \Delta t \quad=\text { time step }(\mathrm{s}) .
\end{aligned}
$$

The parameter $D_{R}$ is given by

$$
D_{R}=\delta(W / P)(M / A)^{a} \exp (-\gamma / T)
$$

where $W$ is the effective radial gap width $(m)$. The parameters $\delta$ and $Y$ were evaluated similarly to the correlating parameters in Equation (3-143) and are also given in Table 3-15 for both cesium and lodine.

The parameter $W$ is the only additional required input. $W$ is termed the effective gap width because it accounts for both the rupture opening size and any ballooning along the length of the fuel rod. When the fue rod disrupts, the parameter $W$ for the disrupted region in effect becomes large; therefore, the rate of release becomes large to the point that all of the cesium or lodine is released in any single time step. However, the authors of Reference 3-29 state that "the diffusion release component over relatively brief time periods (on the order of $10 \mathrm{~min}$ at $1200^{\circ} \mathrm{C}$ for example) involves only the fission product material that is located within a few centimeters of the point of rupture." Therefore, the parameter $W$ for the nondisrupted region of the fuel rod is not so large that all of the cesium or lodine is released in a single time step. 
The diffusion component as modeled by Equations (3-145) and (3-146) does not make use of a fission product concentration gradient or a length over which the cesium or iodine must diffuse in order to escape (see first assumption). Therefore, the diffusion component may not be valid for situations such as disruptions that were not included in the data base. However, the diffusion component is used for all rod failure situations until the cladding is liquefied or fragmented, after which all of the remaining gap gases are released instantiy.

The correlations for the release of cesium and iodine represented by Equations (3-143) through (3-146) account for the release of the individual elements rather than the possible chemical forms of cesium and lodine. This model assumes that cesium and iodine will combine to form cesium iodide, with any leftover cesium reacting with water on release from the gap to form cesium hydroxide or any leftover iodine being released as $\mathrm{I}_{2}$. This assumption is based on fission product chemical states. 3-6

The interaction of cesium with water releases one-half mole of hydrogen gas per mole of cesium hydroxide. This is accounted for in the model by adding the additional hydrogen release to the total release of noncondensible gases. This reaction also releases energy that is accounted for in the enthaipy of the released gap gases.

Release of less-volatile fission products is based on the CORSOR-M mode 7 in NUREG/CR-4173. ${ }^{3-32}$ It assumes a first-order release rate from each node for each species such that

$F P=F P \cdot(1-\exp (-F R C \cdot D T I M E)]$

where

FFP = mass of the species present at the node at the start of the time step

FRC = fractional release rate coefficient. 
The value of FRC is given by an Arrhenius type equation of the form:

$F R C=K O(I) \cdot \operatorname{EXP}[-Q(I) / 1.987 E-3 \cdot T)]$

where

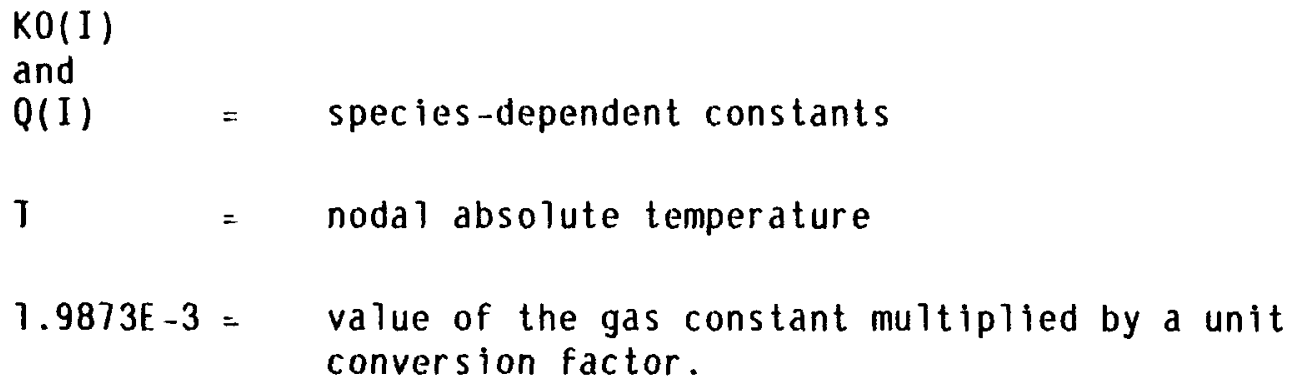

The values of the constants $K O$ and $Q$ are given in Table 3-16.

The tin release rate is calculated by the equation

$d m / d t=K_{w}\left[C_{e q}-C\right]$

where

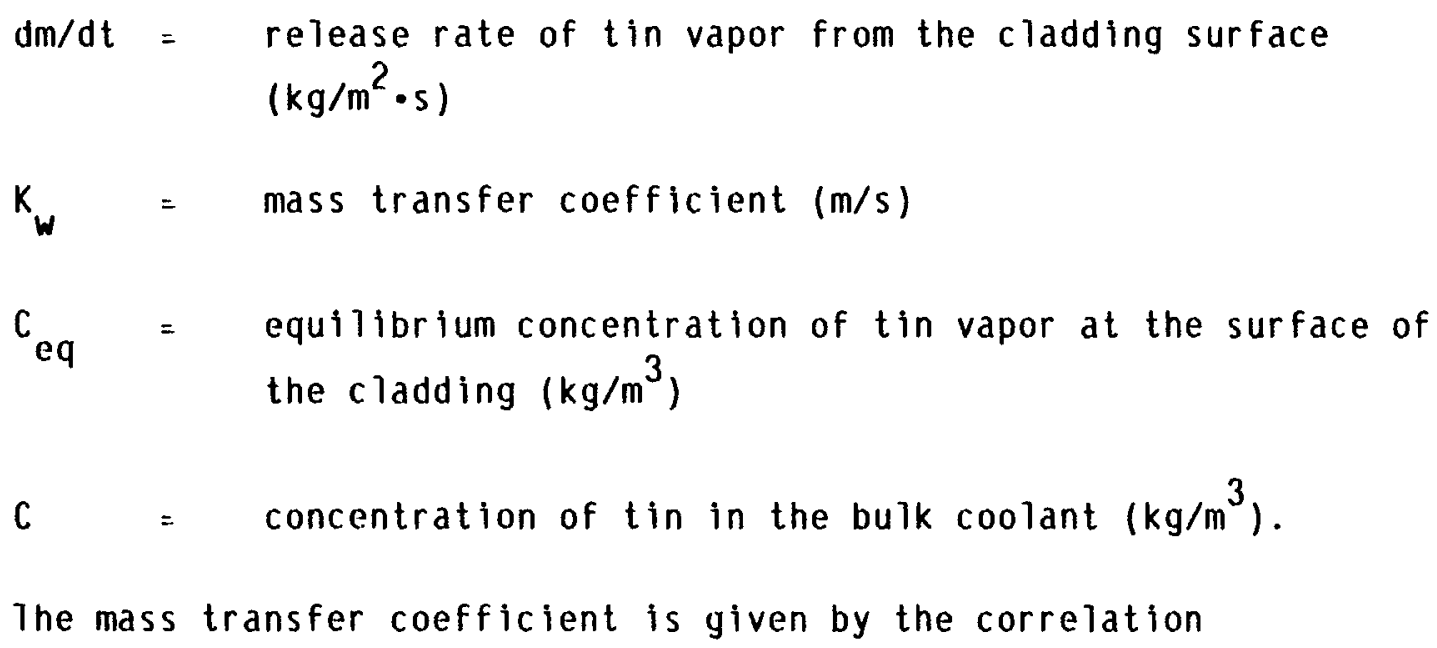

where 
TABLE 3-16. CONSTANTS KO AND Q IN RELEASE RATE COEFFICIENTS TAKEN FROM NUREG/CR -4173

\begin{tabular}{|c|c|c|}
\hline Species & $\begin{array}{c}K 0 \\
\left(\min ^{-1}\right)\end{array}$ & $\begin{array}{c}0 \\
(\mathrm{kca}) / \mathrm{mol})\end{array}$ \\
\hline $\mathrm{UO}_{2}$ & $1.46 \mathrm{E7}$ & 143.1 \\
\hline $\mathrm{Zr}$ & $2.67 \mathrm{E} 8$ & 188.2 \\
\hline Sn (clad) & 5.95 E 3 & 70.8 \\
\hline $\mathrm{Fe}$ & $2.94 \mathrm{E} 4$ & 87.0 \\
\hline $\mathbf{R u}$ & $1.62 \mathrm{E} 6$ & 152.8 \\
\hline $\operatorname{Zr}(\mathrm{clad})$ & $8.55 \mathrm{E} 4$ & 139.5 \\
\hline $\mathbf{B a}$ & $2.95 \mathrm{ES}$ & 100.2 \\
\hline $\mathrm{Sr}$ & $4.40 \mathrm{E} 5$ & 117.0 \\
\hline $\mathrm{Te}$ & $2.00 \mathrm{ES}$ & 63.8 \\
\hline Ag & $7.90 \mathrm{E} 3$ & 67.4 \\
\hline $\mathrm{Cs}^{*}$ & $2.00 \mathrm{ES}$ & 63.8 \\
\hline$I *$ & $2.00 \mathrm{ES}$ & 63.8 \\
\hline
\end{tabular}


Re $=$ Reynold's number of bulk coolant

$=\frac{\text { (fluid density)(fluid velocity)(equivalent diameter) }}{\text { (fluid viscosity) }}$ (unitless)

$S_{C}=$ Schmidt number

$=\frac{\text { (fluid viscosity) }}{\text { (fluid density)(diffusivity of tin in bulk coolant }}$ (unitless)

$D_{r}=$ diffusivity of $t$ in in bulk coolant $\left(m^{2} / s\right)$

$D_{e}=$ equivalent diameter of flow channel $(\mathrm{m})$.

The variable $D_{r}$ is calculated by the equation

$D_{r}=9.8 \times 10^{-5}\left(T_{B}\right) 1.75 / p$

where

$$
\begin{gathered}
T_{B}=\text { temperature of bulk coolant }(K) \\
P=\text { pressure of bulk coolant }(\mathrm{Pa}) . \\
\text { The variable } C_{\text {eq }} \text { is calculated by the equation } \\
C_{\text {eq }}=118.69 P_{s n} /\left(8.31 \times 10^{3} T_{z r}+1.63 \times 10^{-2} \mathrm{P}\right) \\
\text { where } \\
P_{s n}=\text { equilibrium partial pressure of } t \text { in }(P a) \\
T_{z r}=\text { cladding surface temperature }(K) .
\end{gathered}
$$


The variable $P_{S n}$ is calculated by the equation

$P_{s n}=\exp \left\{\frac{-2.847 \times 10^{4}}{T_{z r}}+4.548 \ln \left(T_{z r}\right)-14.31\right\} f_{s n}$

where $f_{s n}$ is the concentration of $t$ in in the cladding (atomic fraction).

The variable $f_{\text {sn }}$ is calculated by the equation

$$
\begin{aligned}
f_{s n} & =\frac{\left(M_{s n} / A_{s n}\right)}{\left(M_{s n} / A_{s n}\right)+\left(M_{z r} / A_{z r}\right)} \\
& =\frac{M_{s n}}{M_{s n}+\left(A_{s n} / A_{z r}\right) \rho_{z r}\left(h_{z r}-M_{s n} / \rho_{s n}\right)}
\end{aligned}
$$

where

$$
\begin{aligned}
& M_{\mathrm{sn}}=\begin{array}{l}
\text { mass of tin remaining in cladding per unit surface area } \\
\left(\mathrm{kg} / \mathrm{m}^{2}\right)
\end{array} \\
& M_{\mathrm{zr}}=\text { mass of unoxidized cladding per unit surface area }\left(\mathrm{kg} / \mathrm{m}^{2}\right) \\
& A_{\mathrm{sn}}=\text { atomic weight of tin }(118.69 \mathrm{~kg} / \mathrm{kg} \cdot \mathrm{mole}) \\
& A_{\mathrm{zr}}=\text { atomic weight of cladding }(\text { zirconium })(91.22 \mathrm{~kg} / \mathrm{kg} \cdot \mathrm{mole}) \\
& \rho_{\mathrm{zr}}=\text { density of zirconium }\left(\mathrm{kg} / \mathrm{m}^{3}\right) \\
& \rho_{\mathrm{sn}}=\text { density of tin }\left(\mathrm{kg} / \mathrm{m}^{3}\right) \\
& h_{\mathrm{zr}}=\text { thickness of unoxidized cladding }(\mathrm{m}) .
\end{aligned}
$$

The control rod release is calculated in the code based on the following method, described also in NUREG/CR -4173. ${ }^{3-32}$ 
At $1673 \mathrm{~K}$, the control rods are assumed to fail; $5 \%$ of the inventory of silver and $50 \%$ of the cadmium are released from the nodes reaching this temperature.

From 1673 to $2573 \mathrm{~K}$, the cumulative fraction of the inventory released is calculated according to:

Silver: $\quad$ FREL $=0.0005 *(T-1673)+0.05$

Cadmium: FREL $=0.00033^{*}(T-1673)+0.50$.

From 2573 to $3073 \mathrm{~K}$, the cumulative fractions of the inventory released are calculated according to:

Silver: $\quad$ FREL $=0.001 *(T-2573)+0.5$

Cadmium: FREL $=0.0004 *(T-2573)+0.8$

which results in complete release at $3073 \mathrm{~K}$.

The cumulative fraction of the inventory released is then scaled by 0.1 for silver and 0.7 for cadmium to take into account the relocation of silver and cadmium.

\subsubsection{Release During $\mathrm{UO}_{2}$ Liquefaction and Fragmentation}

The effect of $\mathrm{UO}_{2}$ liquefaction is modeled by allowing xenon, krypton, cesium, and lodine to be instantaneously released to the gap from any fuel that is liquefied as predicted by the LIQSOL mode1. During the fragmentation of the $\mathrm{U}_{2}$, the fission products accumulated upon grain boundaries, as predicted by the theoretical model, are released instantaneously. Subsequent release within a rubble bed is controlled onty by the intragrain processes. The release of other less-volatile species is not affected by liquefaction or fragmentation processes. 


\subsubsection{Enthalpy of Released Gases}

The noncondensible gases released from the gap are hydrogen, helium, krypton, and xenon. Iodine is also assumed to be noncondensible in this model, even though it is slightly soluble in water at high temperatures. The specific heat of the noble gases (helium, xenon, krypton) is nearly constant with temperature. Therefore, the enthalpy of a particular species can be calculated as a function of specific heat and temperature.

The specific heat of hydrogen is a function of temperature, so the enthalpy must be determined by

$h=h_{0}^{\prime}+\int_{T_{0}}^{T} c_{p}(T) d T$

where

$$
\begin{aligned}
h & =\text { enthaipy of gas }(\mathrm{J} / \mathrm{kg}) \\
c_{p} & =\text { specific heat of gas }(\mathrm{J} / \mathrm{kg} \cdot \mathrm{K}) \\
T & =\text { temperature of gas }(\mathrm{K}) \\
h_{0}^{\prime} & =\text { enthaipy at reference temperature } T_{0}(\mathrm{~J} / \mathrm{kg}) \\
T_{0} & =\text { reference temperature }(K) .
\end{aligned}
$$

The specific heat of hydrogen is expressed as a function of temperature ${ }^{3-33}$ as

$$
c_{p}=\left(a+b T+c T^{2}+d T^{3}+e T^{4}\right) R
$$


Inserting Equation (3-149) into Equation (3-148) and integrating yields

$$
\begin{aligned}
h & =h_{0}^{1}+R a\left(T-T_{0}\right)+\frac{b}{2}\left(T^{2}-T_{0}^{2}\right)+\frac{c}{3}\left(T^{3}-T_{0}^{3}\right)+\frac{d}{4}\left(T^{4}-T_{0}^{4}\right) \frac{e}{5}\left(T^{5}-T_{0}^{5}\right) \\
& =h_{0}+R\left(a T+\frac{b}{2} T^{3}+\frac{c}{3} T^{3}+\frac{d}{4} T^{4}+\frac{e}{5} T^{5}\right) .
\end{aligned}
$$

Reference 3-32 supplies the constants a through e in Equation (3-156) for the temperature range of 300 to $5000 \mathrm{~K}$, with a reference temperature of $300 \mathrm{~K}$. However, the SCDAP/RELAP5 hydrodynamics mode 1 requires that the enthalpy be based on a reference temperature of $0 \mathrm{~K}$. In order to account for this shift in reference temperature, the constant $h$ was adjusted so that the enthalpy calculated with Equation (3-157) coincided with hydrogen enthalpy tables based on a reference temperature of $0 \mathrm{~K}$. The constants in Equation (3-157) (a-e, R,h) are given in Table 3-17. (The thermodynamic properties of all the gap gases are also given in Table 3-17). Figure 3-16 shows a comparison between enthalpy calculated with Equation (3-157) and the data from Reference 3-33.

The enthalpy of iodine is assumed to be

$h\left(I_{2}\right)=c_{p} T+h_{v}+h_{m}$

where

$$
\begin{aligned}
& h_{v}=\text { heat of vaporization }(\mathrm{J} / \mathrm{kg}) \\
& h_{m}=\text { heat of fusion }(\mathrm{J} / \mathrm{kg}) .
\end{aligned}
$$

In order to determine the enthalpy of a mixture of noncondensible gases, the enthalpies of the individual species are combined in the following manner: 
TABLE 3-17. THERMODYNAMIC PROPERTIES OF GAP GASES

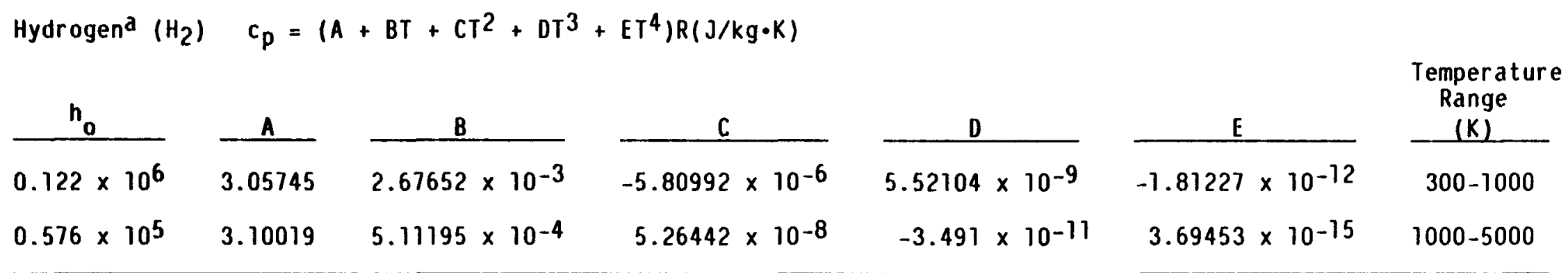

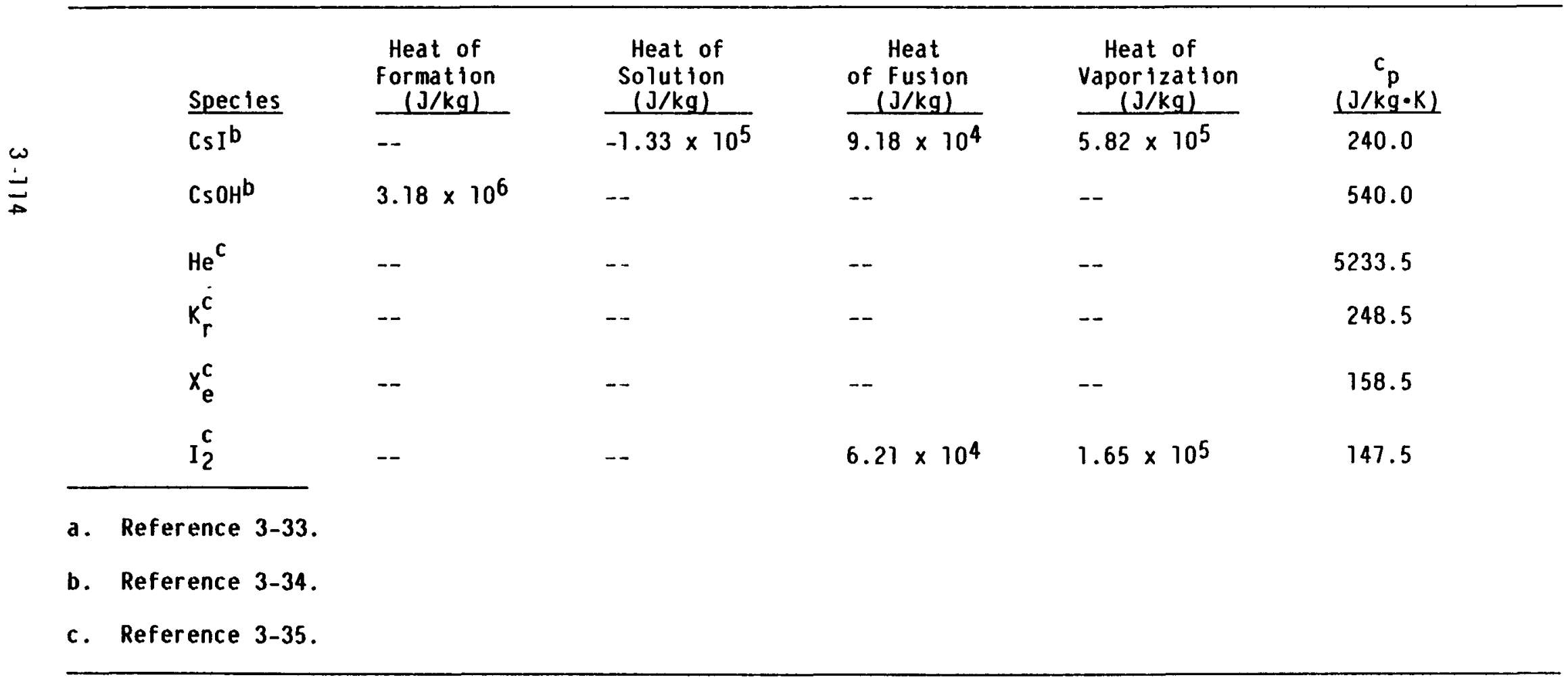




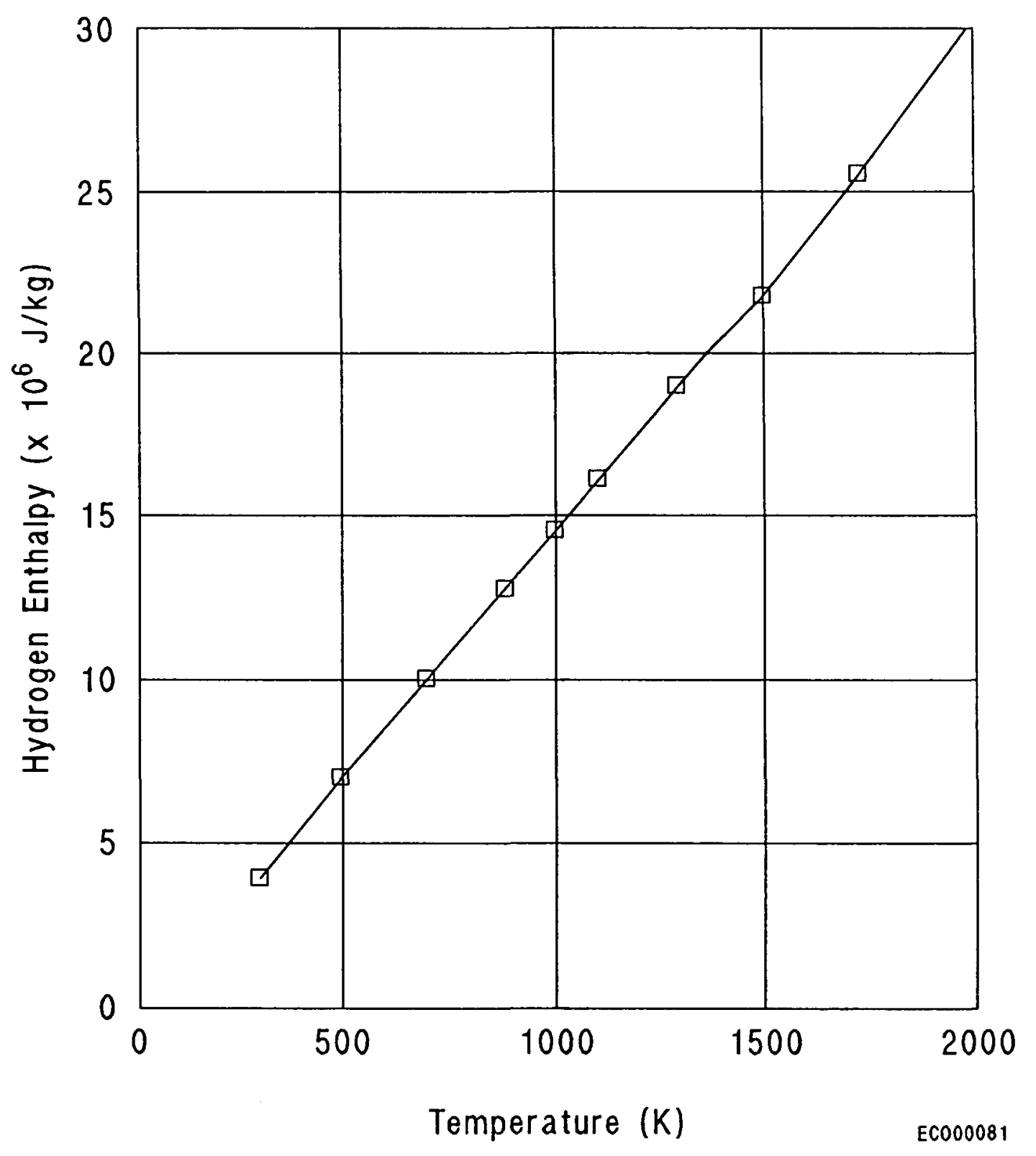

Figure 3-16. Hydrogen enthalpy calculated using Equation (3-157). 
$\bar{h}=\frac{1}{M_{T}} \sum_{i} h_{i} M_{i}$

where

$$
\begin{aligned}
& \overline{\mathrm{h}} \quad=\text { overall noncondensible gas enthalpy }(\mathrm{J} / \mathrm{kg}) \\
& M_{T}=\text { total mass of noncondensible gases }(\mathrm{kg}) \\
& h_{i}=\text { enthalpy of gas species } i(J / k g) \\
& M_{1}=\text { mass of gas species } i(\mathrm{~J} / \mathrm{kg}) \text {. }
\end{aligned}
$$

The enthalpy of cesium hydroxide is assumed to be the heat of formation in water, since the reaction occurs when the cesium is released and is a large energy source compared with the energy carried into the reaction by the cesium compound or water. All of the energy from this reaction is assumed to be imparted to cesium hydroxide rather than hydrogen gas.

The enthalpy of cesium lodide is assumed to be

$h(C s I)=c_{p} T+h_{v}+h_{s}+h_{m}$

where

$$
\begin{aligned}
& h_{v}=\text { heat of vaporization }(\mathrm{J} / \mathrm{kg}) \\
& h_{s}=\text { heat of solution }(\mathrm{J} / \mathrm{kg}) \\
& h_{m}=\text { heat of fusion }(\mathrm{J} / \mathrm{kg}) .
\end{aligned}
$$

The heat of formation is not included because the reaction is thought to occur within the fuel matrix. 
The enthalpy of a mixture of soluble gases is determined as in Equation (3-159).

\subsection{Control Rod and Core Structure Models}

\subsubsection{Control Rod Models}

Control rod temperatures are computed using the same heat conduction model as the fuel rods. User-specified nuclear heating, chemical heating due to oxidation of the zircaloy guide tube and stainless steel cladding, and convective and radiative heat transfer from the coolant and adjacent fuel rods are considered. The melting and relocation of control rod matertals are described in the following manner. If the stainless steel is below its melting temperature, no relocation of molten Ag-In-Cd occurs. If the guide tube melts, or is breached, molten absorber material moves through the breach in the zircaloy guide tube and moves as a film on the outside of the guide tube. Unlike the flow of molten $\mathrm{Zr}-\mathrm{U}-0$ for fuel rods, the momentum and energy equations are not solved to describe the freezing of the molten $\mathrm{Ag}$-In-Cd; rather the material freezes when it reaches a lower elevation where the guide tube temperature is $200 \mathrm{~K}$ less than the solid temperatures of Ag-In-Cd. For subsequent heatup and melting of stainless steel and zircaloy, the molten material relocates internally downward within the oxidized $\mathrm{ZrO}_{2}$ on the guide tube, filling up the voids formed by the allocation of molten Ag-In-Cd. The molten mixture of stainless steel and zircaloy will remain contained within the $\mathrm{ZrO}_{2}$ shell until the $\mathrm{ZrO}_{2}$ is either melted, allowing the molten mixture to flow downward in the flow channel until it freezes, or shattered upon reflood.

\subsubsection{Flow Shroud Models}

The structures internal to the core other than fuel and control rods are modeled using the basic heat conduction equation. Heat generation can be user-specified and oxidation related. The structures can be defined by multiple layers of materials, with the oxidation and relocation of exterior layers due to melting considered. Zircaloy layers are oxidized using the 
same kinetics as described for fuel rods. The molten zircaloy relocates downward to a region where the structural surface temperature is $200 \mathrm{~K}$ less than the solidus temperature of zircaloy. Structures with exterior layers or composed entirely of nonzircaloy materials can also be modeled; however. oxidation rate equations must be user-specified and no material relocation or loss of geometry can be considered. Both melting and nonmelting models can be used for the structures outside the core as we11. The same material limitations apply.

\subsubsection{Spacer Grid Model}

The spacer grid model consists of a simple removal process whereby a spacer grid is removed as an obstruction when the grid temperature reaches or exceeds the melt temperature of the grid material. The spacer grid is only modeled as an obstruction for debris regions or flow of liquefied material.

Spacer grids are constructed from either zirconium or Inconel. The melt temperature of zirconium is approximately $2150 \mathrm{~K}$, while the meit temperature of Inconel is approximately $1670 \mathrm{~K}$.

This model assumes no oxidation of the spacer grid and no chemical interaction between Inconel and the zircaloy fuel rod cladding.

The temperature of the spacer grid is calculated by simply equating the spacer grid temperature with the outside cladding temperature of the axial zone where the spacer grid exists. If the spacer location coincides with the boundary between two component zones, then the spacer grid temperature is the average of the two adjacent zone temperatures.

\subsubsection{Boron Carbide Control Rod Model}

The existence of significant amounts of control rod material in a BWR core might have an important influence on the overall behavior of core degradation and fission product transport during a severe accident event. 
The stainless steel cladding/sheath, and the boron carbide $\left(B_{4} C\right)$ control rod absorber can be oxidized in the high-temperature steam environment. The exothermic oxidation can raise the core temperature, thus increasing the core heatup rate. The combustible gases, such as $\mathrm{H}_{2} \mathrm{CO}$, and $\mathrm{CH}_{4}$, generated through control rod oxidation might pose an additional threat to the containment integrity. The borates, produced in the $B_{4} C$ oxidation, can react to produce cesium borates and alter the distribution of iodine between cesium iodide, hydrogen iodide, and elemental iodine. In order to address these possible impacts, a BWR control rod model has been developed. The model describes the oxidation of the stainless steel cladding/sheath, the $\mathrm{B}_{4} \mathrm{C}$ absorber, the heatup, the melting, and the relocation of the $B_{4} C$ control rods during a BWR severe accident event.

3.10.4.1 Model Description. This section describes the typical BWR fuel assemblies and control rod module and the possible geometrical modeling of the actual configuration. It also presents the theory for the oxidation kinetics of the stainless steel cladding/sheath and the $\mathrm{B}_{4} \mathrm{C}$ absorber. Models for describing the control rod temperature response, control rod melting and relocation, and the slumping of unsupported control rod segments are also provided.

\subsubsection{BWR Fuel Assemblies/Control Rod Module and Geometrical}

Modeling. A typical BWR control rod consists of a sheathed cruciform array of stainless steel tubes filled with $\mathrm{B}_{4} \mathrm{C}$ powder. Each control rod is surrounded by four fuel assemblies. The absorber tube sheath and the tube cladding are made of Type 304 stainless steel. The $\mathrm{B}_{4} \mathrm{C}$ powder in the absorber tubes is compacted to about $70 \%$ of the theoretical density. The $B_{4} C$ is longitudinally separated into individual compartments by stainless steel balls, held in place by a slight crimp in the tube. The control rods are cooled (heated during accident conditions) by the core bypass flow. The tube sheaths are perforated to allow the coolant to circulate freely about the absorber tubes.

Due to the complexity of the actual configuration, a cylindrical rod geometry is assumed in this model. For each $B_{4} C$ control rod, the 
equivalent stainless steel cladding outer radius and thickness are used to represent both tube cladding outer radius, thickness, and the associated portion of the stainless steel sheath for this tube. There are several types of nodalizations that can be used to model the geometry of fuel assemblies and the control rod module, as shown in Figures 3-17a, 3-17b, and 3-77c. As shown in Figure 3-17a, the control rod module together with the four surrounding fuel assemblies are considered as a single channel. The enclosure of the channel is modeled by an equivalent shroud component. The four fuel assemblies can be modeled by one to four individual fuel components. The control rod module is modeled by a BWR control rod component. Figure 3-17b shows a different type of nodalization. Each of the four fuel assemblies is modeled by a fuel component and an enclosure shroud component which forms an individual channel. The control rod module is modeled by a control rod component and its bypass core flow to form an additional channel. The third type of nodalization is shown in Figure 3-17c. The four fuel assemblies are modeled by a representative channel with a fuel component and a surrounding shroud component. The control rod module is modeled by a core bypass channel with a control rod component.

3.10.4.3 Phenomenal Models--0xidation. The stainless steel oxidation considers the following chemical reaction:

$\mathrm{Fe}+\mathrm{H}_{2} \mathrm{O} \rightarrow \mathrm{FeO}+\mathrm{H}_{2}$.

From MATPRO, the stainless steel weight gain and Fe0 layer growth are defined by the parabolic rate equation

$\frac{d \delta}{d t}=\frac{A}{\delta} \exp (-B / 7)$

where

$\begin{aligned} \delta & =\text { weight gain } \\ t & =\text { time }\end{aligned}$




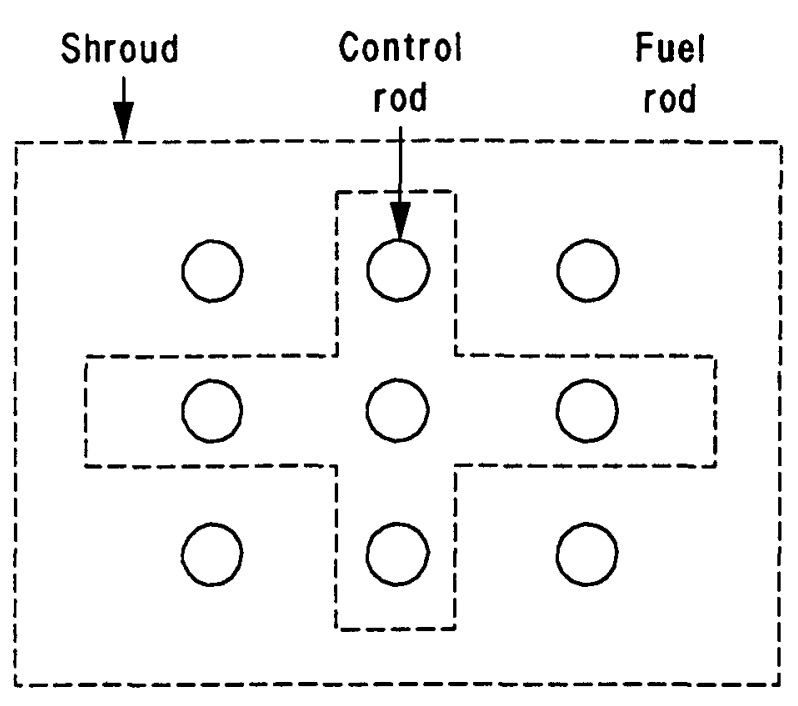

20a (a)

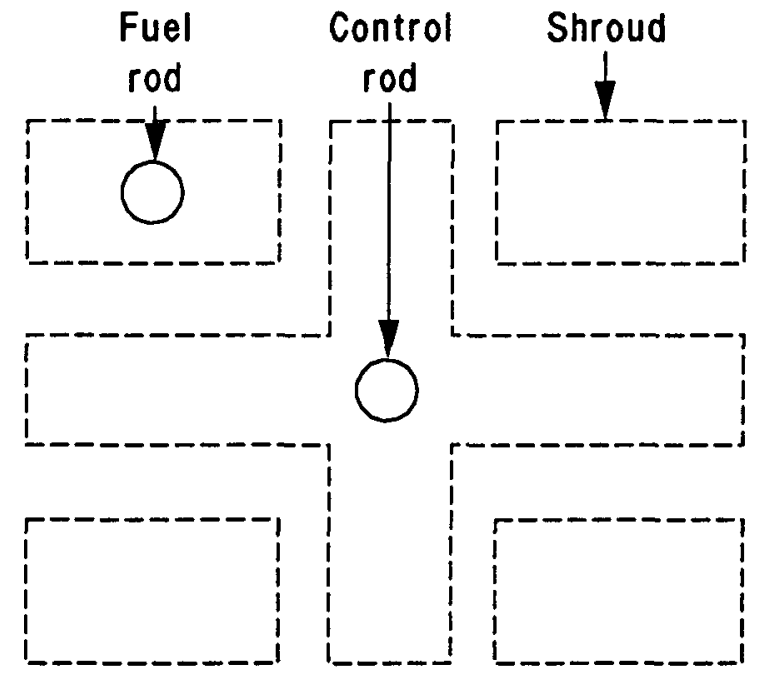

$20 a(b)$

$\stackrel{\omega}{\beth}$

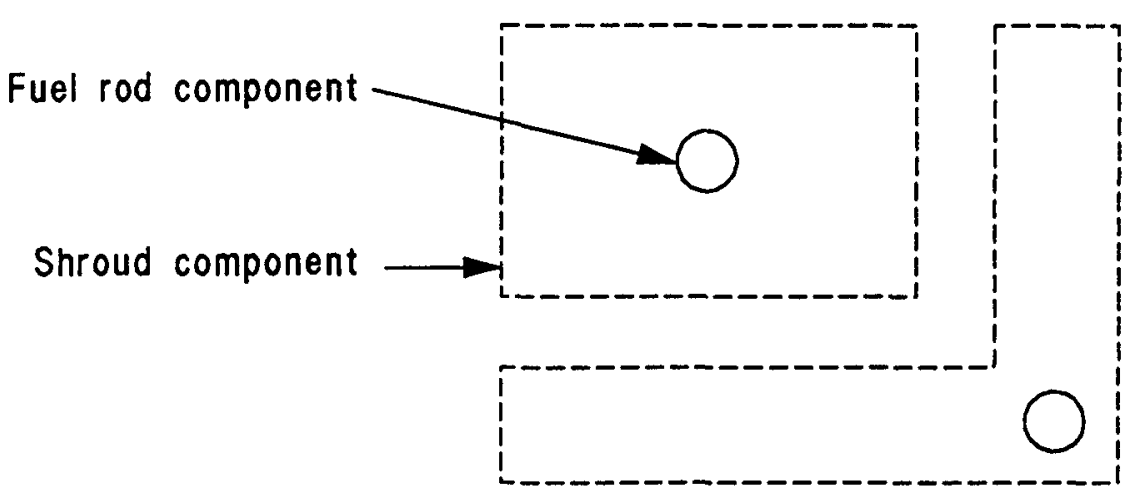

$20 a(c)$
BWR control rod component

Figure 3-17. Nodalization for fuel assemblies and control rods. 


\section{$1=$ cladding temperature}

$A, B=$ parabolic rate constants.

During a time step, $\Delta t$, the cladding temperature is assumed to be constant, thus, Equation (3-162) can be integrated over the current time step to yield

$\delta^{2}-\delta_{0}^{2}=2 A \exp (-B / T) \Delta t$

where $\delta_{0}$ is the value of the weight gain, or Feo layer thickness at the beginning of the time step. The actual weight gain of fe0 during the current time step is $\delta-\delta$. The oxidation heat generation during the current time step is then obtained from the reaction heat and the amount of Fe0 weight gain for the current time step.

For the oxidation of $B_{4} C$ absorber, the current mode 1 considers the following chemical reaction:

$\mathrm{B}_{4} \mathrm{C}+7 \mathrm{H}_{2} \mathrm{O} \rightarrow 2 \mathrm{~B}_{2} \mathrm{O}_{3}+7 \mathrm{H}_{2}+\mathrm{CO}$.

Due to the lack of experimental data, an exponential oxidation model is used and is described by the following equations:

$$
\begin{aligned}
& \frac{d M_{B C}}{d t}=-R(T) M_{B C} \\
& R(1)=C \cdot T+D
\end{aligned}
$$

where

$$
\begin{aligned}
M_{B C}= & \text { mass of } B_{4} C \text { at } t \text { ime } t \\
R(T)= & \text { reaction rate coefficient, assumed to be a linear function } \\
& \text { of the } B_{4} C \text { temperature }(T) .
\end{aligned}
$$


The reaction rate coefficient is further assumed to be zero when the $\mathrm{B}_{4} \mathrm{C}$ temperature is $<1700 \mathrm{~K}$ (stainless steel cladding melting point) and 1.0 at $2700 \mathrm{~K}\left(\mathrm{~B}_{4} \mathrm{C}\right.$ melting point). Thus, the linear fitting constants, $C$ and $D$, are $1.0 \mathrm{E}-3$ and -1.7 , respectively. The reaction rate coefficient $R(T)$ as a function of $B_{4} C$ temperature is shown in Figure $3-18$. If the $B_{4} C$ temperature is assumed to be constant during a time step, $t$, the above equation can be integrated to obtain

$M_{B C}=M_{B C, 0} \exp (-R(T) \Delta t)$

where $M_{B C, 0}$ is the mass of $B_{4} C$ at the beginning of the current time step. Once the mass of oxidized $B_{4} C$ during the current time step is known, the oxidation heat generation can be obtained from the reaction heat.

Both the stainless steel and $B_{4} C$ oxidation consider the unoxidized mass limitation and the steam supply limitation during each time step advancement.

3.10.4.4 Temperature Response. A one-dimensional, two-region energy balance equation is used to predict the absorber and cladding temperature responses. The schematic nodalization for the temperature response calculation is shown in Figure 3-19. The differential equations that govern the region temperature response can be written as:

$M_{1} C_{1} \frac{d T}{d t}=Q_{\text {cond }}+Q_{0 \times, 7}$

$M_{2} C_{2} \frac{\mathrm{dT}_{2}}{\mathrm{dt}}=-Q_{\text {cond }}+Q_{\text {conv }}+Q_{\mathrm{rad}}+Q_{0 \times, 2}$

where

$$
M_{1}, M_{2}=\text { mass of absorber and cladding, respectively }
$$




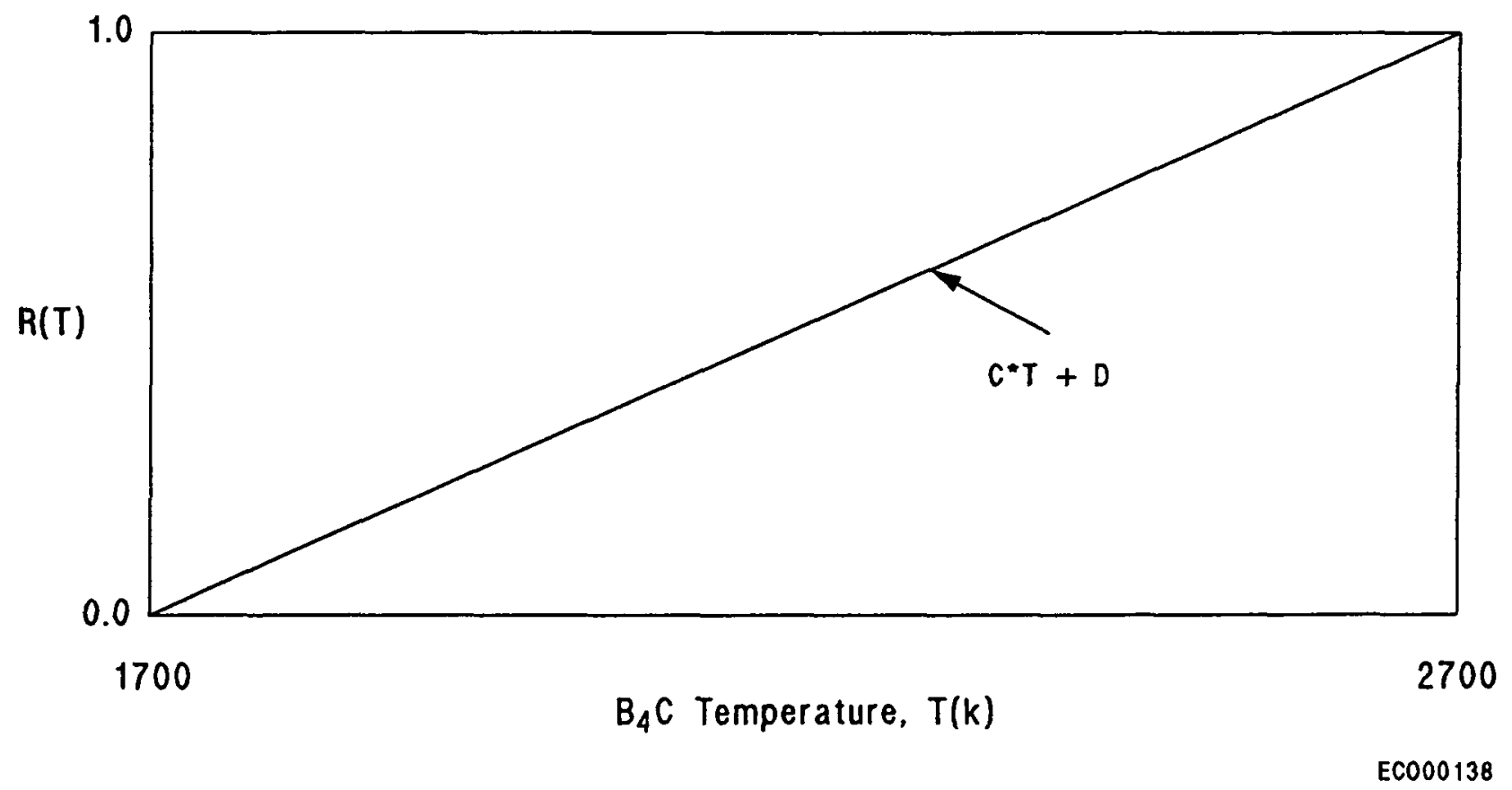

Figure 3-18. $B_{4} C$ oxidation rate coefficient as a function of temperature. 


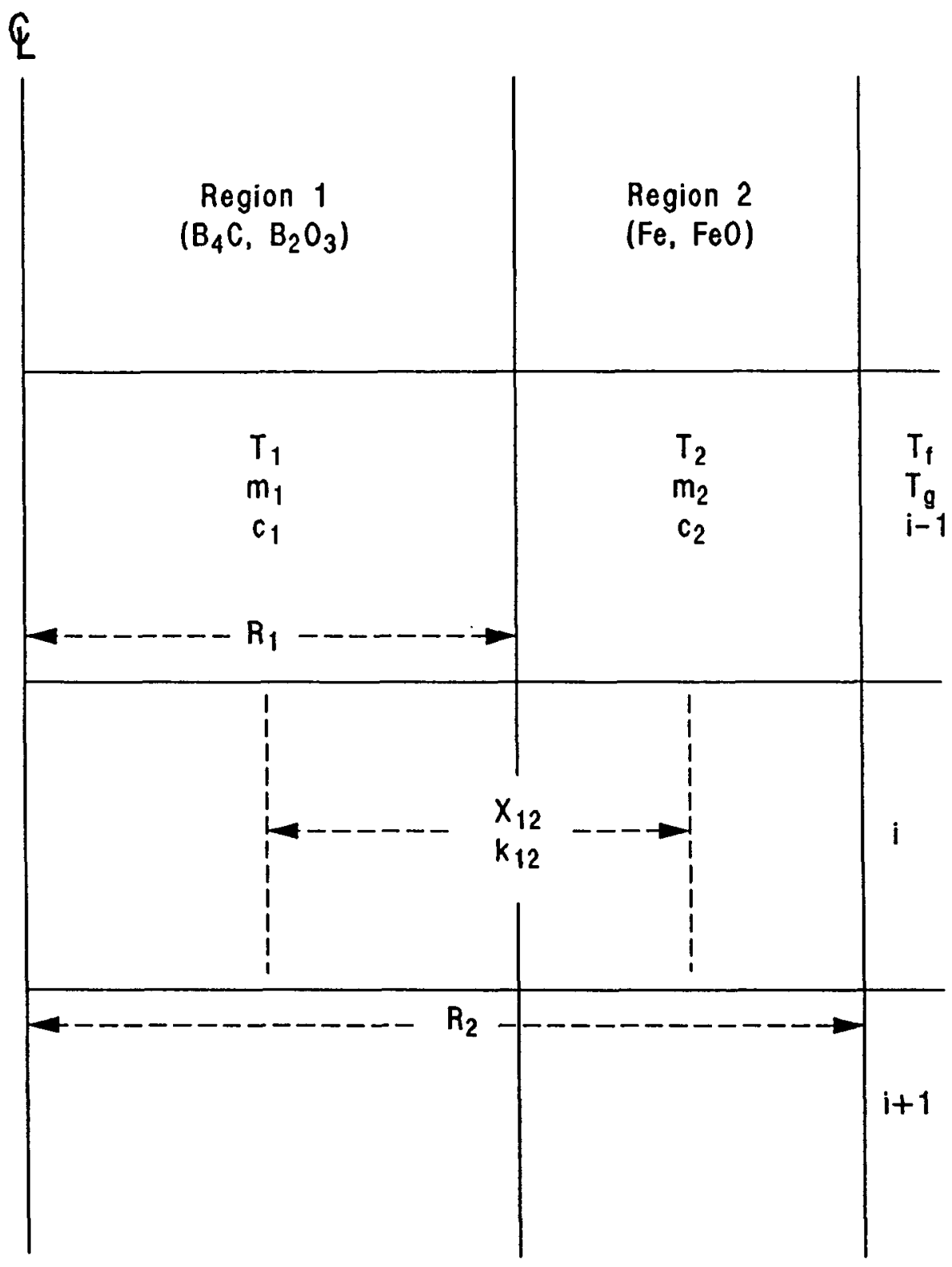

ECO00139

Figure 3-19. One-dimensiona 1, two-region nodalization for temperature response calculation. 


$$
\begin{aligned}
& C_{1}, C_{2}=\text { specific heat of absorber and cladding, respectively } \\
& T_{1} T_{2}=\text { temperatures of absorber and cladding, respectively } \\
& t \\
& Q_{\text {cond }}=\text { convective heat transfer rate at the control rod surface } \\
& Q_{\text {conv }}=\text { conduction heat transfer rate at the interface between the } \\
& Q_{r a d}=\text { rabsorber and the cladding regions } \\
& Q_{0 x, 1}=\text { B } 4 \text { oxidation heat generation rate } \\
& Q_{0 x, 2}=\text { sS oxidation heat generation rate. }
\end{aligned}
$$

The convection and conduction heat transfer rates can further be expressed as

$$
\begin{aligned}
& Q_{\text {conv }}=A_{2}\left[\left(h_{f} *\left(T_{f}-T_{2}\right)+h_{g} *\left(T g-T_{2}\right)\right]\right. \\
& Q_{\text {cond }}=k_{12} A_{1}\left(T_{2}-T_{1}\right) / x_{12}
\end{aligned}
$$

where

$$
\begin{aligned}
A_{1}, A_{2}= & \text { surface areas of absorber and cladding, respectively } \\
h_{f}, h_{g}= & \begin{array}{l}
\text { convective heat transfer coefficients between rod surface } \\
\text { and liquid phase coolant, and between rod surface and vapor } \\
\text { phase coolant, respectively }
\end{array}
\end{aligned}
$$




$$
\begin{aligned}
& 1_{f} \cdot T_{g}=\text { temperatures for the liquid phase and vapor phase coolant } \\
& k_{12}=\begin{array}{l}
\text { effective conductivity across the absorber and the cladding } \\
\text { regions }
\end{array} \\
& x_{12}=\text { effective conduction distance. }
\end{aligned}
$$

The convective heat transfer rate between the control rod surface and the surrounding coolant is calculated through the RELAP5 heat transfer package. The calculation of radiation heat transfer rate depends on the geometric mode1. For the first type of mode1, as shown in figure 3-17a, the radiation heat transfer rate is calculated as in the original SCDAP radiation model. For the other types of geometrical models, as shown in Figures $17 \mathrm{~b}$ and $17 \mathrm{c}$, radiation heat exchange between two parallel planes (fuel canister wall, and control rod sheath) is assumed. The radiation heat transfer rate on one of the control rod surfaces can be expressed as:

$Q_{\mathrm{rad}}=\frac{\sigma A}{n}\left(T_{s}^{4}-T_{2}^{4}\right) /\left(1 / \varepsilon_{s}+1 / \varepsilon_{2}-1\right)$

where

$$
\begin{aligned}
\varepsilon_{s}, \varepsilon_{2} & =\begin{array}{l}
\text { surface emissivities for fuel assembly canister wall and } \\
\text { control rod sheath }
\end{array} \\
& =\begin{array}{l}
\text { surface area for fuel assembly canister wall or control } \\
\text { rod sheath which are facing each other }
\end{array} \\
T_{s} & \text { temperature at the outer surface of the fuel assembly } \\
& \text { canister wall } \\
& =\text { number of control rod tubes within a control rod module } \\
\sigma \quad & \text { Stefan-Boltzmann constant. }
\end{aligned}
$$


During a time step, $\Delta t$, Equations (3-168) and (169) can be expressed in difference forms

$$
\begin{aligned}
M_{1} C_{1}\left(T_{1}(n)-T_{1}^{(0)}\right)= & k_{12} A_{1} \Delta t\left(T_{2}^{(n)}-T_{1}^{(n)}\right) / x_{12}+Q_{0 x, 1}^{(n)} \Delta t \\
M_{2} C_{2}\left(T_{2}^{(n)}-T_{2}^{(0)}\right)= & -k_{12} A_{1} \Delta t\left(T_{2}^{(n)}-T_{1}^{(n)}\right) / x_{12} \\
& +A_{2} \Delta t\left[n_{f}^{(n)}\left(T_{f}^{(n)}-T_{2}^{(n)}\right)\right. \\
& +h_{g}^{(n)}\left(T_{g}^{(n)}-T_{2}^{(n)}\right) \\
& \left.+Q_{r a d}^{(n)} \Delta t+Q_{0 x, 2}^{(n)} \Delta t\right] .
\end{aligned}
$$

The end timestep temperatures, $T_{1}^{(n)}, T_{2}^{(n)}$, can be solved in term of the beginning timestep temperatures, $T_{1}^{(0)}, T_{2}^{(0)}$, explicitiy.

When the control rod cladding is melted away, the $B_{4} C$ absorber is then exposed to the coolant. The temperature response of the $B_{4} C$ region is predicted according to a lumped parameter calculation. The difference equation during timestep, $t$, is

$$
\begin{aligned}
M_{1} C_{1}\left(T_{1}^{(n)}-T_{1}^{(0)}=\right. & A_{1} \Delta t\left[h_{f}^{(n)}\left(T_{f}^{(n)}-T_{1}^{(n)}\right)+h_{g}^{(n)}\left(T_{g}^{(n)}-T_{1}^{(n)}\right)\right. \\
& \left.+Q_{0 x, 1}^{(n)} \Delta t+Q_{r a d}^{(n)} \Delta t\right] .
\end{aligned}
$$

The end timestep temperature $T_{1}^{(n)}$, can then be obtained.

3.10.4.5 Melting and Relocation. Following the conduction solution, should melting occur during the current time step, the amount of material melted is calculated. Since the melting of the materials is not implicitiy 
calculated in the conduction solution, the actual temperature is recalculated through balancing the material internal energy and the heat of fusion.

The downward movement of the molten material is calculated based on the well-developed, incompressible viscous film flow over a cylindrical geometry. Considering a cylindrical geometry, as shown in Figure 3-20, the force balance for the liquid film can be expressed as:

$\frac{d}{d r}\left(\gamma \zeta_{Y Z}\right)=\gamma_{\rho g}$ where $\zeta_{Y Z}=-\mu \frac{d V_{Z}}{d \gamma}$.

The boundary conditions are

$\zeta_{\gamma z}\left(\gamma=R_{2}\right)=0$

$v_{z}\left(r=R_{1}\right)=0$

where

$$
\begin{array}{ll}
r & =\text { the radial coordinate } \\
\rho & =\text { the liquid film density } \\
g & =\text { gravitational acceleration } \\
\mu & =\text { the liquid film viscosity } \\
\zeta_{Y Z} & =\text { viscous shear force } \\
R_{1}, R_{2} & =\text { outer radii for the solid and liquid layers } \\
V_{(\gamma)} & =\text { downward liquid film velocity. }
\end{array}
$$

From the above equations, the liquid film velocity profile can be obtained as 


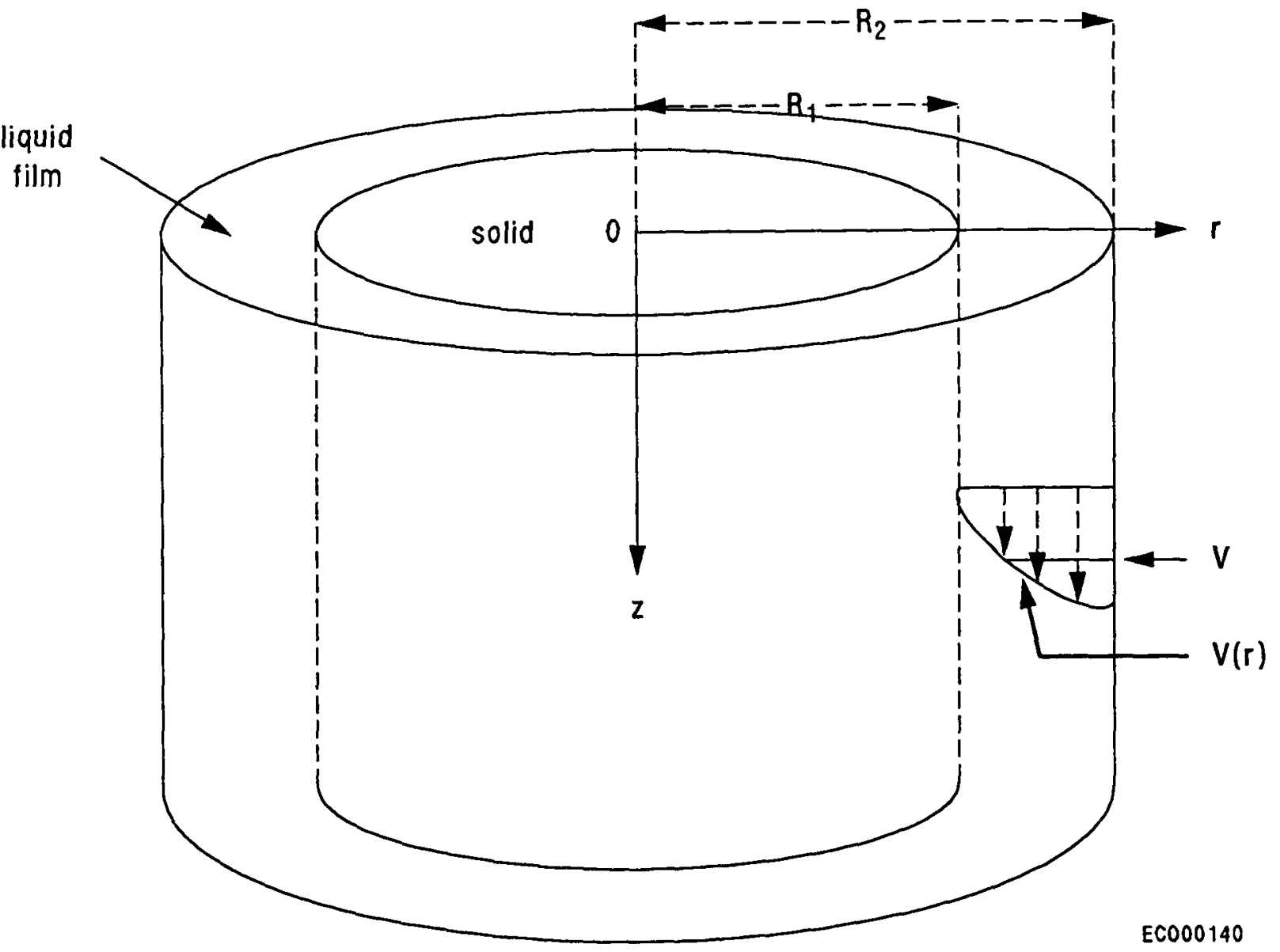

Figure 3-20. Incompressible, viscous film flow over cylindrical geometry. 
$v_{z}(\gamma)=\frac{\rho g}{4 \mu}\left(R_{1}^{2}-\gamma^{2}\right)+\frac{\rho g R_{2}^{2}}{2 \mu} \ln \left(\gamma / R_{1}\right)$.

After integrating the velocity profile across the liquid film, the average film velocity, $v$, is

$V=R_{1}^{4} /\left(R_{2}^{2}-R_{1}^{2}\right)+\frac{\rho g}{\mu}+\frac{4 x^{2}-1-3 x^{4}}{8}+\frac{x^{4}}{2} \ln x$

where $x=R_{2} / R_{1}$. Thus, during a time step $\Delta t$, the liquid film will travel a distance of $v \Delta t$.

During a time step, the actual computation process starts from the top elevation of the control rod. If melting and relocation occur at the top elevation, the molten material moves to the next lower elevation. The internal energy associated with the relocated molten material is assumed to instantly exchange with the internal energy of the material at this lower elevation. Should the liquefied material at this new elevation still appear, the downward moving calculation for the liquefied material is continued. The process is repeated until the lowest elevation is reached. The amount of molten material dripped below the bottom of the control rod is also tracked for each time step.

3.10.4.6 Slumping. If the material, which is located anywhere in the middle section of a control rod, has depleted during a time step, then the unsupported control rod segment, located above the empty section, is assumed to fill the empty section and leave an empty region at the top. This slumping process is shown in Figure 3-21. All of the hydraulic volume connections, the changes of the coolant flow area, and the coolant hydraulic diameter are also updated. 
Before slumping

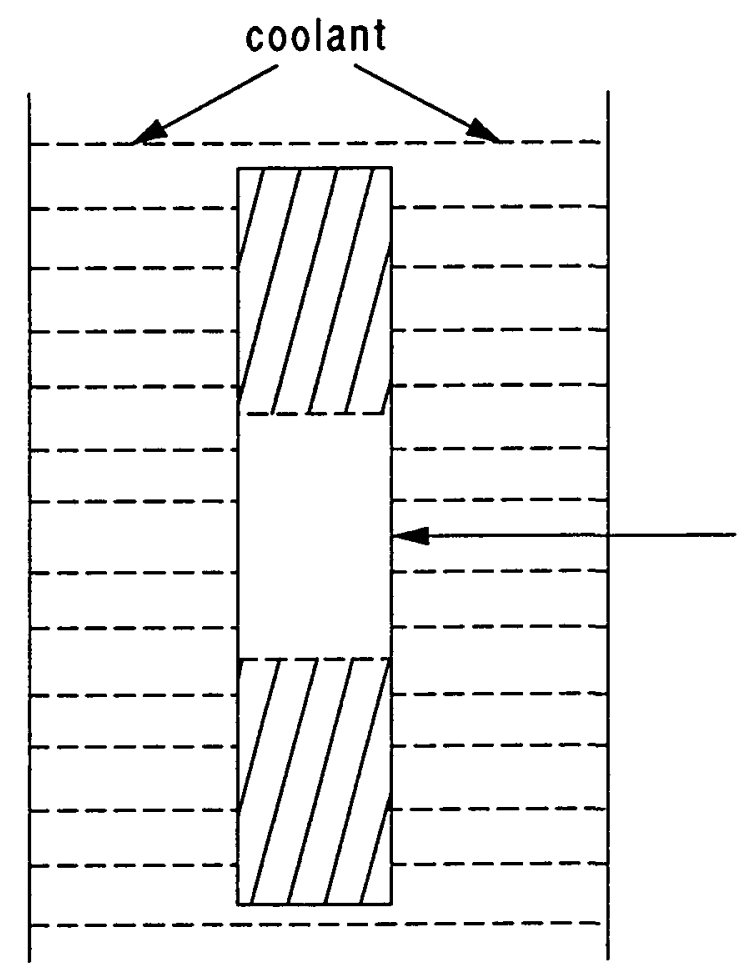

After slumping

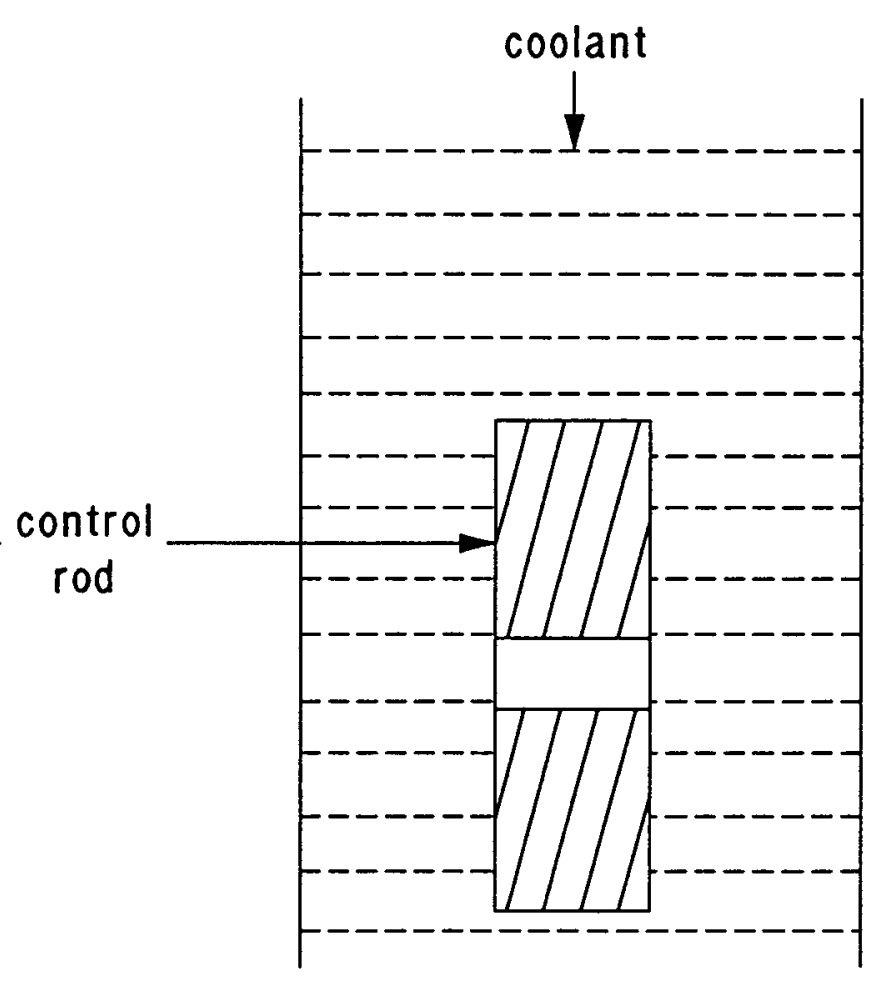

ECO00141

Figure 3-21. Slumping process for unsupported control rod segment. 


\subsection{Radiation Mode1 Description}

This section describes the radiation heat transfer model used for an LWR core. The radiation model analyzes the radiation exchange between the various components in the core, including the coolant. The model calculates the radiation heat flux absorbed by the coolant and the radiant heat exchange between the surfaces of any vessel component (fuel rod, control rod, or shroud). The radiant heat exchange is a thermal boundary condition used in severe accident analysis of fuel rods, control rods, and flow shrouds.

\subsubsection{Radiation Model Governing Equations}

A mechanistic radiative heat transfer formulation, which accounts for each surface, the vapor, and each droplet, is very complex. To develop such a detalled model for SCDAP/RELAP5 would not be cost-effective. Instead, simplified models are used without unduly sacrificing the accuracy of the results.

The radiation model presented here is similar to those developed earlier $^{3-34,35,36,37,38,39,40,41}$ for nuclear reactor applications. The solution method used is the net radiation method for an enclosure. Each component (fuel rod, control rod, or shroud) surface forms one side of an enclosure with $n$ sides, and the enclosure is filled with coolant (see Figure 3-22). The radiation heat transfer equation for each surface is written and describes radiation exchange with all the surfaces (including itseif if it radiates to itself) and absorption and emittance by the enclosed coolant. The $n$ equations are solved simultaneously by a matrix inversion method to obtain the radiosity (the sum of emitted and reflected radiation energy rates) of each surface. The difference between the radiosity and incident energy from the surroundings gives the net heat flux to or from a surface. The algebraic sum of net heat flux corresponding to each surface gives the total radiation heat absorbed by the coolant.

To derive the governing equation of radiation heat exchange for a surface, the following assumptions were made: 


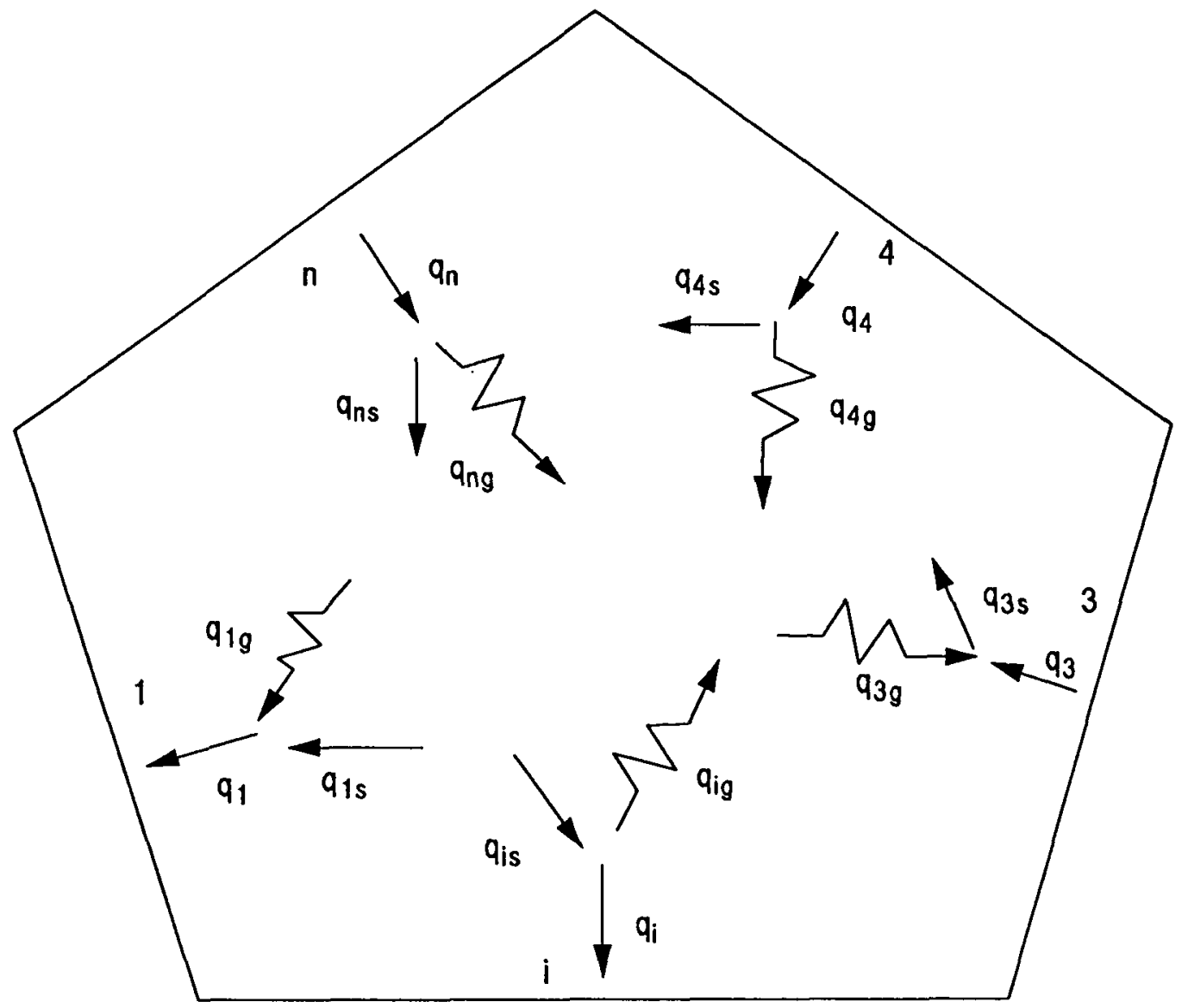

ECO00 105

Figure 3-22. Radiation exchange between surfaces and between surfaces and gas in an enclosure. 
- All surfaces are gray, that is, the absorption is independent of wavelength.

- All surfaces are diffuse for emission and the isotropic portion of the reflected radiant energy.

- Each surface has a uniform temperature and emits radiation uniformly.

o of the reflected radiation from a surface $i$, a fraction, $\left(1-\mu_{i}\right)$, is reflected isotropically (diffuse uniformiy in all the directions); and the rest, $\mu_{i}$, is reflected back toward the origin of the incident radiation.

- The coolant absorbs and emits radiation.

- The coolant is assumed to be steam only with no entrained droplets.

Figure 3-23 shows the radiation exchange mechanism for any surface 1. $I_{1}$ is the rate of radiant flux incoming from the surroundings lother surfaces, gas, and possibly surface $i)$. A portion, $a_{i}$, of $I_{i}$ is absorbed by the surface $i$, and the remaining $\left(1-a_{i}\right)$ is reflected to the surroundings. The surface $i$ also emits radiation. Thus, the outgoing radiant energy flux rate (radiosity), $E_{j}$, from a surface $i$ is composed of enitted and reflected radiation. This gives

$$
\begin{aligned}
E_{i} & =\varepsilon_{i} \sigma T_{i}^{4}+\rho_{i} I_{i} \\
& =\varepsilon_{i} \sigma T_{i}^{4}+\left(T-\varepsilon_{j}\right) I_{i}
\end{aligned}
$$

where

$$
\begin{gathered}
E_{i}=\text { the rate of radiant energy outgoing (radiosity) from a } \\
\text { unit area of surface } i\left(W / m^{2}\right)
\end{gathered}
$$




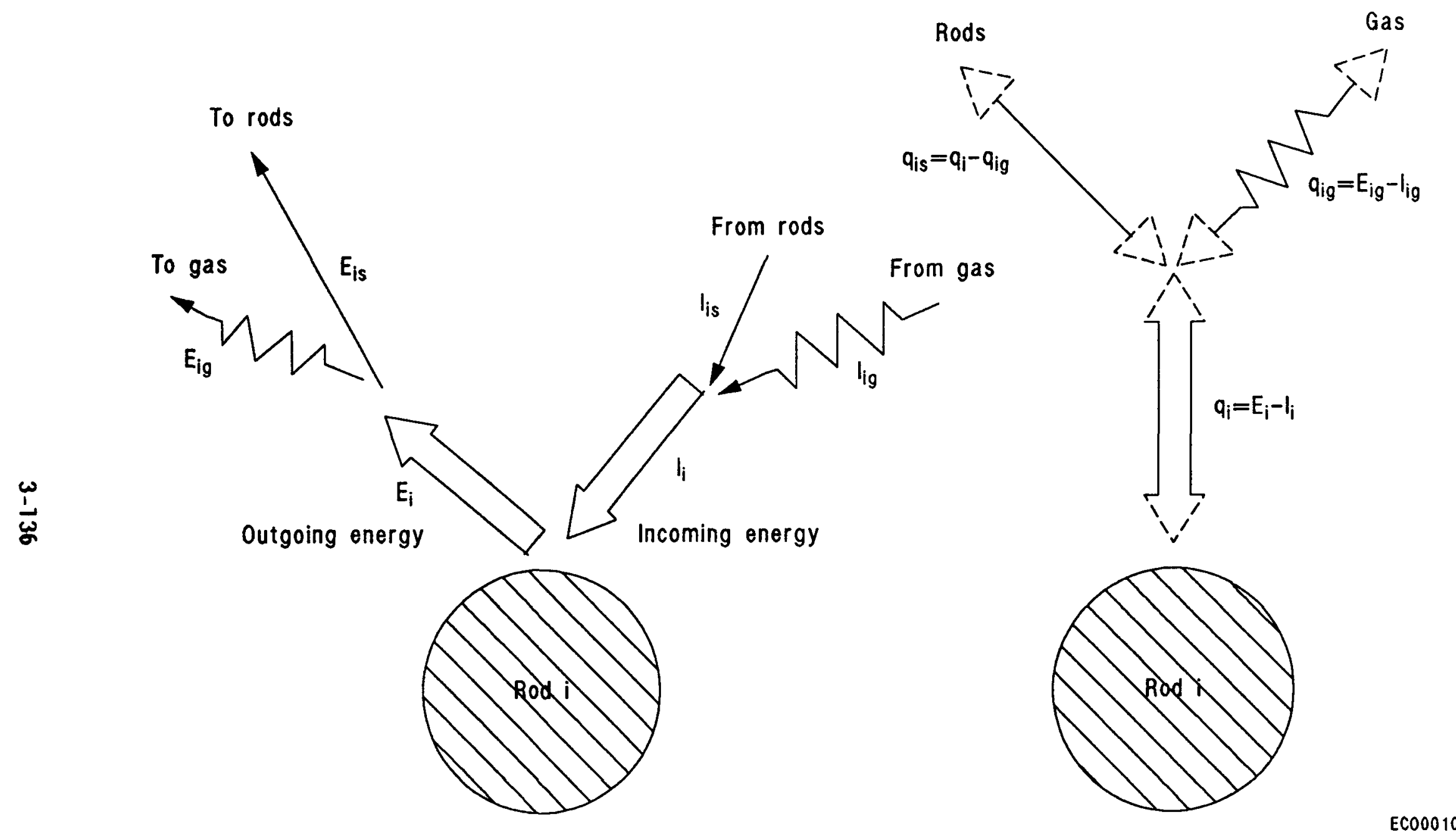

Figure 3-23. Radiation exchange between a rod surface and its surroundings. 


$$
\begin{aligned}
& \varepsilon_{\mathfrak{i}}=\text { the emissivity of surface } \boldsymbol{i} \text {, lequal to } a_{\mathfrak{j}} \text { for } a \\
& \text { gray-diffuse surface) } \\
& a_{i}=\text { the absorptivity of surface } i \\
& \sigma=\text { Stefan-Bo7tzmann constant }\left(5.668 \times 10^{-8} \mathrm{~W} / \mathrm{m}^{2} \cdot \mathrm{K}^{4}\right) \\
& T_{i}=\text { the temperature of surface } i(K) \\
& \rho_{i}=\text { the reflectivity of surface } i \text {, equals }\left(1-a_{j}\right)=\left(1-\varepsilon_{i}\right) \\
& I_{i}=\text { the rate of radiant energy incident upon a unit area of } \\
& \text { surface } i\left(w / m^{2}\right) \text {. }
\end{aligned}
$$

Here a relation, $p_{i}=\left(1-a_{i}\right)=\left(1-\varepsilon_{i}\right)$, has been used for an opaque gray surface. The incoming flux, $I_{1}$, is the sum of the portions of the energy leaving all the surfaces of the enclosure that arrives at the ith surface. The reflected radiation from a surface will mainly leave the surface in a direction that forms an equal but opposite angle with the surface normal to the direction of the incident radiation, whereas the emitted radiation leaves in a 11 the directions. Therefore, for large and/or curved surfaces, generally the radiation is reflected backwards toward the origin of the incident radiation. Hence, it is assumed $3-39,40$ that a fraction, $\mu$, of the incident reflection is reflected backwards and the remaining radiation $(1-\mu)$ is reflected uniformly in all the directions.

The isotropic part of the outgoing radiation (radiosity), $E_{j}^{I}$, from a surface $i$ is given by

$E_{i}^{I}=\varepsilon_{i} \sigma T_{i}^{4}+\left(T-\mu_{i}\right)\left(T-\varepsilon_{i}\right) I_{i}$

and the anisotropic part, which is reflected back to the $\mathrm{j}$-th surface, $E_{i j}^{A}$, is given by 


$$
E_{i j}^{A}=\mu_{i}\left(1-\varepsilon_{i}\right) I_{i j}
$$

or

$$
\sum_{j=1}^{n} I_{i j}=\frac{1}{\mu_{i}\left(1-\varepsilon_{i}\right)} \sum_{j=1}^{n} E_{i j}^{A} .
$$

The total incoming radiation onto surface $i$ is the sum of incoming radiation from all the directions, $I_{i j}$, including itself.

$$
1_{\mathfrak{i}}=\sum_{\mathbf{j}=1}^{n} \mathbf{I}_{\mathbf{i j}}
$$

Combining Equations $(3-182),(184)$, and $(3-185)$, the following equation is obtained

$$
E_{i}^{I}=\varepsilon_{i} \sigma T_{i}{ }^{4}+\frac{\left(1-\mu_{j}\right)}{\mu_{j}} \sum_{j=1}^{n} E_{i j}^{A} .
$$

The incident radiation from the $j$-th surface reaching the $i$-th surface consists of the following parts:

1. Isotropic part of the radiosity of the $j$-th surface multiplied by the view factor from surface $j$ to surface $i$;

2. The anisotropic part of the radiation emitted in the direction of $i$-th surface; the total radiosity, sum of (1) and (2), is reduced by the transmissivity of the coolant; and

3. Radiation emitted by the coolant itself. 
Therefore,

$$
A_{i} I_{i j}=\left(E_{j}^{I} A_{j} F_{j i}+E_{j i}^{A} A_{j}\right) \tau_{j j}+\varepsilon_{g j i} \sigma T_{g}^{4} A_{j} F_{j i}
$$

where

$$
\begin{aligned}
A_{j} & =\text { the area of surface } i\left(m^{2}\right) \\
F_{j i} & =\text { the view factor of surface } j \text { to surface } i \\
\tau_{j i} & =\text { the transmissivity of coolant from surface } j \text { to surface } i \\
& =\exp \left(-k_{g j i} L_{j j}\right) \\
\varepsilon_{g j i} & =\left(1-T_{j j} \cdot\right.
\end{aligned}
$$

Here $L_{j} i$ is the mean path (beam) length between surfaces $i$ and $j$. $K_{g j j}$ is the absorption coefficient (absorptivity per unit length) for the vapor medium and has the units of $\mathrm{m}^{-1}$. Because 1 iquid droplets are assumed to be absent in the path between $i$ and $j$, the absorption coefficient for liquid $K_{\ell j j}$ is taken as zero. Therefore, $\tau_{j i}$ and $\varepsilon_{g j} j$ are equal to $\exp \left(-K_{g j i} L_{j i}\right)$ and $\left(1-\tau_{j j}\right)$, respectively.

From the view factor reciprocity relation,

$A_{\mathfrak{j}} F_{\mathfrak{i j}}=A_{j} F_{j \mathfrak{j}}$.

Equation (3-179) is simplified to

$$
I_{i j}=\left(E_{j}^{I} F_{i j}+E_{j i}^{A} \frac{A_{j}}{A_{j}}\right) \tau_{j j}+\varepsilon_{g j i} T_{g}^{4} \sigma F_{i j} .
$$


Substituting the expression for $I_{j} j$ in Equation $(3-176)$

$E_{i j}^{A}=\mu_{j}\left(1-\varepsilon_{j}\right)\left[\left(E_{j}^{I} F_{i j}+E_{j i}^{A} \frac{A_{j}}{A_{j}}\right) \tau_{j j}+\varepsilon_{g j i} T_{g}^{4} \sigma F_{i j}\right]$.

By interchanging the $i$ and $j$ subscripts in Equation (3-192), an expression for $E_{j}^{A}$ is obtained.

$E_{j i}^{A}=\mu_{j}\left(1-\varepsilon_{j}\right)\left[\left(E_{i} F_{j i}+\frac{A_{j}}{A_{j}} E_{i j}^{A}\right) \tau_{i j}+\varepsilon_{g i j} T_{g}^{4} \sigma F_{j j}\right]$.

Eliminating $E_{j i}^{A}$ from Equations $(3-192)$ and $(3-193)$, the expression for

$E_{i j}^{A}$ is obtained

$$
\begin{aligned}
E_{i j}^{A}= & \mu_{i}\left(1-\varepsilon_{j}\right) F_{i j}\left\{\left[E_{j}^{I}+\mu_{j}\left(1-\varepsilon_{j}\right) E_{i}^{1} T_{i j}\right] \tau_{j i}\right. \\
& \left.+\sigma \varepsilon_{g i j} T_{j}^{4}\left[1+\mu_{j}\left(1-\varepsilon_{j}\right) \tau_{j j}\right]\right\} /\left[1-{ }_{i} \mu\left(1-\varepsilon_{j}\right) \mu_{j}\left(1-\varepsilon_{j}\right) \tau_{i j} \tau_{j j}\right] .
\end{aligned}
$$

Combining Equations (3-186) and (3-187), a relation for $E_{i}^{I}$ is obtained.

$$
\begin{aligned}
& E_{i}^{I}=\varepsilon_{i} \sigma T_{i}^{4}+\left(T-\mu_{j}\right)\left(1-\varepsilon_{i}\right) \sum_{j=1}^{n} F_{i j}\left\{\left[E_{j}^{I}+\mu_{j}\left(T-\varepsilon_{j}\right) \tau_{i j} E_{i}^{I}\right] \tau_{j}\right\} \\
& \left.+\sigma \varepsilon_{g j} T_{g}^{4}\left[1+\mu_{j}\left(1-\varepsilon_{j}\right) \tau_{i j}\right]\right\} /\left[1-\mu_{j}\left(1-\varepsilon_{j}\right) \mu_{j}\left(1-\varepsilon_{j}\right) \tau_{j i} \tau_{i j}\right] .
\end{aligned}
$$

Equation $(3-195)$ is written in the following form 


$$
\begin{aligned}
& \sum_{j=1}^{n}\left\{\left[1-\sum_{k+1}^{n} \frac{\left(1-\mu_{j}\right)\left(1-\varepsilon_{j}\right) \mu_{k}\left(1-\varepsilon_{k}\right){ }^{T_{k j}}{ }^{\top}{ }_{i k}}{1-\mu_{i k}\left(1-\varepsilon_{j}\right) \mu_{k}\left(1-\varepsilon_{k}\right) T_{k i} T_{i k}}\right] \delta_{i j}\right. \\
& -\frac{\left(1-\mu_{i}\right)\left(1-\varepsilon_{j}\right) \tau_{j i} F_{i j}}{1-\mu_{j}\left(1-\varepsilon_{i}\right) \mu_{j}\left(1-\varepsilon_{j}\right) T_{j i} T_{j j}} E_{j}^{I} \\
& =\varepsilon_{i} \sigma T_{i}^{4}+\sigma\left(T-\mu_{j}\right)\left(1-\varepsilon_{j}\right) \sum_{j=1}^{n} \frac{\varepsilon_{g j} j T_{g}^{4}\left[1+\mu_{j}\left(1-\varepsilon_{j}\right) T_{j j}\right] F_{i j}}{1-\mu_{j}\left(1-\varepsilon_{j}\right) \mu_{j}\left(1-\varepsilon_{j}\right) \tau_{j j} T_{i j}}
\end{aligned}
$$

where $\delta_{i j}$ is the Kronecker delta function and is defined as

$$
\delta_{\mathbf{i j}}=\left\{\begin{array}{l}
1 \text { when } \mathbf{i}=\mathbf{j} \\
0 \text { when } \mathbf{i}=\mathbf{j}
\end{array}\right.
$$

Equation $(3-196)$ is solved for $E_{j}^{I}$ by using a matrix inversion method.

As mentioned earlier, in the absence of liquid droplets, $\varepsilon_{\ell j i}$ is zero and $\varepsilon_{g j} j$ is equal to $\left(1-\tau_{j i}\right)$. If the radiation exchange is assumed to be isotropic i.e., $\mu_{j}=0$, Equation $(3-196)$ becomes

$\sum_{j=1}^{n}\left[\delta_{i j}-\left(1-\varepsilon_{j}\right) \tau_{j i} F_{i j}\right] E_{j}=\varepsilon_{i} \sigma T_{i}^{4}+\sigma\left(1-\varepsilon_{j}\right) \sum_{j=1}^{n} \varepsilon_{g j} T_{j}^{4} F_{i j}$

The surface heat flux $q_{j}$, is the difference between the outgoing and incident radiation and can be written as:

$$
q_{i}=E_{i}-I_{i} .
$$

Substituting for $E_{i}$ from Equation $(3-181)$ 


$$
q_{i}=\left[\varepsilon_{i} \sigma T_{i}^{4}+\left(1-\varepsilon_{i}\right) I_{i}\right]-I_{i}
$$

Substituting for $1_{\mathfrak{j}}$ from Equation $(3-182)$,

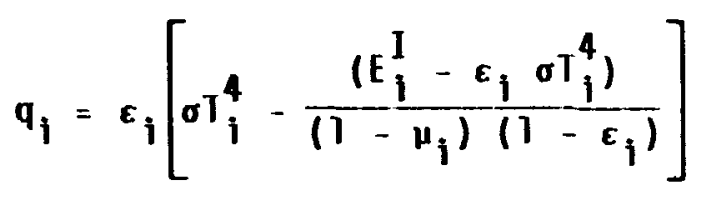

$$
\begin{aligned}
& \left.\left.=\frac{\varepsilon_{i}}{\left(1-\mu_{i}\right)\left(T-\varepsilon_{i}\right)}\{\sigma]_{i}^{4}\left[1-\mu_{i}(]-\varepsilon_{i}\right)\right]-E_{i}^{1}\right\} .
\end{aligned}
$$

The net heat flux, $q_{i}$, to or from any surface $i$ consists of two parts, as shown in Figure 3-23. One part is the net heat flux exchange with other surfaces, $q_{i s}$; and the other part is the net heat flux exchange with the coolant gas, $q_{i g}$. It implies that whatever net surface-to-surface heat flux, $q_{\text {is }}$, is released by the hotter rods gets absorbed by the cooler rods. Therefore,

$$
Q_{r}=\sum_{i=1}^{n} A_{i} q_{i s}=0
$$

This leads to the relation

$$
\begin{aligned}
Q_{i} & =\sum_{i=1}^{n} A_{i} q_{i} \\
& =\sum_{i=1}^{n} A\left\{q_{i g}+q_{i j}\right\} \\
& =\sum_{i=1}^{n} A_{i} q_{i g}+\sum_{i=1}^{n} A_{i} q_{i s}
\end{aligned}
$$




\section{Substituting for}

$\sum_{i=1}^{n} A_{i} q_{i s}$

from Equation $(3-201)$,

$Q_{t}=\sum_{i=1}^{n} A_{i} q_{i g}=Q_{g}$

This means that the algebraic sum of net heat flux exchange with the surroundings for all the surfaces, $Q_{t}$, equals the total heat absorbed by the coolant gas, $Q_{g}$.

The total energy absorbed by the coolant, $Q_{t}$, can be found by the following relation:

$\begin{aligned} Q_{t} & =\sum_{i=1}^{n} A_{i} q_{i} \\ & =\sum_{i=1}^{n} \frac{A_{i} \varepsilon_{i}}{\left(1-\mu_{i}\right)\left(1-\varepsilon_{i}\right)} \operatorname{oT}_{i}^{4}\left[1-\mu_{i}\left(1-\varepsilon_{i}\right)\right]-E_{i}^{I} .\end{aligned}$

The energy absorbed by the gas, $Q_{g}$, is also given by the following relation:

$Q_{g}=\sum_{i=1}^{n} A_{i} \sum_{j=1}^{n}\left[a_{g i j}\left(E_{i}^{I} F_{i j}+E_{i j}^{A}\right)-\varepsilon_{g i j} \sigma T_{g}^{4} F_{i j}\right]$. 
The first term on the right-hand side of Equation $(3-205)$ is the amount of radiation absorbed by the vapor along the path $i$ to $j$. The second term is the amount of radiation emitted by the vapor phase.

\subsection{1 .2 Vjew Factors}

The following expressions for the view factors have been derived using the crossed-string method. This method is described in several text books. 3-42,43 Cox, 3-44 Mande11, ${ }^{3-45}$ and Evans ${ }^{3-46}$ have used this method to derive view factors between rods for nuclear reactor applications. With reference to Figure 3-24, the view factor of Rod 1 with respect to Rod 2 (closest to Rod 1), $F_{12}$, is given by the following:

$$
\begin{aligned}
F_{12}= & 0.5+\frac{\left(R_{2}-R_{1}\right)}{2 \pi R_{1}} \cos ^{-1}\left(\frac{R_{2}-R_{1}}{P_{12}}\right)-\frac{\left(R_{1}+R_{2}\right)}{2 \pi R_{1}} \sin ^{-1}\left\{\frac{\left[P_{12}^{2}-\left(R_{1}+R_{2}\right)^{2}\right]^{1 / 2}}{P_{12}}\right\} \\
& +\frac{1}{2 \pi R_{1}}\left\{\left[P_{12}^{2}-\left(R_{1}+R_{2}\right)^{2}\right]^{1 / 2}-\left[P_{12}^{2}-\left(R_{1}-R_{2}\right)^{2}\right]^{1 / 2}\right\} .
\end{aligned}
$$

where

$$
\begin{aligned}
& R_{1}, R_{2} \ldots=\text { the radii of Rods } 1,2, \ldots \text { respectively }(m) \\
& \begin{array}{l}
P_{12}, P_{23} \cdots=\text { the pitches between Rods } 1 \text { and } 2 \text {, Rods } 2 \text { and } \\
3, \ldots \text { respectively }(m) .
\end{array} \\
& \text { For } R_{1}=R_{2}=R \text { and } P_{12}=P \text {. Equation (3-206) reduces to the following: } \\
& F_{12}=0.5-\frac{1}{\pi} \sin ^{-1}\left[\frac{\left(P^{2}-4 R^{2}\right)^{1 / 2}}{P}\right]+\frac{1}{2 \pi R}\left[\left(P^{2}-4 R^{2}\right)^{1 / 2}-P\right] .
\end{aligned}
$$




\section{$\bullet$}

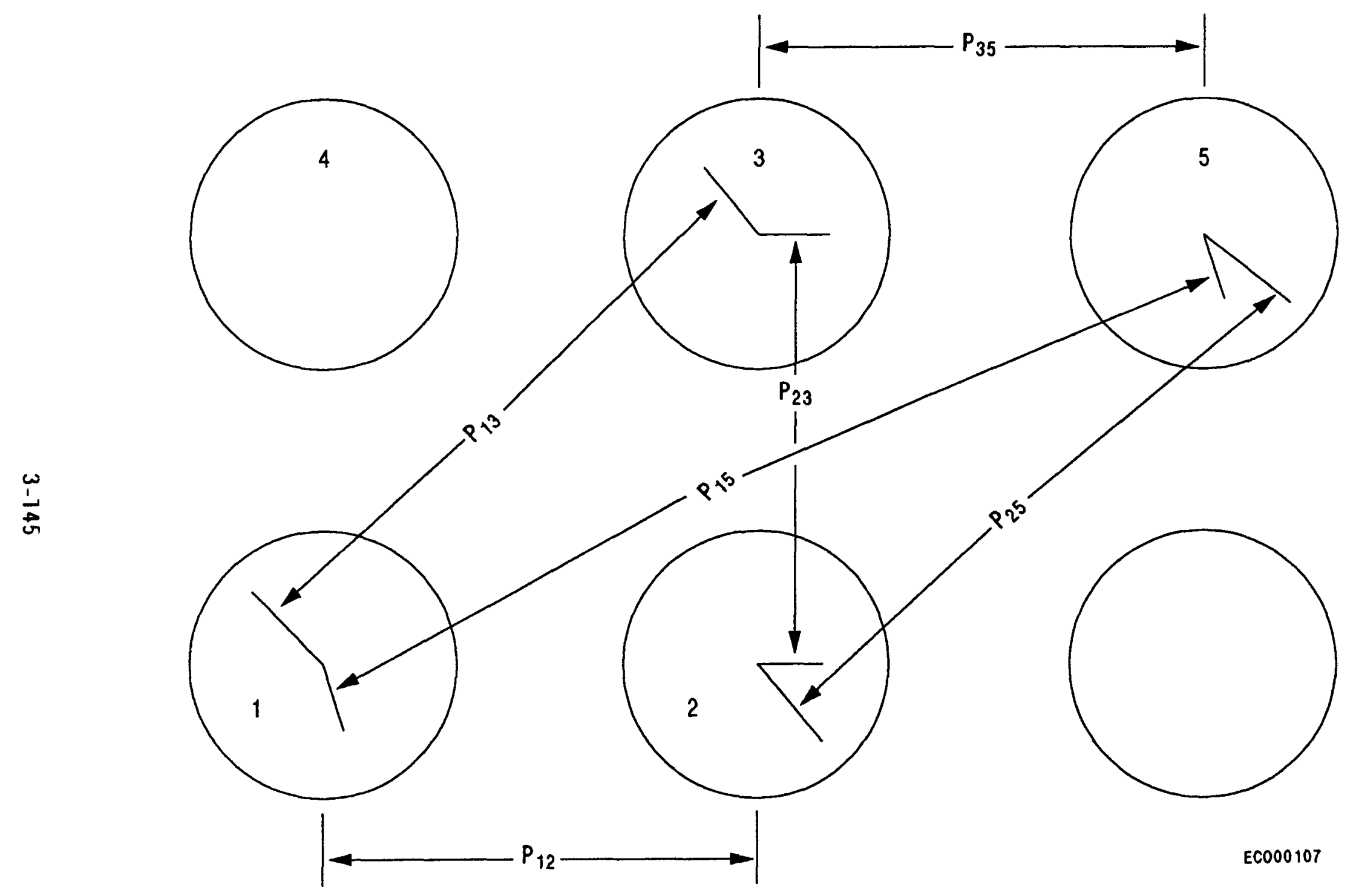

Figure 3-24. Geometry for determining view factors between rods. 
For diagonally located rods, the view factor $F_{13}$ (Figure $3-24$ ) is given by the following relation, which can be derived using the crossedstring method:

$$
\begin{aligned}
& F_{13}=\left\{2\left[P_{13}^{2}-\left(R_{1}+R_{3}\right)^{2}\right]^{1 / 2}-\left[P_{12}^{2}-\left(R_{1}+R_{2}\right)^{2}\right]^{1 / 2}\right. \\
& -\left[P_{23}^{2}-\left(R_{2}+R_{3}\right)^{2}\right]^{1 / 2}-\left[P_{34}^{2}-\left(R_{3}+R_{4}\right)^{2}\right]^{1 / 2} \\
& -\left[P_{14}^{2}-\left(R_{4}+R_{1}\right)^{2}\right]^{1 / 2}+R_{2}\left[-\frac{\pi}{2}+\sin ^{-1}\left\{\frac{\left[P_{12}^{2}-\left(R_{1}+R_{2}\right)^{2}\right]^{1 / 2}}{P_{12}}\right\}\right. \\
& \left.+\sin ^{-1}\left\{\frac{\left[P_{23}^{2}-\left(R_{2}+R_{3}\right)^{2}\right]^{1 / 2}}{P_{23}}\right\}\right]+R_{4}\left[-\frac{\pi}{2}\right. \\
& \left.+\sin ^{-1}\left\{\frac{\left[P_{34}^{2}-\left(R_{3}+R_{4}\right)^{2}\right]^{1 / 2}}{P_{34}}\right\}+\sin ^{-1}\left\{\frac{\left[P_{14}^{2}-\left(R_{1}+R_{4}\right)^{2}\right]^{1 / 2}}{P_{14}}\right\}\right] \\
& +R_{1}\left[\frac{\pi}{2}+\sin ^{-1}\left\{\frac{\left[P_{12}^{2}-\left(R_{1}+R_{2}\right)^{2}\right]^{1 / 2}}{P_{12}}\right\}+\sin ^{-1}\left\{\frac{\left[P_{14}^{2}-\left(R_{1}+R_{4}\right)^{2}\right]^{1 / 2}}{P_{14}}\right\}\right] \\
& +R_{3}\left[\frac{\pi}{2}+\sin ^{-1}\left\{\frac{\left[P_{23}^{2}-\left(R_{2}+R_{3}\right)^{2}\right]^{1 / 2}}{P_{23}}\right\}+\sin ^{-1}\left\{\frac{\left[P_{34}^{2}-\left(R_{3}+R_{4}\right)^{2}\right]^{1 / 2}}{P_{34}}\right\}\right] \\
& \left.-2\left(R_{1}+R_{3}\right) \sin ^{-1}\left\{\frac{\left[P_{13}^{2}-\left(R_{1}+R_{3}\right)^{2}\right]^{1 / 2}}{P_{13}}\right\}\right\} \frac{1}{4 \pi R_{1}}
\end{aligned}
$$

For $R_{1}=R_{2}=R_{3}=R_{4}=R, P_{12}=P_{23}=P_{34}=P_{41}=P$, and $P_{13}=P_{24}=2 P$, the $F_{13}$ view factor is simplified to the following form: 


$$
\begin{aligned}
F_{13}= & \frac{1}{\pi R}\left[\left(P^{2}-R^{2}\right)^{1 / 2}-\left(P^{2}-4 R^{2}\right)^{1 / 2}+2 R \sin ^{-1} \frac{\left(P^{2}-4 R^{2}\right)^{1 / 2}}{P}\right. \\
& -R \sin ^{-1}\left\langle P^{2}-\frac{\left.2 R^{2}\right)^{1 / 2}}{P}\right]
\end{aligned}
$$

Derivation of view factors of a third nearest rod (Figure $3-24$ ), F $75^{\text {, }}$ is similar to that for the diagonal rod:

$$
\begin{aligned}
& F_{15}=\left\{2\left[P_{15}^{2}-\left(R_{1}+R_{5}\right)^{2}\right]^{1 / 2}-\left[P_{12}^{2}-\left(R_{1}+R_{2}\right)^{2}\right]^{1 / 2}\right. \\
& -\left[P_{25}^{2}-\left(R_{2}+R_{5}\right)^{2}\right]^{1 / 2}-\left[P_{35}^{2}-\left(R_{3}+R_{5}\right)^{2}\right]^{1 / 2} \\
& -\left[P_{13}^{2}-\left(R_{1}+R_{3}\right)^{2}\right]^{1 / 2}+R_{1}\left[\frac{\pi}{4}+\sin ^{-1}\left\{\frac{\left[P_{12}^{2}-\left(R_{1}+R_{2}\right)^{2}\right]^{1 / 2}}{P_{12}}\right\}\right. \\
& \left.+\sin ^{-1}\left\{\frac{\left[P_{13}^{2}-\left(R_{1}+R_{3}\right)^{2}\right]^{1 / 2}}{P_{13}}\right\}-2 \sin ^{-1}\left\{\frac{\left[P_{15}^{2}-\left(R_{1}+R_{5}\right)^{2}\right]^{1 / 2}}{P_{15}}\right\}\right] \\
& +R_{3}\left[\frac{\pi}{4}+\sin ^{-1}\left\{\frac{\left[P_{25}^{2}-\left(R_{2}+R_{5}\right)^{2}\right]^{1 / 2}}{P_{25}}\right\}+\sin ^{-1}\left\{\frac{\left[P_{35}^{2}-\left(R_{3}+R_{5}\right)^{2}\right]^{1 / 2}}{P_{35}}\right\}\right. \\
& -2 \sin ^{-1}\left\{\frac{\left[P_{15}^{2}-\left(R_{1}+R_{5}\right)^{2}\right]^{1 / 2}}{P_{15}}\right\}-R_{2}\left[\frac{\pi}{4}-\sin ^{-1}\left\{\frac{\left[P_{\left.12^{-}\left(R_{1}+R_{2}\right)^{2}\right]^{1 / 2}}^{2}\right.}{P_{12}}\right\}\right. \\
& \left.+\sin ^{-1}\left\{\frac{R_{2}+R_{5}}{P_{25}}\right\}\right]-R_{3}\left[\frac{\pi}{4}-\sin ^{-1}\left\{\frac{\left[P_{35}^{2}-\left(R_{3}+R_{5}\right)^{2}\right]^{1 / 2}}{P_{35}}\right\}\right. \\
& \left.\left.+\sin ^{-1}\left\{\frac{R_{1}+R_{3}}{P_{13}}\right\}\right)\right\} \frac{1}{4 \pi R_{1}}
\end{aligned}
$$


For $R_{1}=R_{2}=R_{3}=R_{5}=R$, the relation for view factor $F_{15}$ simplifies to the following:

$$
\begin{aligned}
F_{15}= & \left\{2\left(P_{15}^{2}-4 R^{2}\right)^{1 / 2}-\left(P_{12}^{2}-4 R^{2}\right)^{1 / 2}-\left(P_{25}^{2}-4 R^{2}\right)^{1 / 2}\right. \\
& -\left(P_{35}^{2}-4 R^{2}\right)^{1 / 2}-\left(P_{13}^{2}-4 R^{2}\right)^{1 / 2}+R\left[2 \sin ^{-1}\left\{\frac{\left(P_{12}^{2}-4 R^{2}\right)^{1 / 2}}{P_{12}}\right\}\right. \\
& +2 \sin ^{-1}\left\{\frac{\left(P_{35}^{2}-4 R^{2}\right)^{1 / 2}}{P_{35}}\right\}+\sin ^{-1}\left\{\frac{\left(P_{15}^{2}-4 R^{2}\right)^{1 / 2}}{P_{15}}\right\}+\sin ^{-1}\left\{\frac{\left(P_{25}^{2}-4 R^{2}\right)^{1 / 2}}{P_{25}}\right\} \\
& \left.-4 \sin ^{-1}\left\{\frac{\left(P_{15}^{2}-4 R^{2}\right)^{1 / 2}}{P_{15}}\right\}-\sin ^{-1}\left(\frac{2 R}{P_{25}}\right)-\sin ^{-1}\left(\frac{2 R}{P_{13}}\right)\right] \frac{1}{4 \pi R} \cdot \frac{1}{(3-211)}
\end{aligned}
$$

For the rods placed in a square geometry, this expression is further simplified to the following. In this case,

$$
\begin{aligned}
P_{12}= & P_{35}=P, P_{25}=P_{13}=2 P \text { and } P_{15}=5 P \\
F_{15}= & \left\{\left(5 P^{2}-4 R^{2}\right)^{1 / 2}-2\left(P^{2}-2 R^{2}\right)^{1 / 2}-\left(P^{2}-4 R^{2}\right)^{1 / 2}\right. \\
& +R\left[2 \sin ^{-1}\left\{\frac{\left(P^{2}-4 R^{2}\right)^{1 / 2}}{P}\right\}+\sin ^{-1}\left\{\frac{\left(P^{2}-2 R^{2}\right)^{1 / 2}}{P}\right\}\right. \\
& \left.\left.-2 \sin ^{-1}\left\{\frac{\left(5 P^{2}-4 R^{2}\right)^{1 / 2}}{5 P}\right\}-\sin ^{-1}\left(\frac{\sqrt{2 R}}{P}\right)\right]\right\} \frac{1}{2 \pi R} .
\end{aligned}
$$

All the view factors described above are for cylindrical rods of infinite length. According to Juul, 3.47 for a typical reactor core $(P / R \simeq 3.0)$, the application of infinite-length view factors to a case of finite length does not cause any significant error $(\approx 5 \%)$. Therefore, it 
is reasonable to use Equations (3-206) through (3-212) to calculate view factors for rods of finite length.

To evaluate view factors between all the rods in a bundle, the following methodology and assumptions are used.

For any surface in an enclosure, the summation rule,

$$
\sum_{j=1}^{n} F_{i j}=1
$$

must be satisfied. This rule implies that for an enclosure, all the radiant energy leaving any surface must reach other surfaces (including itself). In the present model, no rod sees another rod beyond two rows or columns. This assumption implies that a portion of energy leaving a rod that would have reached some rods lying beyond two rows or columns has to be accounted for elsewhere. Therefore, the residual view factor of a component group is distributed to other component groups in proportion to the original view factors. To calculate the view factor, $F_{i j}$, from one component group $i$ to another component group $j$, the following relation is used:

$F_{I J}=\frac{1}{N_{I}} \sum_{i=1}^{N_{I}} \sum_{j=1}^{N_{J}} F_{i j}$

where $\mathrm{N}_{I}$ and $\mathrm{N}_{\mathrm{J}}$ are the number of rods in component groups $\mathrm{I}$ and $\mathrm{J}$, respectively.

All the rods in one component group have the same radius. The view factor evaluation must satisfy the reciprocity rule, $A_{I} F_{I J}=A_{J} F_{J I}$, also. This rule implies that the ratio of the view factors of two surfaces with each other is equal to the inverse of the ratio of their respective areas. Therefore, the view factors $F_{I J}$ for $I>J$ have been 
obtained by the reciprocity rule. For $1<J$, the view factors are obtained from first principles and by using Equation (3-214). For $I=J$, the summation rule is used to obtain the view factor of a component group to itself.

If a shroud is present around a bundle of $M \times N$ size, only the outermost rows and columns of rods $(i=1$ or $M$, or $j=1$ or $N)$ are considered to exchange radiant energy with the shroud. In such a case, the residual view factor for these peripheral rods is accounted for in the view factor to the shroud. Thus, for these rods, $F_{i j}=0$; but the component group I to which the rod $i$ belongs can still see itself, that is, $F_{I I}$, can be nonzero. If a rod is missing in the peripheral location of the bundle, the rod next to it in the inner row and column $(1<\mathrm{i}<M$ or $1<j<N)$ is allowed to exchange energy with the shroud just as a peripheral rod. The view factors of the shroud also have to satisfy the summation and reciprocity rules.

\subsubsection{Mean Path Length}

According to Siege 1 and Howe $11^{3-42}$ mean path length is defined as a fictitious length, i.e. the radius of a gas hemisphere, such that the radiation heat flux to the center of its base is equal to the average radiation flux exchange by the gas and two surface areas containing the actual volume of gas.

For any two areas $A_{j}$ and $A_{j}$ located at a distance of $S$ (shortest distance along the path of radiation), let $\beta_{i}$ and $\beta_{j}$ be the angles between the shortest distance line and the normals on the two surfaces, respectively. Then the mean path length, $L_{i j}$, can be evaluated by

$$
L_{i j}=-\frac{1}{a_{g i j}} \ln \frac{1}{A_{i} F_{i j}} \int_{A_{i}} \int_{A_{j}} \exp \left(-a_{g i j} S\right) \frac{\cos \beta_{i} \cos \beta_{j}}{\pi S^{2}} d A_{i} d A_{j} .
$$


This equation is difficult to evaluate for a reactor vessel with complicated rod geometry. Therefore, as is done for other radiation models, 3-34,37 the mean path length is taken to be equal to or a function of the distance between the two geometries for which the radiation solution is being sought. The path length between any two rods is obtained by the following equation:

$L_{i j}=P_{i j}-\pi\left(R_{i}+R_{j}\right) / 2$.

To calculate the average path length between two component groups, the path length between any two rods (subcomponents) is weighted by the corresponding view factor. If $N_{1}$ and $N_{j}$ are the number of rods (subcomponents) in component groups $I$ and $J$ respectively, then the average path length between any two component groups $I$ and $J$ is given by loptically thin approximation)

$L_{I J}=\sum_{i=1}^{N_{I}} \sum_{j=1}^{N_{j}} F_{i j} L_{i j} / \sum_{j=1}^{N_{I}} \sum_{j=1}^{N_{j}} F_{i j}$.

\subsubsection{Absorptivities and Emissivities}

The absorptivities and emissivities of the surfaces are obtained from the MATPRO package. 3-2 The surface emissivity (which equals absorptivity) is computed by the following equations:

$$
\varepsilon_{i}= \begin{cases}0.808642-500 \mathrm{Z}, 1 \leq 1500 \mathrm{~K} & \\
\text { Larger of }\left\{\begin{array}{l}
\varepsilon_{\mathfrak{i}} \exp [(1500-\mathrm{T}) / 300] \\
0.325
\end{array}\right. & , \mathrm{T} \leq 1500 \mathrm{~K} \\
01500 \mathrm{~K}\end{cases}
$$

where $Z$ is the zirconium oxide thickness in meters. Zirconium oxide thickness would be expected to vary from zero to about $900 \mu \mathrm{m}$. A value of $300 \mu \mathrm{m}$ is taken that results in an average value for $\varepsilon_{;}$of 0.7936 . At present, the shroud surface is assumed to have the same radiation properties as the fuel rods. 
Vapor absorptivities and emissivities are calculated in the same manner as is done in TRAC-BDI. 3-34,35 For vapor, the absorption coefficient $K_{g i j}$, is evaluated after determining emissivity and absorptivity,

$K_{g i j}=-\frac{\ln \left(1-a_{g i j}\right)}{L_{i j}}$.

At present, the emissivity and absorptivity of the gaseous medium is obtained in a manner similar to that used in TRAC-BDI. That method is reproduced here for the sake of completeness.

The emissivity of an absorbing gaseous medium for monochromatic radiation of wave length $\lambda$ is given by the following equation

$\varepsilon_{\lambda}=1-\exp \left(-K_{\lambda} \mathrm{PL}_{\mathbf{i j}}\right)$

where

p $=$ pressure $(\mathrm{Pa})$

$k_{\lambda}=$ spectral absorption coefficient $(\mathrm{Pa} \cdot \mu \mathrm{m})^{-1}$.

The total hemispherical emittance is defined as the ratio of the emissive power e of a given surface to that of a black surface $e_{b}$ at the same temperature.

$$
\begin{aligned}
\varepsilon_{g} & =\frac{e}{e_{b}} \\
& =\frac{\int_{0}^{\infty} \varepsilon_{\lambda} e_{b \lambda}(T) d \lambda}{\int_{0}^{\infty} e_{b \lambda}(T) d \lambda}
\end{aligned}
$$




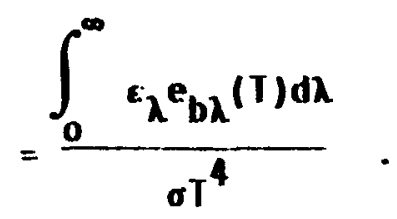

The Planck function, $e_{b \lambda}$, is given by

$e_{b \lambda}=\frac{2 \pi h c^{2} / \lambda^{3}}{\exp (h c / \lambda k T)-1}$

where
$n=$ Planck's constant, $6.625 \times 10^{-34}(\mathrm{~J} \cdot \mathrm{s})$
$k=$ Boltzmann's constant, $1.38 \times 10^{-23}(\mathrm{~J} / \mathrm{K})$
C = the speed of light in the medium,
= speed of light in vacuum/refractive index of the medium,
$=2.998 \times 10^{8}(\mathrm{~m} / \mathrm{s}) /$ refractive index of the medium.

The absorptivity, $a_{g}$, of the medium is obtained by evaluating an equation similar to that for emissivity at the temperature of the surface emitting the radiation incident on the absorbing medium.

$a_{g}=\frac{\int_{0}^{\infty} a_{\lambda} e_{b \lambda}\left(T_{s}\right) d \lambda}{\sigma T_{s}^{4}}$

where $a_{\lambda}=\varepsilon_{\lambda}$ by Kirchhoff's law in thermodynamic equilibrium.

The absorption spectrum of water vapor is considered to consist of six major absorption bands, as reported by Hottel and Sarofim. ${ }^{3-48}$ Table 3-18 shows the wave length and absorption coefficients, $K_{\lambda_{0}}$, of these bands at $300 \mathrm{~K}$. At other temperatures, absorption coefficients can be obtained by 
TABLE 3-18. WATER VAPOR ABSORPIION DATA AT $300 \mathrm{~K}$

\begin{tabular}{|c|c|c|c|}
\hline $\begin{array}{l}\text { Wave Length } \\
\text { at Band Center } \\
\end{array}$ & $\begin{array}{c}\text { Minimum Wave } \\
\text { Length } \\
(\mu \mathrm{m})\end{array}$ & $\begin{array}{l}\text { Maximum Wave } \\
\text { Length } \\
-(\mu \mathrm{m})\end{array}$ & $\begin{array}{l}\text { Absorption Coefficient } \\
\mathrm{K}_{\mathrm{go}}(\mathrm{Pa} \cdot \mu \mathrm{m})^{-1}\end{array}$ \\
\hline 1.1 & 7.1017 & 1.1809 & 0.523 \\
\hline 1.38 & 1.3243 & 1.4405 & 13.42 \\
\hline 1.87 & 1.7693 & 1.9829 & 16.38 \\
\hline 2.7 & 2.495 & 2.942 & 204.19 \\
\hline 6.3 & 5.2854 & 7.7942 & 283.64 \\
\hline 20.0 & 12.43 & 51.1509 & 94.65 \\
\hline
\end{tabular}


$K_{\lambda}=K_{\lambda_{0}}\left(\frac{300}{7}\right)$.

The values of $k_{\lambda}$ used in the present mode 1 are assumed to be constant within each wavelength band and zero elsewhere. Therefore, integral relations for emissivity and absorptivity can be approximated as the sums over the wavelength bands given in Table 3-18.

$$
\begin{aligned}
& \varepsilon_{g}=\frac{1}{\sigma T^{4}} \sum_{i=1}^{6} \varepsilon_{\lambda i} \vec{e}_{\lambda i}(T) \Delta \lambda_{i} \\
& a_{g}=\frac{1}{\sigma T_{s}^{4}} \sum_{i=1}^{6} \varepsilon_{\lambda i} \bar{e}_{\lambda i}\left(T_{s}\right) \Delta \lambda_{j}
\end{aligned}
$$

where

$$
\begin{aligned}
\mathbf{i} & =\text { wavelength band index } \\
\mathbf{e}_{\lambda \mathbf{i}} & =\begin{array}{l}
\text { average value of the Plank black body function evaluated } \\
\text { at the wave length at band center }
\end{array} \\
T_{\mathrm{S}} & =\text { Temperature of the gaseous medium } \\
1_{S} & \text { Surface temperature. }
\end{aligned}
$$

\subsection{Core Region Debris Modeling}

\subsection{2 .1 Introduction}

Damage mechanisms exist during a severe accident in a LWR that can change a reactor core from an array of distinct cylindrical fuel rods located in the center of the reactor vessel to a deep debris bed located in the bottom of the vessel. The reactor vessel itself becomes vulnerable to 
heatup and damage after the core has relocated to the lower head. The TMI -2 accident ${ }^{3-49}$ and severe fuel damage experiments $3-50,51,52,53,54,55$ have shown that reactor core damage proceeds through several stages before the core slumps to the lower head. These stages of damage progression include: (a) embrittlement of cladding due to oxidation; (b) melting of metallic cladding and dissolution of fuel in contact with liquefied cladding; (c) slumping of liquefied cladding and dissolved fuel due to fallure ot the oxide shell containing the liquefied mixture;

(d) solidification of the slumped mixture at a lower and cooler location in the core and concurrent formation of a nonporous debris region that blocks the flow of coolant; (e) meltdown of the reactor core into a molten pool supported by the nonporous debris; and ( $f$ ) meltthrough of the nonporous debris and slumping of the molten pool to the bottom of the reactor vessel. An hour or more of time may elapse before damage has progressed through these six stages. This order of damage progression is established by the differences in melting temperatures of the metallic and ceramic parts of the reactor core. It is also established by the fact that the lower part of the reactor is the last part of the core to be uncovered by water and that this part has a lower level of decay heat than the center of the core.

The damage progression can be either abated or intensified by the injection of water into the reactor vesse1. On one hand, the injected water may cool the damaged core and stop damage progression. On the other hand, the injected water may shatter embrittled fuel rods so that the fuel rod fragments slump into the configuration of a porous debris bed.

Models to predict the progression of reactor core damage have been developed and incorporated into SCDAP/RELAP5. These mode1s calculate the changes in the configuration of the reactor core as damage progresses. The models also calculate the heatup and progression of melting in the damaged regions of the reactor core. This section of the report describes these models for damage progression. 
The reactor core can change into three basic configurations as damage progresses during a severe accident. In the first configuration, nonporous debris supported by intact fuel rods extends radialiy across the core. This configuration is the result of the meltdown of the metallic part of the reactor core. In the case of the TMI-2 accident, this nonporous debris was in the shape of a crucible. ${ }^{3-56}$. The second basic configuration is that of a porous debris bed. The third basic configuration is that of a molten pool supported and contained by the nonporous debris. Before damage has occurred, the configuration of the core is characterized by parameters such as rod spacing and rod diameter. After damage has occurred, the configuration is characterized by parameters such as depth and porosity of debris. If the porosity is large and the debris is covered with water, then most of the decay heat in the debris can be removed by convective cooling. But, if the porosity is small and the debris bed is deep, then a large molten pool may develop. At this stage, there is the potential for rapid slumping of a large amount of hot material onto the lower head of the reactor vessel and the possibility of a vigorous thermal attack of the lower head.

\subsubsection{Formation and Heatup of Nonporous Debris}

The degeneration of part of the reactor core into nonporous debris is a state of damage caused by the meltdown of control rods and the metallic part of fuel rods. The meltdown may begin as soon as a region of the core exceeds the temperature for eutectic melting of stainless steel-clad control rods with silver-indium-cadmium (Ag-In-Cd) absorber material. This temperature is about $1500 \mathrm{~K}$. The meltdown becomes widespread when a region of the reactor core exceeds the melting temperature (about $2200 \mathrm{~K}$ ) of the fuel rod cladding. The meltdown and subsequent solidification of the relocated metalic material may completely fill in the space between fuel rods and result in a nonporous debris bed that consists of a metalic hardpan with embedded, intact fuel rods. The thickness varies depending upon the extent of oxidation of the cladding and the extent of fue 1 dissolution by the liquefied cladding. In the case of the TMI-2 accident, the metaliic nonporous debris was 0.05 - to $0.10-\mathrm{m}$ thick. The nonporous 
debris usually begins to form first in the hot center part of the core and then spreads radially outward as the outer portions of the core oxidize and melt down.

The layer of slumped and solidified material that results from fuel rod meltdown is treated as a nonporous debris bed with a thickness varying in the radial direction. Figure 3-25 shows the configuration of the nonporous debris bed and the heat transfer considered to take place within the debris. The thickness of the debris is constant within each user-defined group of fuel rods. A fuel rod group is a collection of fuel rods defined by the code user to have identical behavior. The behavior of one representative rod in the group is calculated, and all of the other rods are considered to behave in identical behavior. The temperature gradient in the radial direction in the nonporous debris is assumed to be negligible. Based on this simplifying assumption, the heatup of the nonporous debris within each fuel rod group is calculated, taking into account axial heat conduction and the transfer of heat by convection and radiation from the bottom and top surfaces of nonporous debris. The internal heat generation in the embedded fuel rods is also taken into account.

An integral method is used to calculate the neatup of nonporous debris. The heatup is calculated by the calculation

$\alpha\left[\frac{\partial T(\partial, t)}{\partial z}-\frac{\partial T(0, t)}{\partial z}\right]=\frac{d}{d t}\left[\int_{0}^{\delta} T(z, t) d z\right]-\frac{\delta \dot{q}}{\partial C_{p}}$

where

$\begin{aligned} \alpha & =\text { thermal diffusivity of nonporous debris }\left(\mathrm{m}^{2} / \mathrm{s}\right) \\ \delta \quad & \text { thickness of nonporous debris }(\mathrm{m}) \\ T(z, t) & =\text { temperature of nonporous debris }(K) \\ t & =\operatorname{time}(\mathrm{s})\end{aligned}$




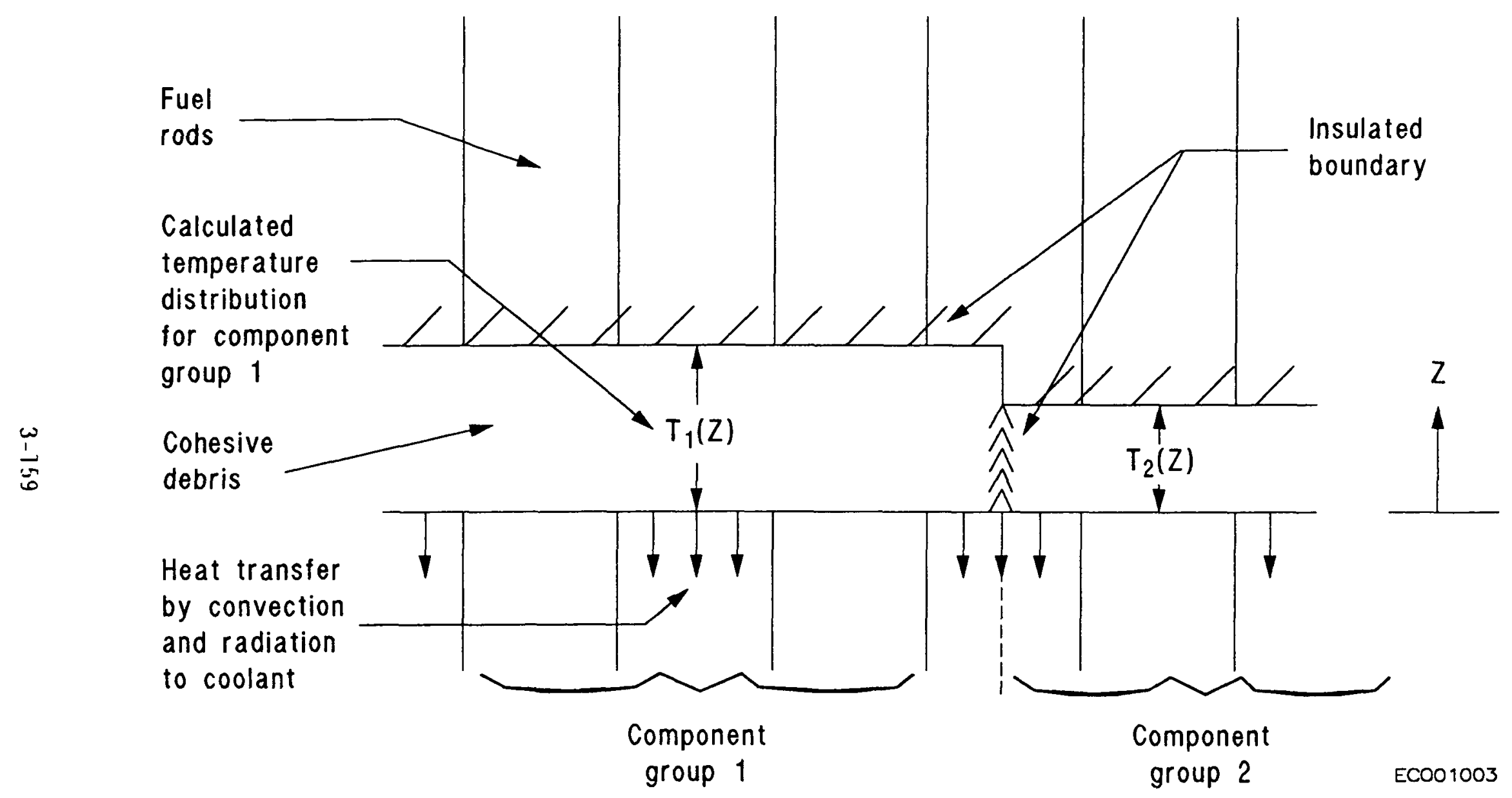

Figure 3-25. Heat conduction process modeled for cohesive debris. 

$z=$ elevation $(\mathrm{m}): z=0=$ bottom surface of debris; $z=\delta=$ top surface
$\dot{q}=$ volumetric heat generation rate in debris, including heat generation of fuel rods embedded in debris $\left(\mathrm{w} / \mathrm{m}^{3}\right)$
$\rho \quad=\operatorname{density}\left(\mathrm{kg} / \mathrm{m}^{2}\right)$
$C_{p}=$ heat capacity $(\mathrm{J} / \mathrm{kg} \cdot \mathrm{K})$.

The boundary conditions applied to Equation (3-227) are:

$$
\begin{aligned}
& k \frac{\partial T(0, t)}{\partial z}=\varepsilon \sigma\left[T(0, t)^{4}-T_{\cos 1}^{4}\right]+h_{\text {conv }}\left[T(0, t)-T_{c 001}\right] \\
& k \frac{\partial T(\delta, t)}{\partial z}=\varepsilon \sigma\left[T(\delta, t)^{4}-T_{\cos 12}^{4}\right]+h_{\operatorname{conv} 2}\left[T(\delta, t)-T_{\cos 12}\right]
\end{aligned}
$$

where

$$
\begin{aligned}
& k=\text { thermal conductivity } \mathrm{W} / \mathrm{m} \cdot \mathrm{K}) \\
& \varepsilon \quad=\text { emissivity } \\
& \sigma \quad \text { Stefan-Boltzmann constant }\left(5.668 \mathrm{E}^{-8} \mathrm{~W} / \mathrm{m}^{2} \cdot \mathrm{K}^{4}\right) \\
& T_{\text {cool }}=\text { coolant temperature }(\mathrm{K}) \\
& T_{\text {cool2 }}=\text { coolant temperature at top surface }(K) \\
& h_{\text {conv }}=\text { convective heat transfer coefficient }\left(\mathrm{W} / \mathrm{m}^{2} \cdot K\right) \\
& h_{\text {conv2 }}=\text { convective heat transfer coefficient at top surface }
\end{aligned}
$$

The temperature distribution in the nonporous debris is assumed to be parabolic: 
$T(z, t)=a+b z+c z^{2}$.

Coefficients $a, b$, and $c$ in Equation (3-230) are obtained by the simultaneous solution of Equations (3-227), (3-228), and (3-229). A solution for the temperature distribution is performed at each time step for each component group of fuel rods where nonporous debris is located.

\subsubsection{Formation and Heatup of Porous Debris}

The thermal shocking by reflood water of a reactor core embrittled by oxidation results in the formation of porous debris. This section describes models for the formation and heatup of porous debris.

A study performed by Haggag ${ }^{3-57}$ concluded that the Chung and Kassner mode $7^{3-58,59}$ accurately predicts the embrittlement and fragmentation of oxidized fuel rods. According to this model, cladding is embrittled when

$\Delta r_{\text {beta }}<0.1$

where $\Delta r_{\text {beta }}$ is the thickness of the cladding in the beta phase (mm).

Embrittled fuel rods are considered to break into particles during cooldown when the cladding temperature has decreased to

$\mathrm{T}_{\text {clad }}<\mathrm{T}_{\text {sat }}+\mathrm{T}_{\mathrm{x}}$

where

$$
\begin{aligned}
& T_{\text {clad }}=\text { the temperature of the cladding }(K) \\
& T_{\text {sat }}=\text { the saturation temperature of the coolant }(K) \\
& T_{x=} \begin{array}{l}
\text { a variable with a value ranging from } 50 \text { to } 1273 \mathrm{~K} \text { that is } \\
\text { a function of the rate of cooldown. The value of this } \\
\text { variable is defined by the code user. }
\end{array}
\end{aligned}
$$


The porosity and particle size of the debris resulting from fragmentation is assumed to be the same as that formed by thermal shock during the TMI-2 accident. Analys is $3-60,61$ of this debris determined that it had an average porosity of $0.54 \mathrm{~mm}$ and an average particle diameter of $0.87 \mathrm{~mm}$. The characteristics of the TMI-2 debris varied spatially, but these varlations are not taken into account in the modeling.

A second mechanism for fragmentation of a reactor core is instigated by the melting of cladding with a very thin oxide layer and a small enough amount of dissolved oxygen that it will not wet the fuel. Evidence for this mechanism is the debris formation that occurred in the upper part of the fue 1 bundle in the PBF Severe Fuel Damage Experiment 1-4. 3-62 Little oxidation occurred in this part of the fuel bundle due to steam starvation. The results of the postirradiation examination for this experiment indicate that the debris in this part of the bundle had characteristics similar to the upper debris bed in the damaged TMI-2 core. This mode of debris formation is modeled to occur when

$\mathrm{T}_{\mathrm{clad}}>\mathrm{T}_{\mathrm{m}}$ and $\mathrm{t}_{\mathrm{ox}}<1 \times 10^{-2}$

where

$$
\begin{aligned}
& \mathrm{T}_{\mathrm{m}}=\begin{array}{l}
\text { the melting temperature of the metallic cladding } \\
\text { (approximately } 2200 \mathrm{~K} \text { ) }
\end{array} \\
& \mathrm{t}_{\mathrm{ox}}=\text { the thickness of the cladding oxide }(\mathrm{mm}) .
\end{aligned}
$$

The heatup of porous debris is calculated using a lumped mass approach. The debris particles at an axial node of a fuel rod group are considered to constitute one lumped mass. Convective heat transfer between the debris particles and the fluid in the debris porosity is considered to be the only mechanism that can remove heat from the debris. The debris heatup is calculated by the equation

$$
\left(M_{1} c_{p l}+M_{2} c_{p l}+\ldots\right)_{i j}\left(d T_{i j} / d t\right)=P_{i j} A_{i j} \Delta z_{i j}+Q_{r i j}
$$


where

\begin{tabular}{|c|c|c|}
\hline$M_{1 i j}$ & $=$ & $\begin{array}{l}\text { mass of a type of material at axial node } i \text { of fuel rod } \\
\text { group } j(\mathrm{~kg})\end{array}$ \\
\hline${ }^{c} p 1 \mathrm{ij}$ & $=$ & heat capacity $(\mathrm{J} / \mathrm{kg} \cdot \mathrm{K})$ \\
\hline$T_{i j}$ & $=$ & temperature of the debris particles (K) \\
\hline$P_{i j}$ & $=$ & volumetric heat generation rate $\left(\mathrm{W} / \mathrm{m}^{3}\right)$ \\
\hline$A_{i j}$ & $=$ & cross-sectional area $\left(m^{2}\right)$ \\
\hline$\Delta z_{i j}$ & $=$ & height of the $i$-th axial node $(m)$ \\
\hline$Q_{r i j}$ & $=$ & $\begin{array}{l}\text { rate of heat transfer between the fluid and the debris } \\
\text { particles at the } i \text {-th axial node of fuel rod group } j \text { (W) }\end{array}$ \\
\hline
\end{tabular}

The method used to calculate the latter variable is described below. The heatup model accounts for decay heat in the debris particles but does not account for any oxidation of the particles. The model accounts for the heat of fusion of each material in the debris. The model is applied when the temperature of the debris is less than the melting temperature of the fuel and cladding oxide. After ceramic melting begins, the debris temperature is calculated by the molten pool model described in the following section.

An arbitrary distribution of porous debris throughout the reactor core region is taken into account in the modeling. At each time step, a map is constructed of the debris regions resulting from degeneration of segments of fuel rods into porous debris. This map is constructed in two steps. In the first step, an examination for fragmentation is made of each axial node of each fuel rod group defined by the code user. An identification is made of each axial node that satisfied the criteria for fragmentation. In the second step, each axial node with fragmented fuel rods is examined to 
determine whether it is contiguous at its bottom or top surface with another axial node with fragmented fuel rods. The axial nodes that are contiguous are combined into one debris region. An example of debris region mapping is shown in Figure 3-26. In the example, the reactor core was discretized into two groups of fuel rods, each of which was discretized into four axial nodes. In the example, fuel rod fragmentation has occurred at axial nodes 3 and 4 of rod group 1 . These two fragmented fuel rods are combined into one debris region.

A fuel rod group defined by the code user may contain control rods. Any residue of control rods in that group is considered to be well mixed with the fuel rod debris.

The method used to calculate the heat removal term $Q_{r i j}$ in the debris heatup equation is presented next. The calculation requires that the code user defines a RELAP5 control volume for each axial node of each group of fuel rods. Three states of the debris are identified, and an equation for the rate of heat removal is presented for each state. The three states of the debris are: (a) debris in state of dryout; (b) debris in process of being quenched; and $(c)$ debris in state of quench. The determination of the state of the debris is based upon the coolant void fraction and the debris temperature. The debris is considered to be in a state of dryout when

$\alpha_{g}>0.9999$

where $a_{g}$ is the volume fraction of coolant in the vapor phase in the RELAP5 control volume containing the debris. The debris is considered to be in a state of quench when

$\alpha_{g}<0.9999$

$T_{i j}<T_{\text {sat }}$

where $T_{i j}$ is the temperature of the debris $(K)$. The debris is considered to be in a transition state when 


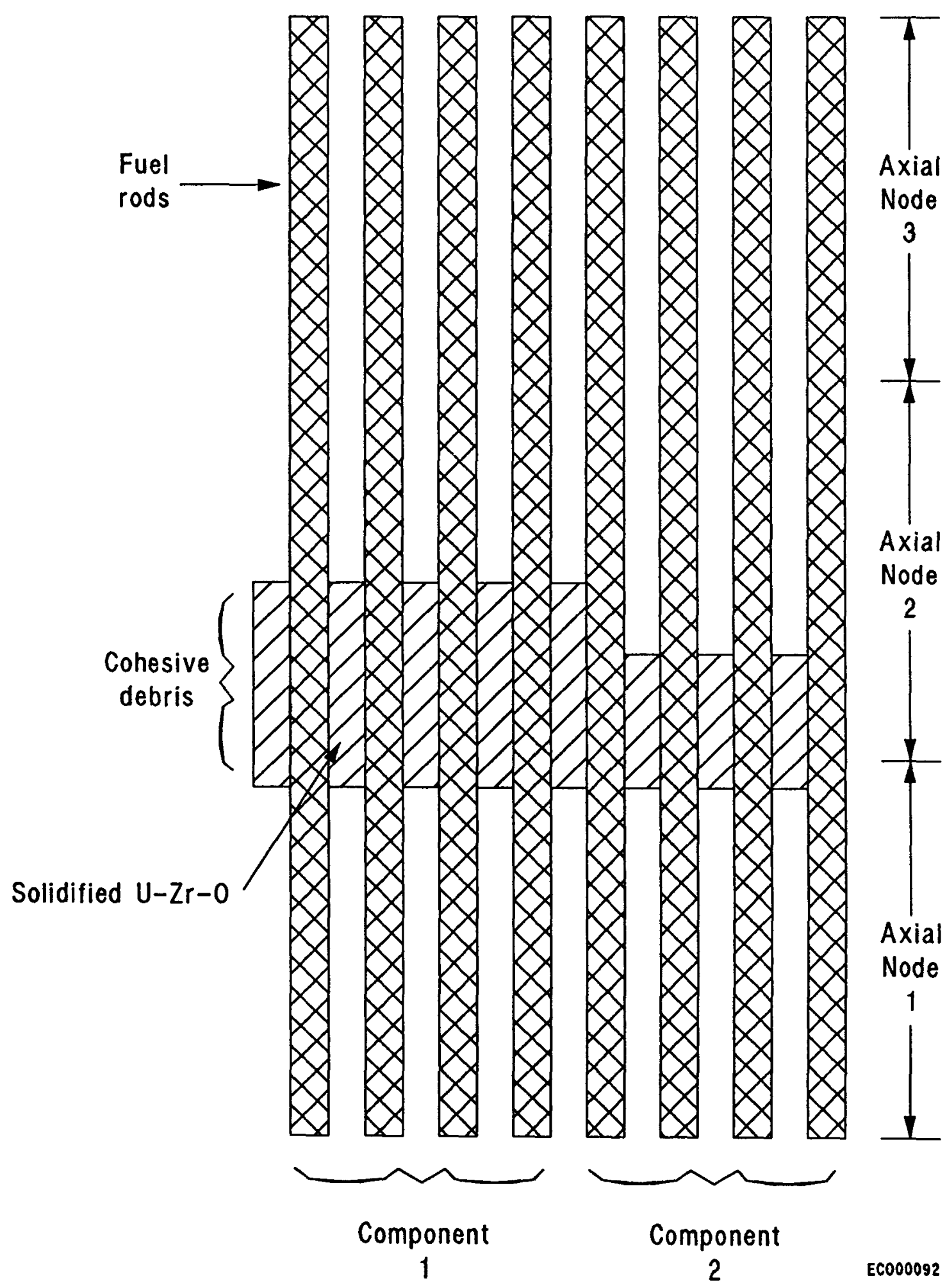

Figure 3-26. Example of calculated layout of rod-like and cohesive debris regions. 
$\alpha_{g}<0.9999$

$T_{i j}>T_{\text {sat }}$

For debris in a state of dryout, the heat transfer between the debris and vapor is calculated taking into account that the vapor has a small heat capacity relative to the debris and that the ratio of surface area to flow area is large. The assumption is made that vapor fluxing through a RELAP5 control volume attains the same temperature as the debris in that volume. This assumption applies for vapor velocities typical of those in a severe accident $(0.01$ to $0.1 \mathrm{~m} / \mathrm{s})$. The rate of heat transfer between the debris and vapor is calculated using the equation

$$
Q_{r i j}=\varepsilon A_{i j} \rho_{i j} v_{i j}\left[h\left(T_{i j}, P_{i j}\right)-h\left(T_{i n}, P_{i j}\right)\right]
$$

where

$$
\begin{aligned}
& \varepsilon=\text { porosity of the debris } \\
& \rho_{\mathbf{i j}}=\text { density of the fluid }\left(\mathrm{kg} / \mathrm{m}^{3}\right) \\
& \mathbf{v}_{\mathbf{i j}}= \text { velocity of the fluid }(\mathrm{m} / \mathrm{s}) \\
& \mathrm{h}(\mathrm{T}, \mathrm{P})= \begin{array}{l}
\text { enthalpy of the fluid }(\mathrm{J} / \mathrm{kg}) \text { at a temperature of } T(K) \\
\text { and pressure of } P(P a)
\end{array} \\
& T_{i n} \begin{array}{l}
\text { temperature of the fluid as it fluxes into the RELAP5 } \\
\text { control volume at the } i \text {-th axial node of the } j \text {-th fue } 1
\end{array} \\
& \text { rod group }(K) .
\end{aligned}
$$

The modeling of heat transfer in debris that is in a state of transition between dryout and quench is based on the idea of a quench front passing through the debris. The presence of such a quench front has been observed in experiments. $3-63,64,65,66$ The modeling assumes that the rate of heat removal from the debris is proportional to the velocity of the 
quench front. For a top-down quench, the quench front velocity is limited by the interphase drag between vapor fluxing upward and liquid fluxing downward.

The quench front velocity is calculated taking into account the force balance between flooding water and vapor produced by contact of flooding water with hot debris. Figure 3-27 shows the process that is modeled. Debris at the location of the quench front is considered to immediately transfer all of its stored thermal energy to the flooding water and generate vapor. The velocity of the quench front and the rate of vapor generation increase until the interphase drag between the vapor and liquid limits the rate at which liquid fluxes downward in response to gravity. The velocity of the quench front is related to the RELAP5-calculated rate of change of the volume fraction of liquid in the control volume containing the debris. The velocity is calculated by

$\left(d z_{q} / d t\right)=\left[\alpha_{f}(t+\Delta t)-\alpha_{f}(t)\right] / \varepsilon A_{1 j} d t$

where

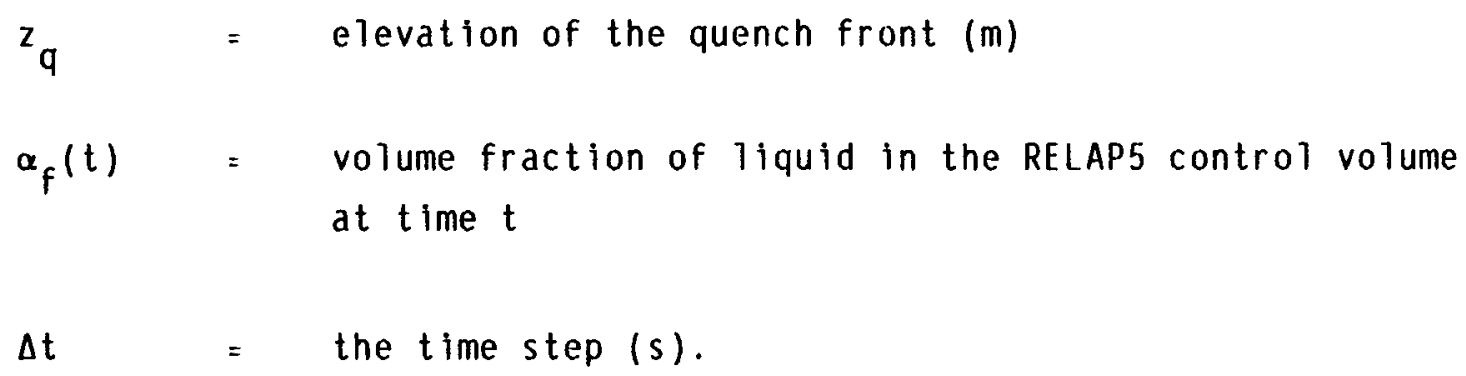

Since debris at the location of the quench front is considered to immediately transfer all of its stored thermal energy to the coolant, the rate of heat removal from the debris is proportional to the velocity of the quench front. This rate of heat removal is calculated by

$Q_{f i j}=u_{i j}(1-\varepsilon) A_{i j}\left(d z_{q} / d t\right)$

where 


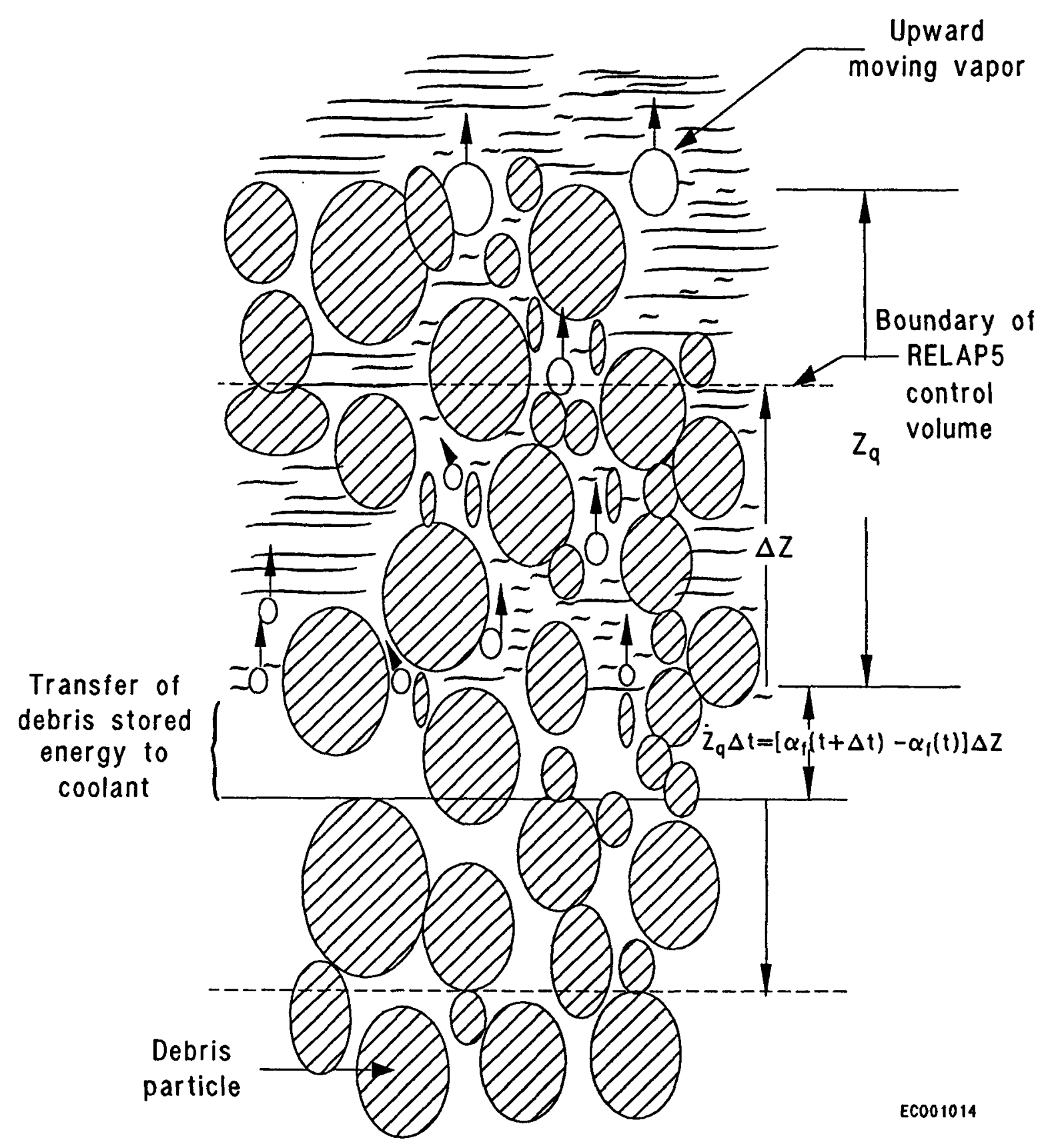

Figure 3-27. Configuration of partially quenched debris bed. 
$Q_{f i j}=$ rate of heat transfer from previously unquenched debris to the liquid at the location of the quench front (W)

$u_{i j}=$ internal energy of the debris with reference to the saturation temperature of the liquid $\left(\mathrm{J} / \mathrm{m}^{3}\right)$.

The rate of heat transfer from debris to liquid in the part of the RELAP5 control volume through which the quench front has already propagated is calculated by

$Q_{q i j}=P_{i j} \in A_{i j} \alpha_{f} \Delta z_{i j}$

where $Q_{q i j}$ is the heat transfer from debris that was already quenched at the start of the time step $(W)$.

The total heat removed from the debris is calculated by

$Q_{r i j}=Q_{f i j}+Q_{q i j}$

where $Q_{r i j}$ is the total rate of heat removal from debris at axial node 1 of fuel rod group $j(W)$.

The volumetric vapor generation rate in a RELAP5 control volume through which the quench front is passing is calculated by

$\Gamma_{g}=Q_{r i j} / h_{f g} A_{i j}^{\Delta z} i j$

where $\Gamma_{g}$ is the volumetric vapor generation rate $\left(\mathrm{kg} / \mathrm{m}^{3} \cdot \mathrm{s}\right)$.

In the portion of the RELAP5 control volume beyond the quench front, heat transfer between debris and coolant is considered to be negligible.

For a control volume through which a quench front has completely passed and all of the debris is thus in a state of quench, the rate of heat transfer from debris to coolant is calculated assuming that heat generated 
in the debris is immediately transferred to the coolant. The calculation takes into account the possibility that the rate of heat transfer is increased by a decreasing coolant pressure, and thus a decreasing saturation temperature. The rate of heat transfer is calculated by

$Q_{r i j}=P_{i j} A_{i j} \Delta z_{i j}+h_{s} A_{s i j} \Delta z_{i j}\left(T_{i j}-T_{s a t}\right)$

where

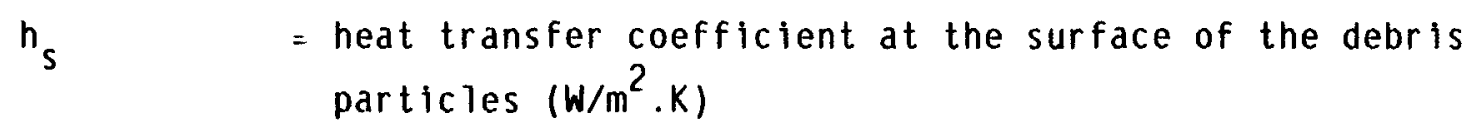

$A_{\text {sij }}=$ surface area of debris per unit volume of debris bed for axial node $i$ of fuel rod group $j\left(\mathrm{~m}^{2} / \mathrm{m}^{3}\right)$.

The variable $h_{s}$ is assumed to have a constant value of $1000 \mathrm{~W} / \mathrm{m}^{2} \cdot K$. This simplification is justified because $T_{i j}$ is almost equal to $T_{\text {sat }}$, and thus the second term in the above equation is small in magnitude compared to the first term.

The volumetric vapor generation rate at a location $i$ at which all of the debris is quenched is calculated by

$\Gamma_{g}=Q_{r i j} / h_{f g} A_{i j} \Delta z_{i j}$

Flow resistance may increase a factor of one hundred at a location where fuel rods have broken into particles. This increase of flow resistance is in part due to the fact that fluid in a debris region contacts more surface area than fluid in a rod-like region. The hydraulic diameter defines the surface area per unit of fluid volume. If a RELAP5 control volume contains fuel rods that have changed from rod-like configuration to porous debris, then the hydraulic diameter of that volume is changed from a value corresponding to rod-like diameter to a value corresponding to porous debris. The hydraulic diameter corresponding to porous debris is calculated by 
$d_{h}=4$ (bed fluid volume) / (surface area of particles)

$$
=0.666 \varepsilon \mathrm{d}_{p} /(1 .-\varepsilon)
$$

where

$$
\begin{aligned}
& d_{h}=\text { hydraulic diameter }(m) \\
& \varepsilon \quad=\text { porosity of the debris } \\
& d_{p}=\text { diameter of the debris particles }(m) .
\end{aligned}
$$

\subsubsection{Molten Pool}

The first occurrence of the melting of fuel and cladding oxide (ceramic melting) marks a significant advancement in the severity of an accident. If the melting has been driven by decay heat and not by oxidation, then melt progression will steadily progress from this time onward. The liquefied material does not immediately slump from the core region. Instead, the liquefied material either permeates into a colder region of the core and freezes or the movement of the liquefied material is blocked by the nonporous debris formed during the metallic meltdown of the core. But, as liquefaction continues and the liquefied material collects into a larger and larger pool, then the possibility increases that the pool may melt the material supporting it and a large amount of molten material may suddenly slump into the lower head of the reactor vessel. Thus, the unabated melting of fuel can lead to a thermal attack of the reactor vessel and a significant increase in the severity of an accident.

For this state of damage progression, our philosophy is to employ simple and clearly defined models. This approach is considered a usefut alternative to using a detailed mechanistic model faced with uncertainties in geometry and in the behavior of material that may experience repeated cycles of liquefaction, movement, and freezing. The basic simplification in our modeling is that liquefied debris is considered to permeate porous 
debris and to be blocked by nonporous debris formed during the metallic meltdown of the core. The modeling assumptions are shown in figure 3-28. The figure shows the transition in configuration that occurs due to meiting of debris. In the left part of the figure, two axial nodes with porous debris are shown. The bottom part of the lower axial node contains a nonporous layer formed during metallic meltdown. Melting has begun in the upper node. As soon as melting has begun at this node, all of the previously porous material in the upper and lower nodes is considered to be mixed together and supported by the nonporous layer. This configuration is shown in the right part of the figure. If this location is the first location in the reactor core where ceramic melting has occurred, then this transition in the characterization of the debris marks the nucleation of a molten pool. If a molten pool already exists, then the material at these two nodes is considered to be mixed with the other material in the molten pool.

Heat is transferred by natural convection from the interior to the exterior of a pool of molten core material. Figure 3-29 shows how the heat loss from a molten pool can be updated at each time step. In the left part of the figure, a reactor core is shown that has been divided into two rod groups, each with four axial nodes. Debris has melted at the second and third axial nodes of rod group 1 and at the third axial node of rod group 2. The material at these three nodes is considered to mix together and form a single molten pool. In order to calculate the heat transfer coefficients at the boundaries of the molten pool, the pool is mapped into a pool of the same volume but with hemispherical geometry. This idealized pool is shown in the right part of the figure. Experiments have been performed to measure the natural convection heat transfer coefficients for a pool with this geometry. The heat transfer coefficients for this idealized geometry are then mapped back into the actual configuration of the molten pool. For example, the heat transfer coefficient at the bottom center of the idealized pool is applied to the bottom center of the actual pool.

The change in temperature of the molten pool during a time step is calculated by 


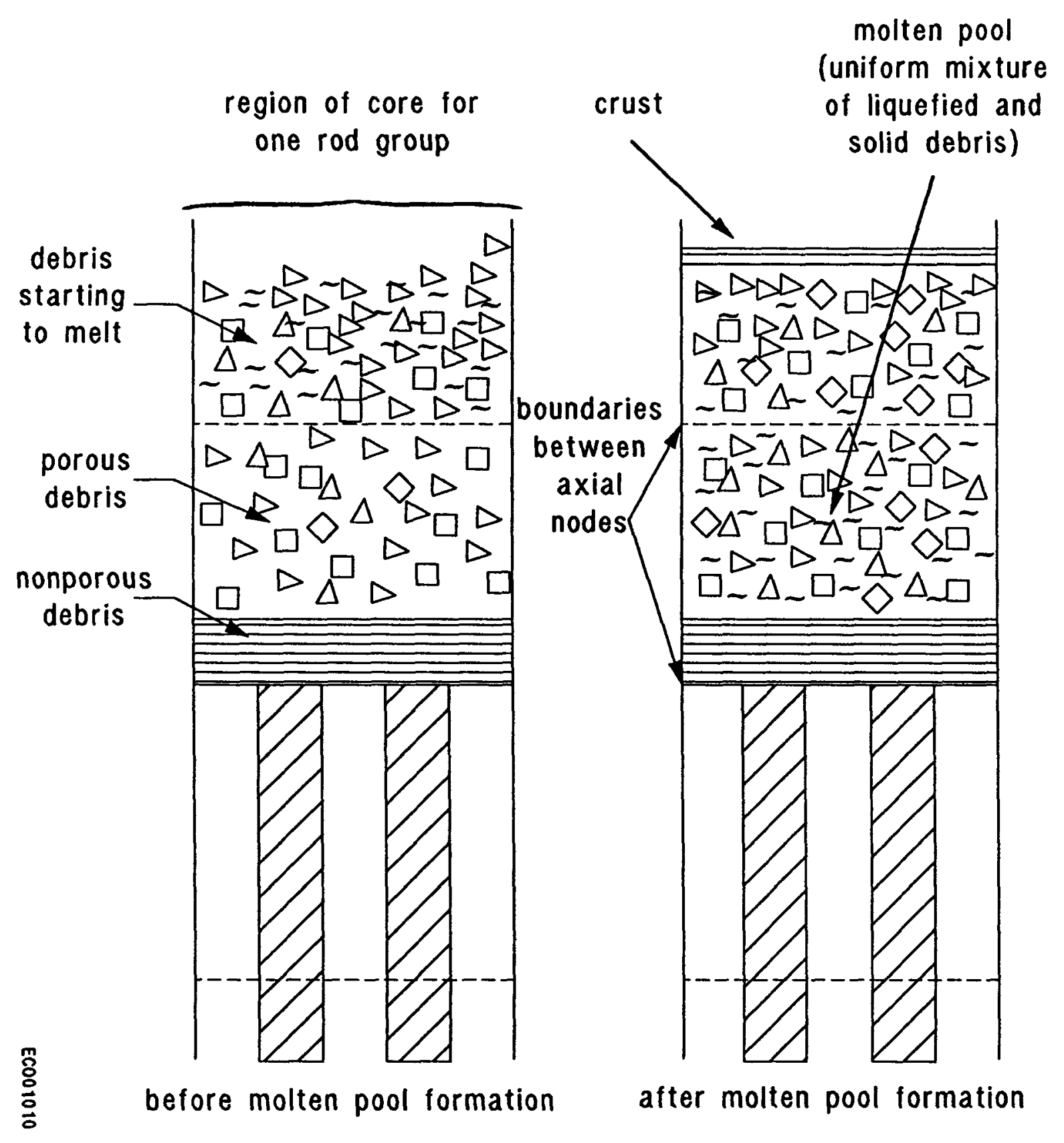

Figure 3-28. Simplification applied in modeling movement of liquefied debris. 


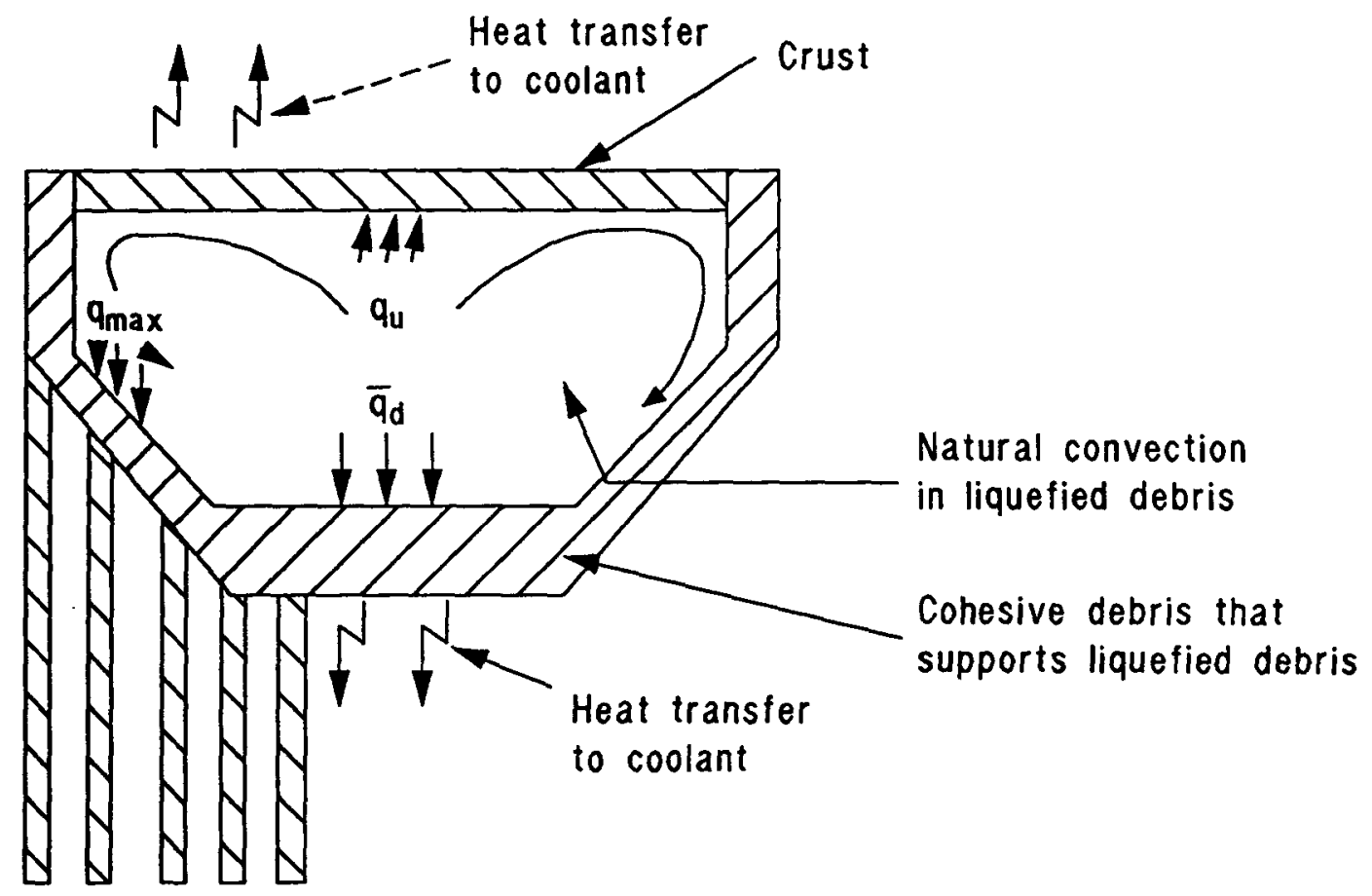

ECO00127

Figure 3-29. Heat transfer from pool of molten debris. 


$$
\left.\Delta T_{\text {pool }}=\left(V_{1} Q_{1}-q_{u} A_{u}-q_{d} A_{d}\right) \Delta t\right) / \rho_{1} c_{p 1} V_{1}
$$

where

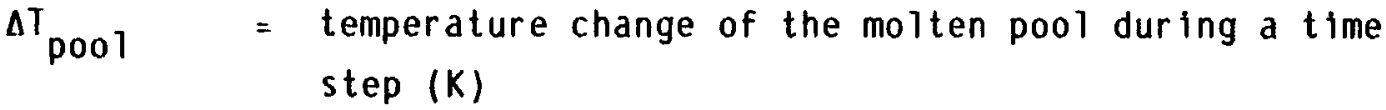

$$
\begin{aligned}
& v_{1}=\text { volume of the molten pool }\left(\mathrm{m}^{3}\right) \\
& 0_{1} \quad=\text { volumetric heat generation in the molten pool }\left(\mathrm{W} / \mathrm{m}^{3}\right) \\
& q_{u} \quad=\text { heat flux from the molten pool into the crust above the } \\
& \text { pool }\left(w / m^{2}\right) \\
& \text { q } \quad=\text { average heat flux from the molten pool into the } \\
& \text { nonporous material that supports the pool }\left(\mathrm{W} / \mathrm{m}^{2}\right) \\
& A_{u} \quad=\text { area of the top surface of the molten pool }\left(\mathrm{m}^{2}\right) \\
& \text { Ad }=\text { area of the bottom surface of the molten poor }\left(\mathrm{m}^{2}\right) \\
& \Delta t \quad=\text { time step (s) } \\
& \rho_{1}=\text { density of the molten pool }\left(\mathrm{kg} / \mathrm{m}^{3}\right) \\
& c_{p 7}=\text { heat capacity of the molten pool }(\mathrm{J} / \mathrm{kg} \cdot \mathrm{K}) \text {. }
\end{aligned}
$$

The heat fluxes at the exterior surfaces of the molten pool are calculated using correlations developed by Jahn and Reineke. ${ }^{3-67}$ They developed these correlations for a heat-generating fluid in a semicircular cavity, and Epstein and Fauske ${ }^{3-68}$ applied the correlations to the pool of liquefied debris that existed during the TMI-2 accident. The heat fluxes are calculated by

$$
q_{u}=0.33336 R^{0} 0.23_{k \Delta T / R}
$$


$q_{d}=0.54 \mathrm{Ra}^{0.18} \mathrm{k \Lambda T/R}$

where

$$
\begin{aligned}
\text { Ra } & =\text { the Rayleigh number of the liquid in the molten pool } \\
k & =\text { thermal conductivity }(W / m \cdot k) \\
R \quad & =\text { effective radius of the molten pool }(\mathrm{m}) .
\end{aligned}
$$

The Rayleigh number is calculated by

$R a=g B Q_{1} R^{5} / a v k$

where

g $=$ acceleration of gravity $\left(9.8 \mathrm{~m} / \mathrm{s}^{2}\right)$

$\beta=$ thermal coefficient of volumetric expansion of the molten pool $(1 / K)$

$\alpha=$ thermal diffusivity of the molten poor $\left(\mathrm{m}^{2} / \mathrm{s}\right)$

$v=v i s c o s i t y$ of the molten pool $\left[\mathrm{Pa} \cdot \mathrm{s} /\left(\mathrm{kg} / \mathrm{m}^{3}\right)\right]$.

The variable $R$ is calculated by

$R=\left(1.5 V_{1} / \pi\right)^{0.333}$

According to the analysis of Jahn and Reineke, ${ }^{3-67}$ the heat flux on the bottom surface varies with location. The maximum downward heat flux is at the upper edge of the pool, and the minimum heat flux is at the bottom center of the pool. The heat flux at the upper edge is double the average heat flux on the bottom surface. 
A modification is required from that presented in Section 3.12 .2 of the calculation of the temperature distribution in the nonporous debris supporting the molten pool to account for contact with the molten pool. Instead of a boundary condition reflecting convective heat transfer to the coolant, the boundary condition is changed to reflect the meiting of the top surface of the nonporous debris due to contact with the molten pool. Thus, the boundary condition as given by Equation (3-229) in Section 3.12.2 is changed to the following two equations

$$
\begin{aligned}
& (d \delta / d t) h_{\text {fus }} \rho=k(d T(\delta, t) / d z)-q_{d} \\
& T(\delta, t)=T_{\text {me } 1 t}
\end{aligned}
$$

where

$$
\begin{aligned}
& k=\text { thermal conductivity of the nonporous debris }(\mathrm{W} / \mathrm{m} \cdot \mathrm{K}) \\
& \mathrm{h}_{\text {fus }} \quad=\text { heat of fusion of the nonporous debris }(\mathrm{J} / \mathrm{kg}) \\
& \rho \quad=\text { density of the nonporous debris }\left(\mathrm{kg} / \mathrm{m}^{3}\right) \\
& \mathrm{T}_{\text {melt }}=\text { melting temperature of the nonporous debris }(\mathrm{K}) .
\end{aligned}
$$

The coefficients $a, b$, and $c$ in Equation (3-230) and the thickness of the layer of nonporous debris (d) are obtained by simultaneous solution of Equations $(3-227),(3-228),(3-254)$, and $(3-255)$. A solution for the temperature distribution and thickness is performed at each time step for each group of fuel rods that contain a segment of the nonporous debris that supports the molten pool.

A crust thick enough to support a debris bed may form above a pool of molten material. The crust may also insulate the molten pool from coolant covering the molten pool. The thickening and thinning of this upper crust is modeled using the same integral method that is used for modeling the bottom crust. The melting of the crust is coupled with both the 
temperature of the molten pool and the thermal-hydraulic conditions above the molten pool. The crust is calculated to thin when the heat it receives from the molten pool is greater than the heat it transfers to the coolant. If the opposite case holds, the crust is calculated to thicken. If a debris bed above the molten pool is calculated to slump into the molten pool and the equilibrium temperature of the mixture is less than its liquidus temperature, then the thickness of the upper crust is set equal to half the depth of the molten pool.

\subsection{Core Slumping Mode 1s}

This section describes the models that determine when material from a molten pool in the core region slumps from this region to the lower head of the reactor vessel. Two mechanisms are considered to trigger this slumping. The first mechanism is the meltthrough and failure of the layer of nonporous debris that supports the molten pool. The second mechanism is the melthrough and faliure of the upper crust and the resulting displacement of liquid from the molten pool by the solid material that falls into the molten pool.

A fallure analysis that examines crust thickness is used to determine the time of failure of the crusts that envelop a molten pool. If melting causes the lower crust to thin to a value of less than $25 \mathrm{~mm}$, then the lower crust is considered to fall and release to the lower head all of the liquid in the molten pool that is above the point of failure. This criterion assumes that the crust is not significantly supported by intact fuel rods. The failure criteria for the upper crust takes into account the support offered to the crust by the liquid in the molten pool. If the crust is supported from beneath by liquid, the crust is considered to fail when its thickness is less than $0.5 \mathrm{~mm}$. If some liquid has drained from the molten pool due to fallure of the lower crust, then the upper crust is considered to fail when its thickness is 1 ess than $25 \mathrm{~mm}$. 3-69

These failure criteria are based on calculations of stress under conditions estimated for the TMI-2 accident and have a large degree of 
uncertainty. Even for a well-defined manufactured structure, the time of failure may be difficult to predict. For a structure that evolves during a severe accident and has uncertainties in configuration, composition, load, and temperature, the prediction of the time of fallure is an order of magnitude more difficult. This large uncertainty in the calculation of crust failure requires that the severe accident analyst examine the effect of the fallure criteria upon the calculated course of a severe accident. The fallure criteria in the SCDAP/RELAP5 code are easily adjusted by the code user so this sensitivity study can be performed.

In the event that the upper crust of the poor is calculated to fail, a simple displacement relation is used to calculate the amount of liquid that spills out of the pool. The displacement process is illustrated in Figure 3 30. The amount of displaced liquid is calculated by

$$
v_{\text {dis }}=\varepsilon Z_{s} A_{\text {deb }}
$$

where

$$
\begin{aligned}
& v_{\text {dis }}=\text { volume of liquid displaced from the molten poot }\left(\mathrm{m}^{3}\right) \\
& Z_{s}=\text { either } Z_{\text {deb }} \text { or } Z_{p} \text {, whichever is less }(m) \\
& Z_{\text {deb }}=\text { depth of the debris above the molten poot }(m) \\
& Z_{p}=\text { depth of the molten poot }(m) \\
& A_{\text {deb }}=\text { cross-sectional area of the debris above the molten poot } \\
& \text { (m) }
\end{aligned}
$$

The rate at which liquid spills out of the molten pool is defined by the code user. For the TMI-2 accident, molten material is considered to have spilled for $100 \mathrm{~s}$ following the failure of the crust surrounding the molten poot. $3-49$ 

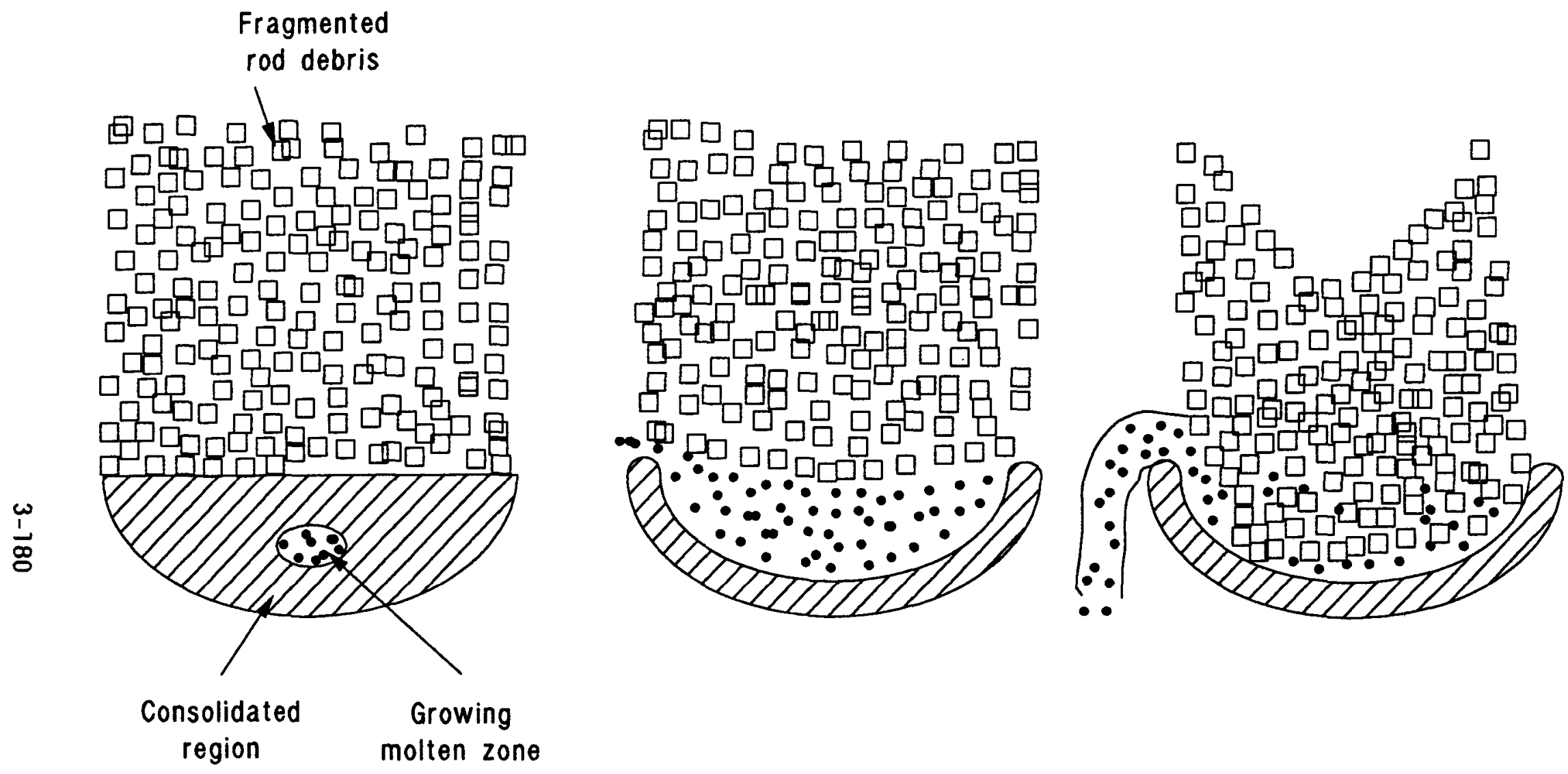

(a) Pool growth

(b) Failure of upper crust

(c) Relocation of displaced volume of core melt

Figure 3-30. Postulated sequence of events leading to core material

ECO01004 relocation. 
The degree of interaction of the slumping material with the water through which it falls is also defined by the code user. If the user defines that no interaction takes place, then the slumping core material is considered to fall as an intact stream and there is no transfer of internal energy from the slumping material to water. The slumped material that accumulates in the lower head is considered to have no porosity. If the user defines a complete interaction between slumping material and the water through which it falls, then the slumping material is considered to break up into small particles and transfer all of its internal energy to the water. The slumped material that accumulates in the lower head is considered to have a porosity of 0.5 . The transfer of internal energy from the slumping material to water may cause a large amount of vapor generation and may significantly increase the pressure in the reactor vessel.

A user prescription of the behavior of slumping material is considered the best approach because of large uncertainties in the size and configuration of the breach through which the molten material drains. Also, an analysis of the breakup of slumping material is complicated by structures in the reactor vessel, such as core former plates, baffle plates, fuel rods, and spacer grids. As a result, it is necessary to enable a severe accident analyst to perform a sensitivity study of the behavior of slumping material.

\subsection{Model for Heatup of Lower Plenum Debris}

A model based upon the COUPLE ${ }^{3-70}$ code is used to calculate the heatup of the debris that slumps into the lower plenum. This model takes into account the decay heat and internal energy of newly fallen debris and then calculates the transport by conduction of this heat in the radial and axial directions to the vessel wall and water above the debris. The most important output of this model is the calculation of the heatup of the vessel wall so that the time at which the vessel may rupture $c$ an be determined. Notable capabilities include the modeling of the following phenomena and conditions: (a) spatially varying porosity, (b) thermal conductivity of porous material, (c) a debris bed whose height grows 
sporadically with time, (d) radiation heat transfer in a porous material, and (e) the melting or freezing of debris. The limitations of this model are: (a) molten material remains in the location where predicted;

(b) convective currents do not exist in molten material; (c) oxidation does not occur in the debris bed; and (d) fission product release does not occur in the debris bed.

\subsubsection{COUPLE Description}

The COUPLE code ${ }^{3-70}$ is a two-dimensional, finite-element, steady-state and transient heat conduction and advection code. The code was developed to solve both plane-and axisymmetric-type heat transfer problems with anisotropic thermal properties, subject to boundary conditions of the first kind (Dirichlet), second kind (Neumen), and third kind (combination of the first and second), and/or nonlinear boundary conditions such as radiation. A boundary condition of the first kind implies that the temperatures are prescribed along the boundary surface. A boundary condition of the second $k$ ind implies that the normal derivatives of the temperatures are prescribed at boundary surface. The code solves the following two-dimensional energy equation:

$$
\left(\rho C_{v}\right)_{e} \frac{\partial T}{\partial t}=\frac{\partial}{\partial x}\left(K_{e} \frac{\partial T}{\partial x}\right)+\frac{\partial}{\partial y}\left(K_{e} \frac{\partial T}{\partial y}\right)+0
$$

where

$$
\begin{aligned}
& \left(\rho C_{v}\right)_{e}=P\left(\rho C_{v}\right)_{1}+(1-P)\left(\rho C_{v}\right) s \\
& \rho \quad \text { density } \\
& C_{v}=\text { constant volume specific heat } \\
& C_{p}=\text { constant pressure specific heat }
\end{aligned}
$$



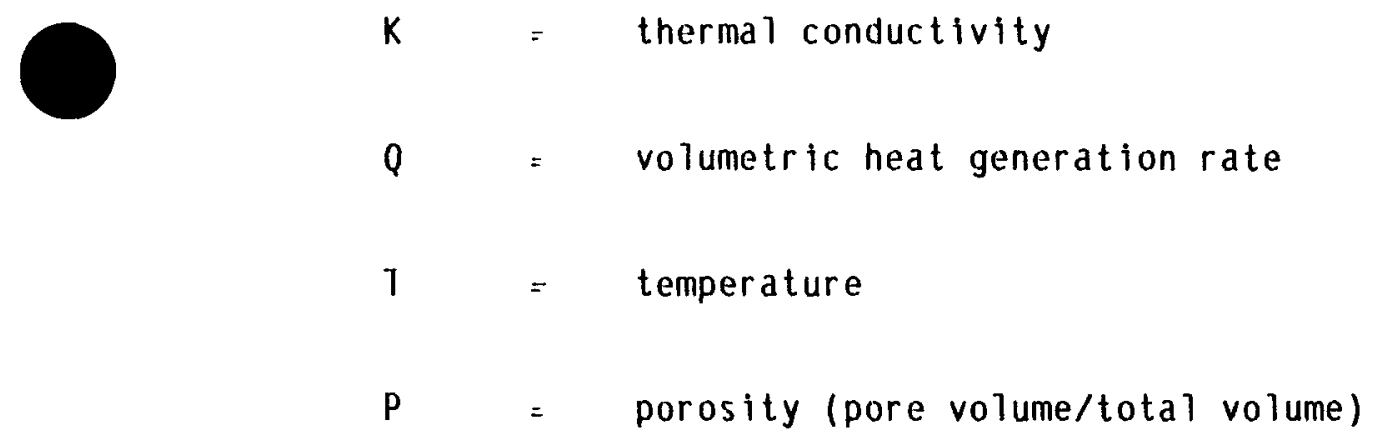

The subscripts are defined as follows:

$\begin{aligned} \mathbf{e} & =\text { equivalent } \\ 1 & =\text { liquid } \\ \mathrm{s} & =\text { solid. }\end{aligned}$

\subsubsection{Variable Element Porosity}

The COUPLE code allows each element in the debris bed model to have its own value of porosity. The porosity of each element can also be varied as a function of time. The thermal property of each element is determined by

$$
\Phi=P \Phi_{f}+(1-P) \phi_{S}
$$

where

$$
\begin{aligned}
& \Phi=\begin{array}{l}
\text { some average thermal property, value, such as thermal } \\
\text { conductivity or specific heat }
\end{array} \\
& \Phi \quad \text { thermal property } \\
& \mathbf{p}=\text { porosity } \\
& f \quad \text { fluid }
\end{aligned}
$$




$$
\text { s }=\text { solid. }
$$

If the porosity is zero, the element represents a volume containing solid debris material, whereas a porosity value of 1.0 means the element is completely filled with coolant. A value between 0.0 and 1.0 indicates that the volume contains both coolant and debris material.

\subsubsection{Thermal Conductivity Model}

The heat transfer in a dry porous bed involves both conduction and radiation. The overall thermal conductivity of the bed can be represented as

$$
K_{\text {et }}=K_{e c}+K_{r}
$$

where

$$
\begin{aligned}
& k_{e t}=\text { total effective conductivity } \\
& k_{e c}=\text { effective conductivity (conduction on iy) } \\
& K_{r}=\text { radiation conductivity. }
\end{aligned}
$$

There have been a number of thermal conductivity models proposed for modeling a dry porous bed. Reference 3-7l gives a good review and comparison of five such models. The Imura-Takegoshi ${ }^{3-72}$ model combined with the Vortmeyer ${ }^{3-73}$ radiation model yields the best overall results and produces an upper bound on the temperature.

The Imura-Takegoshi mode $7^{3-72}$ in equation form is given as follows:

$$
K_{e c}=\Psi+\frac{1-\Psi}{\phi+\frac{1-\phi}{v}}
$$


$\phi+0.3 p^{1.6} v^{-0.44}$

$v=K_{g} / K_{s}$

$\Psi=\frac{P-\phi}{1-\phi}$

where

$$
\begin{aligned}
& K_{g}=\text { gas or vapor thermal conductivity } \\
& K_{s}=\text { solid thermal conductivity } \\
& P \quad=\text { porosity. }
\end{aligned}
$$

The Vortmeyer mode $7^{3-73}$ is given as

$\mathrm{Kr}=4 \operatorname{noDT}^{3}$

where

$$
\begin{aligned}
n & =\text { radiation exchange factor } \\
\sigma \quad & =\text { Stefan-Boltzmann constant } \\
D \quad & =\text { particie diameter } \\
1 & =\text { temperature. }
\end{aligned}
$$

The combined Imura-Takegoshi and Vortmeyer model is input into the CNDUCT subroutine of COUPLE. This same model is used by Sandia in their MELPROG mode1..$^{3-74}$ Sandia also included a lower-bound model which has not as yet been incorporated into the COUPLE code. The lower-bound model used by Sandia is one which combines a conduction model by willhite ${ }^{3-75}$ with a radiation model by Luikov. ${ }^{3-76}$ 


\subsubsection{Phase Change Mode 1}

At the present time, there are two generally accepted ways of numerically approximating a phase-change problem. One method uses a moving mesh technique. At this time, the moving mesh technique has been mainiy applied to one-dimensional problems. This technique is not easily applied to two-dimensional problems because mesh distortion may result.

The other method uses a fixed mesh and is usually referred to as an enthalpy method. The particular method we have chosen is described in Reference 3-71. The method consists of using the material enthalpy to determine an effective density times specific heat $\left(\rho C_{p}\right)$ value to use in Equation (3-250). The enthalpy change per unit volume is defined as

$d H=\rho C_{p} d T$;

thus,

$\rho C_{p}=d H / d T$

which can be written as

$\rho C_{p}=\frac{d H}{d X} \frac{d X}{d T}$

where $X$ is the coordinate boundary of a phase change (m).

For computational purposes, it is easier to calculate $\mathrm{dH} / \mathrm{dX}$ and $\mathrm{dX} / \mathrm{dT}$ than it is $d H / d T$ directly. The necessary coding required to use this approach is contained in the subroutine USERP.

\subsection{4 .5 Dryout of Debris}

The COUPLE model has a model to determine whether debris is quenched or in a state of dryout. This determination is made using the 0 -d Lipinski 
equation, $3-77$ which calculates dryout as a function of debris power density, depth, porosity, particle size, and coolant properties. If debris is in a state of dryout, the COUPLE model calculates debris heatup considering steam in the voids in the debris bed. If debris is quenched, the model calculates debris heatup considering liquid water in the voids. The amount of heat transferred from debris to coolant is added to the energy term for the RELAP5 control volumes modeling the lower plenum. If the debris is quenched, an addition is also made to the volumetric vapor generation rate from these control volumes.

\subsection{Model for Creep Rupture of Structural Components}

A model based upon creep rupture theory is used to calculate the damage and nearness to rupture of structural components selected by the code user. Two different theories are applied: (a) Larson and Miller, ${ }^{3-78}$ and (b) Manson and Haferd. 3-79 The particular theory to be applied is dependent on the material composition and stress. The materials that can be modeled for creep rupture are: (a) A-508 Class 2 carbon stee 1, (b) 316 stainless steel, and (c) Inconel 600. For 316 stainless steel and Incone 600 materials, the Larson-Miller theory is used. For A-508 Class 2 carbon stee1, the Manson-Haferd theory is applied for the lower range of stress and the Larson-Miller theory for the higher range of stress.

Criteria for choosing the theory best suited for a particular material and temperature range are presented by Goldhoff. ${ }^{3-80}$ His criteria determine the applicable theory by examining the results of creep rupture tests performed on specimens at a constant stress and temperature. After tests have been performed with a range of stresses and temperatures, the data are plotted to produce a family of curves of the $10 \mathrm{~g}$ of rupture versus temperature and the log of rupture time versus reciprocal temperature. The Larson-Miller theory ${ }^{3-78}$ gives the best prediction when the family of curves on a plot of $\log$ of rupture time versus reciprocal of test temperature meet at a point with a value of $T / T=0$, where $T=$ temperature in degrees $R$. The Dorn ${ }^{3-81}$ theory is used when the family of curves are parallel. The Manson-Haferd theory ${ }^{3-79}$ is used when the family of curves on a plot of rupture time versus temperature meet at a point. 
A parameter that measures creep damage is calculated at each time step for each structure being monitored for creep rupture. The creep damage is evaluated by the equation

$$
D_{c}(t+\Delta t)=D_{c}(t)+\frac{\Delta t}{t_{r}(t)}
$$

where

$$
\begin{aligned}
& D_{c}(t)=\text { creep damage at time } t \\
& \Delta t=\text { time step at current problem time (s) } \\
& t_{r}(t)=\text { time required for the structure to fail by creep rupture at } \\
& \text { the current state of temperature and stress ( } s \text { ) } \\
& t=\text { problem time }(s) \text {. }
\end{aligned}
$$

If the value of $D_{C}$ is zero, the structure has not experienced any creep damage. If the value is one, the structure has falled due to creep damage.

The equation for calculating $t_{r}$ is dependent upon the material composition and stress. The equations for three materials considered by SCDAP/RELAP5 are shown in Table 3-19. The Manson-Haferd theory is applied to A-508 carbon steel for effective stresses less than $14 \mathrm{ksi}$ (96.6 MPa). The Larson-Miller theory is applied to this material for effective stresses greater than $14 \mathrm{ksl}(96.6 \mathrm{MPa})$ and to 316 stainless steel and Inconel-600 at all levels of stress.

Tests were performed at the INEL to obtain creep rupture data on A-508 Class 2 carbon stee1. 3-82 Data were obtained in the temperature range of 900 to $1025 \mathrm{~K}$ and in the stress range of 56 to $141 \mathrm{MPa}$. The creep rupture data for 316 stainless steel were obtained from Reference 74 . Data were avallable in the temperature range of 700 to $1089 \mathrm{~K}$. The creep rupture data for Inconel 600 were obtained from References 83 and 84 and were available in the temperature range of 811 to $1366 \mathrm{~K}$. 
TABLE 3-19. EQUATIONS FOR CALCULATING THE TIME TO CREEP RUPTURE

Material

Carbon stee] A-508

Class 2
Range of Stress Equation for Creep Rupture Time ${ }^{a}$

$\left.0.0<\sigma_{e f f}<14.0 \quad t_{r}=10\left(\frac{T-1503.69}{p}\right)+3.499\right)$.

$P=157.233 \log _{10} \sigma_{\text {eff }}-255.346$

$14.0 \leq \sigma_{\text {eff }}$

$t_{r}=10\left(\frac{p}{T}-20\right)$,

$P=9603.0 \log _{10}{ }^{\sigma}$ eff +46454.0
316 stainless steel

$t_{r}=10\left(\frac{p}{T}-20\right)$.

$P=-13320.0 \log _{10} \sigma_{\text {eff }}+54870.0$

$52.0 \leq \sigma_{\text {eff }} \quad t_{r}=10\left(\frac{P}{T}-20\right)$.

$P=-64000.0 \log _{10} \sigma_{\text {eff }}+142000.0$

Incone 1600
$t_{r}=10\left(\frac{p}{T}-15\right)$.

$P=-11333.0 \log _{10} \sigma_{\text {eff }}+43333.0$

a. $t_{r}=$ time to rupture $(h)$

$T=$ average temperature of structure (R)

$\sigma_{\text {eff }}=$ effective stress in structure (ksi) 


\subsection{Model for CORA Out -of -Pile Experiments}

This model is used to represent electrically heated fuel rods with a central tungsten heater rod. The total power input is specified by user input, while the axial and temperature-dependent power release is calculated by the model.

\subsubsection{Description of the Electric Heater Rod Model}

This model computes the axial and temperature-dependent power release in the heated area of the tungsten heater rod and also includes the effects of the molybdenum electrode and the copper at the top and bottom of the tungsten heater rod. The model first computes the resistances of copper, molybdenum, and tungsten. The model currentiy has the dimensions of the tungsten rod and molybdenum and copper electrodes at the top and bottom of the tungsten heater rod built into the resistance equations. The specific dimensions are based upon the CORA ${ }^{3-52}$ heater rod elements. The resistances are calculated by the equations:

$$
\begin{aligned}
& R_{M o}= 2.25 \times 10^{-2}+5.36 \times 10^{-5} \mathrm{~T}_{M_{0}} \\
&+1.38 \times 10^{-7} \mathrm{~T}_{M_{0}}{ }^{2}-2.22 \times 10^{-11} \mathrm{~T}_{\mathrm{Mo}^{3}}^{3} \\
& \mathrm{R}_{\mathrm{Cu}}=-7.89 \times 10^{-3}+9.90 \times 10^{-5} \mathrm{~T}_{\mathrm{Cu}}-5.49 \times 10^{-8} \mathrm{~T}_{\mathrm{Cu}}{ }^{2} \\
&+3.16 \times 10^{-11} \mathrm{~T}_{\mathrm{Cu}}^{3} . \\
& \mathrm{R}_{W}(\mathrm{I})=\left[-.0199+0.247 \times 10^{-3} \mathrm{~T}+0.224 \times 10^{-7} \mathrm{~T}(\mathrm{I})\right] \\
& \cdot \mathrm{DZ}(\mathrm{I}) \cdot 2.5367 \times 10^{-2}, \mathrm{I}=1, \mathrm{~N}
\end{aligned}
$$

where

$$
\begin{aligned}
& \text { NAZ }=\text { number of axial levels } \\
& \text { DZ(I) }=\text { height of } 1 \text {-th axial node }(\mathrm{m})
\end{aligned}
$$




$$
\begin{aligned}
T & =\text { fuel rod centerline temperature at node } I(K) \\
T_{M 0} & =0.5 \cdot[T(I)+350] \\
T_{C U} & =0.5 \cdot\left(T_{M_{0}}+350\right) \\
T(I) & =\text { fuel center temperature at the } 1 \text { st axial leve } 1
\end{aligned}
$$

The total resistance is then given by

$$
R_{t}=\sum_{i=1}^{N A Z} R_{w}(I)+8.6 \times 10^{-3}\left(R_{M 0}+R_{C U}\right)+1.6 \times 10^{-3}
$$

The total power in each axial node is then

$$
\operatorname{UNUC(I)}=\frac{R_{W}(I)}{R_{t} L} \cdot \frac{P_{t}}{D_{z}(I)}
$$

where

$$
\begin{aligned}
& \mathrm{L} \quad=\text { total rod length }(\mathrm{m}) \\
& \mathrm{P}_{\mathrm{t}} \quad=\text { total input rod power }(\mathrm{W} / \mathrm{m})
\end{aligned}
$$

\subsection{References}

3-1. W. T. Shack et al., Materials Science and Technology Diviston Light Water Reactor Safety Research Program Quarterly Report, January through March 1983, Volume I, NUREG/CR-3689. ANL-83-85 Volume I, June 1983.

3-2. D. L. Hagrman, G. A. Reyman, and R. E. Mason, MATPRO-Version 11 (Revision 2), A Handbook of Materlals Properties for Use in the Analys is of Light Water Reactor Fuel Rod Behavior, NUREG/CR-0479, TREE-1280, Revision 2, August 1981. 
3-3. D. L. Hagrman, Materials Properties for Severe Core Damage Analysis, EGG-CDD-5801, May 1982.

3-4. ENDF/B-V Library Tape 511 MATNO-1395, National Neutron Cross Section Center, Brookhaven National Laboratory, July 1979.

3-5. American National Standard for Decay Heat Power in Light Water Reactors, ANSI/ANS-5.1-1979.

3-6. B. G. Schnitzler, Fission Product Decay Heat Modeling for Disrupted Fue 1 Regions (FDECAY). EGG-PHYS-5698, December 1981.

3-7. H. G. Kraus and C. E. Lemmon, SINGLE/CE--A One-Dimensional Finite Element Steady-State and Transient Heat Conduction Code with Cont iguum Element Capabilities for Use on a CDC Cyber $76 /$ Cyber 173 Computer. RE-A-78-210, June 1978.

3-8. W. Sengple1, Effective Heat Transfer Model (EFFHT) for SCDAP, EGG-CDD-5686, February 1982.

3-9. G. A. Berna and C. M. Allison, Component State Models for SCDAP, EGG-CDD-5872, June 1982.

3-10. H. G. Kraus and C. E. Lemmon, COUPLE/MOD3--A Two-Dimenstona 1 F inite Element Steady State and Transient Heat Conduction Code with Inverse and Cont iguum Element Capabilities for Use on a CDC Cyber 76/Cyber 173 Computer, RE-A-78-191, August 1978.

3-11. K. H. Huebner. The Finite Element Method for Engineers, New York: John Wiley \& Sons, 1975.

3-12. 0. C. Zienkiewicz and Y. K. Cheung, The Finite Element Method in Structural and Cont inuum Mechanics, New York: McGraw-H171 Publishing Company Limited, 1967.

3-13. R. D. Cook, Concepts and Applications of Finite Element Analysis, New York: John Wliey \& Sons, Inc., 1974.

3-14. G. A. Berna, Finite Element Method Heat Conduction for SCDAP, EGG -CDD-5697, December 1981 .

3-15. A. Mendelson, Plasticity: Theory and Application, New York: Macmillan, 1968, pp. 100-104.

3-16. R. Hill, The Mathematical Theory of Plasticity, Oxford: Clarendon Press, 1950, pp. 317-325.

3-17. M. P. Bohn, FRACAS: A Subcode for the Analys is of Fuel Pellet-Cladding Mechanical Interaction, TREE-NUREG-1028, Apr 111977. pp. 29-33.

3-18. D. L. Hagrman, Zircaloy Cladding Shape at Fallure (BALON2), EGG-CDAP-5397, JuTy 1981. 
3-19. L. J. Siefken et a 1., FRAP-T6: A Computer Code for the Transient Analysis of 0xide Fuel Rods, EGG-CDAP-5410, Apri1 1981.

3-20. E. R. Carlson, Probabilistic Flow Area Reduction Model, EGG-CDD-5567, November 1981.

3-21. G. A. Berna et a1., FRAPCON-2 Developmental Assessment, NUREG/CR-1949, PNL-3849, Ju 1y 1981 .

3-22. J. P. C. Kleijnen, Statistical Techniques in Simulation--Part II, New York: Marcel Dekker, Inc., 1975.

3-23. P. Hoffmann and H. Ostereka, "Dissolution of Solid U0, by Molten Zircaloy and the Modeling," Paper IAEA-SM-296/1, International Symposium on Severe Accidents in Nuclear Power Plants, Sorrento, Italy, March 21-25, 1988.

3-24. J. Rest, in: Proceedings of the International Meeting on Thermal Nuc lear Reactor Safety, Chicago, IL, August 29-September 2, 1982, NUREG/CP-0027, 1, February 1983, pp. 111-121

3-25. J. Rest, "Evaluation of Volatile and Gaseous Fission Product Behavior in Water Reactor Fuel under Normal and Severe Core Accident Conditions," Nuclear Technology, 61, 1983, pp. 33--48.

3-26. J. Rest, "An Improved Model for Fission Product Behavior in Nuclear Fuel under Normal and Accident Conditions," Journal of Nuclear Materia7s, 120, 1984, pp. 195-212.

3-27. J. Rest, "The Mechanistic Prediction of Xenon, Iodine, and Cesium Release from LWR Fuel under Degraded-Core Accident Conditions," Proceedings of the Topical Meeting on Fission Product Behavior and Source Term Research, Snowbird Utah, July 15-19, 1984.

3-28. J. Rest, "The Coupled Kinetics of Grain Growth and Fission Product Behavior in Nuclear Fuel under Degraded-Core Accident Conditions," Journal of Nuclear Materials, 131, 1985, pp. 291-302.

3-29. 3. Rest, "The Prediction of Translent Fission-Gas Release and Fue 1 Microcracking under Severe Core-Accident Conditions," Nuclear Technology, 56, 1981, pp. 553.

3-30. M. H. Wood and J. R. Matthews, "On the Use of Grain Boundary Loss Terms in Fission Gas Release and Swelling Models," Journal of Nuclear Materla1s, 89, 1980, pp. 53-61.

3-31. R. A. Lorenz et a1., "Fission Product Source Terms for the Light Water Reactor Loss-of-Coolant Accident," Nuclear Technology, 46. 1979.

3-32. M. R. Kuhlman et a 1., CORSOR User's Manual, NUREG/CR-4173, BMI-2122, March 1985. 
3-33. Technical Bases for Estimating Fission Product Behaviour during LWR Accidents NUREG-0772, June 1981.

3-34. J. W. Spore et a1., TRAC-BD1: An Advanced Best Estimate Computer Program for Bolling Water Reactor Loss-of-Coolant Accident Analys is, NUREG/CR-2178, EGG-2109, October 1981.

3-35. J. W. Spore, M. M. Giles, R. W. Shumway, "A Best Estimate Radiation Heat Transfer Mode1 Developed for TRAC-BD1," ASME Paper

No. 81-HT-68, 20th Joint ASME/AIChE National Heat Transfer Conference, Milwaukee, Wisconsin. August 1981.

3-36. C. J. Shaffer, "Importance of Thermal Radiation to Steam in Rod Bundles," Topical Meeting on Water-Reactor Safety, Salt Lake City, Utah, March 26-28, 1973, pp. 371-379.

3-37. D. A. Mande11. A Radiative Heat Transfer Model for the TRAC Code, NUREG/CR-0994, LA-7965-MS, November 1979.

3-38. J. G. M. Andersen et a1., NORCOOL I, A Model for the Analys is of a BWR Under LOCA Conditions, NORHAV-D-47, August 1977.

3-39. J. G. M. Andersen and H. Abe1-Larsen, CORECOOL Model Description of the Programme, RISO-M-2138, November 1978.

3-40. J. G. M. Andersen and C. L. Tien, "Radiation Heat Transfer in a BWR Fuel Bundle Under LOCA Conditions," Fluid Flow and Heat Transfer Over Rod or Tube Bundles, S. C. Yao and P. A. Pfund eds., ASME, New York, NY, 1979, pp. 197-207.

3-41. K. H. Sun, J. M. Gonzales-Santa10, C. L. Tien, "Calculations of Combined Radiation and Convection Heat Transfer in Rod Bundle Under Emergency Cooling Conditions," J. Heat Transfer, 98, 1976, pp. 414-420.

3-42. R. Siegel and J. R. Howe 11, Thermal Radiation Heat Transfer, New York: McGraw-Hill Book Company, 1972.

3-43. E. M. Sparrow and R. D. Cess, Radiation Heat Transfer, Belmont: Brooks/Cole Publishing Company, 1966.

3-44. R. L. Cox, Radiative Heat Transfer in Arrays of Parallel Cylinders, ORNL-5239, June 1977.

3-45. D. A. Mande11, "Geometric View Factors for Radiative Transfer Within Boiling Water Reactor Fuel Bundles," Nuclear Technology, 52, 1981, pp. 383-392.

3-46. D. R. Evans, The MOXY Digital Computer Program for Boiling Water Reactor Core Thermal Analysis, RE-A-77-081, September 1981.

3-47. N. H. Juul, "View Factors in Radiation Between Two Parallel Oriented Cylinders of Finite Lengths," J. Heat Transfer, 104, 1982, pp. 384-388. 
3-48. H. C. Hottel and A. F. Sarofim, Radiative Transfer, New York: McGraw-Hill Book Company, 1967.

3-49. E. L. Tolman et a)., TMI-2 Accident Scenario Update, EGG-TMI-7489, December 1986.

3-50. 2. R. Martinson et a 1., PBF Severe Fuel Damage Test 1-1 Test Results Report. NUREG/CR-4684, EGG-2463, October 1986.

3-51. D. A. Petti et a 1., PBF Severe Fuel Damage Test 1-4 Test Results Report, NUREG/CR-5163, EGG-2542, May 1989 .

3-52. S. Hagen et a1., "Out-of-Pile Experiments on Severe Fuel Damage Behavior of LWR Fuel Elements (CORA Program)," International Symposium on Severe Accidents in Nuclear Power Plants, Sorrento, Italy, March 21-25, 1988, paper IAEA-SM-296/26.

3-53. A. B. Wahba and E. F. Hicken, "Ten Years ot Experimenting in the Loss of Fluid Test (LOFT) Facility," Atomkernenergie-kerntechnik, 49. No. 1/2, 1986, pp. 68-73.

3-54. R. 0. Gauntt et a1., "Results and Phenomena Observed from the DF -4 BWR Control Blade Channel Box Test," Proceedings of the International ENS-ANS Conference on Thermal Reactor Safety, 5 , Avignon, France, October 2-7, 1988.

3-55. D. 0. Lanning and N. J. Lombardo, Data Report for Full-Length High-Temperature Experiment S, PNL-6540, Apri11 1988.

3-56. M. L. Russe11, "TMI-2 Core Geometry," Proceedings of the TMI-2 Topical Meeting, Washington, D. C., November 1988.

3-57. F. M. Haggag, Zircaloy Cladding Embrittlement Criteria: Comparison of In-Pile and Out-of-Pile Results, NUREG/CR-2757, JuTy 1982.

3-58. F. M. Haggag, Fuel Bundle Damage Propagation Models for SCDAP, EGG-NSMD-5738, June 1983.

3-59. H. M. Chung and T. F. Kassner, Embrittlement Criteria for Zircaloy Fuel Cladding Applicable to Accident Situations in Light Water Reactors, NUREG/CR-1344, ANL-79-48, January 1980.

3-60. D. W. Akers et a1.. TMI-2 Core Debris Grab Samples--Examination and Analys is, GEND-INF-975, September 1986.

3-61. Pui Kuan, TMI-2 Upper Core Particle Bed Thermal Behavior, EGG-TMI-7757, August 1987.

3-62. R. R. Hobbins et al., "PBF Severe Fuel Damage Test $1-4$ Me $1 \mathrm{t}$ Progression Scenario," Severe Accident Research Program Partner's Review Meeting, Sandia National Laboratories, Albuquerque, New Mexico, Apr i $125-30,1988$. 
3-63. L. Barleon et a1., "Extended Dryout and Rewetting of Small-Particle Core Debris," Proceedings of the Sixth Information Exchange Meeting on Debris Coolability, EPRI NP-4455, March 1986, p. 17.

3-64. K. R. Boldt et a7., DCC-3 Degraded Core Coolability: Experiment and Ana lys is. NUREG/CR-4606, SAND86-1033, September 1986.

3-65. T. Ginsberg et a)., "Core Debris Quenching Heat Transfer Rates under Top and Bottom Flooding Conditions," Proceedings International Meeting on LWR Severe Accident Evajuation, Volume 2, Cambridge, MA, August 1983 .

3-66. D. H. Cho et a1.. "On the Pattern of Water Penetration into a Hot Particle Bed," Nuclear Technology, 65, 23, Apr 111984.

3-67. M. Jahn and H. Reineke, "Free Convection Heat Transfer with Internal Heat Sources, Calculations and Measurements," Proceedings of the 5th International Heat Transfer Conference, Tokyo, Japan, September 1974.

3-68. M. Epstein and H. K. Fauske, The TMI-2 Core Relocation - Heat Transfer and Mechanism, FAI/87-44, July 1987.

3-69. Pui Kuan, Core Relocation in the TMI-2 Accident, EGG-TMI-7402, September 1986.

3-70. E. C. Lemmon, COUPLE/FLUID A Two-Dimensional Finite Element Thermal Conduction and Advection Code," EGG-ISD-SCD-80-7, February 1980.

3-71. J. E. Kelly, J. T. Nitchevek, and M. L. Schway, "Heat Transfer Characteristics of Dry Porous Particular Beds with Internal Heat Generation," Proceedings of ASME/JSME Thermal Engineering Joint Conference, Honolulu, Hawali, Volume 4, 1983, p. 83.

3-72. S. Imura and E. Takegoshi, "Effect of Gas Pressure on the Effective Thermal Conductivity of Pack Beds," Heat Transfer Japanese Research, 3, 4, 1974, p. 13.

3-73. D. Vortmeyer, "Radiation in Packed Solids," 6th International Heat Transfer Conference, Toronto, Canada, 1978.

3-74. W. J. Camp et. al., MELPROG-PWR/MOD0: A Mechanistic Code for Analys is of Reactor Core Melt Progression and Vessel Attack Under Severe Accident Conditions, NUREG/CR-4909, SAND85-0237, Apr 111987.

3-75. G. P. Willhite, D. Kunil, and J. M. Smith, "Heat Transfer in Beds of Fine Particles (Heat Transfer Perpendicular to Flow)." AIChE Journal, 8, 3, 1952, p. 340 .

3-76. A. V. Luikov, A. G. Shashkov, L. L. Vasiliev, and Yu E. Fraiman, "Thermal Conductivity of Porous Systems," International Journal Heat Mass Transfer, 11, 1968, p. 117. 
3-77. E. C. Lemmon, "Multidimensional Integral Phase Change Approximations for Finite Element Conduction Codes," Numerical Methods in Heat Transfer. John Wiley \& Sons, 1981, p. 201-213.

3-78. F. R. Larson and J. Miller, "A Time-Temperature Relationship for Rupture and Creep Stress," Transaction of the ASME, July 1952, pp. $765-775$.

3-79. S. S. Manson and A. M. Haferd, "A Linear Time-Temperature Relation for Extrapolation of Creep and Stress Rupture Data", NACA TN 2890, March 1953.

3-80. R. M. Goldhoff, "A Comparison of Parameter Methods for Extrapolating High-Temperature Data". ASME Journal of Basic Engineering. 1959, pp. 629-643.

3-81. R. L. Orr, 0. D. Sherby, and J. E. Dorn, "Correlation of Rupture Data for Metals at Elevated Temperatures, "Transactions of ASME, 46. 1954, p. 113.

3-82. B. L. Harris, V. N. Shah, and G. E. Korth, Creep Rupture Failure of Three Components of the Reactor Primary Coolant System During the TMLB' Accident, EGG-EA-7437, November 1986.

3-83. F. R. Larson and J. Miller. "A Time-Temperature Relationship for Rupture and Creep Stress," Transactions of the ASME, July 1952, pp. $765-775$.

3-84. "Inconel 600," Technical Bulletin of the International Nickel Company Incorporated, Fifth Edition, 1978. 


\section{AEROSOL AND FISSION PRODUCT BEHAVIOR}

The aerosol and fission product behavior models, including aerosol agglomeration, aerosol particle deposition, vapor evaporation and condensation, and vapor chemisorption effects, are described in this

section. Most of these models are based on the TRAP-MELT ${ }^{4-3}$ Version 2.0 computer code, but all of them have been extensively recoded to make the formulation consistent with the SCDAP/RELAP5 scheme for dynamic dimensioning and to remove some of the limiting assumptions made in the deve Topment of TRAP-MELT.

\subsection{Formulation of the Fission Product Transport Problem}

The configuration considered is illustrated in Figure 4-1, which represents one cylindrical control volume. The transport problem is divided into modeling the behavior of different physical states and the mass and energy transport between those states. The major states for a high-temperature environment are the mass of each chemical species in the aerosol, vapor, condensate, aerosol plateout, and absorbed states. Only the aerosol and vapor states are mobile. In addition, noncondensible gases (hydrogen, xenon, and krypton) and steam fields are modeled by the thermal-hydraulic behavior code.

The chemical species that can be considered by the fission product transport models for SCDAP/RELAP5 are iodine, cesium iodide, cesium hydroxide, tellurium, cadmium, silver, and tin. In contrast to TRAP-MELT, all chemical species are allowed to evaporate or condense. The code does not consider silver in the fission product transport equations because most of the silver will remain inside of the RCS. Also, the large rate of condensation of silver can increase the stiffness of the system of ordinary differential equations (ODEs) being solved, thereby causing problems in the efficient integration of the fission product transport equations. Currentiy, the code does not use stiff ODE software to integrate the transport equations because of the highly oscillatory nature of the solution curves. 


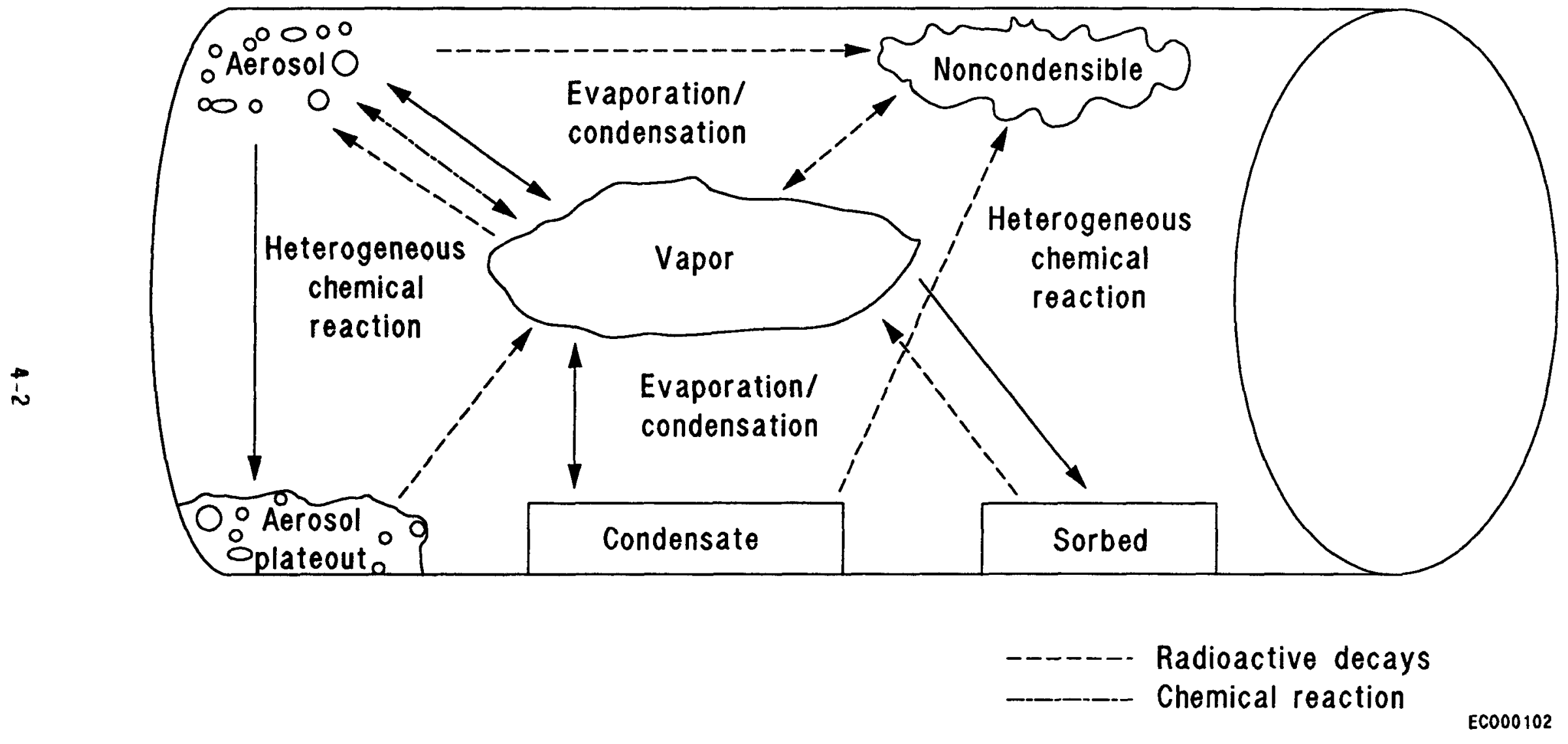

Figure 4-1. Major physical states and couplings at high temperature. 
Figure 4-1 also shows the several classes of interstate coupling that are present. Several radioactive decays are shown as dashed lines because they are not part of the current SCDAP/RELAP5 mode1s. The heterogeneous chemical reaction between silver aerosols and tellurium or (perhaps) cesium iodide vapors is also represented as a broken line because it is not modeled.

Interstate couplings that are considered are aerosol particle deposition; evaporation and condensation between the aerosol, vapor, and condensate states; and the heterogeneous chemical reaction between molecular lodine, cesium hydroxide, or tellurium and stainless steel for zircaloy) walls. Several aerosol particle deposition mechanisms are included. They are gravitational setting, thermophoresis from a well-mixed turbulent fluid, diffusion from turbulent or laminar fluid flow, impaction from turbulent flow, and impaction due to pipe bends.

The only intrastate behavior modeled is aerosol agglomeration. No chemical interaction between cesium iodide and silver or tellurium and silver vapor is considered. Also, no chemical interaction between the various absorbed states is considered.

\subsection{Aerosol Agglomeration Models}

The proposed aerosol agglomeration models are very similar to the aerosol agglomeration models of the QUICK code. ${ }^{4-2}$ These models assume that the aerosol in any control volume is a homogeneous mixture, except for narrow boundary layers near the volume walls. The particles are assumed to be spherical, with an average density given by a material property subcode to be discussed in Section 4.3. Any process which can cause particles to have non-zero relative velocities will cause them to collide and agglomerate. The processes considered are Brownian motion, differential gravitational settling, and turbulent fluid flow. Since a key feature of the agglomeration models is the differential response of particles of different sizes, the aerosol size distribution must be modeled. 


\subsubsection{Definition of Particle Size Bins}

The aerosol size distribution is described by defining a collection of twenty bins into which the particles in any control volume are sorted. The twentieth bin is an overflow bin that counts all particles with radij greater than $5 \times 10^{4} \mathrm{~m}$. The remaining nineteen bins extend over equal $\log$ (particle volume) ranges so that the $L-t h$ bin is defined by

$$
\begin{aligned}
& \frac{X_{L+1}}{X_{L}}=\left(\frac{X_{20}}{X_{1}}\right)^{\frac{1}{19}}, \\
& x_{20}=\frac{4}{3} \pi\left(5 \times 10^{-4} \mathrm{~m}\right)^{3},
\end{aligned}
$$

and

$$
x_{1}=\frac{4}{3} \pi\left(5 \times 10^{-9} m\right)^{3}
$$

where $X_{L}$ is the smallest particle volume included in the $L-$ th bin $\left(m^{3}\right)$.

For each mechanism that can cause two particles to collide, a kernel equal to the number of collisions between particles of two particular bins, the $L_{1}$-th and $L_{2}$-th bins, per unit time per unit volume is calculated and multiplied by the number of particles per unit volume in each of those bins. The appropriate number of particles are removed from the $\mathrm{L}_{7}$-th and $\mathrm{L}_{2}$-th bins and the agglomerated particles are added to the bins that correspond to the agglomerated particle size. Since aerosols consist of condensed vapors, the appropriate amount of each species mass is removed from the $\mathrm{L}_{1}$-th and $\mathrm{L}_{2}$-th bins and added to the bins that correspond to the agglomerated particle size.

If all collisions between one particle from bin $L_{1}$ and another from bin $L_{2}$ resulted in a particle belonging to bin $L_{4}$ defined by 
$\bar{x}_{L_{4}}=\bar{x}_{L_{1}}+\bar{x}_{L_{2}}$

where $\bar{x}$ is the geometric average particle volume of the $L$-th particle bin, $\left(\mathrm{m}^{3}\right)$, then the rate of change of the number of particles in bin $L_{4}$ could be determined by adding the rates from all bins with $L_{1} \leq L_{2}$ that satisfy Equation (4.4). It turns out for the equal-log particle volume bin sizes specified by Equations (4-1) and (4-2) that the product of a collision between a particle from bin $L_{1}$ and a particle from bin $L_{2}$ may be found in either of two bins, so the collision products must be distributed among these bins as follows:

A fraction $(1-f)$ goes into the bin one size larger than the larger of $L_{1}$ and $\mathrm{L}_{2}$; and the remaining fraction, $f$, goes into the larger of $L_{1}$ and $L_{2}$. The fraction $f$ is given by

$f=\frac{\bar{x}_{L_{3}}-\bar{x}_{L_{1}}-\bar{x}_{L_{2}}}{\bar{x}_{L_{3}}-\bar{x}_{L_{3}-1}}$

where

$$
\begin{aligned}
& f \quad=\quad \text { fraction of colliding particles which go into bin } \mathrm{L}_{3-1} \\
& \mathrm{~L}_{3}=\text { number of the } \mathrm{b} \text { in which is one larger than the larger of } \\
& \mathrm{L}_{1} \text { and } \mathrm{L}_{2} \\
& \mathrm{~L}_{1}, \mathrm{~L}_{2}=\text { bin numbers of the colliding particles. }
\end{aligned}
$$

In the above, we assumed that the number of bins does not exceed 50 so that the so-called 'skip a bin' phenomenon does not occur. (Otherwise, $\mathrm{L}_{3}$ can be two or more larger than the larger of $L_{1}$ and $L_{2}$. This necessitates a search routine to determine $L_{3}$, and the code can become quite inefficient.) To enhance efficiency even further, we offer two 
agglomeration models. The simpler model assumes that when particles in bin 1 collide with those of bin 2, where bin 2 is always at least one size smaller than bin 1, the agglomerated particles will only go into bin 1 . In this case, the volume fraction $f$ is set to one except in the case when particles of the same bin collide with each other.

The regular model, on the other hand, allows the volume fractions to be computed, i.e., not preset to one, when particles of different bins collide with each other. One may, however, also specify different levels of sophistication. The regular model with level of sophistication set to two, e.g., will allow the volume fraction to be computed when bin 1 is not more than two sizes larger than bin 2. In the DERV subroutine of the code, IAGMOD $=1$ corresponds to the simplified mode, while IAGMOD $=2$ corresponds to the regular model. Leve $1=2$, e.g., will set the level of sophistication to two in the regular model.

Equation (4-5) is derived in Appendix A. Detailed expressions for the kernels are presented in the following subsections.

\subsubsection{Agglomeration of Particles from Brownian Motion}

The derivation of the kernel for Brownian motion agglomeration is

discussed in Chapter 12 of Hinds, ${ }^{4-3}$ in the HAARM-3 users manual, ${ }^{4-4}$ and in Appendix B. The expression used for the Brownian motion agglomeration kernel is

$K_{B}=4 \pi 1.38 \times 10^{-23} T_{g} B \bar{r}_{L_{1}}+B \bar{r}_{L_{2}}\left(\bar{r}_{L_{1}}+\bar{r}_{L_{2}}\right)$

where

$$
\begin{aligned}
K_{B}= & \text { number of collisions due to Brownian motion } \\
& \text { between particies of radius } \vec{r}_{L_{1}} \pm \Delta_{L_{1}} \text { and } \\
& \bar{r}_{L_{2}} \pm \Delta_{L_{2}} \text { per unit time per unit }
\end{aligned}
$$


volume/(number of particles per unit volume with radius in the range $\bar{r}_{L_{1}} \pm \Delta_{L_{1}}$ times number of particles per unit volume with radius in the range $\left.\bar{r}_{L_{2}} \pm \Delta_{L_{2}}\right)\left[m^{3} /(s \cdot\right.$ particle $\left.)\right]$

$\begin{aligned} & B(r)=\text { mobility of a particle with radius } r[m /(s \cdot N)] \\ & 1.38 \times 10^{-23}=\text { Boltzmann's constant in } \mathrm{J} /(\text { molecule } K) \\ & \bar{r}_{L} \text { geometric average particle radius for } L-t h \\ & \text { particle bin }(m)\end{aligned}$

The particle mobility ${ }^{a}$ is, in turn, given by

$$
B(r)=\left\{\begin{array}{l}
\frac{1}{6 \pi \mu r}(1+1.246 K n), \text { if } K n \leq 0.1 \\
\frac{1}{6 \pi \mu r}\left(1+1.246 K n+0.42 K n e^{-0.87 / K n}\right), \text { if } K n \geq 0.1
\end{array}\right.
$$

where

$$
\begin{aligned}
\mu & =\text { dynamic viscosity of the gas }[\mathrm{kg} /(\mathrm{m} \cdot \mathrm{s})] \\
r & =\operatorname{particle~radius~}(\mathrm{m})
\end{aligned}
$$

a. The mobility of a particle in a fluid is the steady-state velocity divided by the applied force. The factor $(1+1.246 \mathrm{Kn})$ or $\left(1+1.246 \mathrm{Kn}+0.42 \mathrm{Kn} \mathrm{e}^{-0.87 / \mathrm{Kn}}\right)$ is the Cunningham slip correction for a particle moving through a fluid.4-3 The numbers used are from Millikan oil drop experiments. $4-1$ 
$K n=$ Knudsen number of the particle, the gas molecular mean free path divided by the particle radius (unitless ratio).

\subsubsection{Agglomeration Due to Differential Gravitational Settling and Turbulence}

The kernel for agglomeration due to gravitational setting is derived by multiplying the relative speed of particles of radii $\bar{r}_{L_{2}}$ and $\bar{r}_{L_{1}}$ by a circular cross-sectional area of radius $\bar{r}_{L_{1}}+\vec{r}_{L_{2}}$ and by an empirical collision efficiency ${ }^{147}$ of $1.5\left[\bar{r}_{L_{1}} /\left(\bar{r}_{L_{1}}+\bar{r}_{L_{2}}\right)\right]^{2}$. The resultant
expression is

$$
\begin{aligned}
K_{G}= & 1.5 \bar{r}_{L_{1}}^{2} \rho_{L_{1}} g \frac{4}{3} \pi^{2}\left[\vec{r}_{L_{2}^{3}}^{3}\left(\bar{r}_{L_{2}}\right) v_{+}\left(\bar{r}_{L_{2}}\right)\left(1-\frac{\rho}{\rho_{L_{2}}}\right)\right. \\
& \left.-\bar{r}_{L_{1}}^{3} B\left(\bar{r}_{L_{1}}\right) v_{+}\left(\bar{r}_{L_{1}}\right)\left(1-\frac{\rho}{\rho_{L_{1}}}\right)\right]
\end{aligned}
$$

where

$$
\begin{aligned}
& \mathrm{K}_{\mathrm{G}}=\text { number of collisions due to different steady-state } \\
& \text { velocities in a gravitational field of particles of } \\
& \text { radius } \vec{r}_{L_{2}} \pm \Delta_{L_{2}} \text { and } \vec{r}_{L_{1}} \pm \Delta_{L_{1}} \text { per unit time per unit } \\
& \text { volume//number of particles per unit volume with } \\
& \text { radius in the range } \vec{r}_{L_{2}} \pm \Delta_{L_{2}} \text { times number of } \\
& \text { particles per unit volume with radius in the } \\
& \text { range } \left.\vec{r}_{L_{1}} \pm \Delta_{L_{1}}\right)\left[m^{3} /(\text { particle.s })\right] \\
& \bar{r}_{L_{1}}=\begin{array}{l}
\text { geometric average particle radius for the bin of the } \\
\text { smaller particle }(m)
\end{array}
\end{aligned}
$$



$\bar{r}_{L_{2}}=$ geometric average particle radius for the bin of the larger particle $(\mathrm{m})$
$\rho_{L_{j}}=$ particle density of particle in the $L_{j}-$ th $b$ in $\left(\mathrm{kg} / \mathrm{m}^{3}\right)$
$\rho \quad=$ gas density $\left(\mathrm{kg} / \mathrm{m}^{3}\right)$
g = acceleration of gravity $\left(9.8 \mathrm{~m} / \mathrm{s}^{2}\right)$
$v_{t}(r)=$ ratio of non-Stokesian to Stokesian settiing velocity for a particle of radius $r$ (unitless).

The non-Stokesian velocity used in $v_{+}(r)$ is determined from empirical data obtained from Fuchs ${ }^{4-6}$ and tabulated in the subroutine NSTOKE of TRAP-MELT Version 2. Equation (4-8) differs from that used in TRAP-MELT Version 2 by the buoyancy factor.

$1-\frac{\rho}{\rho_{p}}$.

When turbulent fluid motion adds to the relative motion of particles caused by differing steady-state velocities in a gravitational field, Equation (4-8) is generalized following the work of Saffman and Turner. ${ }^{4-7}$ The expression when one considers both gravity and turbulent fluid motion is

$$
\begin{aligned}
& K_{T+G}=\left[\left\{1 . 5 \vec { r } _ { L _ { 1 } } ^ { 2 } \rho _ { p } g \frac { 4 } { 3 } \pi ^ { 2 } \left[\vec{r}_{L_{2}}^{3} B\left(\vec{r}_{L_{2}}\right) v_{+}\left(\vec{r}_{L_{2}}\right)-\bar{r}_{L_{1}}^{-3} B\left(\vec{r}_{L_{1}}\right)\right.\right.\right. \\
& \left.\left.v_{+}\left(\vec{r}_{L_{1}}\right)\right] 1-\frac{\rho}{\rho_{L_{1}}}\right\}^{2}+\left\{2 \sqrt { 2 \pi } 1 . 5 \overline { r } _ { L _ { 1 } } ^ { - 2 } \frac { 4 \pi } { 3 } \rho _ { p } \left[\vec{r}_{L_{2}}^{3} B\left(\bar{r}_{L_{2}}\right) v_{+}\left(\bar{r}_{L_{2}}\right)\right.\right. \\
& \left.\left.-\vec{r}_{L_{1}}^{3} B\left(\bar{r}_{L_{1}}\right) v_{+}+\left(\bar{r}_{L_{1}}\right)\right]_{v}^{\frac{3}{4}} \frac{\frac{1}{4}}{1}\left(-\frac{\rho}{\rho_{L_{j}}}\right)^{2}\right\}
\end{aligned}
$$




$$
\left.+\left\{\sqrt{2 \pi} \frac{2}{3}\left(\bar{r}_{L_{2}}+\bar{r}_{L_{1}}\right)^{3} \frac{E^{\frac{1}{2}}}{\frac{1}{2}}\right\}^{2}\right]^{\frac{1}{2}}
$$

where

$$
\begin{aligned}
\mathrm{K}_{\mathrm{G}+\mathrm{T}}= & \text { number of collisions due to turbulent gas flow and } \\
& \text { different velocities in a gravitational field of particles } \\
& \text { of radius } \bar{r}_{L_{2}} \pm \Delta_{L_{2}} \text { and } \bar{r}_{L_{1}} \pm \Delta_{L_{1}} \text { per unit } \\
& \text { time per unit volume/(number of particles per unit } \\
& \text { volume with radius in the range } \bar{r}_{L_{2}} \pm \Delta_{L_{2}} \text { times number } \\
& \text { of particles per unit volume with radius in the range } \\
& \left.\bar{r}_{L_{1}} \pm \Delta_{L_{1}}\right)\left[m^{3} /(\text { particles)]. }\right. \\
E \quad & \text { turbulent dissipation energy per unit mass }\left(m^{2} / s^{3}\right) \\
v & \text { kinematic viscosity of the gas }\left(m^{2} / \mathrm{s}\right) .
\end{aligned}
$$

The turbulent dissipation energy per unit mass is, in turn, given by a correlation taken from Delichasios and Probstein. 4-8

$$
E=\frac{0.03746 v^{3}}{D_{e} \operatorname{Re}^{0.375}}
$$

where

$$
\begin{aligned}
& v \quad=\text { gas speed }(\mathrm{m} / \mathrm{s}) \\
& D_{e} \quad=\text { equivalent diameter of volume under consideration }(\mathrm{m}) \\
& \operatorname{Re} \quad=\text { Reynolds number (unitless). }
\end{aligned}
$$


The first term of Equation (4-10) represents the effect of the gravitational field, the second term accounts for differing motion of different sized particles relative to the fluid, and the third term adds collisions between particles moving with the turbulent fluid.

The derivation of Saffman and Turner ${ }^{4-7}$ calculates the collision rate between particles moving with a turbulent fluid first, assuming isotropic turbulence and particle sizes much smaller than the length scale of the small eddies in the fluid. Next, the collision rate due to differing motion of different sized particles relative to the fluid is calculated from an equation of motion of the particle. It is then argued that the probability distribution of the relative velocity of two particles (which is, in general, a function of their separation because of the turbulent fluid flow) can be deduced from the equation of motion of a particle and a knowledge of the statistical properties of the small eddies of the turbulence. Next, the probability distribution is related to the rate of collision between particles of different radii. Once this relation is established, statistical arguments are used to replace the probability distribution with a simplified probability distribution that has the same variance as the relative particle velocity.

Equation (4-10) differs from the result of Saffman and Turner because the TRAP-MELT collision efficiency factor, $1.5\left[\bar{r}_{L_{1}}\left(\vec{r}_{L_{2}}+\vec{r}_{L_{1}}\right)\right]^{2}$, the Cunningham slip correction factors, and the non-Stokesian velocity correction have been included in the first two terms. It differs from

a. Inclusion of the Cunningham slip correction and non-Stokesian velocity correction replaces Saffman and Turner's term:

${ }^{\tau} L=\frac{2}{9} \bar{r}_{L}^{2} \frac{\rho_{L}}{\mu}$ by $\bar{r}_{L}^{3} B\left(\bar{r}_{L}\right) v_{+}\left(\bar{r}_{L}\right) \frac{4}{3} \pi \rho_{L}$.

This relation is derived by neglecting all but the first term of Equation (4-7). 
the corresponding expression in TRAP -MELT Version 2 by the buoyancy factor, $1-\rho / \rho_{L_{j}}$, in the first two terms and by the fact that the TRAP-MELT coding has a factor of $\frac{2}{9}$, where this result has $\frac{4}{3} \pi$ in the second term.

\subsubsection{Total Agglomeration Kerne}

The net effect of the kernels defined by Equations (4-6) and (4-8) or (4-10) is assumed to be the sum of the two contributions.

$K=K_{B}+\left[K_{G}\right.$ or $\left.K_{G+T}\right]$.

The expression is not exact because it ignores coupling between the various contributions to particle motion; but the contributions are of similar magnitude for only a limited particle size range $\left(K_{B}\right.$ dominates for small particles and $K_{G+T}$ dominates for large particles), so significant error from Equation $(4-13)$ is not likely.

\subsection{Aerosol Particle Deposition Models}

Most of the aerosol deposition models are formulated in terms of a deposition velocity,

$v_{d}=\frac{J}{C}$

where

$$
\begin{aligned}
v_{d}= & \text { deposition velocity }(\mathrm{m} / \mathrm{s}) \\
\mathrm{J}= & \text { deposition flux to volume surfaces (particles or } \\
& \left.\mathrm{kg} / \mathrm{m}^{2} \cdot \mathrm{s}\right) \\
\mathrm{C} \quad & \text { material concentration in the volume (particles or } \\
& \left.\mathrm{kg} / \mathrm{m}^{3}\right) .
\end{aligned}
$$


The use of a single deposition velocity and a single concentration for each volume is a result of the well-mixed assumption. This assumption and an alternate assumption, the steady-state assumption, are discussed briefiy.

Consider an element of volume like the one in Figure 4-2 through which material is flowing. Conservation of mass dictates that the accumulation of material in the volume element is equal to the amount of material carried into the volume by a flowing fluid, less the amount carried out by the fluid and the amount lost from the fluid to the volume surface area.

Accumulation = In - out - Loss

$\Delta\left(C A_{C} \Delta x\right)=\left.C A_{C} v \Delta t\right|_{x}-\left.C A_{C} v \Delta t\right|_{x+\Delta x}-C v_{d} \Delta A_{d} \Delta t$

where

$$
\begin{aligned}
& v \quad=\text { fluid speed }(\mathrm{m} / \mathrm{s}) \\
& \Delta t \quad=\text { time increment }(\mathrm{s}) \\
& A_{c}=\text { flow cross-sectional area }\left(\mathrm{m}^{2}\right) \\
& \Delta A_{d}=\text { increment of surface area, } 2 \pi \text { tube radius } \Delta x \text { for a } \\
& \text { circular cross section, }\left(\mathrm{m}^{2}\right) .
\end{aligned}
$$

Dividing Equation (4-15) by $\Delta t \Delta X$ and taking the limit as $\Delta t$ and $\Delta X$ approach zero gives

$\frac{\partial\left(C A_{C}\right)}{\partial t}=-\frac{\partial\left(C A_{C} v\right)}{\partial x}-C v_{d} \frac{\partial A_{d}}{\partial x}$.

The steady-state solution is found by setting the temporal derivative equal to zero: 


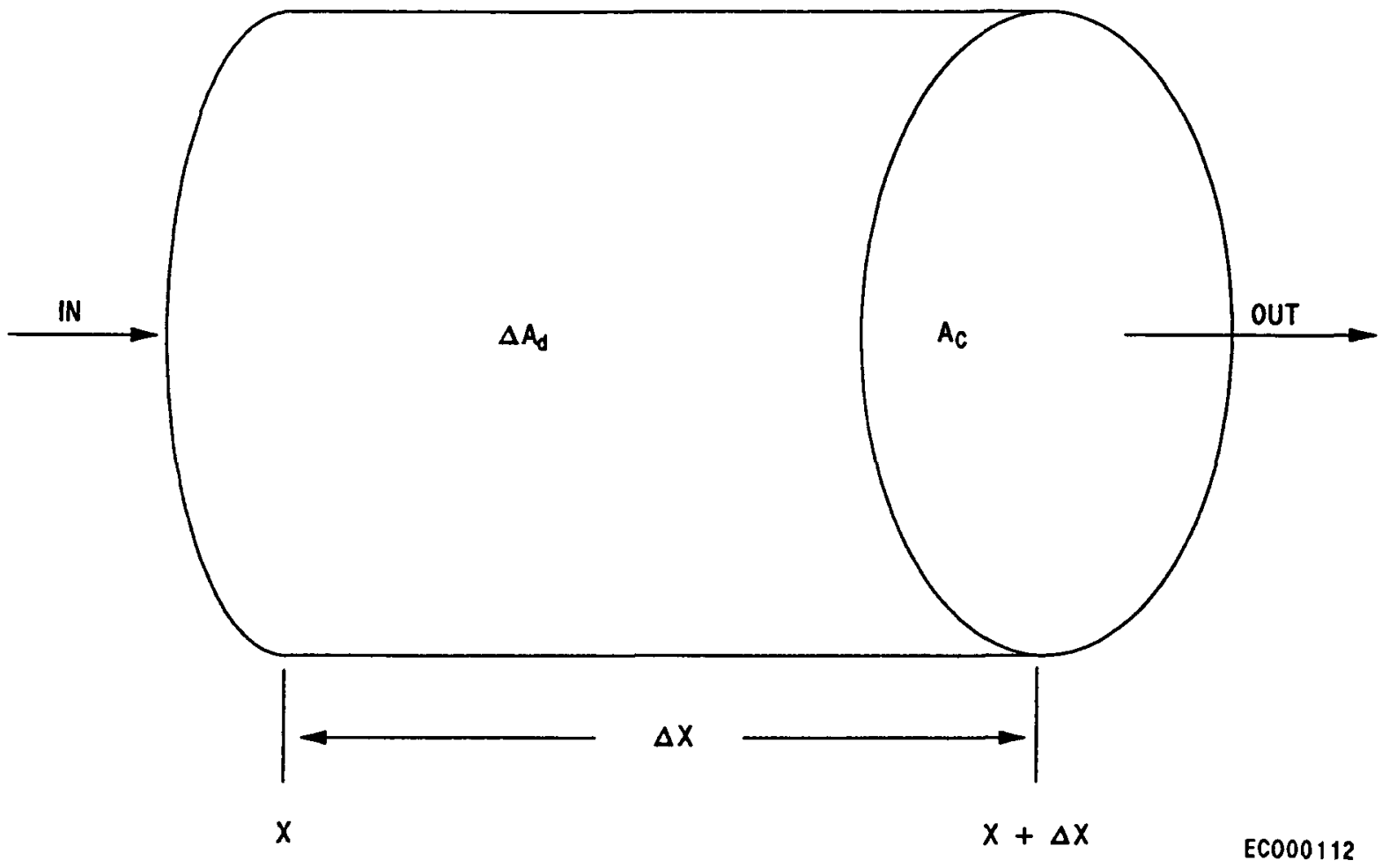

Figure 4-2. Element of volume used to illustrate steady-state and wellmixed assumptions. 
$\frac{\partial\left(C A_{C} v\right)}{\partial x}=-C V_{d} \frac{\partial A_{d}}{\partial x}$

or, for a right-eircular cyinder.

$\frac{\partial C}{\partial x}=\frac{-2 C}{R} \frac{v_{d}}{v}$

where $R$ is the radius of the right-circular cylinder $(m)$. Integration of Equation $(4-18)$ yie]ds

$C=C_{0} \exp \left(\frac{-2 V_{d} x}{V R}\right)$

where

$$
\begin{aligned}
C_{0}= & \text { material concentration in the volume at } x=0 \text { (particles } \\
& \text { or } \left.\mathrm{kg} / \mathrm{m}^{3}\right) \\
x \quad & \text { distance along the cylinder }(\mathrm{m}) .
\end{aligned}
$$

Equation (4-19) is a useful approximation for long, thin tubes with slowly varying conditions.

Genera1-purpose computer codes usually make the opposite approximation to that used in Equation (4-76), namely that the first partial with respect to position on the right-hand side is much smaller than the partial with respect to time (i.e. the we11-mixed assumption). With this assumption,

$$
\frac{\partial\left(C A_{C}\right)}{\partial t}=C v_{d} \frac{\partial A_{d}}{\partial x}
$$

or, for a right-circular cylinder,

$$
\frac{\partial C}{\partial t}=\frac{-2 C v_{d}}{R}
$$




$$
\begin{aligned}
& =-C v_{d} \frac{A_{d}}{x A_{c}} \\
& =-C v_{d} \frac{A_{d}}{v}
\end{aligned}
$$

where $V$ is the volume of the volume being considered $\left(\mathrm{m}^{3}\right)$. The we 11 -mixed assumption, which results in Equation (4-21), requires that

$$
\left|\frac{1}{v} \frac{\partial C}{\partial t}\right|>>\left|\frac{\partial C}{\partial x}\right|
$$

Since SCDAP/RELAP5 has both steady-state and transient components, both the steady-state and well-mixed approximations will have to be developed at some time. However, the well-mixed approximation is 1ikely to have far more use than the steady-state approximation.

Gravitational settling, thermophoresis from the well mixed fluid, diffusion from turbulent or laminar fluid flow, impaction from turbulent or laminar fluid flow, and impaction due to pipe bends all contribute to aerosol deposition. The expressions used to calculate deposition velocities for these effects are discussed in the following subsections.

\subsubsection{Gravitational Settling}

The expression used for the deposition velocity due to a gravitational fieid is

$$
v_{d g}=\frac{4}{3} \approx \bar{r}^{3} \rho_{p}\left(1-\frac{\rho}{\rho_{p}}\right) g B(\bar{r}) v_{t}(\bar{r}) \text { ASED }
$$

where

$$
v_{d g}=\begin{aligned}
& \text { particle deposition velocity due to gravitational field } \\
& (\mathrm{m} / \mathrm{s})
\end{aligned}
$$


ASED = normal component of surface area avallable for particle deposition $\left(m^{2}\right)$.

Equation (4-23) is derived by multiplying by the particle mobility times the gravitational force on the particle and adding the component of fluid velocity parallel to the gravitational field. Since this expression actually is for a settling velocity and not a deposition velocity, the area used with Equation (4-23) to find the amount of aerosol deposited is the projection of surface area with normal vector opposite to the gravitational field direction. Equation (4-23) differs from the one used in TRAP-MELT Version 2 by the buoyancy factor, $1-\rho / \rho_{p}$.

\subsubsection{Thermophoresis}

The expression used for the deposition velocity due to thermophoresis was derived by Brock ${ }^{4-9}$

$v_{d t}=-\frac{3}{2}\left(\frac{1}{1+3 C_{m} K_{n}}\right)\left(\frac{k_{g} / k_{p}+C_{T} k n}{1+2 k_{g} / k_{p}+2 C_{T} k n}\right) B(r) 6 \frac{\pi m^{2} \vec{r}}{p_{L}} \frac{\nabla T}{T_{g}}$

where

$\begin{aligned} v_{d t}= & \text { particle deposition velocity due to thermophores is }(\mathrm{m} / \mathrm{s}) . \\ c_{m}= & \begin{array}{l}\text { momentum accommodation coefficient (unitiess), taken as } \\ 1.0 . \text { This material property will be discussed in } \\ \text { Section } 4.6 .\end{array} \\ k_{g}= & \text { thermal conductivity of the gas }[\mathrm{W} /(\mathrm{m} \cdot \mathrm{K})] . \text { This material } \\ & \text { property will be discussed in Section } 4.6 . \\ k_{p} \quad= & \text { thermal conductivity of the particle }[\mathrm{H} /(\mathrm{m} K)] . \text { This }\end{aligned}$


$C_{T}=$ temperature accommodation coefficient (unitless), taken to be 2.5. This material property will be discussed in

\section{Section 4.6 .}

$\nabla T=$ temperature gradient at the deposition surface $(K / m)$.

Equation (4-24) was derived by calculating the force on an individual particle in a fluid thermal gradient when the molecular mean free path in the fluid is much less than the particle radius and multiplying that force times the mobility of a particle in the fluid to determine the velocity.

The expression for estimating the temperature gradient in Equation (4-24) is from the FLUID subrout ine of TRAP-MELT. The Dittus-Boelter correlation of the Nusselt number ${ }^{4-10}$ with the Reynolds number is employed.

$\nabla T=\frac{T_{w}-T_{g}}{D_{e}} 2.310^{-2} \operatorname{Re}_{t}^{0.8}$

where

$T_{w}=$ dry wall surface temperature $(K)$

$$
\begin{aligned}
& \operatorname{Re}_{t}=\operatorname{larger} \text { of }\left(\frac{\text { Grashof number }}{70}\right)^{\frac{1}{2}} \text { and Reynold's number } \\
& \text { for the volume being considered. The expression involving } \\
& \text { the Grashof number, } \\
& \frac{\text { diameter }^{3} \times \text { acceleration of gravity }{ }^{T_{w}}-{ }^{\top} g}{\text { kinematic viscosity }{ }^{2} \times \text { fluid temperature }} \text {. } \\
& \text { is supposed to be an effective Reynolds number for natural } \\
& \text { convection (Reference 4-1), but there is no reference } \\
& \text { indicated to document the basis for this correlation. }
\end{aligned}
$$


Equation (4-25) is valid only for fully developed turbulent flow, and its use for both turbulent and laminar flow is questionable. However, no better alternative is presently avajuable.

\subsubsection{Diffusion and Inertial Deposition from Turbulent Flow}

The equation used to calculate the deposition velocity due to diffusion from turbulent flow (Reynold's numbers greater than or equal to 2300) is from Davies ${ }^{4-11}$ :

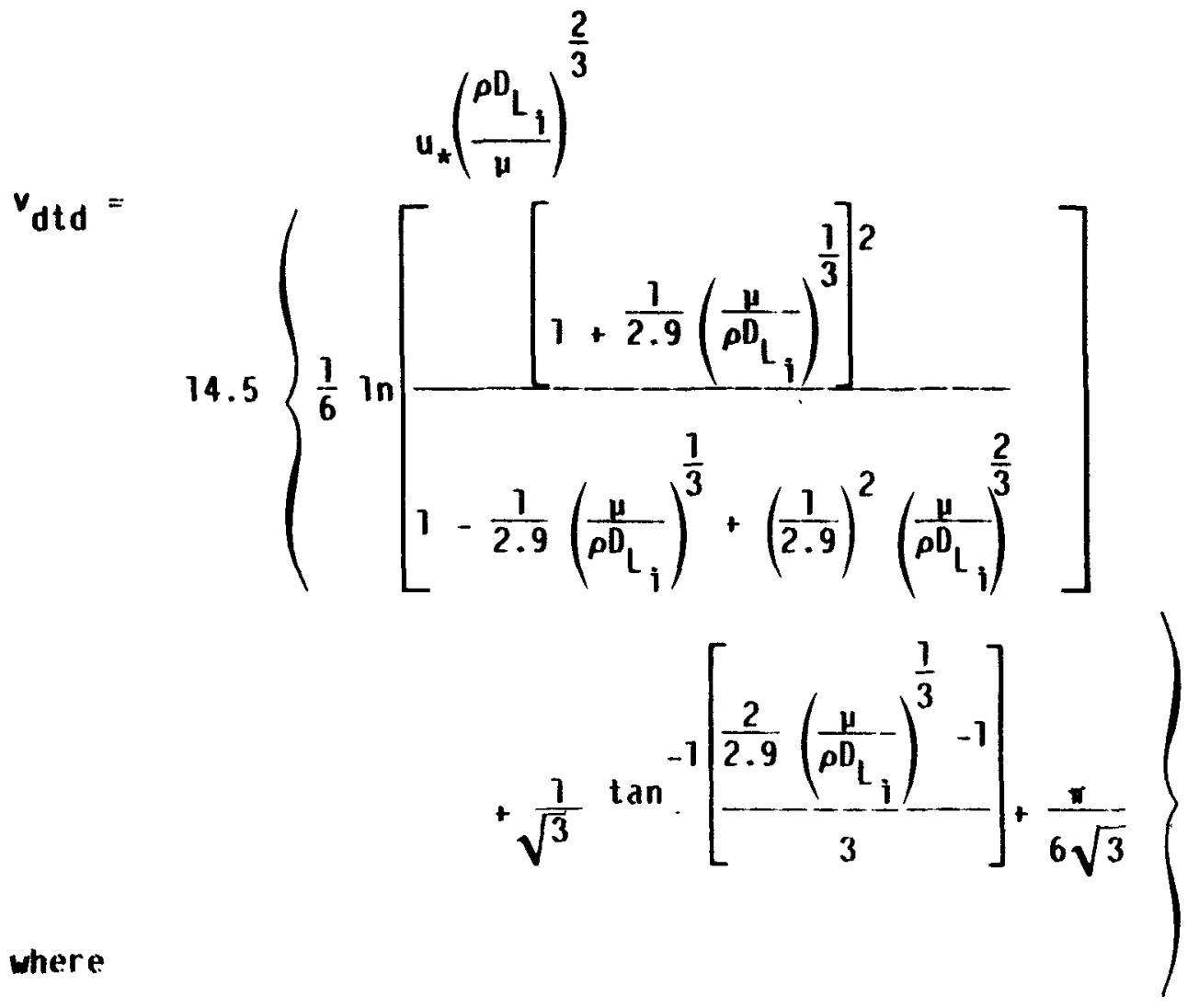

$$
\begin{aligned}
& v_{d t d}=\begin{array}{l}
\text { particle deposition velocity due to diffusion from } \\
\text { turbulent flow }(\mathrm{m} / \mathrm{s})
\end{array} \\
& u_{*}=\text { friction velocity }(\mathrm{m} / \mathrm{s}) \\
& D_{L_{i}}=\text { diffusion coefficient of particles of radius } r_{L_{i}}\left(\mathrm{~m}^{2} / \mathrm{s}\right) .
\end{aligned}
$$


The friction velocity, $u_{\star}$, is from Sehme $7^{4-12}$

if $\operatorname{Re}>0$,

$u_{*}=\left(\frac{0.00140+0.125 \mathrm{Re}^{-0.32}}{2}\right)^{\frac{1}{2}} \mathrm{v}$

if $\operatorname{Re}=0$,

$u_{\star}=0$

When flow is turbulent, the deposition velocity due to diffusion is increased by a deposition velocity due to impaction. The expressions used to model this contribution are based on work by $\mathrm{Friedlander}$ and Johnstone $e^{4-13}$ and by Gieseke, Lee, and Goldenber ${ }^{4-14}$ and are a function of a dimensionless particle relaxation time parameter,

$T=\frac{4}{3} \frac{\pi \bar{r}^{-3} \rho_{L_{i}} B(\bar{r}) p u_{\star} \mu_{\star}}{\mu}$

where $T$ is the particle relaxation time parameter (unitiess). The expressions used are:

a. For $t<5.6$,

$v_{d t i}=\left(\frac{\text { The lesser of } 0.1 \text { and }}{\frac{v}{u_{\star}}+\frac{1525}{0.81 \tau^{2}}-50.6}+2 \times 10^{-8} \operatorname{Re}\right) u_{\star}$

b. For $5.6 \leq \mathrm{t}<3.3$, 


$$
\begin{aligned}
& v_{d t i}=\left(\frac{\text { The lesser of } 0.1 \text { and }}{\frac{v}{u_{\star}+5.0} \text { ln } \frac{1.04}{0.18 \tau}-0.959-13.73}+2 \times 10^{-8} \operatorname{Re}\right) u_{*} \\
& \text { c. For } 33.3 \leq \tau, \\
& v_{d t i}=\left(\begin{array}{l}
\text { The lesser of } 0.1 \text { and } \\
\frac{u_{\star}}{v}+2 \times 10^{-8} \operatorname{Re}
\end{array}\right) u_{\star}
\end{aligned}
$$

where $v_{d t i}$ is the particle deposition velocity due to impaction from turbulent flow $(\mathrm{m} / \mathrm{s})$.

Equations (4-26) to (4-32) were taken from TRAP-MEL.T Version 2 but differ from the current version of that code by the presence of the factor $u_{*}$ at the far right-hand side of Equations (4-30) to (4-32).

\subsubsection{Diffusion from Laminar Flow}

For laminar flow (Reynold's numbers less than 2300), Equations (4-30) to (4-32) are replaced by the following correlation:

a. For fluid speeds less than $10^{-3} \mathrm{~m} / \mathrm{s}$,

$$
v_{d \ell}=10^{3} D_{L_{1}}
$$

b. For fluid speeds greater than or equal to $10^{-3} \mathrm{~m} / \mathrm{s}$ and

$$
\begin{aligned}
& h=\frac{2 \times D_{L_{1}}}{v D_{e}^{2}} \leq 0.0156 . \\
& v_{d \ell}=\left[\left(1-4.07 h^{\frac{2}{3}}+2.4 h+0.466 h^{\frac{4}{3}}\right)^{-1}-1\right] \frac{D_{e}}{4 x}
\end{aligned}
$$


c. For fluid speeds greater than or equal to $10^{-3} \mathrm{~m} / \mathrm{s}$ and

$h=\frac{2 \times D_{1}}{v D_{t}^{2}}>0.0156$

$V_{d \ell}=\{[0.8191 \exp (-7.314 h)+0.0975 \exp (-44.6 h)$

$\left.+0.0325 \exp (-114 h)]^{-1}-1\right\} \quad \frac{D_{e} v}{4 x}$

where $V_{d \ell}$ is the particle deposition velocity due to diffusion from laminar fluid flow $(\mathrm{m} / \mathrm{s})$.

These equations are adaptations of results of Gormley and Kennedy ${ }^{4-15}$ to make the results compatible with the use of well-mixed volumes and deposition velocities. 4-16 The equations correspond to those equations of Reference 4-16 but differ from the coding in TRAP-MELT Version 2 by the fact that the SCDAP/RELAP5 coding replaces $h$ by 0.25 times the value given in Equations $(4-33)$ to $(4-35)$.

\subsubsection{Effects of Pipe Bends}

A model for aerosol deposition due to impaction at pipe bends is obtained by considering the displacement of particles with respect to the fluid. The centripetal acceleration, $a$, of the particle is the squared linear speed divided by the pipe bend radius,

$a=\frac{v^{2}}{R_{b}}$

a. The model presented was developed from an unpublished model constructed by $N$. Newman, Central Electric Generating Board attache' at the INEL. 
where $R_{b}$ is the radius of the pipe bend $(m)$.

Let $s$ be the lateral displacement of a particle with respect to the fluid during the time it takes to pass around a pipe bend which changes the direction of flow by an angle $\theta$,

$s=\frac{R_{b} \theta}{v}$

The average radial speed of the particle will be the distance divided by the time

$$
v_{r}=\frac{s v}{R_{b} \theta}
$$

where

$$
\begin{aligned}
& s=\text { lateral displacement of a particle }(\mathrm{m}) \\
& v_{r}=\text { radial component of particle velocity }(\mathrm{m} / \mathrm{s}) .
\end{aligned}
$$

From the definition of mobility, the radial viscous force on this particle will be

$$
F_{r}=\frac{v_{r}}{B(r)}=\frac{s v}{R_{b} \theta B(r)}
$$

where $F_{r}$ is the radial force on the particle $(N)$. Since the effective force on a particle in a fluid is the differential mass times the acceleration,

$F_{r}=\left(\rho_{L}-\rho\right) \frac{4}{3} \pi r^{3} \frac{v^{2}}{R_{b}}$ 
The two expressions for force, Equations (4-39) and $(4-40)$, can be solved to find $s$ :

$s=\left(\rho_{L}-\rho\right) \frac{4}{3} \pi r^{3} \vee B(r) \theta$

The fraction of particles of radius $r$ that impact is simply related to s. Figure 4-3 shows a cross section of a circular pipe and a displaced circle corresponding to the field of particles which have moved a radial distance $s$. Assuming the particles were originally well-mixed, those particles in the shaded area will impact. The fraction of particles of size $r$ which do not impact is thus the ratio of the the lens-shaped area that is not shaded to the original area. This ratio is

$$
\begin{aligned}
& f_{T}=\left\{\begin{array}{l}
0, \text { for } s \geq D_{e} \\
\frac{2}{\pi}\left[\cos ^{-1}\left(\frac{s}{D_{e}}\right)-\frac{s}{D_{e}}-\sqrt{1-\left(\frac{s}{D_{e}}\right)^{2}}\right], \text { for } s<D_{e}
\end{array}\right. \\
& f_{T}=\left\{\begin{array}{l}
0, \text { for } x \geq D_{e} \\
\frac{2}{\pi}\left\{\cos ^{-1}\left[\frac{\left(\rho_{L}-\rho\right) \frac{4}{3} \pi^{2} r^{3} v B(r) \theta}{D_{e}}\right]-\left(\rho_{L}-\rho\right) \frac{2}{3} \frac{\pi^{2} r^{3} v B(r) \theta}{D_{e}}\right. \\
\left.-\sqrt{1-\left[\left(\rho_{L}-\rho\right) \frac{2}{3} \frac{\pi}{2} \frac{v B(r) \theta}{D_{e}}\right]^{2}}\right\} \text { for } s<D_{e} \text {. }
\end{array}\right.
\end{aligned}
$$

a. This area is easily calculated by noting that half of the lens shaped area is the area of a pie-shaped part of a circle minus the area of the triangle formed by two radil and the chord $A A^{\prime}$. 


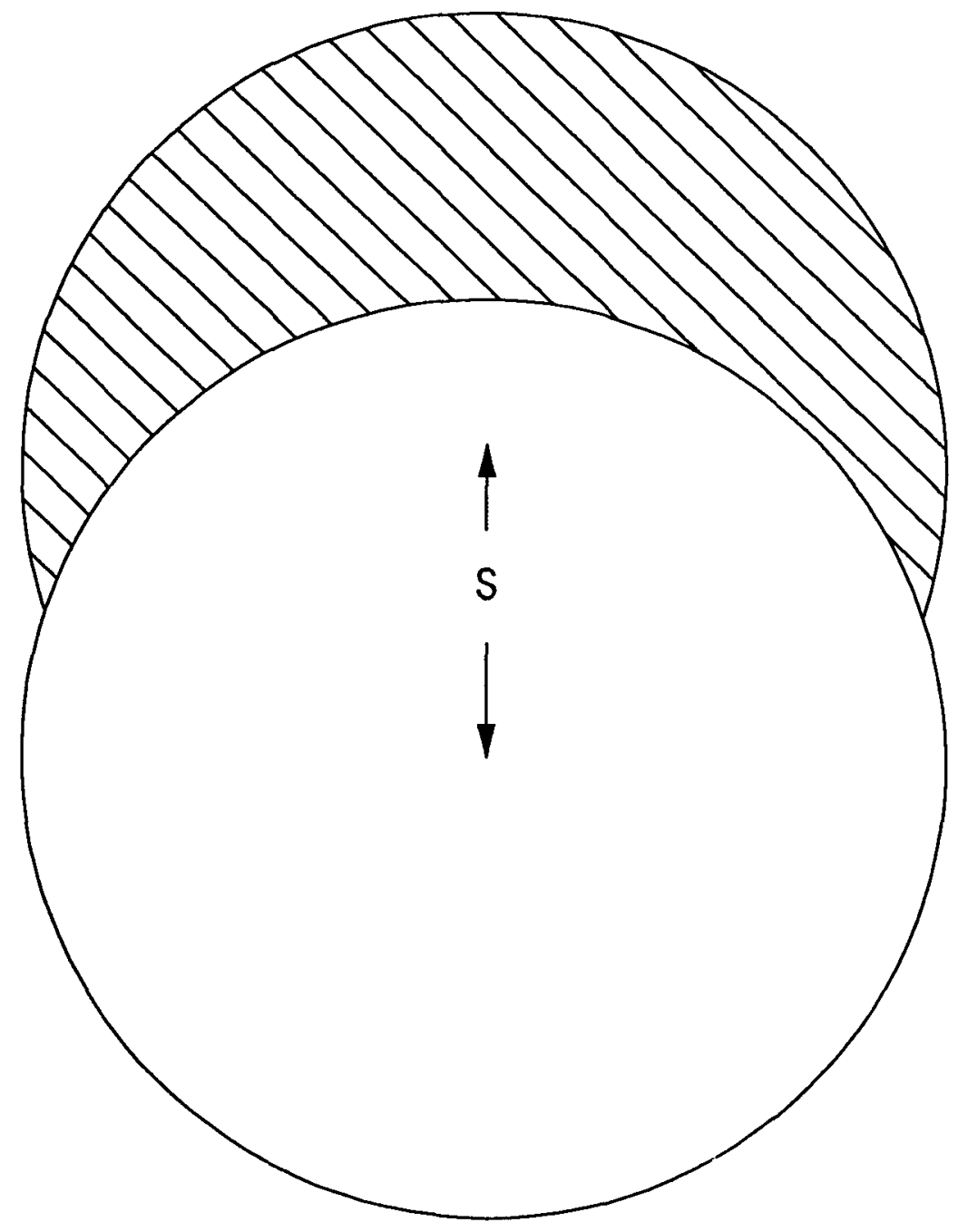

EC000113

Figure 4-3. Diagram used to calculate the fraction of particles that do not hit the pipe wall at a $90^{\circ}$ bend. 
The rate of impact of particles is the fraction of particles that impact times the rate at which the fluid carries particies past the pipe bend

$$
\frac{d N_{L}}{d \tau}=-N_{L} v A_{C}\left(1-f_{T}\right) \frac{1}{V}
$$

where

$$
\begin{aligned}
& A_{C}=\text { flow cross sectional area }\left(m^{2}\right) \\
& \left.N_{L}=\text { concentration of particles of radius } \Gamma_{L} \text { (particles } / \mathrm{m}^{3}\right) \\
& V \quad=\text { control volume }\left(\mathrm{m}^{3}\right) .
\end{aligned}
$$

Equations (4-21) and (4-44) can be combined to find an effective deposition velocity due to pipe bends

$v_{d \theta}=v \frac{A_{C}\left(1-f_{T}\right)}{A_{d}}$

where $v_{d \theta}$ is the effective deposition velocity due to pipe bends $(\mathrm{m} / \mathrm{s})$.

\subsection{Vapor Evaporation and Condensation}

The following rate equations are used to model the evaporation and condensation of each chemical species:

$$
\begin{aligned}
\frac{d C}{d t}= & -\frac{A_{W} k_{W}}{V}\left(C-C_{W}^{e}\right) S\left(M_{W,} C-C_{W}^{e}\right) \\
& -{ }_{L=1}^{19} P_{L} \frac{A_{p}\left(\bar{r}_{L}\right)}{V} \frac{k_{p}\left(\bar{r}_{L}\right)}{V}\left(C-C_{p}^{e}\right) S\left(M_{p_{L}} C-C_{p}^{e}\right)
\end{aligned}
$$




$$
\begin{aligned}
& \frac{d M_{w}}{d t}=A_{w} k_{w}\left(C-C_{w}^{e}\right) S\left(M_{w}, C-C_{w}^{e}\right) \\
& \frac{d M_{L}}{d t}=P_{L} A_{p}\left(\bar{r}_{L}\right) k_{p}\left(\bar{r}_{L}\right)\left(C-C_{p}^{e}\right) S\left(M_{P_{L}}, C-C_{p}^{e}\right)
\end{aligned}
$$

where

$$
\begin{aligned}
& \mathrm{C}=\begin{array}{l}
\text { concentration of the species vapor in the gas } \\
\left(\mathrm{kg} / \mathrm{m}^{3}\right)
\end{array}
\end{aligned}
$$

$\begin{aligned} & A_{w} \quad \text { wall surface area }\left(\mathrm{m}^{2}\right) \\ & k_{w} \quad=\quad \begin{array}{l}\text { mass transfer coefficient (deposition velocity) for } \\ \text { species transfer between bulk gas and wall } \\ \end{array} \quad \text { surfaces-gas interface }(\mathrm{m} / \mathrm{s})\end{aligned}$

$c_{w}^{e} \quad=\quad$ equilibrium vapor concentration of the species at the temperature of the wall surfaces $\left(\mathrm{kg} / \mathrm{m}^{3}\right)$

$P_{L} \quad=\quad$ number of particles in the $L-t h$ particle $b$ in (unit!ess)

$$
\begin{aligned}
A_{p}\left(r_{L}\right)= & \text { surface area of the geometric average sized particle } \\
& \text { in the } L-t h \text { particle bin, } 4 \pi r_{L}^{2}\left(m^{2}\right)
\end{aligned}
$$

$k_{p}\left(r_{L}\right)=$ mass transfer coefficient deposition velocity for species transfer between bulk gas and particle surface-gas interface of the geometric average sized particle in the $L-t h$ particle bin $(\mathrm{m} / \mathrm{s})$

$c_{p}^{e}=$ equilibrium vapor concentration of the species at the temperature of the particle surface $\left(\mathrm{kg} / \mathrm{m}^{3}\right)$. The particle surface temperature is assumed equal to the gas temperature. 


$$
\begin{aligned}
& S(a, b)=a \text { function which is zero when } a \text { is zero and } b \text { is } \\
& \text { negative and one if } a \text { is not zero or } b \text { is not } \\
& \text { negative. } \\
& M_{W} \quad=\text { mass of species vapor condensed on walls }(\mathrm{kg}) \\
& M_{L} \quad=\quad \text { mass of species vapor condensed on aerosol particles } \\
& \text { in the L-th bin's size range }(\mathrm{kg}) \text {. }
\end{aligned}
$$

Expressions for the equilibrium vapor concentrations will be discussed in Section 4.6. The mass transfer coefficient for species transfer between bulk gas and the wall surface-gas interface, $k_{w}$, is given by

$k_{w}=0.023 \operatorname{Re}^{0.83} \mathrm{Sc}^{0.33} \mathrm{D}_{v} \frac{\left(\frac{\mathrm{T}}{\mathrm{g}}\right)}{\mathrm{D}_{\mathrm{e}}}$

where

$$
\begin{aligned}
\text { Sc }= & \begin{array}{l}
\text { Schmidt number of the gas in the volume under } \\
\text { consideration, }
\end{array} \\
& \begin{array}{l}
\text { gas density odiffusivity of vapor in gas } \\
\text { (unitiess) }
\end{array} \\
D_{v}\left(T_{g}\right)= & \begin{array}{l}
\text { diffusivity of the species vapor in gas at gas } \\
\text { temperature, } T_{g},\left(\mathrm{~m}^{2} / \mathrm{s}\right) .
\end{array}
\end{aligned}
$$

The mass transfer coefficient for species transfer between bulk gas and the particle surface-gas interface of the geometric-average-sized particle in the $L$-th particle bin is

$$
k_{p}\left(r_{L}\right)=\frac{D_{v}\left(T_{p}\right)}{r_{L}}
$$


where $D_{v}\left(T_{p}\right)$ is the diffusivity of the species vapor in gas at particle surface temperature, $T_{p},\left(\mathrm{~m}^{2} / \mathrm{s}\right)$. The particle surface temperature is assumed equal to the gas temperature.

The diffusivities are discussed in Section 4.6 along with the other materials properties.

The model was taken from TRAP-MELT Version $2^{4-1}$ but differs from the TRAP-MELT model by the factor of 4 instead of $4 / 3$ in the definition of $A_{p}\left(r_{L}\right)$ and by the use of separate equations for each particle bin size. TRAP-MELT Version 2 uses a single representative particle radius, $r_{p}$. defined by

$\sum_{L=1}^{19} P_{L} D_{V}\left(T_{p}\right) 4 \pi r_{p}=\sum_{L=1}^{19} P_{L} A_{p}\left(\bar{r}_{L}\right) k_{p}\left(\bar{r}_{L}\right)$

$$
=\sum_{L=1}^{19} P_{L} 4 \pi \bar{r}_{L}^{-2} \frac{D_{V}\left(T_{P}\right)}{r_{L}}=D_{V}\left(T_{p}\right) \sum_{L=1}^{19} 4 \pi \bar{r}_{L} P_{L} .
$$

The principal limitation of this approximation is the fact that the varying dry-out times of different sized aerosol particles are ignored.

The derivation of expressions for evaporation and condensation in the presence of aerosols is discussed in Chapter 13 of Reference 4-3 and in problem 17G of Reference 4-11.

Changes in the aerosol size distribution caused by evaporation or condensation are calculated directly by considering the rate of transfer of aerosol populations between size classes. The expression used to calculate the rates of transfer assumes that the distribution of sizes within a bin is uniform so that the fractional rate at which particles leave a bin due to evaporation or condensation is the ratio of the rate of volume condensed per particle to the width of a bin 
$\frac{1}{Z_{L}} \frac{d Z_{L}}{d t}=-\frac{\left|\frac{d V_{L}}{d t}\right|}{z_{L}} \frac{1}{x_{L+1}-x_{L}}$

where

$$
\begin{aligned}
& \frac{d V_{L}}{d t}=\begin{array}{l}
\text { volume added to } L-t h \text { size classification by } \\
\text { evaporation/condensation per second }\left(\mathrm{m}^{3} / \mathrm{s}\right)
\end{array} \\
& Z_{L}=\text { number of particles in } L-t h \text { bin. }
\end{aligned}
$$

The rate at which mass leaves a bin due to evaporation or condensation is found by multiplying the fractional rate by the mass that is present.

$\left.\frac{d M_{L}}{d t}\right|_{\text {evap/cond }}=-\frac{\left|\frac{d V_{L}}{d t}\right|}{Z_{L}} \frac{M_{L}}{X_{L+7}-X_{L}}$

where

$$
\begin{aligned}
& \frac{d M_{L}}{d t} \mid=\text { rate of change of mass of any species vapor } \\
& \text { evap/cond condensed on aerosol particles due to changes in } \\
& \text { aerosol size caused by the evaporation and } \\
& \text { condensation. }
\end{aligned}
$$

\subsection{Heterogeneous Chemical Reaction between Chemical Species and Walls}

All of the heterogeneous chemical reactions are modeled with vapor deposition velocities which are constant or simple exponential functions of temperature. The expressions used are presented in Table 4-1. A number of zeros are shown in the table. In most of these cases, some reaction is expected; but no data for the rate have been located. 
TABLE 4-1. VAPOR DEPOSITION VEI OCITIES FOR HETEROGENEOUS CHEMICAL REACTIONS

\begin{tabular}{|c|c|c|}
\hline Vapor & Wa 11/Aerosol & $\begin{array}{c}\text { Deposition Velocity } \\
(\mathrm{m} / \mathrm{s})\end{array}$ \\
\hline $\mathrm{I}_{2}$ & Stainless steel & $9.0 \times 10^{-10} \exp (4076 / \mathrm{T})$ \\
\hline CsI & Stainless steel & 0 \\
\hline $\mathrm{CsOH}$ & Stainless steel & $10^{-4}$ \\
\hline Te & Stainless steel & $10^{-2}$ \\
\hline $\mathrm{Ag}$ & Stainless steel & 0 \\
\hline Cd & Stainless steel & 0 \\
\hline $\mathrm{I}_{2}$ & Lircaloy & $1.2 \times 10^{-9} \exp (3955 / \mathrm{T})$ \\
\hline $\operatorname{CsI}$ & Zircaloy & 0 \\
\hline $\mathrm{CsOH}$ & Zircaloy & 0 \\
\hline $\mathrm{Te}$ & Zircaloy & $2 \times 10^{-3}$ \\
\hline $\mathrm{Ag}$ & Zircaloy & 0 \\
\hline Cd & Zircaloy & 0 \\
\hline
\end{tabular}




\subsection{Materials Properties Models}

Table 4-2 is a summary of the required materials properties and the models they support. The table demonstrates the importance of providing accurate expressions for the density, viscosity, and molecular mean free path of molecules in the gas.

The model for gas density is the smaller of one and

$$
\rho=\frac{\sum_{i=1}^{n} F_{i} M_{i}}{\frac{8.314 \times 10^{3} T}{P}+\sum_{i=1}^{n} F_{i} b_{i}-\left(\frac{\sum_{i=1}^{n} F_{i}^{2} a_{i}}{8.314 \times 10^{3} T}\right)}
$$

where

$$
\begin{aligned}
& F_{1}=\text { mole fraction of } i \text {-th component in the gas (unitless) } \\
& M_{1}=\text { kilogram-molecular weight of } 1 \text {-th major component of the } \\
& \operatorname{gas}^{2}(\mathrm{~kg} / \mathrm{kg}-\mathrm{mole}) \\
& \mathrm{P} \quad=\text { gas pressure }(\mathrm{Pa}) \\
& b_{i}, a_{i}=\text { gas constants presented in Table 4-3 } \\
& n=\text { number of components in the gas mixture. }
\end{aligned}
$$

Equation (4-54) is derived from the Van der Waals equation of state for a gas, as discussed in Appendix B. The expression differs only siightly from the TRAP-MEIT Version 2 density correlation for pure steam,

a. It is presumed that trace elements like tellurium vapor will be neglected. 


\section{Property}

Density of gas

Dynamic viscosity of gas

Mean free path of gas molecules

\section{Models Supported}

Agglomeration due to gravitational setting, Equation $(4-8)$

Agglomeration due to turbulent fluid motion. Equation (4-9)

Particle deposition due to gravity.

Equation (4-23)

Particle deposition due to thermophoresis, Equation (4-24)

Particle deposition due to diffusion from

turbulent flow, Equation (4-26)

Particle deposition due to impaction from

turbulent flow, Equation (4-29) to (4-32)

Particle deposition due to pipe bends

Equation (4-43)

Vapor evaporation and condensation,

Equations $(4-46)$ to $(4-50)$

Agglomeration due to Brownian motion, Equations $(4-6)$ and (4-7)

Agglomeration due to gravitational setting, Equations $(4-8)$ and $(4-7)$

Agglomeration due to turbulent flutd motion, Equation (4-10) and (4-7)

Particle deposition due to gravity,

Equations $(4-23)$ and $(4-7)$

Particle deposition due to thermophoresis, Equation (4-24)

Particle deposition due to diffusion from

turbulent flow, Equation (4-26)

Particle deposition due to impaction from

turbulent flow, Equations (4-29) to (4-32)

Particle deposition due to laminar flow,

Equations $(4-33)$ to $(4-35)$, and $(4-7)$

Particle deposition due to pipe bends,

Equations (4-43) and (4-7)

Vapor evaporation and condensation,

Equations $(4-46)$ to $(4-50)$

Agglomeration due to Brownian motion, Equations $(4-6)$ and (4-7)

Agglomeration due to gravitational settiing, Equations (4-8) and (4-7)

Agglomeration due to turbulent fluid motion, Equation (4-10) and (4-7)

Particle deposition due to gravity,

Equations (4-23) and (4-7)

Particle deposition due to thermophoresis, Equations (4-24) and (4-7) 
TABLF $4-2 . \quad$ (CONTINUED)

\section{Property}

Mean free path of gas

molecules (continued)
Models Supported

Particle deposition due to diffusion from

turbulent flow, Equations (4-6), and (4-7)

Particle deposition due to impaction from

turbulent flow, Equations $(4-29)$ to $(4-32)$

and (4-7)

Particle deposition due to laminar flow,

Equations $(4-33)$ to $(4-35)$, and $(4-7)$

Particle deposition due to pipe bends,

Equations (4-43) and (4-7)

Vapor evaporation and condensation,

Equilibrium vapor

pressures, concentrations

Diffusivities of vapors in gas

Gas and particle thermal conductivities

Temperature and momentum accommodation coefficients for gas-aerosol surfaces

Density of aerosol particles
Equations $(4-46)$ to $(4-50)$

Vapor evaporation and condensation, Equations $(4-46)$ to $(4-50)$

Particle deposition due to thermophoresis, Equation (4-24)

Particle deposition due to thermophoresis, Equation (4-24)

Agglomeration due to gravitational setting, Equation (4-8)

Agglomeration due to turbulent fluid motion, Equation (4-10)

Particle deposition due to gravity, Equation (4-23)

Particle deposition due to impaction from turbulent flow, Equations (4-29) to (4-32)

Particle deposition due to pipe bends, Equation (4-43) 
TABLE 4-3. CONSTANTS FOR EQUATION (4-54)

\begin{tabular}{|c|c|c|c|}
\hline Components & $\begin{array}{c}M_{i} \\
(\mathrm{~kg} / \mathrm{kg} \cdot \mathrm{mole})\end{array}$ & $\begin{array}{c}b_{i} \\
\left(m^{3} / k g \cdot m o l e\right)\end{array}$ & $\begin{array}{l}{ }_{i} \\
-\frac{k g}{m^{5}} \\
-(s-k g \cdot m o l e)^{2} \\
\end{array}$ \\
\hline Helium & 4.003 & $3.17 \times 10^{-2}$ & 0 \\
\hline Argon & 39.948 & $2.85 \times 10^{-2}$ & 0 \\
\hline Krypton & 83.80 & $3.22 \times 10^{-2}$ & 0 \\
\hline Xenon & 131.30 & $4.29 \times 10^{-2}$ & 0 \\
\hline Hydrogen molecules & 2.016 & $2.84 \times 10^{-2}$ & 0 \\
\hline Nitrogen molecules & 28.014 & $3.46 \times 10^{-2}$ & 0 \\
\hline Steam & 18.01 & $1.80 \times 10^{-2}$ & $3.34 \times 10^{5}$ \\
\hline
\end{tabular}




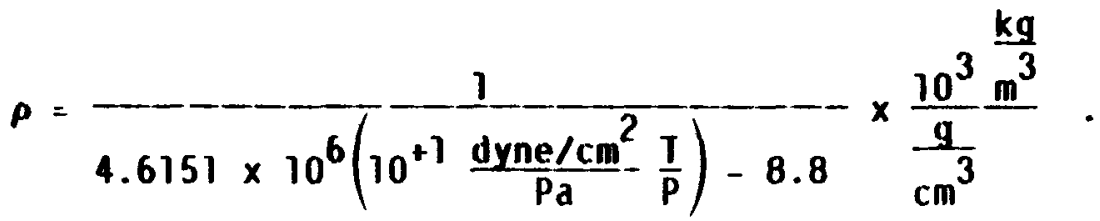

A slightly modified ${ }^{a}$ version of the MATPRO ${ }^{4-17}$ subcode GVISCO is employed for gas viscosity. The formulation used in MATPRO is from Bird et a $1 .^{4-10}$ and is

$$
\mu=\sum_{i=1}^{n} \frac{F_{i} \mu_{i}}{\sum_{j=1}^{n} F_{j} \frac{1}{\sqrt{8}}\left[1+\left(\frac{M_{i}}{M_{j}}\right)\right]^{-\frac{1}{2}}\left[1+\left(\frac{\mu_{j}}{\mu_{j}}\right)^{\frac{1}{2}}\left(\frac{M_{j}}{M_{j}}\right)^{\frac{1}{4}}\right]^{-2}}
$$

where $u_{q}$ is the dynamic viscosity of the 1 -th gas component $[\mathrm{kg} /(\mathrm{m} \cdot \mathrm{s})]$.

The viscosity of a pure monatonic species is expressed as

$\mu_{i}=2.6693 \times 10^{-26} \frac{\sqrt{M_{1} T}}{\sigma^{2} \Omega}$

where

$\sigma=$ the collision diameter for gas molecules $(\mathrm{m})$

$\Omega \quad=$ a slowly varying function of the dimensionless temperature, $\mathrm{kT} / \varepsilon$.

$k=$ Boltzmann's constant, $1.38 \times 10^{-23}[\mathrm{~J} /($ molecule $\mathrm{K})]$

a. The modification is the removal of the MATPRO correlation for steam and its replacement by the TRAP-MELT Version 2 correlation for steam. 
$\varepsilon \quad=\quad$ the maximum energy of attraction between a pair of molecules (J/molecule pair).

The MATPRO subcode interpolates a table of values of $\Omega$ from

Reference 4-10. Equation (4-57) is used for all components except steam.

For steam, the TRAP-MELT Version 2 correlation

$\mu=\frac{1.851 \times 10^{-5} \mathrm{~T}^{0.5}}{1+\frac{680}{\mathrm{~T}}} * 10^{-1} \frac{\frac{\mathrm{kg}}{\mathrm{m} s}}{\frac{\mathrm{g}}{\mathrm{cm} s}}$

is used.

The expression used for the mean free path of gas molecules is

$\lambda=\frac{\mu}{\rho}\left(\frac{g}{8} \pi \frac{j F_{i} M_{1}}{k N_{A}}\right)^{0.5}$

where

$\lambda=$ mean free path of gas molecules $(\mathrm{m})$

$N_{A}=$ Avogadro's number, $6.023 \times 10^{26}$ molecules $/ \mathrm{kg} \cdot \mathrm{mole}$.

Equation (4-59) differs from the TRAP-MELT Version 2 expression by the factor $9 \pi / 8$. The relation can be obtained from Equations (1.4-8) and (1.4-1) of Reference 4-10 by replacing the molecular weight by the average molecular weight.

Equilibrium vapor concentrations are calculated with the following correlations:

For lodine: 
With $\mathrm{T}_{\mathrm{g}} \leq 385.8472 \mathrm{~K}$,

$$
\begin{aligned}
C_{I_{2}}^{e}= & \frac{254}{8.31 \times 10^{3} T_{g}+5.15 \times 10^{-2} p}-\exp \left\{\frac{-8.24 \times 10^{3}}{T_{g}}\right. \\
& \left.+45.7-5.78 \log _{10}\left(T_{g}\right)+\frac{6.19 \times 10^{-6}}{T_{g}}\left[P-1.01 \times 10^{5}\right]\right\} .
\end{aligned}
$$

With $1000 \mathrm{~K} \geq \mathrm{T}_{\mathrm{g}}>385.8472 \mathrm{~K}$,

$$
\begin{aligned}
C_{I_{2}}^{e}= & \frac{254}{8.31 \times 10^{3} T_{g}+5.15 \times 10^{-2} p} \exp \left\{\frac{-7.38 \times 10^{3}}{T_{g}} .\right. \\
& \left.+59.3-11.9 \log _{10}\left(T_{g}\right)+\frac{6.19 \times 10^{-6}}{T_{g}}\left[P-1.01 \times 10^{5}\right]\right\} .
\end{aligned}
$$

With $\mathrm{Tg}>1000 \mathrm{~K}$. Equation (4-61) with $\mathrm{Tg}$ replaced by $1000 \mathrm{~K}$ is used.

For cesium lodide:

With $T_{g} \leq 885.8950 \mathrm{~K}$,

$$
\begin{aligned}
c_{C S I}^{e}= & \frac{260}{8.31 \times 10^{3} T_{g}+5.16 \times 10^{-2} p} \exp \left\{\frac{-2.40 \times 10^{4}}{T_{g}}\right. \\
& +50.2-6.95 \log _{10}(\mathrm{Tg})+\frac{\left.6.93 \times 10^{-6} \mathrm{~T}-1.01 \times 10^{5}\right\} .}{T_{g}} .
\end{aligned}
$$

With $\mathrm{T}_{\mathrm{g}}>885.8950 \mathrm{~K}$,

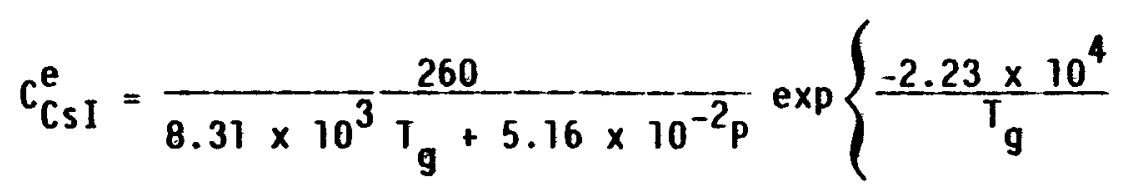




$$
\left.+51.7-8.11 \log _{10}\left(7_{g}\right)+\frac{6.93 \times 10^{-6}}{T_{g}}\left[P-1.01 \times 10^{5}\right]\right\} \text {. }
$$

For cesium hydroxide:

$$
\begin{aligned}
& c_{\mathrm{CSOH}}^{\mathrm{e}}=\frac{150}{8.31 \times 10^{3} \mathrm{~T}_{\mathrm{g}}+4.08 \times 10^{-2} \mathrm{p}} \exp \left\{\frac{-1.54 \times 10^{4}}{\mathrm{~T}_{\mathrm{g}}}\right. \\
& \left.+22.8+\frac{4.91 \times 10^{-6}}{T_{g}}\left[P-1.01 \times 10^{5}\right]\right\} \text {. }
\end{aligned}
$$

For tellurium:

$$
\text { With } \mathrm{T}_{\mathrm{g}} \leq 720.5908 \mathrm{~K} \text {, }
$$

$$
\begin{aligned}
c_{T e}^{e}= & \frac{128}{8.31 \times 10^{3} T_{g}+2.04 \times 10^{-2} p} \exp \left\{\frac{-2.15}{T_{g}} \frac{10^{4}}{g}\right. \\
& \left.+50.6-6.24 \log _{10}\left(T_{g}\right)+\frac{2.46 \times}{T_{g}} \frac{10^{-6}}{g}\left[P-1.01 \times 10^{5}\right]\right\} .
\end{aligned}
$$

With $\mathrm{T}_{\mathrm{g}}>720.5908 \mathrm{~K}$,

$$
\begin{aligned}
c_{T e}^{e}= & \frac{128}{8.31 \times 10^{3} T_{g}+2.04 \times 10^{-2} p}-\exp \left\{\frac{-1.84 \times 10^{4}}{T_{g}}\right. \\
& \left.+56.9-9.95 \log _{10}\left(1_{g}\right)+\frac{2.46 \times 10^{-6}}{T_{g}}\left[P-1.01 \times 10^{5}\right]\right\} .
\end{aligned}
$$

For cadmium: 


$$
\begin{aligned}
c_{c d}^{e}= & ---\frac{112}{8.31 \times 10^{3}} \frac{112}{T_{g}+1.30 \times 10^{-2} p} \exp \left\{\frac{-1.42 \times 10^{4}}{T_{g}}\right. \\
& \left.+38.5-4.42 \log _{10}\left(T_{g}\right)+\frac{1.57 \times 10^{-6}}{T_{g}}\left[P-1.01 \times 10^{5}\right]\right\} .
\end{aligned}
$$

For silver:

$$
\begin{aligned}
c_{A g}^{e}= & \frac{108}{8.31 \times 10^{3} T_{g}+1.03 \times 10^{-2} p} \exp \left\{\frac{-3.69 \times 10^{4}}{T_{g}}\right. \\
& +53.0-7.83 \log _{10}\left(7_{g}\right)+\frac{\left.1.24 \times \frac{10^{-6}}{T_{g}}\left[P-1.01 \times 10^{5}\right]\right\} .}{} .
\end{aligned}
$$

For tin:

$$
\begin{aligned}
c_{S n}^{e}= & \frac{118.69}{8.31 \times 10^{3} \mathrm{Tg}+1.6310^{-2} \mathrm{P}} \exp \left\{\frac{-2.847}{\mathrm{~T}_{\mathrm{g}}} \times 10^{4}\right. \\
& \left.+4.548 \ln \mathrm{T}_{\mathrm{g}}-14.31+\frac{1.96 \times 10^{-6}}{\mathrm{~T}_{\mathrm{g}}}\left[\mathrm{P}-1.01 \times 10^{5}\right]\right\} .
\end{aligned}
$$

These equations are derived from partial pressure correlations in References 4-18 and 4-19 (lodine, cesium iodide, and tellurium). Reference 4-20 (cesium hydroxide), and from Table A.1 of Reference 4-21 (cadmium, silver, and $t i n)$. Appendix $C$ presents the derivations. Equations (4-67), (4-68), and (4-69) are not part of TRAP-MELT Version 2; and the temperature ranges of Equations (4-60) through (4-63), (4-65), and (4-66) have been altered slightiy from those used in TRAP-MELI Version 2 in order to remove discontinuities. Equation (4-64) was used to replace the TRAP -MELT calculation of $\mathrm{CSOH}$ equilibrium vapor concentrations because Equation (4-64) is supported by data while the TRAP-MELT Version 2 equation 
is theoretical. Also, the small pressure-dependent term in the denominator of the preexponential factor of Equations (4-60) to (4-66) has been neglected in TRAP-MELT Version 2. The term is kept here because it is not necessarily smaller than the correction to the partial pressure correlations for pressure differences.

The expression used for the diffusivities of vapors in the gas is

$D_{v}=\frac{9.8 \times 10^{-5} T_{g}^{1.75}}{p}$

where $D_{v}$ is the diffusivity of vapor in steam $\left(\mathrm{m}^{2} / \mathrm{s}\right)$. Equation $(4-64)$ was taken from TRAP-MELT Version 2 coding.

The expression used for diffusivity of a particle of radius $r_{L}$ is

$D_{L}=1.3810^{-23} \mathrm{Tg} B(r)$

For gas and particle thermal conductivities, the MATPRO subroutines GASCON $^{4-17}$ and ATHCON ${ }^{4-22}$ are employed. The expression used in MATPRO to calculate the thermal conductivity of gas mixtures is

$$
k_{g}=\sum_{i=1}^{n}\left(\frac{k_{i} F_{i}}{F_{i}+\sum_{j=1}^{n} \psi_{i j} F_{j}}\right)
$$

where

$k_{g}=$ thermal conductivity of the gas mixture $(W / m \cdot k)$

$\nabla_{i j}=\Phi_{i j}\left[1+2.47 \frac{\left(M_{i}-M_{j}\right)\left(M_{j}-0.142 M_{j}\right)}{\left(M_{j}+M_{j}\right)^{2}}\right]$ 


$$
\Phi_{i j}=\frac{\left.\left[1+\frac{k_{i}}{k_{j}} \frac{M_{j}}{M_{j}}\right]^{1 / 4}\right]^{\frac{3}{2}}\left(1+\frac{M_{i}}{M_{j}}\right)^{\frac{1}{2}}}{2^{2}}
$$

$$
\begin{aligned}
& M_{i}=\text { molecular weight of component } i(\mathrm{~kg} / \mathrm{kg} \cdot \mathrm{mole}) \\
& k_{i}=\text { thermal conductivity of the component } i(W / m \cdot K) .
\end{aligned}
$$

The correlations used in Equation (4-72) for pure noble or diatomic gases are all of the form $k^{\mathfrak{i}}=A T_{g}^{B}$. The constants $A$ and $B$ for each noble or diatomic gas are given in Table 4-4. The following conductivity equations are used for carbon dioxide and steam

$k_{\text {carbon dioxide }}=9.460 \times 10^{-6} \mathrm{~T}_{\mathrm{g}}^{1.312}$.

For $\mathrm{T}_{\mathrm{g}} \leq 973.15$

$k_{\text {steam }}=-2.8516 \times 10^{-8}+9.424 \times 10^{-10} T_{g}-6.005 \times 10^{-14} T_{g}^{2}\left(\frac{P}{T_{g}}\right)$

$$
\begin{aligned}
& +\frac{1.009 p^{2}}{T_{g}^{2}\left(T_{g}-273\right)^{4.2}}+1.02448 \times 10^{-2}-8.21 \times 10^{-6} T_{g} \\
& +1.40957 \times 10^{-7} T_{g}^{2}-4.51 \times 10^{-11} T_{g}^{3} .
\end{aligned}
$$

For $\mathrm{T}_{\mathrm{g}}>973.15$,

$k_{\text {steam }}=4.44 \times 10^{-6} \mathrm{~T}_{\mathrm{g}}^{1.45}+9.5 \times 10^{-5} 2.1668 \times 10^{-9} \frac{\mathrm{p}}{\mathrm{T}_{\mathrm{g}}}{ }^{1.3}$

$-1.283660 \times 10^{-3}$ 
TABLE 4-4. CONSTANTS USED IN GAS THERMAL CONDUCTIVITY CORRELATIONS

\begin{tabular}{lll} 
& \multicolumn{3}{c}{ Constant } \\
\hline Gas & \multicolumn{1}{c}{ A } & 0.7085 \\
Helium & $2.639 \times 10^{-3}$ & 0.7224 \\
Argon & $2.986 \times 10^{-4}$ & 0.8363 \\
Krypton & $8.247 \times 10^{-5}$ & 0.8616 \\
Xenon & $4.351 \times 10^{-5}$ & 0.8785 \\
$\mathrm{H}_{2}$ & $1.097 \times 10^{-3}$ & 0.6898 \\
$\mathrm{~N}_{2}$ & $5.314 \times 10^{-4}$ & 0.8729 \\
$0_{2}$ & $1.853 \times 10^{-4}$ & 0.9090 \\
$\mathrm{CO}$ & $1.403 \times 10^{-4}$ & \\
\hline
\end{tabular}


The MATPRO expressions for the thermal conductivity of silver-indium-cadmium control rod material follow:

For temperature in the range $300 \leq \mathrm{T}_{\mathrm{a}}<1050 \mathrm{~K}$.

$k_{p}=2.805 \times 10^{1}+T_{a}\left(1.101 \times 10^{-1}-4.436 \times 10^{-5} T_{a}\right)$.

For temperature in the range $1050 \leq T_{a}<1110 \mathrm{~K}$,

$k_{p}=1.076458 \times 10^{3}-0.93496261_{a}$.

For temperatures $\geq 1100 \mathrm{~K}$.

$k_{p}=48$

where $T_{a}$ is the aerosol temperature $(K)$. This temperature is assumed equal to the gas temperature, $\mathrm{T}_{\mathrm{g}}$.

Since the gas and aerosol thermal conductivities are used on $7 y$ in Equation (4-24) and only as a ratio, the only significant predictions of Equations $(4-72),(4-78),(4-79)$, and $(4-80)$ are the ratio $k_{g} / k_{p}$. For pure steam at $1000 \mathrm{~K}$, this ratio is $\sim 10^{-3}$. For hydrogen, it is $\sim 4 \times 10^{-3}$. These ratios are increased by about a factor of two when the aerosol melts and its conductivity increases. The ratio differs by approximately an order of magnitude from the fixed ratio of $10^{-2}$ used in TRAP-MELT Version 2.

The temperature and momentum accommodation coefficients proposed are the TRAP-MELT Version 2 coefficients, 2.5 and 1.0 , respectively.

For aerosol particle densities, the following expressions are employed:

for $T_{a}<1050 \mathrm{~K}$

$\rho_{p}=3 \times 10^{3}$ 
For $1050 \leq T_{a}<1100 K$.

$\rho_{p}=-1.44 \times 10^{5}+1.4 \times 10^{2} \mathrm{~T}_{\mathrm{a}}$

For $T_{a} \geq 1100 K$

$\rho_{p}=10^{4}$

The low-temperature density is intended to approximate the density of a fluffy agglomeration of silver aerosols, while the high-temperature density is intended to represent the density of a liquid aerosol. (Ag-In-Cd control rod material melts in the range 1050 to $1100 \mathrm{~K}$.) Because of the extensive appearance of $\rho_{p}$ in the modeling equations and the great uncertainty about the average density of an agglomerated aerosol particle from control rods, the uncertainty in $\rho_{p}$ at low temperature is probably the most damaging uncertainty in the materials properties models. No comparison between Equations (4-81) to (4-83) and TRAP-MELT Version 2 is possible because the particle density is a user-supplied input parameter in the TRAP-MELT Version 2 code.

\subsection{References}

4-1. H. Jordan and M. R. Kuhlman, TRAP-MELT2 User's Manual, NUREG/CR-4205, BMI-2124, May 1985.

4-2. H. Jordan, P. M. Schumacher, and J. G. Gieseke, QUICK User's Manual, NUREG/CR-2105, BMI-2082, Apr 111981.

4-3. W. C. Hinds, Aerosol Technology, New York: John Wiley and Sons, 1982.

4-4. J. A. Gieseke, K. W. Leem and L. D. Reed, HAARM-3 User's Manual, BMI-NUREG-1991, January 1978.

4-5. J. M. Kelly, "Quench Front Modeling and Reflood Heat Transfer in COBRA-TF," ASME Winter Annual Meeting, 79-WA/HT-63, New York, 1979.

4-6. N. A. Fuchs, The Mechanics of Aeroso7s, 0xford: Pergamon Press, 1964.

4-7. P. G. Saffman and J. S. Turner, "On the Collision of Drops in Turbulent Clouds," Journal of Fluid Mechanics, 1, 1956, pp. 16-30. 
4-8. M. A. Delichasios and R. F. Probstein, Coagulation in Turbulent Flow-Theory and Experiment, AD-A031 297, p. 22, 1974.

4-9. J. R. Brock, "On the Theory of Thermal Forces Acting on Aerosol Particles," Journal of Colloid Science, 17. 1962, pp. 768.

4-10. R. B. Bird, W. E. Stewart, and E. N. Lightfoot, Transport Phenomena, New York: John Wiley and Sons, 1960.

4-11. C. N. Davies, Aerosol Science, New York: Academic Press, 1966, TP 244 A3D25.

4-12. G. A. Sehme1, "Particle Deposition from Turbulent Air Flow," Journal of Geophysical Research, 75, 1970, pp. 1766.

4-13. S. K. Friediander and H. F. Johnstone, "Deposition of Suspended Particles from Turbulent Gas Streams," Industrial and Engineering Chemistry 49, pp. 1151-1156.

4-14. J. A. Gieseke, K. W. Lee, and M. A. Goldenberg, Measurement of Aerosol Deposition Rates in Turbulent Flows, NUREG/CR-1264, BMI -2041, January 1980.

4-15. P. G. Gormley and M. Kennedy, "Diffusion from Steam flowing through a Cylindrical Tube," Proceedings of the Royal Irish Academy A52, 1949, pp. 163-169.

4-16. H. Jordan, J. A. Gieseke, and Paul Baybutt, IRAP-MELT Users Manual, NUREG/CR-0632, BMI-2017, February 1979.

4-17. D. L. Hagrman, G. A. Reymann, R. E. Mason, MATPRO-Version 11 (Revision 2). A Handbook of Materials Properties for Use in the Analys is of Light Water Reactor Fuel Rod Behavior, NUREG/CR-0479, TREE-1280, Revision 2, August 1981.

4-18. J. A. Gieseke, P. Baybutt, H. Jordan, R. S. Denning, and R. 0. Wooten, Analysis of Fission Product Transport Under Terminated LOCA Conditions, BMI-NUREG-1990, December 1977.

4-19. J. A. Gieseke, P. Baybutt, R. S. Denning, H. Jordan, and R. 0. Wooten, Fission Product Transport Analysis Quarterly Progress Report for Apr 11 Through June, 1976. BMI-NUREG-1955, September 1976.

4-20. J. C. Cummings et a1.. Status Report on the Fission-Product Research Program. NUREG/CR-1820, SAND 80-2662, March 1982.

4-21. J. L. Margrave, The Characterization of High-Temperature Vapors, New York: John Wiley and Sons, Inc., QC 304 M32.

4-22. D. L. Hagrman, Materials Properties for Severe Core Damage Analysis, EGG-CDD-5801, May 1982 . 


\section{DECAY HEAT DISTRIBUTIONS FOR VOLATILES RELEASED \\ FOLLOWING FUEL DISRUPTION}

\subsection{Fission Product Decay Heat Mode1}

The reduction in fission product decay heat resulting from loss of volatile elements can be accounted for using the model described in Reference 5-1. Fission product decay heat for the intact fuel is calculated from the power history using ASN-5.1. After a major disruptive event, the decay heat reduction is determined from a set of precalculated tabular values describing the time-dependent fractional changes in decay heat following fuel disruption. The existing SCDAP tables correspond to several possible irradiation history-volatile element release scenarios. This method provides a mechanism for treating decay heat reduction in the disrupted fuel region but provides no information on the distribution of decay power among the released materials.

SCDAP/RELAP5 decay heat models address transport and deposition of the decay energy carried by the released fission products. Implementation of these models requires estimates of decay heat contributions from the volatile elements being tracked (tellurium, iodine, and cesium) and the distribution of this decay energy between photons and electrons.

\subsection{Fission Product Decay Heat Methodology}

This section summarizes the methodology and results of calculations performed to obtain decay heat distributions for the released fission products. Based on model reviews, it was agreed to limit the analysis to one of the irradiation history-volatile release scenarios in Reference 5-1 and to isolate contributions from tellurium, lodine, and cesium. Decay heat contributions from the remaining fission products are lumped into a single composite group.

The generic PWR-rapid fuel heatup scenario described in Reference 5-1 was selected for this analysis. Fission product inventories were 
calculated using ORIGEN2, ${ }^{5-2}$ assuming full-power operation at the end of an equilibrium cycle. Fuel failure was assumed to occur at 2 min after shutdown. Fission product releases were calculated using ORIGEN2 and the time-dependent release rate constants listed in Table 4 of Reference $5-1$. These best-estimate (circa 1981) release rate constants are not necessarily the current best-estimate values but were used for this analys is to maintain compatibility with the existing SCDAP volatile element release scenarios.

\subsubsection{Fission Product Decay Heat Model Results}

The time-dependent decay heat contributions from selected elements are shown in Table 5-1 and in Figure 5-1. The decay heat fraction is defined as the ratio of the decay heat from all isotopes of that element to the decay heat of all released fission products. The decay heat contribution from all released fission products other than tellurium, lodine, and cesium is about $76 \%$ at $130 \mathrm{~s}$ and drops to about $23 \%$ at $15.6 \mathrm{~h}$. Table $5-2$ 1ists estimated decay heat gamma fractions for the three elements as a function of time following shutdown.

\subsubsection{Fission Product Decay Heat Model Additional Observations}

The decay heat contributions from elements other than tellurium, lodine, and cesium are appreciable at some periods following release. Fractional contributions from other elements can be isolated with minimal effort (a few hours and a few dollars computer time per element) if the decision is made to track them.

\subsection{References}

5-1. B. G. Schnitzler, Fission Product Decay Heat Modeling for Disrupted Fuel Regions (FDECAY), EGG-PHYS-5698, December 1981.

5-2. A. G. Croff, ORIGEN2--A Revised and Updated Version of the Oak Ridge I sotope and Depletion Code, ORNL -562T, July 1980. 


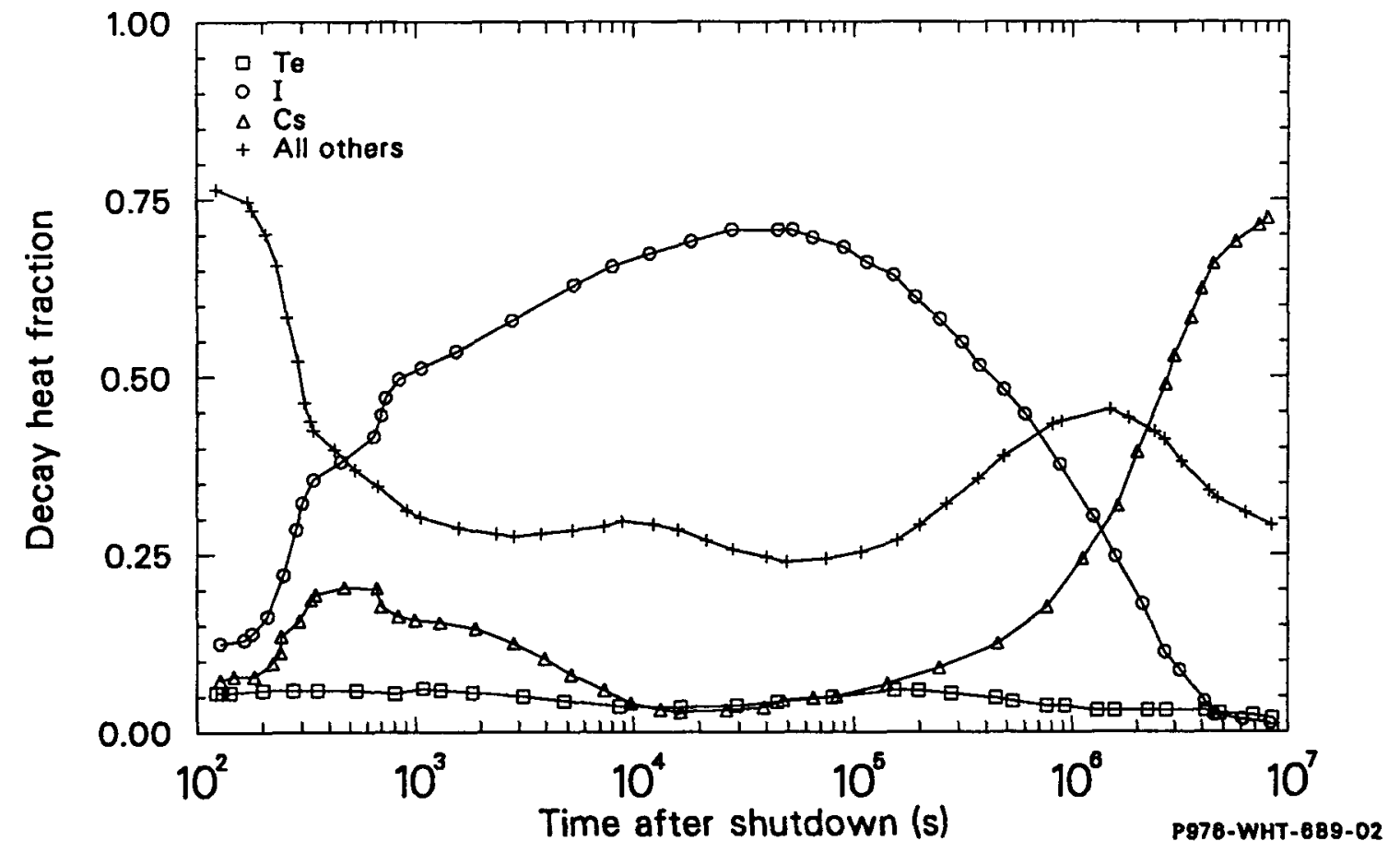

Figure 5-1. Decay heat contributions of selected elements (based on total decay heat of all released fission products). 
TABLE 5-7. FRACTIONAL DECAY HEAT CONTRIBUTIONS FOR SELECTED FISSION PRODUCT ELEMENTS (based on total decay heat from all released fission products)

Time After Shutdown

\begin{tabular}{|c|c|c|c|}
\hline$(s)$ & Tellurium & Iodine & Cesium \\
\hline $\begin{array}{l}130 . \\
150 . \\
170 . \\
180 . \\
200 . \\
220 . \\
240 . \\
260 . \\
280 . \\
300 . \\
320 . \\
340 . \\
360 . \\
480 . \\
540 . \\
600 . \\
660 . \\
720 . \\
750 . \\
780 . \\
840 . \\
1020 . \\
1080 .\end{array}$ & $\begin{array}{l}0.0485 \\
0.0504 \\
0.0522 \\
0.0531 \\
0.0530 \\
0.0530 \\
0.0529 \\
0.0515 \\
0.0506 \\
0.0502 \\
0.0505 \\
0.0511 \\
0.0518 \\
0.0524 \\
0.0526 \\
0.0528 \\
0.0530 \\
0.0532 \\
0.0518 \\
0.0534 \\
0.0505 \\
0.0519 \\
0.0534\end{array}$ & $\begin{array}{l}0.1179 \\
0.1214 \\
0.1248 \\
0.1265 \\
0.1437 \\
0.1594 \\
0.1737 \\
0.2149 \\
0.2440 \\
0.2659 \\
0.3094 \\
0.3313 \\
0.3452 \\
0.3727 \\
0.3839 \\
0.3939 \\
0.4030 \\
0.4113 \\
0.4421 \\
0.4538 \\
0.4729 \\
0.4970 \\
0.5000\end{array}$ & $\begin{array}{l}0.0739 \\
0.0756 \\
0.0774 \\
0.0783 \\
0.0891 \\
0.0986 \\
0.1070 \\
0.1286 \\
0.1431 \\
0.1536 \\
0.1732 \\
0.1822 \\
0.1874 \\
0.1948 \\
0.1971 \\
0.1986 \\
0.1995 \\
0.2000 \\
0.1773 \\
0.1710 \\
0.1584 \\
0.1516 \\
0.1521\end{array}$ \\
\hline $\begin{array}{l}1.7783 \times 10^{3} \\
3.1623 \times 10^{3} \\
5.6234 \times 10^{3} \\
1.0000 \times 10^{4} \\
1.7783 \times 10^{4} \\
3.1623 \times 10^{4} \\
5.6234 \times 10^{4} \\
1.0000 \times 10^{5} \\
1.7783 \times 10^{5} \\
3.1623 \times 10^{5} \\
5.6234 \times 10^{5} \\
1.0000 \times 10^{6} \\
1.7783 \times 10^{6} \\
3.1623 \times 10^{6} \\
5.6234 \times 10^{6} \\
1.0000 \times 10^{7}\end{array}$ & $\begin{array}{l}0.0498 \\
0.0436 \\
0.0359 \\
0.0288 \\
0.0267 \\
0.0311 \\
0.0381 \\
0.0448 \\
0.0484 \\
0.0448 \\
0.0354 \\
0.0251 \\
0.0197 \\
0.0214 \\
0.0190 \\
0.0099\end{array}$ & $\begin{array}{l}0.5321 \\
0.5726 \\
0.6162 \\
0.6521 \\
0.6755 \\
0.6965 \\
0.6988 \\
0.6731 \\
0.6287 \\
0.5564 \\
0.4702 \\
0.3707 \\
0.2403 \\
0.0960 \\
0.0118 \\
0.0002\end{array}$ & $\begin{array}{l}0.1429 \\
0.1177 \\
0.0738 \\
0.0322 \\
0.0197 \\
0.0248 \\
0.0340 \\
0.0468 \\
0.0640 \\
0.0858 \\
0.1177 \\
0.1772 \\
0.2944 \\
0.4814 \\
0.6532 \\
0.7123\end{array}$ \\
\hline
\end{tabular}


TABLE 5-2. ESTIMATEO GAMMA DECAY POWER FRACTIONS FOR RELEASED FISSION PRODUCTS (based on total decay heat from all released fission products)

Time After Shutdown

(s)

170.

320.

540 .

1080 .

$1.7783 \times 10^{3}$

$3.1623 \times 10^{3}$

$5.6234 \times 10^{3}$

$1.0000 \times 10^{4}$

$1.7783 \times 10^{4}$

$3.1623 \times 10^{4}$

$5.6234 \times 10^{4}$

$1.0000 \times 10^{5}$

$1.7783 \times 10^{5}$

$3.1623 \times 10^{5}$

$5.6234 \times 10^{5}$

$1.0000 \times 10^{6}$

$1.7783 \times 10^{6}$

$3.1623 \times 10^{6}$

$5.6234 \times 10^{6}$

$1.0000 \times 10^{7}$
Tellurium

\subsection{4}

0.6616

0.6638

0.6657

0.6718

0.6791

0.6830

0.6763

0.6653

0.6721

0.6821

0.6809

0.6662

0.6363

0.5796

0.4579

0.2437

0.1400

0.1302

0.1219
Iodine

0.7832

0.7924

0.7948

0.7945

0.7929

0.7895

0.7833

0.7729

0.7591

0.7452

0.7335

0.7291

0.7367

0.7499

0.7486

0.7269

0.6970

0.6787

0.6759

0.6757
Cesium

0.5082

0.5715

0.6025

0.6379

0.6723

0.6983

0.7169

0.7642

0.8506

0.8663

0.8673

0.8670

0.8659

0.8639

0.8606

0.8554

0.8477

0.8386

0.8314

0.8267 


\section{SCDAP/RELAP5 DECAY HEAT DEPOSITION MODEL}

\section{1 Energy Deposition Model}

An energy deposition model is described to be used in conjunction with the SCDAP/RELAP5 heat distribution model. The fission product transport model apportions the decay energy from fission products carried in the vapor space as an aerosol or deposited on a structural surface according to the local group population in a given cell. When a decay occurs, the released energy can be assigned to either (a) the vapor space, (b) the solid which is first impacted by the decay particle, or (c) the solid upon which the fission product is deposited. The model described in this section provides a means of determining the location in which the released energy is deposited.

\subsubsection{Gamma Energy Deposition - Airborne Release}

Gamma energy released from airborne fission products will be treated as a volumetric energy contribution in the heat structures connected to the control volume. The energy will be apportioned according to the relative surface area of each heat structure compared to the total surface area of a 11 the heat structures connected to that control volume. In this manner, a simple model of the appropriate view factors is provided.

The distribution of the gamma energy within the solid structure is determined by an attenuation calculation based on an average, predetermined attenuation factor corresponding to the particular heat structure. The volume of each computational cell within the solid is already available to SCDAP/RELAP5, so the volumetric energy can be multiplied by the known volume to give a total energy source addition to the heat conduction equation. 


\subsubsection{Deposited Fission Product Release--Gamma Energy}

Gamma energy released from deposited fission products is treated in a manner similar to that released from airborne fission products. Assuming isotropic release from fission products on the surface of a heat structure, one-half the gamma energy would enter the heat structure and one-half would be released toward the adjacent vapor space. The half entering the solid is attenuated in the same manner as that which enters from airborne release. The half which is released toward the vapor space is, by assumption, not attenuated in the vapor. Therefore, this portion of the gamma energy must be distributed among the heat structures bounding the control volume. After being apportioned according to the relative surface area of each heat structure, the gamma energy is attenuated within the solid structure in the manner already described.

A question of modeling gamma energy released from deposited fission products arises when a particular cell is modeled with only one heat structure. The energy released to the vapor space has nowhere to go. In fact, however, the energy can be assigned to the surface which emitted it in a manner consistent with the 1-D approximation used to model the physical system. Since the flow region is generally bounded by the entire modeled heat structure, the 1-D model actually represents a reentrant surface. Therefore, it is appropriate to return the emitted energy to the same surface from which it came. In the event a control volume has only one associated heat structure, the entire gamma energy emitted from deposited fission products is assigned to the emitting heat structure and is attenuated therein. If the control volume has more than one associated heat structure, the determination of view factors based on relative surface area should include the surface area of the emitting surface, thereby making reabsorption by the emitting surface just as likely as absorption by another surface within that control volume.

\subsubsection{Beta Energy Deposition}

The airborne release of beta energy is similar to that of gamma energy in that the energy will be apportioned to the various heat structures 
according to the relative surface area of each. The beta calculation differs, however, in that beta energy is attenuated within the vapor space through which the beta particle must pass.

Each fission product group is characterized by a beta endpoint energy corresponding to the endpoint energy of the most active isotope in the group. This endpoint energy is used as a constant for each fission product group throughout the calculation, although it is possible that the ORIGEN $2^{6-1}$ calculations used for input could also be used to determine a time-dependent endpoint energy. The endpoint energy is used in a range calculation based on a relation by Katz and Penfold ${ }^{6-2}$ for absorption of beta-rays in aluminum.

$R=\frac{0.412}{\rho}\left[\mathrm{E}_{0}\left(1.265-0.095417 \mathrm{nE}_{0}\right)\right]$

where

$R=$ range of the beta particle, i.e., the distance at which the beta flux is indistinguishable from the background flux.

$E_{0}=$ endpoint energy of the beta decay.

$\rho=$ density of vapor in the volume.

The calculated beta range is compared to a characteristic distance to the solid surfaces determined by calculating an equivalent radius for a right-circular cylinder with the same volume and surface area as the control volume. Thus, the equivalent radius for airborne release is:

$r=2 \frac{V}{A}$

The energy attenuation calculated for this distance for each group is taken as a volumetric energy source for the control volume. The remaining beta 
energy for each group is apportioned among the various heat structures as an incident energy flux at the surface.

\subsubsection{Deposited Fission Product Release--Beta Energy}

The treatment of beta energy from deposited fission product release is similar to that for gamma energy. One half of the released energy is incident on the heat structure as a surface flux; the other half is released toward the vapor space, just as in the gamma calculation. The difference is that some of the beta energy is absorbed in traversing the vapor space. Therefore, an attenuation calculation is performed to determine the fraction of beta energy reaching the other heat structures bounding the control volume. The equivalent distance to the bounding heat structures is again based on a right-circular cylinder approximation, this time using an equivalent diameter instead of an equivalent radius:

$d=4 \frac{V}{A}$.

The attenuation calculation is again based on a characteristic endpoint energy for each group, and the attenuated energy is assigned to the control volume as a volumetric source. The remaining energy is incident on the bounding heat structures as a surface flux.

The interpretation of the surface flux for beta energy in the event of only one heat structure is the same as that for gamma energy under similar conditions. A single heat structure is treated as a reentrant surface, and energy released from it and not completely attenuated by the intervening vapor is considered to be incident on the same heat structure from which it was emitted. In keeping with the assumptions listed above, none of the energy, etther beta or gamma, escapes the control volume.

\subsection{Gamma Attenuation Complete Absorption Model}

Gamma attenuation within a given heat structure is a function of both the gamma energy and the material properties of the structure. As a first 
approximation, this model will presume a characteristic gamma energy for the radioactive decays and use a characteristic density for each heat structure provided from input. The gamma energy will determine an appropriate attenuation constant for the structure, which can then be multiplied by the density of the structural material to calculate the penetration distance of the gammas.

The attenuation within the heat structure is presumed to be exponential with penetration distance. The structure will be assumed to be a slab geometry, and all gamma energy will be absorbed within the heat structures associated with the cell in which the radioactive decay occurred.

The exponentially varying volumetric energy generation rate is given by the expression:

$u(x)=U_{0} e^{-\mu \rho x}$

where

$$
\begin{aligned}
& x \quad=\text { distance from energy source } \\
& u(x)=\text { volumetric energy generation rate } \\
& u_{0}=\text { volumetric energy generation at } x=0 \\
& \mu \quad=\text { attenuation constant } \\
& \rho \quad=\text { material density. }
\end{aligned}
$$

If this expression is integrated over the thickness of the heat structure, $d$, the energy generation rate at $x=0$ can be replaced with an expression in terms of the incident gamma energy flux,

$$
u(x)=Q_{Y} \mu \rho \frac{e^{-\mu \rho x}}{1-e^{-\mu \rho d}}
$$


where

$$
\begin{aligned}
& \mathbf{Q}_{\mathbf{Y}}=\text { incident gamma flux } \\
& \mathbf{d} \quad=\text { thickness of heat structure. }
\end{aligned}
$$

Then, the energy deposited in an interval $x_{1}$ to $x_{2}$ within the slab is:

$$
\int_{x_{1}}^{x_{2}} u(x) d x=\frac{-Q_{r}}{1-e^{-\mu \rho d}}\left(e^{-\mu \rho x 2}-e^{-\mu \rho x 1}\right) .
$$

Note that the denominator is just a multiplier which ensures that the total energy deposited within the heat structure is the same as that delivered to the surface.

A similar calculation can be performed for a radial geometry heat structure. The resultant expression is somewhat more complicated but has the same general structure. It seems unlikely, however, that the difference in deposition rates would be significant enough to warrant the extra effort of modeling two different geometries. Clearly, the effect of the different geometries gets smaller as the characteristic radius of the heat structures increases.

\subsubsection{Partial Absorption Mode1}

It is possible to write a model in which the gamma energy is not completely absorbed within the cell containing the initial radioactive decay. The problem is determining what to do with the gamma energy which escapes the cell.

A possible solution to the problem of distributing energy which escapes from a given cell is to form a background energy pool, which is uniformly distributed among all the heat structures in the model. The assumption in using such a background pool is that enough gamma energy 
would escape all the cells in the model that an essentially uniform background radiation field would be established within the modeled reactor. At each time step, an appropriate portion of the pool energy could be extracted and added to the source energy of every heat structure. At the same time, energy which escaped the cell would be added to the pool, with careful attention paid to conserving total energy.

Although the background energy idea could probably be developed and defended, this approach is not recommended at this time. In the event that heat structure temperatures are too high using the fairly conservative assumption that a 11 the gamma energy remains within the emitting ce11, the background energy concept can be added to smear the gamma energy and 1ikely reduce the energy input to the calculated hot spots.

\subsection{References}

6-1. A. G. Croff, ORIGEN2--A Revised and Updated Version of the Oak Ridge Isotope and Depletion Code, ORNL-5621, JuTy 1980.

6-2. L. Katz and A. S. Penfold, "Range-Energy Relations for Electrons and the Determination of Beta-Ray End-Point Energies by Absorption," Rev. Mod. Phys., 24, 1952, p. 28. 


\section{APPENDIX A}

DISTRIBUTION OF AGGLOMERATED PARTICLES

\section{$A-1 / A-2$}


Th

-

$\bullet$

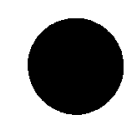




\section{APPENDIX A \\ DISTRIBUTION OF AGGLOMERATED PARTICLES}

When particles from one of the particle bins described in Section 4.1 coagulate with particles from another bin, the resultant particles are distributed between two bins in a way that yields the correct number density. Figure A-1 illustrates the distribution of the actual particles on a $\log$ scale of particle volume. The source bins, $L_{2}$ and $L_{1}$, are shaded, and the smallest bin which receives coagulated particles is the $\mathrm{L}_{3}$-th bin. The code represents all particles in a bin by a collection of particles whose volume is the geometric average of the bin size.

By conservation of mass (density is assumed constant), the collision of particles from the range $\left[X_{L_{1}}, X_{L_{1}+7}\right]$ and the range $\left[X_{L_{2}}, X_{L_{2}+1}\right]$, that is bin $L_{1}$ and bin $L_{2}$, will produce a particle in the range $\left[x_{L_{1}}+x_{L_{2}}\right.$, $\left.X_{L_{1}+1}+X_{L_{2}+1}\right]$. Let $\log w=$ the width of any bin in $\log$ space. That is, let

$w \equiv\left(\frac{x_{20}}{x_{1}}\right)^{\frac{1}{19}}=\frac{x_{L+1}}{x_{L}}$.

The statement that the particle resulting from a collision of a particle from bin $L_{1}$ with a particle from bin $L_{2}$ belongs to at most one of two bins is equivalent to showing that

$\log \left(X_{L_{1}+1}+X_{L_{2}+1}\right)-\log \left(X_{L_{1}}+X_{L_{2}}\right)<2 \log w$

or that

$$
\frac{x_{L_{1}+1}+x_{L_{2}+1}}{x_{L_{1}}+x_{L_{2}}}<w^{2} .
$$




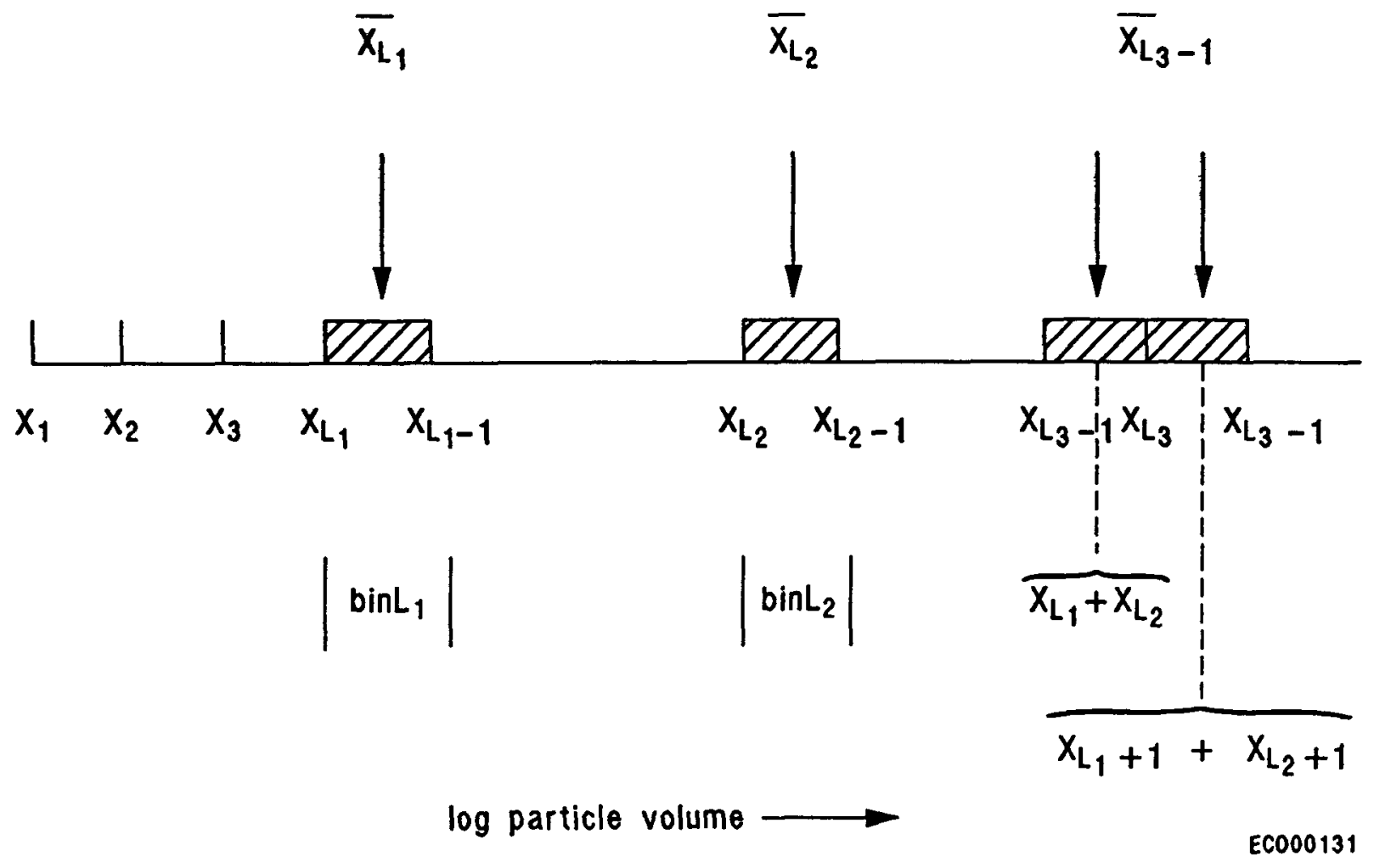

Figure A-1. Distribution of particles resulting from coagulation of a particle from bin $L_{1}$ and a particle from bin $L_{2}$. 
Since

$w=\frac{X_{L_{1}+1}}{X_{L_{1}}}=\frac{X_{L_{2}+1}}{X_{L_{2}}}$.

Equation $(A-3)$ is equivalent to

$\frac{x_{L_{1}+1}+x_{L_{2}+1}}{x_{L_{1}}+x_{L_{2}}}<\frac{x_{L_{1}+1}}{x_{L_{1}}} \frac{x_{L_{2}+1}}{x_{L_{2}}}$.

or

$X_{L_{1}+1} X_{L_{1}} X_{L_{2}}+X_{L_{2}+1} X_{L_{1}} X_{L_{2}}<X_{L_{1}+1} X_{L_{2}+1} X_{L_{1}}+X_{L_{1}+1} X_{L_{2}+1} X_{L_{2}}$

The first term on the left side is less than the first term on the right side, since $X_{L_{2}}<X_{L_{2}+1}$; and the second term on the left side is less than the second term on the right side, since $X_{L_{1}}<X_{L_{1}+1}$. Thus, the range of coagulated particles covers at most two bins.

Once convinced that the coagulated particles are distributed over two bins, the next question is, "Which two bins?" That is, the definition of the index $\mathrm{L}_{3}$ of Equation (4-5) of the main text must be derived. The derivation begins with the observation that the geometric average particle size for each bin is $1 / 2 \log w$ from either end of the bin if the particle size distribution is uniform across the bin's span. The proof of this observation follows.

$$
\bar{x}_{L}=\sqrt{X_{L} X_{L+1}}
$$




$$
\begin{aligned}
\log \bar{X}_{L} & =\log \sqrt{X_{L} X_{L+1}} \\
& =\frac{1}{2} \log \left(X_{L} X_{L+1}\right) \\
& =\frac{1}{2}\left(\log X_{L}+\log X_{L+1}\right) . \\
\log X_{L}-\log X_{L} & =\frac{1}{2}\left(\log X_{L}+\log X_{L+1}\right)-\log X_{L} \\
& =\frac{1}{2}\left(\log X_{L+1}-\log X_{L}\right) \\
& =\frac{1}{2}\left(\log \frac{X_{L+1}}{X_{L}}\right) \\
& =\frac{1}{2} \log w .
\end{aligned}
$$

where the symbols are the same as those defined in the main text.

The index $L_{3}$ of Equation (4-5) is defined to be the number of the smallest particle bin with $\bar{x}>\bar{x}_{L_{1}}+\bar{x}_{L_{2}}$. The definition is equivalent to stating that the $\log$ scale distance between $\bar{x}_{L_{3}}$ and $\bar{X}_{L_{1}}+\bar{x}_{L_{2}}$ is greater than 0 and less than or equal to $\log (w)$. This is shown to be the correct definition by showing that the log scale distance between $X_{L_{1}}+X_{L_{2}}$ and $\bar{X}_{L}$ is the same as the log scale distance between $X_{L_{1}}+X_{L_{2}}$ and $X_{L}$ for any index, $L$, and noting that the $\log$ scale distance between $X_{L_{3}}$ and $X_{L_{1}}+X_{L_{2}}$ must be between 0 and $\log (w)$ because each bin covers only a $\log$ scale diftance of $\log (w)$ and the $L_{3}$-th bin was defined to be the smallest bin which receives coagulated particles. 
The difference between the two $\log$ scale distances, $\bar{x}_{L_{1}}+\bar{x}_{L_{2}}$ to $\bar{x}_{L}$ and $X_{L_{1}}+x_{L_{2}}$ to $X_{L}$, is

$$
\begin{aligned}
& \log \left(\bar{x}_{L_{1}}+\bar{x}_{L_{2}}\right)-\log \bar{x}_{L}-\left[\log \left(x_{L_{1}}+x_{L_{2}}\right)-\log \left(x_{L_{1}}\right)\right] \\
& =\log \left[\left(1+\frac{\bar{x}_{L_{2}}}{\bar{x}_{L_{1}}}\right) \bar{x}_{L_{1}}\right]-\log \bar{x}_{L}-\left\{\log \left[\left(1+\frac{x_{L_{2}}}{x_{L_{1}}}\right)_{L_{1}}\right]-\log \left(x_{L_{1}}\right\}_{\left(A-T_{5}\right)}\right. \\
& =\log \left(1+\frac{\bar{x}_{L_{2}}}{\bar{x}_{L_{1}}}\right)+\log \left(\bar{x}_{L_{1}}\right)-\log \left(\bar{x}_{L}\right)-\left[\log \left(1+\frac{x_{L_{2}}}{\bar{x}_{L_{1}}}\right)+\log \left(x_{L_{1}}\right)\right. \\
& \left.-\log \left(x_{L}\right)\right] \\
& =\log \left(1+w^{M}\right)+\log \left(\bar{x}_{L_{1}}\right)-\log \left(x_{L_{1}}\right)-\left[\log \left(1+w^{N}\right)+\log \left(\bar{x}_{L}\right)-\log \left(x_{L}\right)\right] \\
& =\log \left(1+w^{N}\right)+\frac{1}{2} \log (w)-\left[\log \left(1+w^{N}\right)+\frac{1}{2} \log (w)\right] \\
& =0
\end{aligned}
$$


where

$N=$ the number of bins from $L_{1}$ to $L_{2}=L_{2}-L_{1}$.

$\frac{\bar{X}_{L_{2}}}{\overline{x_{L}}}=w^{N}$ because the centers of any two bins on the log scale are

separated by the same distance as the left or right sides of the bins.

$\frac{x_{L_{2}}}{x_{L_{1}}}=w^{N}$ because each bin is $\log (w)$ wide on the $\log$ scale. The definition

of the index $L_{3}$ in Equation (4-5) of the main text is thus the correct definition to cause the $\left(L_{3}-1\right)$-th and $L_{3}$-th bins to be the two bins receiving conglomerated particles from bins $L_{1}$ and $L_{2}$.

The form of Equation (4-5) of the main text (and Equation (A-21) below) is derived by requiring conservation of mass (volume) and a net loss of one particle on the average. That is, one must define $f$ so that

$\bar{x}_{L_{1}}+\bar{x}_{L_{2}}=f \bar{x}_{L_{3}-1}+(1-f) \bar{x}_{L_{3}}$

or

$\bar{x}_{L_{1}}+\bar{x}_{L_{2}}-\bar{x}_{L_{3}}=f\left(\bar{x}_{L_{3}-1}-\bar{x}_{L_{3}}\right)$ 
or

$f=\frac{\bar{x}_{L_{3}}-\bar{x}_{L_{2}}-\bar{x}_{L_{1}}}{\bar{x}_{L_{3}}-\bar{x}_{L_{3}-1}}$, which is Equation $(4-5)$

One can see that $\bar{x}_{L_{3}-1}$ is actually the larger of $\bar{x}_{L_{1}}$ and $\bar{x}_{L_{2}}$ for $W \geq 2$.

In order to show this, let $L_{1}$ be the index of the large bin or one of two equal bins, then

$\bar{x}_{L_{1}}+\bar{x}_{L_{2}} \leq 2 \bar{x}_{L_{1}}$

For $X \geq 2, \frac{\bar{x}_{L+1}}{x_{L}}=W$ implies that $2 \bar{x}_{L} \leq \bar{x}_{L}$

Equations $(A-22)$ and $A-23)$ can be combined to show that

$\bar{x}_{L}<\bar{x}_{L_{1}}+x_{L,} \leq x_{L_{1+1}}$.

Thus, the number of the smallest bin with $\bar{x}>\bar{x}_{L_{1}}+\bar{x}_{L_{2}}$ is $L_{1}+1$. 


\section{APPENDIX B}

DERIVATION OF GAS DENSITY EQUATION

${ }^{B-1} / B-2$ 


\section{APPENDIX B}

\section{DERIVATION OF GAS DENSITY EQUATION}

Equation (918) of the main text is based on the Van der Waals equation of state for a gas $B-1, B-2$

$R_{g} T_{g}=\left(\frac{v}{N}-b\right)\left(P+\frac{a N^{2}}{v^{2}}\right)$

where

$$
\begin{aligned}
T_{g} & =\text { gas temperature }(K) \\
R_{g} & =\text { gas law constant, } 8.3144 \times 10^{3} \mathrm{~kg} \mathrm{m^{2 }} /\left(\mathrm{s}^{2} \mathrm{~kg} \cdot \mathrm{mole} \mathrm{K}\right) \\
V & =\text { volume }\left(\mathrm{m}^{3}\right) \\
\mathbf{N} & =\text { number of } \mathrm{K} \text { ilogram moles of gas }(\mathrm{kg} \cdot \mathrm{moles}) \\
\mathbf{P} & =\text { gas pressure }(\mathrm{Pa}) \\
\mathrm{a,b} & =\text { constants characteristic of the gas in question. }
\end{aligned}
$$

The constant $b$ can be interpreted as representing the hard sphere repulsion volume of one mole of the gas molecules, ${ }^{B-1}$ while the term $a N^{2} / N^{2}$ represents intermolecular forces at distances larger than the hard sphere radius. ${ }^{B-3}$ With these interpretations, a reasonable extension of Equation ( $B-1)$ to approximate a mixture of components is

$$
\sum_{i=1}^{n} N_{i} R_{g} T_{g}=\left[V-\sum_{i=1}^{n} N_{i} b_{i}\right]\left[P+\sum_{i=1}^{n} \frac{N_{i}^{2} a_{i}}{v^{2}}\right]
$$


where

$$
\begin{aligned}
& N_{i}=k i l o g r a m \text { moles of } i \text {-th gas component }(\mathrm{kg} \cdot \mathrm{moles}) \\
& \mathrm{n}=\text { number of gas components } \\
& b_{i}=\text { constant characteristic of the } i \text {-th component of the gas } \\
& \left(\mathrm{m}^{3} / \mathrm{kg} \cdot \mathrm{mo} \mathrm{le}\right) \\
& a_{i}=\text { constant characteristic of the } i-\text { th component of the gas } \\
& \left.\left(\mathrm{kg} \cdot \mathrm{m}^{5} /\left[\mathrm{s}^{2}(\mathrm{~kg} \cdot \mathrm{mo}] \mathrm{e}\right)^{2}\right)\right] \text {. }
\end{aligned}
$$

In this case, $b_{1}$ is the hard-sphere volume per mole of the $i$-th component, and $a_{i} N_{j}^{2} / v^{2}$ represents the intermolecular forces between 1 -th component molecules at distances greater than the hard sphere radius. Interactions between molecules of different components have been neglected in Equation $(B-2)$.

Terms with $b_{i}$ and $a_{j}$ are much smaller than the other terms in Equation $(B-2)$. The equation can thus be approximated by

$$
\sum_{i=1}^{n} N_{i} R_{g} T_{g}=V P-\sum_{i=1}^{n} N_{i} b_{i} P+\sum_{i=1}^{n} \frac{N_{i}{ }^{2} a_{i}}{V}
$$

to first order in the small terms. Solution of this quadratic equation in $V$ for the volume as a function of the other parameters yields

$$
V=\frac{\sum_{i=1}^{n} N_{i}\left(R_{g} T_{g}+b_{i} P\right) \pm\left\{\left[\sum_{i}^{n} N_{i}\left(R_{g} T_{g}+b_{i} P\right)^{2}\right]-4 P \sum_{i=1}^{n} N_{i}{ }^{2} a_{i}\right\}^{1 / 2}}{2 P}
$$


or

$$
V=\sum_{i=1}^{n} \frac{N_{i} R_{g} T_{g}+b_{i} p}{2 p}\left[1 \pm\left\langle 1-\frac{4 p \sum_{i=1}^{n} N_{i}{ }^{2} a_{i}}{\left[\sum_{i=1}^{n} N_{i}\left(R_{g} T_{g}+b_{i} p\right)\right]^{2}}\right\}^{1 / 2}\right]
$$

Since the second term under the radical is much less than one, the two solutions can be written

$$
V=\sum_{i=1}^{n} \frac{N_{i}\left(R_{g} T_{g}+b_{i} P\right)}{2 P}\left[1 \pm\left\{1-\frac{2 P \sum_{i=1}^{n} N_{i}^{2} a_{i}}{\left[\sum_{i=1}^{n} N_{i}\left(R_{g} T_{g}+b_{i} P\right)\right]^{2}}\right] .\right.
$$

The solutions can be rewritten as

$$
\begin{aligned}
& \sum_{i=1}^{n} \frac{N_{i}\left(R_{g} T_{g}+b_{j} P\right)}{P}\left\{1-\frac{p \sum_{i=1}^{n} N_{i}^{2} a_{i}}{\left[\sum_{i=1}^{n} N_{i}\left(R_{g} T_{g}+b_{i} P\right)\right]^{2}}\right\} \\
& \text { or } \sum_{i=1}^{n} N_{i}\left(R_{g} T_{g}+b_{i} P\right) \quad \frac{\sum_{i=1}^{n} N_{i}{ }^{2} a_{i}}{\left[\sum_{i=1}^{n} N_{i}\left(R_{g}{ }^{T}+b_{i} P\right)\right]^{2}}
\end{aligned}
$$

The first solution is the proper one for a gas because it reduces to the ideal gas law as all the $a_{i}$ and $b_{i}$ approach zero. The second solution 
represents a condensed state, ${ }^{B-2}$ since it approaches zero as the $a_{i}$ approach zero. To first order in the small terms $a_{i}$ and $b_{j}$, the first solution is

$$
v=\sum_{i=1}^{n} \frac{N_{i} R_{g}{ }^{\top} g}{P}+\sum_{i=1}^{n} N_{i} b_{i}-\frac{\sum_{i=1}^{n} N_{i}{ }^{2} a_{i}}{\sum_{i=1}^{n} N_{i} R_{g} T_{g}} .
$$

In order to calculate the gas density, one needs only divide the mass by this volume

$$
p=\frac{\sum_{i=1}^{n} N_{i} M_{i}}{V}=-\frac{\sum_{i=1}^{n} N_{i} M_{i}}{\sum_{i=1}^{n} \frac{N_{i} R_{g} T^{T}}{P}+\sum_{i=1}^{n} N_{i} b_{i}-\frac{\sum_{i=1}^{n} N_{i}{ }^{2} a_{i}}{\sum_{i=1}^{n} N_{i} R_{g} T_{g}}}
$$

or

$$
\rho=\frac{\sum_{i=1}^{\frac{1}{n} N_{i}} \sum_{i=1}^{n} N_{i} M_{i}}{\sum_{i=1}^{n} N_{i}} \sum_{i=1}^{n} \frac{N_{i} R_{g}{ }^{\top} g}{P}+\sum_{i=1}^{n} N_{i} b_{i}-\frac{\sum_{i=1}^{n} N_{i}{ }^{2} a_{i}{ }^{2}}{\sum_{i=1}^{n} N_{i} R_{g}{ }^{T} g}
$$


or

$$
\rho=\frac{\sum_{i=1}^{n} F_{i} m_{i}}{\frac{R_{g}{ }^{\top} g}{p}+\sum_{i=1}^{n} F_{i} b_{i}-\sum_{i=1}^{n} \frac{F_{j}^{2} a_{j}}{R_{g} T_{g}}}
$$

where use has been made of the fact that $F_{i}=\frac{N_{i}}{\sum_{i=1}^{n} N_{i}}$, the mole fraction of i-th gas component.

Estimated values for the parameters $b_{j}$ shown in Table 4-3 are calculated by assuming that the hard sphere volume of a mole of each gas is the mole-weight divided by the density of the liquid or solid state. State densities and the gram-mole weights were taken from Reference B-4.

Most of the values of $a_{j}$ of Table 4-3 are zero because the corresponding components are either present in very small concentrations ${ }^{a}$ (argon, krypton, xenon, nitrogen) or known to have small intermolecular forces (helium, hydrogen molecules). The non-zero value for steam was calculated using Equation $(B-1)$ and a specific volume table from Reference B-5.

In order to calculate $a_{i}$ for steam, a temperature of $1073.15 \mathrm{~K}$ was selected for the calculation because that is the range where important fission product transport begins to occur. Pressures of 10 and 1 bar were selected to estimate the range of values of $a_{i}$ that would be calculated.

a. The small concentrations mean that the $a_{j}$ will be multiplied by a very sma 11 number and is therefore unimportant. 
The corresponding table values of specific volume, $0.494 \mathrm{~m}^{3} / \mathrm{kg}$ and $4.9517 \mathrm{~m}^{3} / \mathrm{kg}$, were converted to values of $\frac{V}{N}$ by multiplying them by the kilogram-molecular weight, 18.01 and values of a were calculated with

Equation (B-1). The two results, $3.19 \times 10^{5}$ and $3.45 \times 10^{5} \frac{\mathrm{kg} \mathrm{m}^{5}}{\mathrm{~s}(\mathrm{~kg} \cdot \mathrm{mole})^{2}}$. were averaged to obtain the value given in Table 4-3.

\section{References}

B-1. K. Huang, Statistical Mechanics, New York: John Wiley and Sons, Inc., 1963, pp 180-182.

B-2. M. Planck, Treatise on Thermodynamics, New York: Dover Publications, 1926, p 14, (Translated by A. Ogg).

B-3. C. Kitte1, Elementary Statistical Physics, New York: John Wiley and Sons, Inc., 1967, pp 222-224.

B-4. E. H. Sargent and Co., Periodic Table of the Elements, Chicago, I11., 1964.

B-5. C. A. Meyer, R. B. McClintock, G. J. Silverstri, and

R. C. Spencer, Jr., Thermodynamic and Transport Properties of Steam, New York: The American Society of Mechanical Engineers, 1967, p 43. 
APPENDIX C

DERIVATION OF EQUATIONS FOR EQUILIBRIUM VAPOR CONCENTRATIONS FROM VAPOR PRESSURE INFORMATION

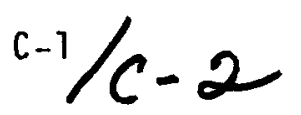




\section{DO NOT MICROFLLM \\ THIS PAGE}




\section{APPENDIX C \\ DERIVATION OF EQUATIONS FOR EQUILIBRIUM VAPOR CONCENTRATIONS \\ FROM VAPOR PRESSURE INFORMATION}

Equations (4-60) through (4-68) of the main text are all derived from expressions for the equilibrium vapor pressure. This pressure is converted to equilibrium concentration using an approach which is similar to the approach used to derive the expression for gas density in Appendix $B$. The concentration is given by

$c_{1}^{e}=\frac{\text { mass }}{\text { volume }}=\frac{N_{1} M_{1}}{V}$

where

$$
\begin{aligned}
& c_{i}^{e}=\text { equilibrium vapor concentration for } i-t h \text { component }\left(\mathrm{kg} / \mathrm{m}^{3}\right) \\
& N_{i}=\text { number of moles of } 1 \text {-th component }(\mathrm{kg} \cdot \text { moles }) \\
& M_{i}=k i l o g r a m \text { mole weight of } i \text {-th component }(\mathrm{kg} / \mathrm{kg} \cdot \mathrm{mole}) \\
& v \quad \text { volume }\left(m^{3}\right) \text {. }
\end{aligned}
$$

From Equation (B-3) of Appendix $B$, the gas equation of state can be approximated by

$$
\sum_{i=1}^{n} N_{i} R_{g} T_{g}=V P-\sum_{i=1}^{n} N_{i} b_{i} P+\sum_{i=1}^{n} \frac{N_{i}{ }^{2} a_{i}}{v^{2}}
$$

where

$R_{g}=$ gas law constant, $8.3144 \times 10^{3} \mathrm{~kg}^{2} /(\mathrm{s} \cdot \mathrm{kg} \cdot \mathrm{mole} \cdot \mathrm{K})$ 


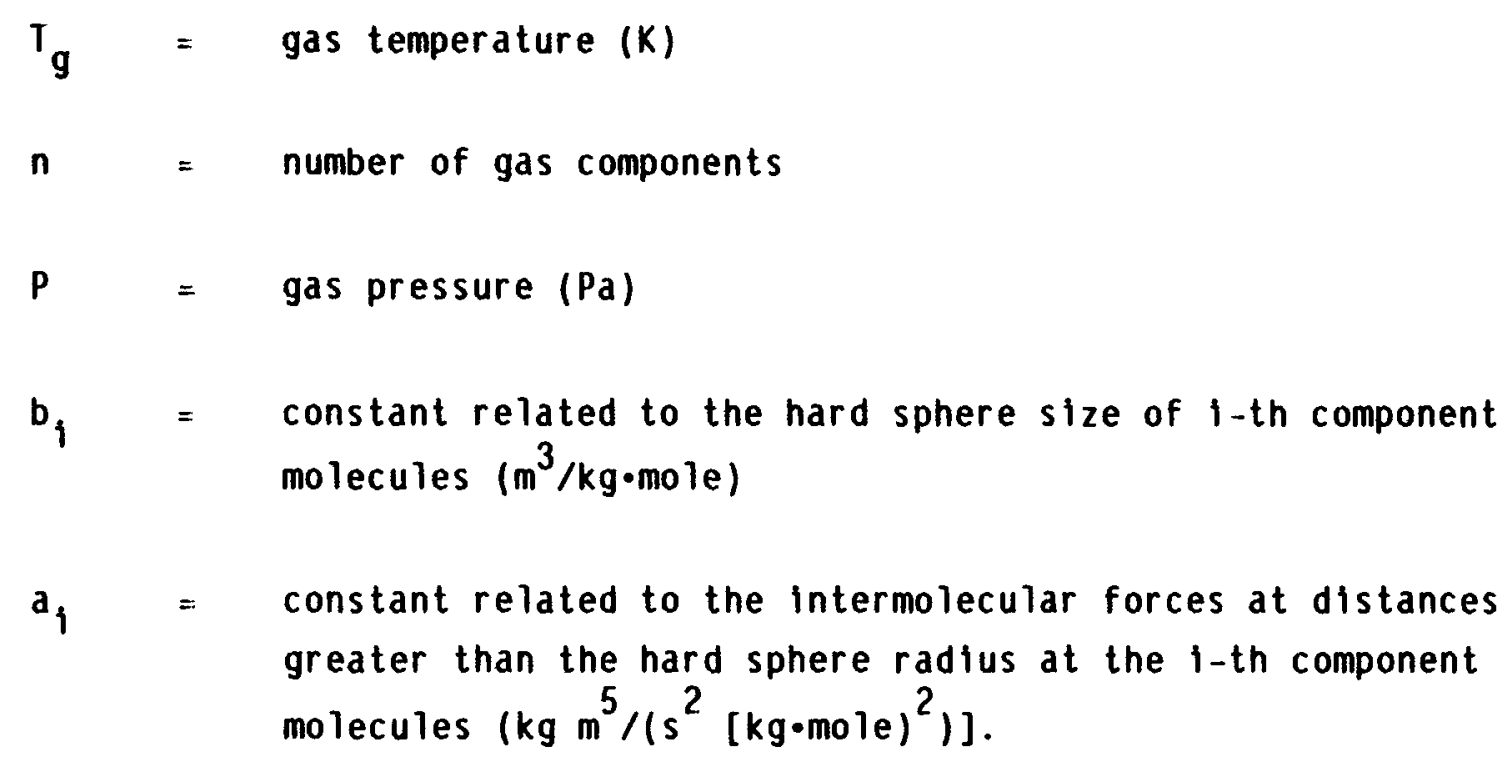

In order to use Equation ( $C-2)$ with expressions for the equilibrium vapor pressure, the pressure in the first term on the right hand side is expanded into a series of partial pressures due to the gas components

$$
\sum_{i=1}^{n} N_{i} R_{g} T_{g}=v \sum_{i=1}^{n} P_{i}-\sum_{i=1}^{n} N_{i} b_{i} P+\sum_{i=1}^{n} \frac{N_{i}{ }^{2} a_{j}}{v^{2}}
$$

where $P_{1}$ is the partial pressure due to $i$-th gas component $\left(P_{a}\right)$. The 1 -th term of each sum can then be interpreted as an equation of state for the i-th component,

$N_{i} R_{g} T_{g}=V P_{i}-N_{i} b_{i} P+\frac{N_{i}{ }^{2} a_{1}}{V^{2}}$.

For a condensable majority like steam, the second and third terms on the right-hand side of Equation $\left(C_{-}-4\right)$ are of similar magnitude and much smaller 
than the other terms. For a minority component, $\frac{N_{j}^{2}}{v^{2}}$ of the third term is small enough to neglect. Thus,

$N_{i} R_{g} T_{g}=V P_{i}-N_{1} b_{i} P$

This approximate equation of state for minorities is used in two ways: It is solved for the volume for use with Equation ( $C-1$ ) and it is used to correct equilibrium vapor pressure correlations for the effect of pressure. Solution of $\left(C_{-}-5\right)$ for the volume and substitution of this result into Equation $(C-1)$ yields

$c_{1}^{e}=\frac{M_{1} P_{1}}{R_{g} T_{g}+b_{i} P}$

This is the expression that will be used to convert partial pressure to equilibrium vapor concentrations.

Solution of Equation ( $C-5)$ for the partial pressure yields

$P_{i}=\frac{N_{1}\left(R_{g} T_{g}+b_{i} P\right)}{V}$

Equation $(C-7)$ is used to estimate the effect of changes in total pressure on the partial pressure of any component. Since literature correlations for pressure are usually given in the form ${ }^{\mathrm{C}-1}$

$\log P_{i}=A_{i} T_{g}^{-1}+B_{i}+C_{i} \log T_{g}+D_{i} T_{g}+E_{i} T_{g}^{2}$

where

$$
A_{1}-E_{1}=\text { coefficients characteristic of the } 1 \text {-th component, }
$$


Equation $(C-7)$ is converted to an expression in terms of the logarithm

$\ln P_{i}=\ln \left[\frac{N_{1} R_{g} T g}{V}\left(1+\frac{b_{1} P}{R_{g} T_{g}}\right)\right]$.

or

$\ln P_{i}=\ln \left(\frac{N_{i} R_{g} T g}{V}\right)+\ln \left(1+\frac{b_{i} P}{R_{g} T_{g}}\right)$.

or, since $\frac{b_{1} P}{R_{g} T^{\prime}}$ is $<<1$,

$\ln P_{i} \approx \ln \left(\frac{N_{1} R_{g} T g}{V}\right)+\frac{b_{i} P}{R_{g} T g}$

where the Taylor series approximation

$\ln (1+x) \simeq x-\frac{1}{2} x^{2}+\frac{1}{3} x^{3}+\ldots$

has been employed.

Equation ( $C-11)$ provides a convenient means of converting correlations for $P_{1}$ at pressure $P_{0}$ to correlations at pressure $P$.

$\left.\ln P_{i}\right|_{P}=\left.\ln P_{1}\right|_{P_{0}}+\frac{b_{1}}{R_{g}^{T}}\left(P-P_{0}\right)$ 
where

$P_{0} \quad=\quad$ pressure at which a correlation for $\ln P_{i}$ is obtained (Pa)

$\mathrm{P} \quad=$ pressure for which a correlation for in $\mathrm{P}_{\mathfrak{i}}$ is desired (Pa)

$\left.\ln P_{1}\right|_{P}=$ natural $\log$ of $P_{i}$ at pressure $P$

$\left.\ln P_{\mathfrak{i}}\right|_{P_{0}}=$ natural $\log$ of $P_{i}$ at pressure $P_{0}$.

Conversion of the $\left.\ln P_{i}\right|_{P_{0}}$ to $\left.\log P_{i}\right|_{P_{0}}$ and solution of Equation $(C-12)$ for

the partial pressure $P_{i}$ at a total pressure $P$ provides an expression for $P_{i}$ that can be used with Equation $(C-6)$. The solution is

$P_{i}=\exp \left[\left.2.3026 \log P_{i}\right|_{P_{0}}+\frac{b_{i}}{R_{g} T_{g}}\left(P-P_{0}\right)\right]$

Substitution of Equations $(C-13)$ and $(C-8)$ into Equation $(C-6)$ and an index change yields the desired expression

$$
\begin{aligned}
C_{K}^{e}= & \frac{M_{k}}{R_{g} T_{g}+b_{k} P} \exp \left\{2.3026\left[A_{K} T_{g}^{-1}+B_{k}+C_{k} \log T_{g}+D_{k} T_{g}+E_{k} T_{g}^{2}\right]\right. \\
& \left.+\frac{b_{k}}{R_{g} T_{g}}\left(P-P_{0}\right)\right\}
\end{aligned}
$$


Values of the constants in Equation $(C-14)$ for lodine, cesium lodide, cesium hydroxide, tellurium, silver. and cadmium are presented in Table $C-1$. The molecular weights were computed from Reference $C_{-}-2$. The constants $b_{k}$ were estimated from the ratio of the gram-molecular weight to the liquid or solid-state density, as was explained in Appendix $B$. The densities were obtained from Reference $\mathbf{C}-3$. The equilibrium vapor pressure correlation constants for lodine, ceslum lodide, and tellurlum are from Table 3 of Reference $C-4$. (They are also in Table 4 of Reference $C-5$ ). The equilibrium vapor pressure correlation constants for cesium hydroxide are from Reference $C-6$. The equilibrium vapor pressure correlation constants for silver and cadmium were obtained by requiring that Equation $(C-8)$ with $D_{q}$ and $E_{q}$ equal to zero match patch points in Table $A .1$ of Reference $\mathrm{C}-1$. The points used for silver were $\left(10^{-7}\right.$ torr, $\left.899 \mathrm{~K}\right)$, $\left(10^{-5}\right.$ torr, $\left.1025 \mathrm{~K}\right)$, and $\left(10^{-3}\right.$ torr, $\left.1195 \mathrm{~K}\right)$. The points used for cadmium were $\left(10^{+1}\right.$ torr, $\left.762 \mathrm{~K}\right),\left(10^{+2}\right.$ torr, $\left.885 \mathrm{~K}\right)$, and $\left(10^{+3}\right.$ torr, $\left.1060 \mathrm{~K}\right)$. In all cases except the cesium hydroxide data, the correlations in the references were for $\log P_{i}$ in torr, so the constant $B_{k}$ obtained was increased by 2.124881 to convert the units to Pa. This factor was obtained by noting

$$
P_{\text {in } P a}=P_{\text {in tor }} \times 1.33322 \times 10^{2} \text {, }
$$

so

$\log P_{\text {in } P a}=\log \left(P_{\text {in torr }} \times 1.33322 \times 10^{2}\right)$

or

$\log P_{\text {in } P a}=\log \left(P_{\text {in tor }}\right)+\log \left(1.333 .22 \times 10^{2}\right)$

or

$\left.\log P_{\text {in } P a}=\log \left(P_{\text {in torr }}\right)+2.12488\right)$. 
TABLE C-1. CONSTANTS FOR EQUATION (C-14)

\begin{tabular}{|c|c|c|c|c|c|c|c|c|}
\hline Vapor & $\begin{array}{c}M_{k} \\
(\mathrm{~g} / \mathrm{mole})\end{array}$ & $\begin{array}{c}b_{k} \\
\left.\left(\mathrm{~cm}^{3} / \mathrm{mo}\right) \mathrm{e}\right)\end{array}$ & $A_{k}$ & ${ }^{B}{ }_{k}$ & $C_{k}$ & $D_{k}$ & $\underline{E_{k}}$ & $\begin{array}{c}\text { Temperature } \\
\text { Range }\end{array}$ \\
\hline $\mathrm{I}_{2}$ & 253.81 & 51.48 & $\begin{array}{l}-3578 \\
-3205\end{array}$ & $\begin{array}{l}19.84 \\
25.77\end{array}$ & $\begin{array}{l}-2.51 \\
-5.18\end{array}$ & $\begin{array}{l}0 \\
0\end{array}$ & $\begin{array}{l}0 \\
0\end{array}$ & $\begin{array}{l}\text { Low } \\
\text { High }\end{array}$ \\
\hline CsI & 259.81 & 57.61 & $\begin{array}{r}-10420 \\
-9678\end{array}$ & $\begin{array}{l}21.82 \\
22.47\end{array}$ & $\begin{array}{l}-3.02 \\
-3.52\end{array}$ & $\begin{array}{l}0 \\
0\end{array}$ & $\begin{array}{l}0 \\
0\end{array}$ & $\begin{array}{l}\text { Low } \\
\text { High }\end{array}$ \\
\hline $\mathrm{CsOH}$ & 149.91 & 40.79 & -6700 & 9.92 & 0 & 0 & 0 & \\
\hline Tellur tum & 127.60 & 20.42 & $\begin{array}{l}-9320 \\
-7980\end{array}$ & $\begin{array}{l}21.97 \\
24.70\end{array}$ & $\begin{array}{l}-2.71 \\
-4.32\end{array}$ & $\begin{array}{l}0 \\
0\end{array}$ & $\begin{array}{l}0 \\
0\end{array}$ & $\begin{array}{l}\text { Low } \\
\text { High }\end{array}$ \\
\hline Siliver & 107.87 & 10.27 & -16044 & 23.02 & -3.40 & 0 & 0 & \\
\hline Cadmium & 112.40 & 13.01 & -6765 & 16.74 & -1.92 & 0 & 0 & \\
\hline Tin & 118.69 & 16.3 & -12360 & -6.21 & 4.548 & 0 & 0 & \\
\hline
\end{tabular}




\section{References}

C-1. J. L. Margrave, The Characterization of High-Temperature Vapors, New York: John Wiley and Sons, Inc., pp 475-494, QC 304 M32.

C-2. E. H. Sargent and Co., Periodic Table of the Elements, Chicago, I11., 1964.

C-3. C-D. Hodgman et a1., Handbook of Chemistry and Physics, Cleveland, Ohio: Chemical Rubber Publishing Co., 1956, pp 460-631.

C-4. J. A. Greseke, P. Baybutt, R. S. Denning, H. Jordan, and R. 0. Wooton, Fission Product Transport Analys is Quarterly Progress Report for Apr 17 Through June, 1976. BMI-NUREG-1955, September 7, 1976.

C-5. J. A. Gieseke, P. Baybutt, R. S. Denning, H. Jordan, and R. 0. Wooton, Analys is of Fission Product Transport under Terminated LoCA Conditions Topical Report, BMI-NUREG-1990, December 30, 1977.

C-6. J. C. Cummings et a7., Status Report on the Fission-Product Research Program. NUREG/CR-1820, SAND 80-2662, March 1982. 